
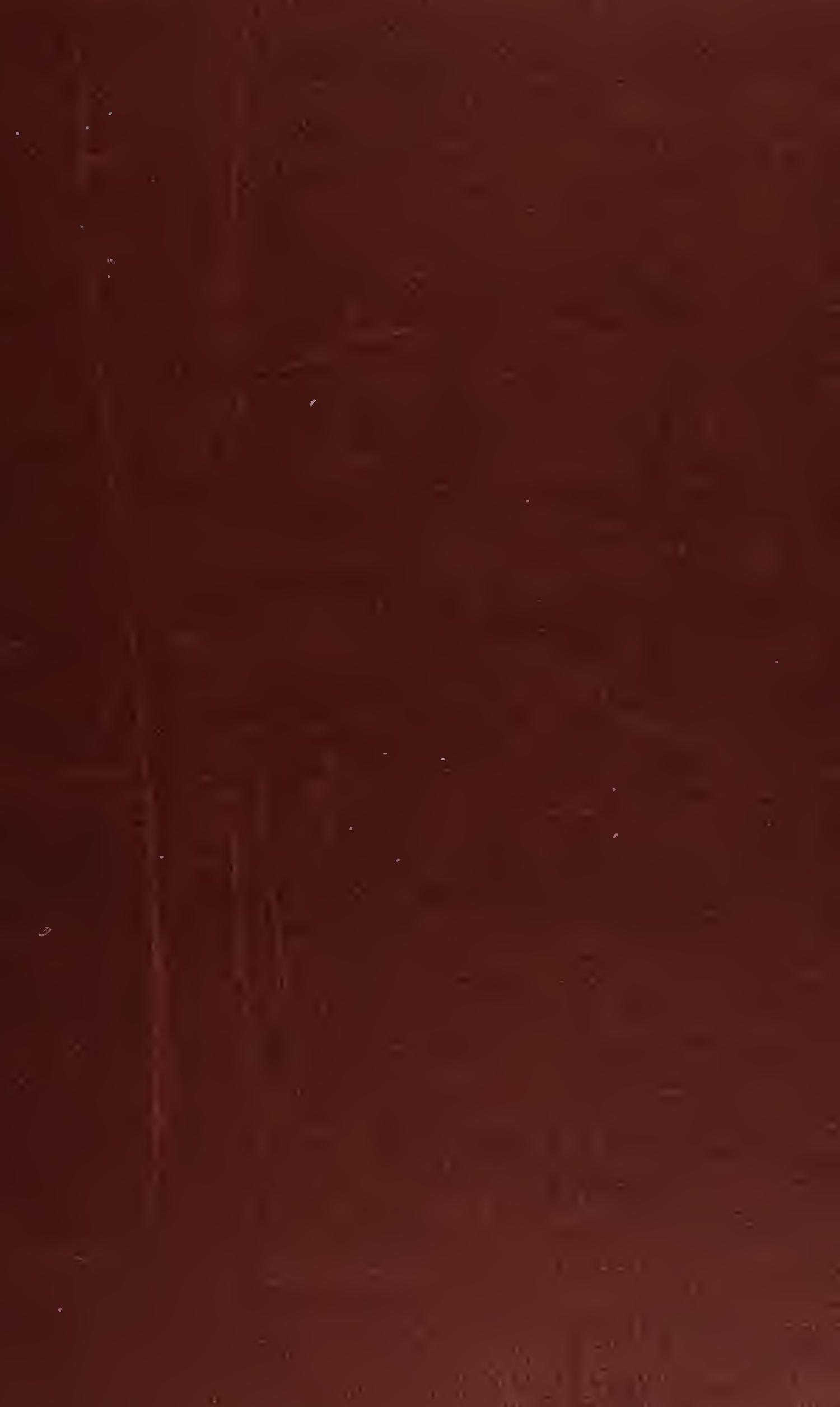


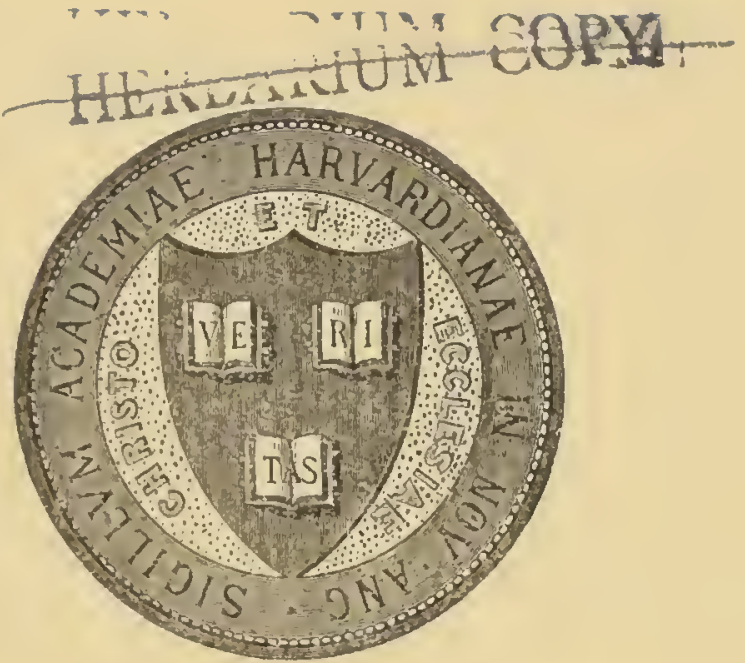

HARVARD UNIVERSITY

L I B R A R Y

OF THE

GRAY HERBARIUM

Receiver 1866

Rebound April 12,1955 




\title{
MONOGRAPIIE
}

\author{
DE LA FAMILLE
}

\section{DES ANONACÉES.}

HARVARD UNIVERSITY HERBARIUM.

FEEA-GIFT OF

Namigh I shb 
$Y^{-}$

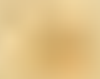

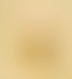

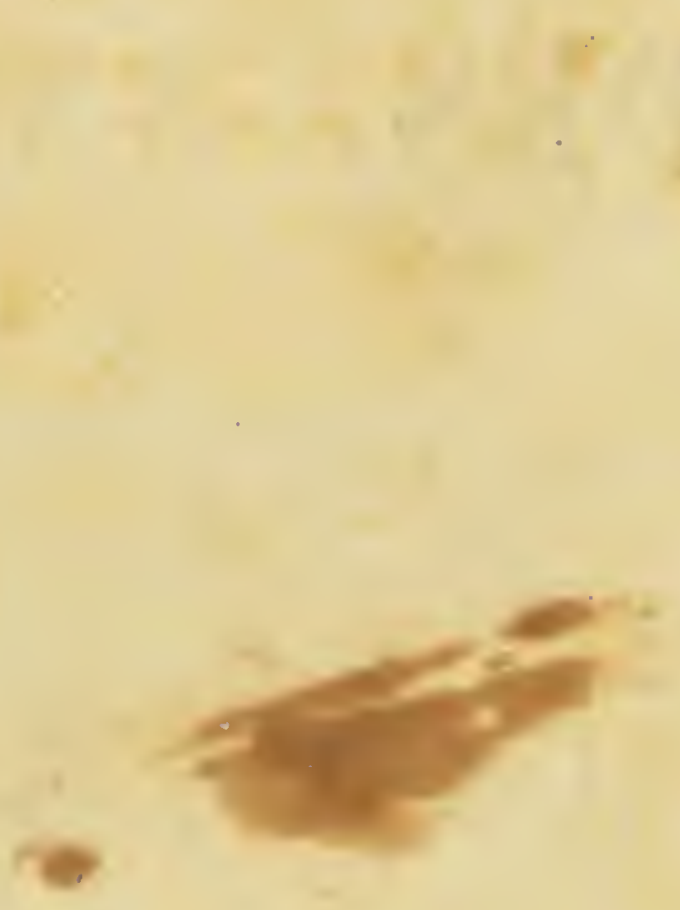

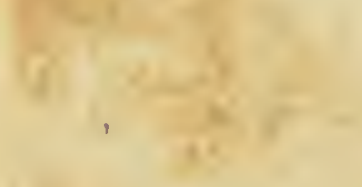




\title{
MONOGRAPHIE
}

DE L A FAMIL E

\section{DES ANONACEES;}

\author{
P A R \\ Michel - Fétix DUNAL， \\ D. M. M.
}

UN VOLUME IN-4. AVEC TRENTE-CINQ PLANCHES GRAVEES.

A PARIS, chez TREUTTEL et WÜRTZ, rue de Bourbon, n. $0^{\circ} 7^{\circ}$

A LONDRES, même Maison de Commerce, 30 soho-square.

A STRASbourG, même Maison de Commerce, rue des Serruricrs, n. ${ }^{\circ} 30$.

A MONTPELLIER, chez RENAUD, Libraire, à la Grand'rue.

1817 . 


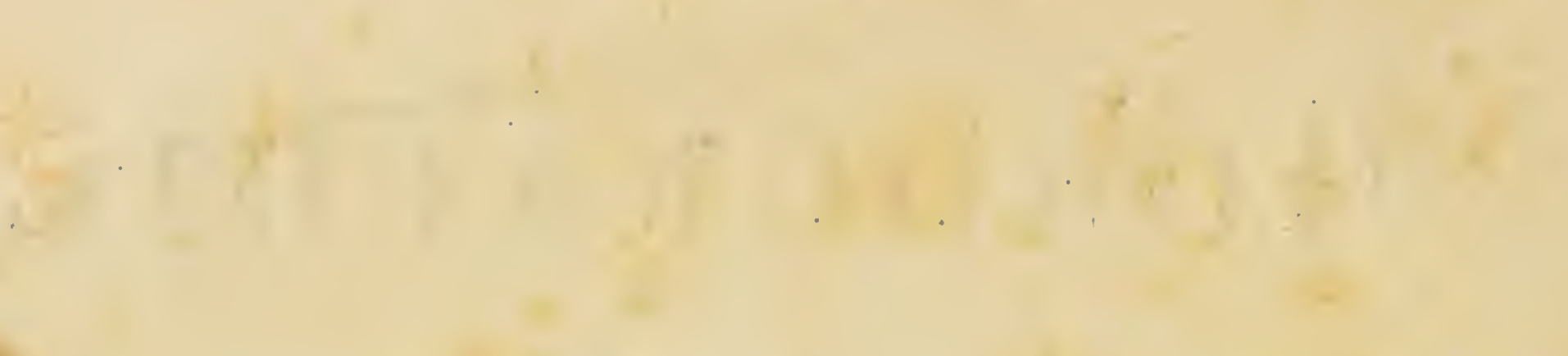

35 


\section{TABLE· DES CHAPITRES.}

Avant-propos. . . . . . . . . . Page. 3.

I. Histoire générale. . . . . . 5.

Époques de la découverte des espéces. . . . . . 5.

I. Histotre et description de la famille. • . 6. Organes de la reproduction. . . . . . . 10. Organes de la végétation. . . . . . . . 15. Propriétés et usages. . . . . . . . 17. Habitations, stations et culture.. . . . $1 \%^{\circ}$

II. Histolre générale des genres. . . . . ig. Époques de l'établissement des genres, et considérations générales sur leur nature. . . . . . rğ. Tableaux analytiques des genres. . . . . . 23. Série linéaire des genres. . . . . . . . 24.

III. Histoires particulières des Genres. . . 25.

I. du genre Kadsura.. . . . . . . 25.

II. _-_ Anona... . . . . . . . 28.

III. - - Monodora. . . . . . . 34.

IV. _- Asimina......... 35.

v. _- Porcelia. . . . . . . . 38.

VI. _— Uvaria. . . . . . . 39.

VII. - - Unona.......... 42.

VIII. _—— Xylopia. . . . . . . 48. 48.

IX. _- Guatteria. . : . . . . 50.

II. Monographia. . . . . . . . 53.

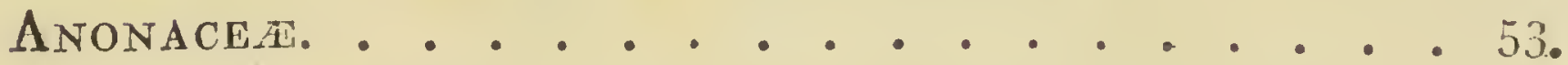

Conspectus generum. . . . . . . . . 55.

Genera excludenda.. . . . . . . . . 56. 
I. Kadsura. . . . . . . . . Page 57.

II. Anona. . . . . . . . . . . . . 58.

Conspectus specierum. . . . . . . . . 59.

Historia specialis. . . . . . . . . . . . 6\%。

Anonce excludenda. . . . . . . . . . . . 78.

III. Monodora. . . . . . . . . . . 79 .

Conspectus specierum. . . . . . . . . . 79.

Historia specialis. . . . . . . . . . . . 80.

IV. Asimina. . . . . . . . . . . 82.

Conspectuis specierum. . . . . . . . . 82.

Historia specialis. . . . . . . . . . . 82.

V. Porcelia. . . . . . . . . 85.

Porcelia excludenda. . . . . . . . . 86.

VI. Uvaria. . . . . . . . . . . . . 87.

Conspectus specierum. . . . . . . . . 87 .

Historia specialis. . . . . . . . . . . . 88.

Uvarice excludenda. . . . . . . . . . . . 93 .

VII. Unona. . . . . . . . . . . . 94.

Conspectus specierum. . . . . . . . . . $9^{5}$

Historia specialis. . . . . . . . . . . . . . 99.

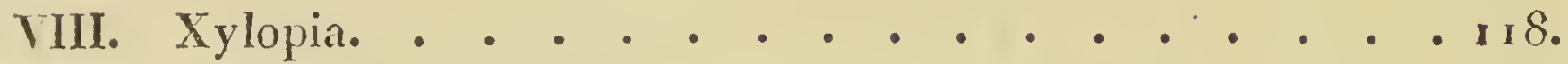

Conspectus specierum. • • . . . • • • . . Irg.

Historia specialis. . . . . . . . . . . . 120.

Xylopia excludenda. . • • • . • • . . . . 123.

IX, Guatleria. . . . . . . . . . . . . I23.

Conspectus specierum. • . . . . . . . . . 124.

Historia specialis. . . . . . . . . . . . 126.

Tabula Anonacearum chronologica. . . . . . . 136 .

Tabularum explicatio. . . . . . . . . . . 137 .

Vocum abbreviatarum explicatio. . . . . . . . 138.

Index generum, specierum et synonymorum. . . . . . . r3g. 
S'IL est vrai de dire qu'en Histoire naturelle on doit accueillir tous les faits bien observés, même ceux qui au premier coup-d'œil paraissent les plus indifférens, il n'en est pas moins certain que les objets employés par l'homme et pour son usage, sont d'un intérêt plus grand et plus général, que ceux dont la seule utilité apparente est d'offrir quelque trait nouveau ou plus précis de l'immense tableau de la naturc. Par ce motif, les objets utiles à l'homme ont des droits plus particuliers à notre étude, et sous ce rapport, la famille des Anonacées, dont je publie aujourd'hui l'Histoire et la Monographie, mérite de fixer notre attention. Les diverses parties des espèces qui la composent sont employées à des usages trèsmultipliés et très-divers, dans les régions où croissent ces élégans végétaux. Ainsi la beauté de leur forme fait cultiver certaines espèces dans les promenades des Indes Orientales; quelques autres servent, par leur bois, à la construction des habitations; d'autres donnent une écorce épaisse ou un bois souple qui remplace le liége de nos pays; un principe colo. rant rouge est retiré, par les habitans de Ceylan, des racines d'une espèce indigène de leur île; le tronc d'une autre laisse découler un suc visqueux, qui se condense en une gomme odorante; le mucilage que fournissent l'écorce et les feuilles d'une espèce, est employé dans la confection du papier a Japon; les écorces et les feuilles d'un grand nombre, à cause de leur saveur âcre ou aromatique, sont employces à des usagec 
médicinaux; l'odeur forte et suave des fleurs d'une espèce en arbre, la fait cultiver à Java et dans la Chine, et l'art communiquant à des corps graisseux ou huileux l'odeur recherchée de ces fleurs, prolonge les jouissances qu'elles procurent. Enfin, et c'est ici l'usage le plus répandu et le plus important de ces végétaux, les fruits de plusieurs espèces sont d'un usage fréquent sous la Zone torride, les uns comme condiment, les autres comme aliment. Les arbres qui produisent ces derniers sont cultivés comme nous cultivons en Europe nos arbres fruitiers de la famille des Rosacées, et c'est à cause de cela qu'une espèce d'Anone porte le nom vulgaire de Pommiercannellier. Si, d'un côté, l'intérêt que peut inspirer la connaissance de ces objets diminue par l'éloignement des lieux où leur usage est journalier, ils ont, d'un autre côté, l'attrait particulier de la singularité et de la rareté, celui qui est attaché à la connaissance des usages différens des nôtres et à celle des objets nouveaux ou peu connus.

Les matériaux de cet ouvrage m'ont été fournis par les bibliothèques de MM. Gouan, de Candolle et Bouchet, par les herbiers de MM. Humboltd et Bonpland, Delessert, de Candolle; et par la belle collection de plantes du Méxique de M. Moçino. En outre, M. De Candolle a bien voulu me communiquer les descriptions manuscrites des espèces nouvelles qu'il a vues à Paris dans les vastes herbiers de MM. de Jussieu, Desfontaines et du Muséum d'Histoire naturelle, et ¿ Londres dans les riches herbiers de sir J. ${ }^{\mathrm{h}}$ Bancks et de M. Lambert. Les Hommes célèbres que je viens de citer ont mis leurs collections à ma disposition avec la plus grande bienveillance. Ils voudront bien recevoir ici l'expression de ma juste reconnaissance. 


\section{MONOGRA PHIE}

D E L A F A M I L L E

\section{DES ANONACÉES.}

\section{I.}

\section{HISTOIRE GÉNÉRALE.}

\section{Époques de la découperte des espèces.}

A ucune espèce d'Anonacée n'a été connue des anciens; la raison en est que presque toutes les plantes qui composent cette famille sont originaires de pays qui leur étaient inconnus. Toutes les notions que les Européens ont de ces plantes sont postérieures à la découverte de l'Amérique; les premières datent de la première moitié du seizième siècle. Dans l'ouvrage d'Oviedo sur l'Amérique, une des premières descriptions de cette belle partie du monde ( $\mathrm{r}$ ), on trouve sous le nom de Guanabanus, la description du fruit de l'Anona squamosa $I_{\text {. }}$, arbre fruitier cultivé aujourd'hui dans les deux Indes. Matthiol (2), à peu près à la mêrne époque, a décrit

(1) Historia general de las Inclias. 1546.

(2) Commentaria in Dioscoridem. 1548. 
un fruit qui se trouvait alors dans le commerce sous le nom de Poivre d'Ethiopie, fruit qui appartient à une espèce d'Unona. Vers le milieu du siècle suivant, Pison et Marcgrave (I) ont décrit incomplètement 3 ou 4 espèces du Brésil. A la fin du même siècle ou au commencement du siècle suivant, Rheed (2) a fait connaître plusieurs espèces du Malabar; Plumier (3) en a décrit plusieurs des Antilles. Dans tout le cours du $180^{\mathrm{e}}$ siècle, presque tous les botanistes qui ont parcouru des pays situés sous les tropiques, ont apporté quelques espèces nouvelles qu'ils ont fait connaître ou qui ont été décrites depuis par les possesseurs de leurs collections. Dans les ouvrages généraux, on voit le nombre des espèces de cette famille suivre la progression suivante. Linné (4) en indique 13 dans les divers genres qui la constituent; Willdenow (5) en signale 36 , et Persoon (6) 44. Je me propose, dans ce mémoire, de faire connaître 103 espèces, de donner les figures de 32 , et de caraclériser les genres d'une manière plus précise qu'on ne l'a fait jusqu'à ce jour. Avant de passer à l'histoire particulière de ces genres, je vais tracer l'histoire et la description générale de la famille qu'ils composent.

\section{Histoire et description de la famille.}

Parmi les plantes polypetales hypogynes, on remarque plusieurs groupes de genres qui ont entr'eux une grande analogie de structure et de port, quoiqu'ils constituent aujourd'hui, et avec raison, plusieurs familles distinctes, savoir: les Dilleniacées, les Magnoliacées, les Anonacées, les Ochnacées et les Simaroubées; aussi allons-nous voir que les premiers botanistes qui se sont occupés de rapports

(1) Historia naturalis Brasilia. 1648.

(2) Hortus Malabavicus. $1678-1703$.

(3) Nova gencra Americana. I 703.

(4) Species plantarum. I 753. Si»plementum plantarum. 178 .

(5) Species plantartun. tom. II, pars 2. 1799.

(6) Enchiridium botanicum. vol. II. 1807 . 
naturels ont plus ou moins rapproché les genres qui les composent:

Linné, avec sa sagacité ordinaire, avait formé son $52 .{ }^{\circ}$ ordre naturel, sous le nom de Coadunata (1), des genres Liriodendrum, Magnolia et Michelia, qui sont les types de la famille des Magnoliacées, et des genres Xylopia, Anona el Uvaria, types de la famille des Anonacées. Ces deux familles sont, en efret, les plus voisines; leur affinilé est telle, que quelle que soit la série linéaire qu'on adopte pour la disposition des familles des plantes, elles ne pourront jamais être éloignées l'une de l'autre.

Adanson(2), procédant à la formation des familles naturelles par une méthode artificielle, réunit, dans sa $460^{\circ}$ famille, sous le nom d'Anones, 13 genres polypétales polygynes. L'un d'eux, son genre Fragara, a les étamines périgynes et se trouve tout-à-fait déplacé dans ce groupe. Les douze autres, qui sont polypétales hypogynes, ont entr'eux de nombreuses affinités et appartiennent aux familles suivantes: les Renonculacées, les Dilleniacées, les Magnoliacées, les Anonacées, les Ochnacées et les Menispermées.

En 1759 , Bernard de Jussieu, dans la disposition du jardin de Trianon, réunit les genres connus alors de nos Anonacées actuelles, avec les genres Ochna, Curatella et Illicium, et plaça ce groupe immédiatement après les genres Liriodendrum et Magnolia.

Il était réservé au célèbre Ant. Laur. de Jussieu, de tracer d'une manière précise les caractères et les limites de la famille dont nous nous occupons. Son immortel Genera (3) nous offre la description exacte de cette famille, distinguée par des caractères clairs et précis de celles avec lesquelles elle avait été jusque-là confondue, et formant un groupe parfaitement naturel.

La famille des Anonacées diffère de toutes celles avec lesquelles elle a des affinités, par son calice à trois lobes, rarement à quatre; par ses pétales, le plus souvent au nombre de six, disposés sur

(1) L. Ordines naturales, in Gen. pl. $17^{3} 7$.

(2) Famille des plantes. I 763. vol. II. p. 359 .

(3) Genera plantarum secundim ordines naturales disposita. I $789 \cdot p \cdot 283$. 
deux rangs; quelquefuis au nombre de trois, par avortement du rang intérieur; par ses anthères nombretises et agglomérées, presque sessiles, à conneclif glanduleux au sommet; et surtout par la structure singulière de sa graine, dont l'endoplèvre ou tunique interne se loge étroilement dans le corps de l'albumen en replis nombreux, transversaux ol linéaires.

Le tableau suivant servira à montrer en quoi la famille des Anonacées diffëre de chacune des familles avec lesquelles elle a le plus de rapports, et avec lesquelles elle a été confondue.

Familles de Plantes dont les genres ont été précédemment groupés ayec ceux qui composent la Famille des ANONACEES.

Polypétales hypogynes; pétales cn nombre déterminé; plusieurs ovaires ou apparence de plusieurs ovaires, rarement ovaire unique. -- Arbres on Arbrisseanx.

Style unique; Cruit gynobasique; graines dépourvues d'albumen.
Plusicurs styles ou point de style; plusieurs ovaires, rarcment ovaire unique; graines pourvues d'albumen.

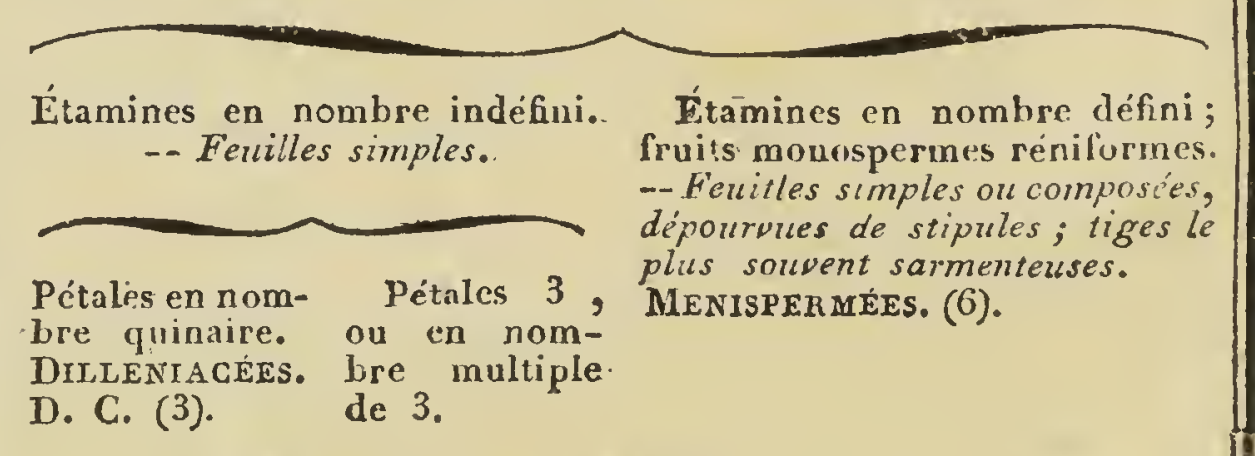

(1) D. C. Annal. du Mus. 17. p. 422.

(3) D. C. l. . .

(3) D. C. l. c.

(द) Juss. Gen. p. $280 .-$ - D. C. l. c. p. $4^{20}$.

(5) Juss Gen. p. 283.

(G) Juss. Gen. p. 284.
Fleurs toujours hermaphrodites; pétales dressé ; loges du fruit un peu charnucs. - Feutles simples, entières ou dentées, pourvies de derix stipules a leur culés. Ocriacies. D. C. (2).

\begin{tabular}{|c|c|}
\hline $\begin{array}{l}\text { Pétales } 3 \text {, ou } \\
\text { multiples de ce } \\
\text { nombre. -Feuilles } \\
\text { pourvues de sti- } \\
\text { pulles caduques. } \\
\text { MIAG Noliacés. } \\
\text { (4). }\end{array}$ & $\begin{array}{l}6 \text { Pétales sur } \\
\text { dcux rangs, rare- } \\
\text { ment } 3 \text { paravor- } \\
\text { tement du rang } \\
\text { interne; étamines } \\
\text { agglomérées sur } \\
\text { un réecptacleglo- } \\
\text { buleux; anthères } \\
\text { presque sessiles, } \\
\text { à loges en dehors } \\
\text { et en bas d'un } \\
\text { connectif glandu- } \\
\text { leux au sommet. } \\
\text { Endoplevre for- } \\
\text { mant de nom- } \\
\text { hreux replis dans } \\
\text { l'albumen.-Feuil- } \\
\text { les dépourvues de } \\
\text { stipules. } \\
\text { ANoNAcEs. (5). }\end{array}$ \\
\hline
\end{tabular}


Outre les affinités que nous venons de mentionner, les Anonacées ont quelques rapports avec des familles bien plus éloignées dans la série naturelle des familles de plantes. Ces rapports ont été signalés par quelques auteurs, et je ne dois pas les passer sous silence. $\mathrm{A}^{\prime}$ cause d'une ressemblance d'aspect ou d'une ressemblance apparente de structure, Sloane, dans son histoire de la Jamaïque ( $\mathrm{I}$ ), a décrit sous le nom générique d'Anona, le Crateya tapia L. , l'Achras sapota a. L.Zapota Willd., l'Achras sapota $\beta$ L. Zapotilla Willd. et Io Chrysophyllum cainito $L$. Catesby a indiqué, sous le même nom, une autre espèce de Sapotée, dont le genre est encore douteux. Le Crateva tapia offre à peine quelque ressemblance de port avec les Anones; la structure de toutes ses parties est entièrement différente. L'analogie des feuilles et une ressemblance apparente des fruits expliquent pourquoi Sloane et Cateshy ont décrit quelques espèces de Sapotées, comme faisant partie du genre Anona; mais des rapports qui quoiqu'éloignés méritent davantage de fixer notre attention, sont ceux que M. Aubert du Petit-Thouars a indiqués entre les Myristicées et les Anonacées. Ces deux familles se trouvent dans tous nos livres très-éloignées les unes des autres, la première étant composée de plantes apétales, la seconde de plantes polypétales. Cette différence n'est pas ce qui peut faire rejeter l'idée de leur affinité ; car on sait aujourd'hui que plusieurs familles apétales sont très-voisines de familles polypétales. Ainsi, les Amentacées touchent aux Thérébinthacées, les Euphorbiacées aux Frangulacées; les Éléagnées, les Santalacées et les Thymelées ont de nombreux rapports avec les Onagraires et les Combretacées; les Laurinées en ont avec les Berberidées ; les Chenopodées, les Paronichiées et les Amaranthacées sont très-liées aux Portulacées et aux Caryophillées. Les affinilís entre les apétales et les polypétales, sont telles que vraisemblablement plusicurs familles rangées. aujourd'hui dans une de ces classes, seront placées un jour auprès de familles rangées dans l'autre classe, et cela lorsqu'on aura étudié avec plus de soin l'organisation symé-

(x) History of Jamaica. Vol. II. 
trique des groupes. Mais revenons aux Anonacées et aux Myrislicées. Celles-ci diffèrent beaucoup des premières par leurs fleurs diö̈ques et dépourvues de pétales, par leurs étamines en nombre défini et soudées à leur base, par leur ovaire unique et toujours monosperme, par leur albumen crevassé : mais on observe dans les deux familles, un calice à trois divisions, des anthères à deux loges et extrorses, les ovaires libres, la structure du fruit analogue, les graines attachées à la partie inférieure des loges qui les renferment, munies d'un arille qui est beancoup plus prononcé et d'une forme particulière dans les Myristicées. La structure de la graine est la même dans les deux groupes; un test mince, fragile et de couleur brune, recouvre l'endosperme ou membrane interne qui, intimement soudée à l'albumen, s'enfonce dans sa substance en replis nombreux et: membraneux; l'embryon situé de la même manière ne diffère que par la forme des cotylédons. Outre ces caractères communs, les Anonacées et les Myrislicées sont toutes des arbres ou arbrisseaux de la Zone torride, à feuilles alternes, entières et dépourvues de stipules, à pédoncules souvent axillaires, à pédicelles presque toujours munis de bractées; enfin, les diverses parties des deux groupes jouissent de propriétés aromaliques remarquables et généralement connues.

Examinons maintenant la structure particulière de chacun des organes des Anonacées.

Organes DE LA reproduction. Calice. Le calice est court, persislant après la floraison, mais se détruisant lors du développement des fruits; à 3 ou 4 lobes, le plus souvent à 3 parties presque en forme de cœur, ovales, concaves, et se prolongeant en angle aigu; quelquefois presque en cloche à 3 ou 4 divisions, et alors de consistance coriace.

Corolle. Les pétales doni la disposition est toujours constante, présentent des formes très-diverses, et ces diverses formes se retrouvent dans le même genre. Ils sont le plus souvent au nombre de 6 , et alors toujours disposés sur deux rangs; ceux du premier rang alternes avec les lobes du calice; ceux du second rang alternes avec ceux du premier rang. Dans un très-petit nombre d'espèces 
le rang interne manque entièrement. Les pétales du même rang sont toujours de même forme et d'égale grandeur; mais jamais les pétales d'un rang ne sont égaux à ceux de l'autre rang: tantût ceux du rang externe sont plus grands que ceux du rang interne, comme cela arrive dans toutes les espèces du genre Anona, et principalement dans quelques espèces de ce genre dont les pétales internes sont 6 à 8 fois plus petits que les externes; tantôt, au contraire, ceux du rang interne sont plus petits que ceux du rang externe, et ce phénomène est quelquefois extrêmement prononcé, comme dans le Guatteria suberosa et l'Uvaria tomentosa.

Les pétales sont le plus souvent de consistance épaisse et un peu coriace. Leur forme varie beaucoup, mais elle est constante dans chaque espèce. Tantôt ovales, en pointe ou obtus, concaves dans toute leur étendue; tantôt très-étroits, oblongs, terminés par une pyramide triangulaire, épaisse et charnue, portant une concavité à leur base du côté interne, concavilé qui est souvent colorée d'une manière différente que le reste du pétale : les concavités de tous les pétales réunis forment un hémisphère creux qui loge le corps des étamines et des pistilis. Dans ce dernier genre de structure, les pétales internes sont quelquefois échancrés à leur base latéralement, de manière à laisser à découvert la partie du corps des organes génitaux qui répond à la concavité des pétales. internes; c'est là ce qu'on voit dans mon Unona acutiflora (1).

La couleur des pétales-varie selon les espèces et souvent ceux. d'un rang sont colorés différemment de ceux de l'autre rang. Diverses nuances de blanc, de jaune et de rouge, sont les couleurs. ordinaires de ces organes; on n'en connait point de bleus.

Étamines. Celles-ci sont en très-grand nombre, agglomérées sur un réceptacle souvent hémisphérique qu'elles recouvrent en entourant très-étroitement les ovaires qui se trouvent à leur centre; de telle sorte qu’elles forment une masse, le plus souvent hémisphérique,

(I) Voyez la planche 2 
qui ne laisse apercevoir que la partie supérieure des étamines. Cette structure n'a d'exception que pour un petit nombre d'espèces (I) qui ont un réceplacle plane, et qui par cela même ne peuvent avoir la masse des étamines hémisphérique, quoique ces étamines soient disposées comme dans les autres espèces.

Les anthères sont sessiles ou presque sessiles, oblongues, d'apparence tétragone ou pentagone par suite de la pression qu'elles éprouvent dans leur position. Elles sont composées d'un connectif linéaire, s'élargissant un peu au sommet et se terminant en un corps souvent glanduleux, plane et quelquefois comme tronqué, corps qui dans certaines espèces sécrète un mucus particulier. Audessous de ce corps glanduleux et à la partie externe du connectif, se trouvent situées les deux loges de l'anthère qui sont oblongues et s'ouvrent en dehors selon leur longueur. Les étamines les plus intérieures, entourant immédiatement les ovaires, se trouvent quelquefois soudées avec quelques-uns de ceux-ci. Voilà pourquoi linné avait placé son genre Xylopia dans la Gynandrie. Dans quelques espèces, les étamines les plus extérieures sont stériles. Dans ce cas, les anthères manquent et les filets élargis ont une forme et une consistance pétalö̈de. Si celte forme était plus prononcée, les étamines auraient l'aspect de vrais pétales, et la fleur alors serait double; mais on ne connaît pas encore d'Anonacée qui présente ce phénomène.

Pistils. Toutes les Anonacées ont plusieurs pistils, 3-roo, si l'on en excepte deux espèces qui vont constituer mon genre Monodora, et qui n'en ont qu'un. Ces pistils sont silués d'une manière très-serrée au centre du réceptacle, entourés d'étamines qui quelquefois les recouvrent en partie et avec lesquelles on les confond au premier coup d'œil. Chacun des ovaires a un stigmate sessile ou porté sur un style court. Les stigmates sont souvent garnis de

(1) Asimina parvifiora; Porcelia nitidifolia; Xylopia prinoides; Gualteria virgata; G. laurifolia. 
poils. Les ovaires sont tantôt distincls les uns des autres, tantốt soudés entr'eux; c'est ce qui est surtout remarquable dans les fruits.

Fruits. Ceux-ci formés par le développement de plusieurs ovaires g' excepté dans le genre Monodora, diffèrent entr'eux par le nombre, la réunion ou l'isolement des fruits partiels qui résultent du développement de chaque ovaire, fruits partiels que j'appellerai Carpelles ( $\mathrm{I}$ ). D'après ces différences, on peut considérer trois formes principales de fruits dans les Anonacées: $10^{\circ}$ ceux qui proviennent d'un seul ovaire; $20^{\circ}$ ceux qui sont le résultat de plusieurs ovaires isolés et qui sont composés en conséquence de plusieurs carpelles isolés ; $30^{\circ}$ ceux qui résultent de l'aggrégation et de la soudure de plusieurs ovaires et par suite de plusieurs carpelles. Lorsque ces carpelles ou fruits parliels, qui sont tantôt des baies, tantùt des capsules, sont aggrégés et soudés entr'eux sur. un réceptacle commun le plus souvent conique, il en résulte un fruit unique renfermant un grand nombre de loges, nombre qui est égal à celui des carpelles soudés; tels sont les fruits des genres Kadsura et Anona. La partie extérieure de ces agglomérations est souvent dure, coriace, et présente une surface différente, selon le degré d'aggrégation et la forme des carpelles. Ainsi, on voit ces masses couvertes de pointes ou d'écailles charnues dans certaines espèces; d'autres offrent des réseaux plus ou moins profonds ; d'autres, enfin, sont entièrement lisses et ressemblent, dans ce cas, par leur surface, à ceux qui ne sont formés que d'un seul ovaire.

Ces derniers ne seraient-ils pas le résultat d'une union plus intime de carpelles? Ce que nous en savons aujourd'hui ne peut nous.le faire affirmer. Ce sont des baies presque globuleuses, à péricarpe épais, à une seule loge, dans laquelle se trouvent les graines sans

(I) Il serait utile et commode d'avoir un mot particulier pour exprimer dans un fruit multiple, le fruit partiel résultant de chaque ovaire fécondé et développé; je propose ici celui de Carpelle, Canpeluum. 
ordre apparent et environnées de pulpe. Il est à présumer que dans les jeunes fruits les graines sont disposées d'une manière régulière: La connaissance exacte des ovaires ou des jeunes fruits de ce gemre nous manque entièrement; elle serait pourtant très - importante, puisqu'elle nous apprendrait si le fruit des Monodora résulte du développement d'un seul ovaire, ou s'il résulte de l'aggrégation très-intime de plusieurs ovaires, aggrégation dans laquelle toutes les cloisons internes seraient rompues par le développement du fruit et formeraient la pulpe dans laquelle les graines se trouvent placées.

Il nous reste à parler des fruits formés par plusieurs ovaires isolés, ou pour mieux dire, par plusieurs carpelles distincts. Ces carpelles sont sessiles dans certaines espèces, longuement stipités dans d'autres; sphériques, ovales ou oblongs; à péricarpe charnu ou sec, souvent coriace, rarement membraneux; monospermes. dans certains genres, polyspermes dans d'autres. Dans ces derniers, les graines sont disposées sur un seul rang ou sur deux rangs, souvent séparées les unes des autres par des cloisons. Les carpelles ont souvent une forme à laquelle contribuent la disposition des graines qu'ils renferment. Ainsi, les uns se rétrécissent sur chaque graine et forment des fruits en chapelet; d'autres ont des bosselures qui répondent à la convexité des graines. Le nombre des carpelles varie selon les espèces depuis 3 jusqu’à 50 ou 6o. Ils sont portés sur un réceptacle souvent peu apparent, ordinairement presque hémisphériṛue, marqué de cicatrices après la chute des carpelies, ou portant les supports de ceux qui sont stipités quand ces carpelles sont tombés.

Péricarpe. I'épicarpe de ces fruits est le plus souvent lisse, velu dans un petit nombre d'espèces, sur-tont dans la jeunesse du fruit, marqué de rugosités ou d'aspérités dans quelques autres. Le sarcocarpe est charnu, coriace ou mol, quelquefois membraneux. L'endocarpe est presque toujours lisse et luisant; le placenta est peu apparent. Dans les genres où les fruits résultent de l'aggrégation de plusieurs carpelles, le réceptacle de la fleur développé se trouve au centre du fruil et parait un vrai placenta, mais il n'en a que 
lapparence. Un cordon ombilical tris-court attache chaque graine à la base de chaque loge qui la renferme el à la partie latérale interne de cette loge. Ce cordon ombilical se termine quelquefois par un arille qui recouvre la graine en totalité ou en partic.

Graines. Les graines des Anonacées solitaires ou géminées dans chaque logge, sont ovales ou ovales-oblongues, souvent comprimées de divers cûtés par la pression qu'elles éprouvent dans leur péricarpe. Elles ont souvent à leur base une pointe, à côté de laquelle ou sur laquelle s'insère le cordon ombilical. Leur test est lisse, sec, souvent brunâtre, peu épais, le plus souvent de la consistance d'une carte à jouer, mais fragile. Le sarcoderme se confond avee le test; la membrane interne est très-remarquable, comme nous l'avons dit ailleurs; elle s'enfonce en replis transversaux, planes ou en pointe, dans le corps même de l'albumen, de telle sorte que ce dernier corps coupé longitudinalement présente de nombreuses raies transversales ou des points très-multipliés.

L'albumen ainsi divisé par la membrane interne remplit exactement le spermoderme, dont il a par conséquent la forme. L'embryon se trouve logé à la partie inférieure de cet albumen ; il est trèspetit, droit, à cotylédons un peu comprimés et à radicule presque cylindrique et inférieure.

Organes de la végétation. Comme nous l'avons déjà dit, les Anonacées sont toules des arbres ou des arbrisseaux.

Racines. Leurs racines sont encore peu connues. Celles de l'Asimina triloba sont cylindriques, d'un brun noirâtre, tortueuses, se recourbant sur elles-mêmes et garnies d'une grande quantité de chevelu. Pison et Marcgrave ( I) rapportent que celles d'une espèce qui croît dans les pays marécageux, et qui est peut-être l'Anona palustris, sont très-légères, très-longues et d'un grand diamètre, puisqu'on en fait des boucliers d'une seule pièce. Burmann (2) assure que celles de l'Anona Asiatica renferment un principe colorant rouge.

(1) Pison. Bras. p. 69. Marcg. $9^{3}$.

(2) Thesaurus Zeylanicus. p. 2 I. 
Tiges. Leurs tiges sont toutes ligneuses. Leur écorce est souvent: parsemée de petits tubercules glanduleux auxquels elles sont vraisemblablement redevables de leurs propriétés excitantes et aromatiques. L'écorce prend la consistance du liége dans le Guatteria suberosa. Serait-ce l'écorce de l'Anona palustris dont on se sert dans la Guiane pour faire des bouchons? Ce serait un second exemple d'écorces subéreuses dans cette famille. Le bois des Anonacées est blanchàtre, souple et facile à fendre.

Feuilles. Celles-ci, souvent portées par des pétioles courts, quelquefois sessiles, sont toujours alternes, souvent distiches, simples, solitaires, entières dans toutes les espèces connues, excepté dans le seul genre Kadsura qui les a dentées en scie; leur forme est ovale ou oblongue; souvent elles sont prolongées en pointe. Leur parenchyme, dans certaines espèces, est parsemé de petites glandes transparentes, semblables à celles des millepertuis, glandes qui doivent sûrement contribuer à l'odeur pénétrante que les feuilles exhalent.

Inflorescence. Les fleurs sont portées sur des pédoncules le plus souvent axillaires, quelquefois opposés aux feuilles, rarement latéraux. Ces pédoncules, le plus souvent solitaires et uniflores, sont quelquefois géminés, quelquefois à plusieurs fleurs, mais celles-ci sont toujours en petit nombre. Excepté les pédoncules de l'Unona penduliflora et du Guatteria pendula, qui sont plus longs que les feuilles, les pédoncules de toutes les autres espèces de la familie sont plus courts que les feuilles et ordinairement beaucoup plus courts. Ces pédoncules portent souvent une ou plusieurs petites bractées demi-embrassantes.

Organes accessoires. Les poils qui revêtent plusieurs partié de certaines espèces sont le plus souvent courts et étoilés. Ceux qui couvrent les jeunes rameaux et les jeunes feuilles de quelques-unes, se détachent graduellement à mesure que la plante avance en âge, et finissent par disparaître entièrement. Les poils ne couvrent jamais de gros rameaux. Ceux qu'on voit sur les feuilles ne sont souvent qu'à la surface inférieure, mais toujours plus serrés et plus nombreux sur celte surface que sur la supérieure. Quelquefois les pédoncules 
et les calices seuls en sont pourvus, quand les autres parties de la plante sont glabres. Quelques espèces de Xylopia offrent des poils simples, longs et couchés sur la partie qu'ils recouvrent.

On ne connait ancune Anonacée munie d'aiguillons. Un pelit nombre d'espèces portent des crochets analogues aux vrilles; ces crochets ne sont que des pédoncules avortés; car plusieurs d'entr'eux portent encore des. fleurs fertiles et des traces de fleurs avortées.

\section{Propriètés et Usages.}

Cette famille étant très-naturelle, les propriétés des diverses espèces qui la composent doivent avoir la plus grande analogie. En effet, presque toutes les parties de ces espèces jouissent d'une odeur et d'une saveur forte, âcre, piquante et aromatique. Ces propriétés ont fait rechercher certaines parties pour des usages thérapeutiques : ce sont Ies écorces et les feuilles; d'autres parties, comme les fleurs, ont été recherchées pour l'agrément. Certains fruits, dont le péricarpe est secet dont la saveur est aromatique et piquante, sont employés comme condimens; d'autres fruits, qui sont charnus et dans lesquels le principe aromatique se trouve combiné avec un mucilage sucré et quelquefois avec un acide, sont recherchés comme aliment. Les voyageurs s'accordent à dire que la saveur de la plupart de ces fruits n'est agréable que pour les naturels des pays où ils croissent, et que celle des fruits des Anones les plus généralement cultivées, ne plaît aux Européens que lorsqu'ils en ont fait asage pendant quelque temps.

Nous ferons connaitre avec plus de détail l'usage des diverses espè-ces employées, à la suite de l'examen particulier de chaque genre.

\section{Habilations, Stations et Culture des Anonacées.}

'Aucune espèce de cette famille ne croît spontanément en Europe. Les arbres et les arbrisseaux qui la composent sont tous originaires de pays situés sous la zone torride ou sous la zone tempérée sep- 
tentrionale, au sud du $33 .^{\circ}$ degré de latitude, c'est-à-dire, dans la partie de cette zone qui avoisine le plus le tropique. Ils croissent dans les forêts, sur les montagnes, ou aux bords des lacs et deș rivières. On en connait 44 espèces dans l'ancien continent, 52 dans le nouveau, I dans la Nouvelle - Hollande, 2 dont la patrie est inconnue, 4 qui paraissent originaires des Antilles ou pays voisins et qui sont cultivées partont dans les deux Indes. Ces ro3 espèces sont distribuées de la manière suivante:

4 Vraisemblablement d'origine Américaine, cultivées partout dans les deux Indes.

5 De pays situés sous la zone tempérée septentrionale Américaine, savoir ; la Caroline, la Géorgie, la Virginie et la Floride.

47 Des îles ou de la pariie du continent d'Amérique située entre les tropiques, savoir: les Antilles, Cayenne, le Mexique, la Guiane, le Pérou, le Bassin de I'Orenoque et le Brésil.

I D'Égypte, vraisemblablement cultivée.

7 De Sierra-Léone, d'Oware ou de Guinée.

3 De Madagascar, des îles de France et de Bourbon.

13 Du Coromandel ou du Malabar.

13 Des líes de la Sonde ct des Moluques.

6 De la Chine on du Japon.

$x$ De la Nouvelle-Calédonie.

I De la Nouvelle-Hollande.

2 Dont la patrie est inconnue.

103 espèces.

Nous ne savons rien sur les procédés employés dans les deux Indes pour la culture des Anonacées. On ne les cultive en Europe que dans les jardins de botanique et dans les grandes collections; jusqu’à ce jour, on n’a cultivé que quelques espèces des genres Anona et Asimina.

Les Asimina, originaires de l'Amérique septentrionale, passent en pleine terre en France et surtout l'Asimina triloba qui est la plus réprandue. Ces plantes fleurissent dans nos climats mais n'y fructi- 
fient pas. On les multiplie de graines qu'on sème comme toutes celles d'orangerie. Elles sont deux ans à lever. On doit garder en orangerie et en pot les jeunes individus qui en résultent, jusqu’à ce qu'ils aient acquis assez de consistance pour être plantés en pleine terre. L'accroissement de ces plantes parait très-lent.

Les Anona, originaires de la Zone torride, ne peuvent être cultivés chez nous qu'en serre chaude. On les multiplie par leurs graines tirées de leur pays natal et semées sur couche sous châssis. Si elles sont fraîches, elles lèvent en peu de temps et les jeunes plants bien conduits acquièrent bientôt trois pieds de haut. On ne doit les changer de terre, que lorsque leurs racines ont bien tapissé les parois de leur vase (1).

Les Anona ne fructifient jamais en Europe, où ils ne sont cultivés que pour leur feuillage.

\section{Histoire générale des genres.}

Époques de l'établissement des genres et considérations générales sur leur nature.

Le premier genre de cette famille a été créé par Plumier (2), sous le nom de Guanabanus. C'est celui que nous connaissons aujourd'hui sous le nom d'Anona, et le type de la famille. Linné créa plus tard les genres Uvaria et Xylopia (3) dans son admirable Genera. Plus tard encore, dans son supplément (4), il établit le genre Unonc. Adanson, en $1763(5)$, créa le genre Asimina, qui fut négligé. mal-à-propos et qui a été rétabli depuis, comme nous le verrons. Deux autres genres de cette famille se trouvent dans la Flore du:

(1) Dumont-Courset. Bot. cult. t. III:

(2) Nova genera Americana. 7 o3.

(3) Genera plantarum. I 33 .

(4) Supplementum plantarum. $178 \mathrm{I}$ :

(5) Familles des plantes. I 763. 
Pérou de MM. Ruiz et Pavon ( 1 ); ce sont les genres Porcelic et Guatteria. Plusieurs espèces qui avaient été groupées dans les genres Uyaria ou Unona rentrent daus le second de ces genres. M. de Jussieu (2) a reconnu que la plante de Kæmpfer, (ésignée dıns nos livres sous le nom d'Uvaria Japonica, devait constituer un genre dislinct et il a établi ce genre sous le nom de Kadsura. Eufin, deux espèces dont les fruits seuls ont été figurés, l'un par Gærtner (3), et l'autre par Jacquin (4), me paraissent devoir constituer un nouveau genre; je le décrirai plus bas sous le nom de Monodora.

Plusieurs auteurs ont décrit plusieurs genres d'Anonacées sous les noms de Miarenteria, Krockeria, Desmos., Melodorum, Bulliarda, Aberemoa, Orchidocarpum; mais tous ces genres rentrent dans ceux que nous avons indiqués ou sont les mêmes, et ceux que nous avons indiqués étaient tous établis précéẻemment.

M. Robert Brown a décrit en dernier lieu, sous le nom d'Eupomatia laurina (J), une espèce singulière et très-remarquable de la Nouvelle-Hollande, espèce qui, selon lui, appartient à la famille des Anonacées, et qui a effectivement ses graines semblables à celles des espèces de cette famille; mais les autres parties de la fleur offrent de telles différences de structure, que je n'ose pas encore regarder cette plante comme une Anonacée; en conséquence je ne ferai pas mention du genre qu'elle constitue.

Nous venons de voir à quelles époques et par qui ont été créés les divers genres qui composent cette famille. Nous verrons plus loin, dans l'histoire particulière de chaque genre, les modifications que j’ai fait éprouver à certains d'entr'eux, les causes de l'établis-

(1) Flora Peruviana et Chilensis prodromus, auctoribus Ruiz et Pavon. × 79 \%

(2) Annales du Muséum d'histoire naturelle. t. r6. p. 340.

(3) De fructibus et seminibus plantarum. vol. II. t. 125. $f$. r.

(4) Jacq. Fragmenta. p. 40. t. 44. $f$. 7 .

(5) General remarcks onche Botany of terra australis. London. 1814 . p. 66. t. 2 . 
sement d'un nouveau genre et la raison des noms que j’ai adoptés. Maintenant je vais rapidement considérer, en général, sur quelles bases reposent les genres de cette famille et examiner leurs divers degrés d'importance.

La famille des Anonacées est si naturelle qu'elle n'est presque qu'un grand genre; aussi ceux qui la composent sont-ils difficiles à circonserire; ils ont été mal circonscrits par la plupart des Botanistes, et ce qui le prouve, c'est que plusieurs espèces ont été portées successivement dans plusieurs de ces genres. M. de Jussieu ( I) est celui de tous les Botanistes qui a le mieux caractérisé les genres de cette famille, dans un excellent mémoire inséré dans les Annales du Muséum d'histoire naturelle, mémoire qui m’a servi de base pour cette partie de mon travail.

Le calice, les pétales et les étamines de Anonacées ne peuvent pas servir à distinguer les genres. Le calice et les étamines présentent peu de différences; les pétales qui en présentent de trèsremarquables, ne peuvent servir de base à aucune coupe naturelle, puisque les difiérences de forme les plus prononcées de ces organes se trouvent quelquefois dans les espèces les plus voisines par leur port, par la structure de leur fruit, par l'analogie de l'ensemble des autres organes, et que, d'une autre part, des pétales de forme semblable se trouvent dans des espèces qui diffèrent entièrement par toutes leurs autres parties. Les fruits offrent des différences notables, qui donnent d'assez bonnes bases pour l'établissement des genres. Le nombre des ovaires et par suite celui des carpelles, leur état d'agrégation ou de séparation, fournissent de bons caraclères. La forme des carpelles, la nature de leur péricarpe, le nombre et la disposilion de leurs graines, donnent des caractères d'une moindre importance. Aussi les genres fondés sur ces dernières bases sont moins naturels que ceux qui sont établis sur les premières que nous avons indiquées, et à toute rigueur, comme l'a

(r) Anu. du Mus, t. i6. pag. 3亿o. 
fort bien dit M. de Jussieu ( 1 ), ils pourraient bien ne constituer qu'un seul groupe. Ce groupe, s'il existait, réunirait trop de formes: diverses et à cause de cela il doit être divisé. Je donnerai, je. l'espère, les caractères des genres que j'admets aujourd'hui d'une manière plus précise qu'on ne l'a fait jusqu'à ce jour. Les formes des fleurs me serviront à établir des sous-divisions dans chacun. d'eux.

Avant de passer à l'histoire et à la description de chaque genre en particulier, je vais présenter ici quatre tableaux de ces genres. tels que je les conçois aujourd'hui. Les deux premiers sont des tableaux analytiques, semblables à ceux que M. Lestiboudois a donnés dans son estimable Botanographie Belgique; tableaux dont le but est de rendre saillantes les différences. Le troisième est la série linéaire des genres, ou l'ordre selon lequel je les décrirai. Le quatrième représente les fruits de chaque genre, disposés et liés selon leurs affinités naturelles. (Voyez la planche $\mathbf{1}^{\mathrm{re}}{ }^{\mathrm{C}}$ ) Ce dernier tableau est analogue à ceux qu'a publiés Giseke, pour faire sentir les affinités. mulliples des familles des plantes. Des tableaux semblables sé trouveront dans l'immense et superbe ouvrage auquel M. de Candolle travaille dans ce moment et dont il va bientôt enrichir la science. J'ai donné ici deux tableaux analytiques des genres à cause du. Kadsura. Le fruit de cet arbuste n'est pas décrit complètement, et d'après ce qu'on en sait, on peut concevoir de deux manières. sa structure anatomique (2). Chacun des tableaux analytiques sui-. vans est fait dans une de ces deux hypothèses.

(x) Gen. p. 284.

(2) Voyez p. 26. 
TABLEAU I. ${ }^{\mathrm{er}}$

Tableau analytique des genres.

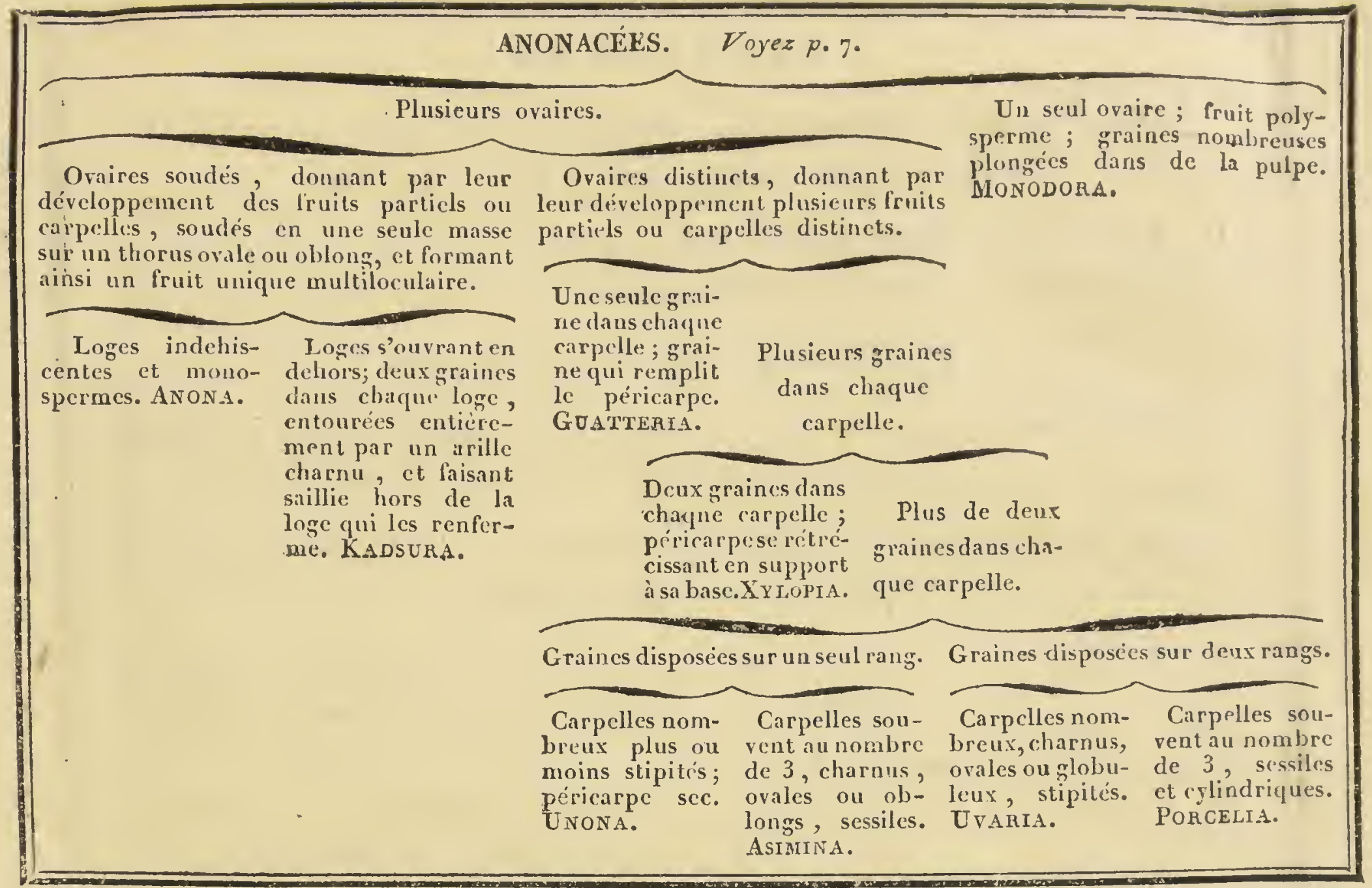

TABLEAU II. ${ }^{\mathrm{e}}$ Autre Tableau analytique des genres.

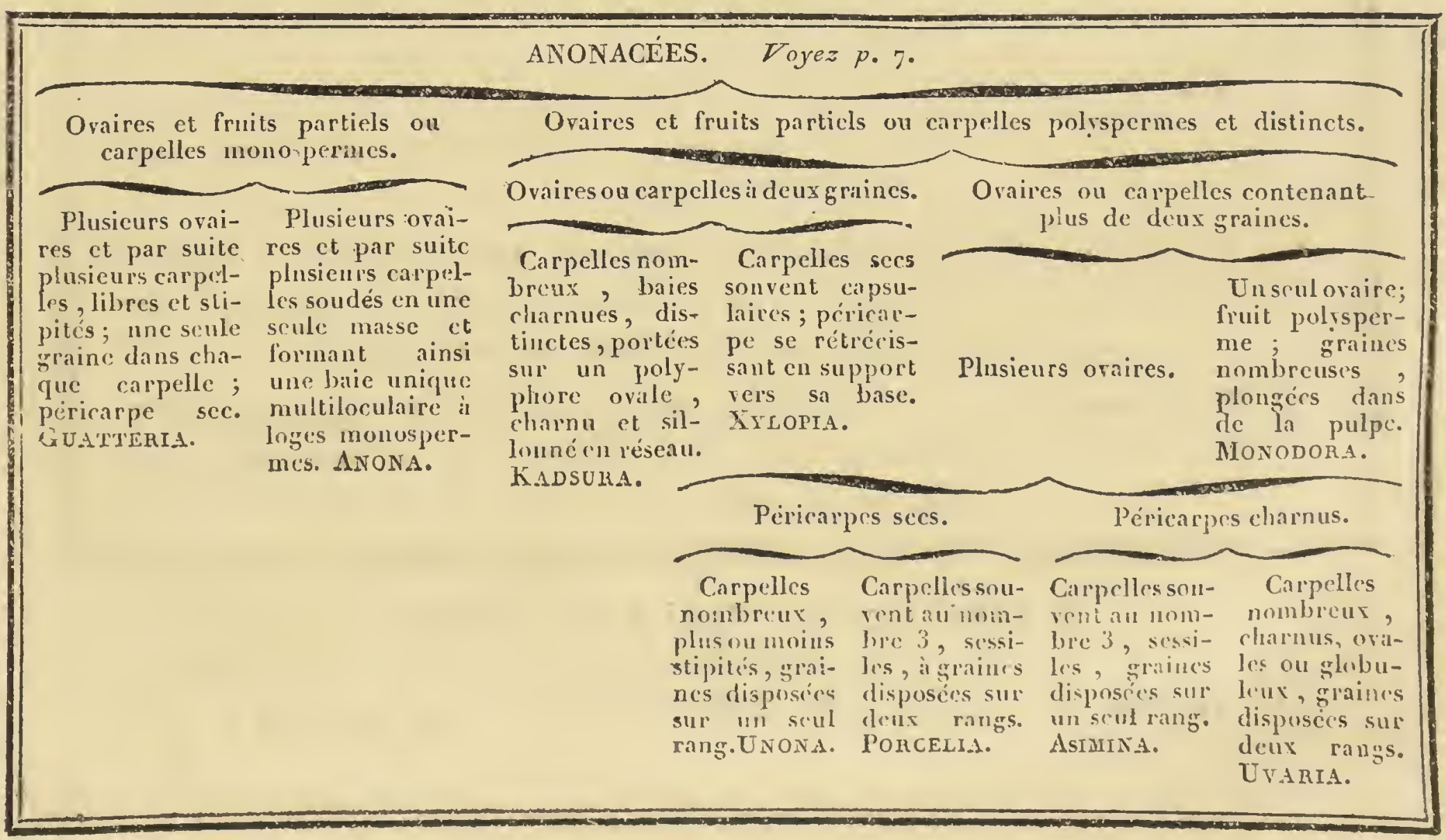




\section{A N O N A C E E S.}

§. Fruit unique multiloculaire, résultat de l'agrégation de plusieur's. fruits partiels ou curpelles à une seule loge.

1. KADSURA. Loges du fruit à deux graines.

2. ANONA. Loges à une seule graine.

\section{\$5. Un seul ovaire ou un seul fruit.}

3. Monodora. Un seul fruit globuleux à un grand nombre de graines placées sans ordre apparent dans de la pulpe.

\$55. Plusieurs ovaires distincts, donnant par leur développement plusieurs carpelles distincts.

4. ASIMINA. 3 à 6 carpelles, ordinairement 3 , sessiles, ovales ou oblongs, à péricarpe charuu et à plusieurs graines sur un seul rang:

5. Porcelia. 3 à 6 carpelles, sessiles, cylindriques, à péricarpe coriace et à plusieurs graines sur deux rangs.

6. UvARIA. 6 à i 5 carpelles, plus ou moins stipités, ovales ou globuleux, à péricarpe charuu et à plusieurs graines sur deux rangs.

7. XyLOpıA. 6 à 20 carpelles, à péricarpe sec rétréci à sa base en forme de support, à deux graines sur deux rangs ou sur un seul rang.

8. UNONA. 8 à 30 carpelles, plus ou moins stipités, ovales, oblongs ou en forme de chapelet, à péricarpe sec et à plusieurs graines sur un seul rang.

9. Cuatteria. 8 à 40 carpelles, stipités, ovales ou spluériques, à péricarpe sec, et à seule graine qui remplit entièrement le péricarpe.

T A B L A U Q UATRIEME.

Tableau des genres selon leurs affinités. Voy. planche I. 


\section{Historre particulière des genres.}

\section{Du genre KADSURA.}

L'arbrisseau qui constitue ce genre a été décrit pour la première fois par Kæmpfer en 17 I 2 ( I). Linné (2), Thunberg (3), Lamarck (4) et Willdenow (5), l'ont regardé sans aucun doute comme une Anonacée, puisqu'ils l'ont placé dans le genre Uvaria. M. de Jussieu (6), en le signalant depuis comme un genre distinct, l'a placé avec doute dans la famille dont nous nous occupons. Ce doute était fondé sur deux choses importantes; l'une était le défaut de la connaissance exacte de la structure interne de la graine; l'autre, que le Kadsura a les feuilles dentées en scie, forme qui ne se retrouve dans aucune autre Anonacée, toutes les autres espèces connues ayant les feuilles entières. Par la forme des feuilles, cette plante paraissait se rapprocher du genre Michelia, de la famille des Magnoliacées; mais elle en différait par sa corolle à 6 pétales et non à 15 , par les loges des fruits partiels ou carpelles renfermant 2 graines et non 3 ou 4. Les 6 pétales, les carpelles à 2 graines faisaient penser que cette espèce était une Anonacée ; et de plus, Thunberg disant que ses anthères étaient courtes et persistantes, on conjecturait de-là qu'elles étaient adnées et semblables à celles des autres Anonacées.

D'après ce que nous venons d'exposer, il paraissait tout-à-fait probable que le Kadsura appartenait à cette dernière famille. Le

(I) Amanitatum exoticarum fasciculi 5. Fas. 2. p. 476. tab. p. 477:

(2) $S p . p l \cdot p \cdot 7^{56 .}$

(3) Fl. Jap. p. 237 .

(4) Lam. Dict. I. p. 597.

(5) Sp. pl. 2.p. 2265.

(6) Ann. l. c. 


\section{6}

célèbre Rob. Brown, qui a eu occasion de voir celte espèce et une autre du même genre qui n'est encore connue que de lui, a communiqué à $M$. de Candolle, qu'après un examen atlentif de ces plantes, il s'est assuré que ce sont de vraies Anonacées. Celle qui nous est encore inconnue a des feuilles dentées dans la jeunesse de la plante, et n'a que des feuilles entières quand elle est plus âgée. Nous espérons que ce savant eslimable nous fera connaître d'une manière claire et précise la structure intime de ces végétaux, sur lesquels nous n'avons pas encore des données suffisamment exactes.

Voici ce que nous savons de positif sur la structure de l'espèce décrite, la seule dont nous puissions nous occuper.

Organes de la reproduction. Thunberg dit que les feurs di Kadsura sont monoïgues, mais sa description prowve quelles sont hermaphrodites. Le calice est à trois parties; les pétales, au nombre de 6 , sont de forme ovale; les étamines en grand nombre sont contes et adnées ( 1 ) ? La structure anatomique dn fruit, d'après ce que nous sarons aujourd'hui, peut être conçue de deux manières. Un corps charnu ou fongueux, très-blanc à linntérieur, un peu rougcấtre à la surface, rond ou ovale el sillonné en réseau, porte 30 à 40 corps globulenx charnus, de consistance molle et de couleur rouge, renfermant chacun deux graines géminées en forme de rein, corys globuleux qui naissent d'autant d'excavalions situées au centre des losanges formés par les sillons en réseau. - Ce fruit multiple peut être considéré comme le résultat d'une agrégation sur un réceptacle commun (2) de fruits particls ou carpelles charnus, s'ouvrant en deliors, comme s'ouvrent les carpelles de certains $X_{Y-}$ lopia, et laissant sortir par celte ourerture deux graines géminćes renfermées dans un arille complet et charnu, de mème que les

(1) Ces premiers caractères sont d'après Thunberg; la forme du fruit est d'après Thunberg et Kimpfer.

(2) Comme dans les Anona. 
capsules de Xylopia laissent apercevoir, par leur ouverture, deux graines entourées à leur base d'un arille incomplet et membraneux. Dans cette hypothèse, les sillons en réseau qui s’aperçoivent sur le corps charnu qui porte les petils corps globuleux, sillons semblables à ceux de l'Anona reliculata, seraient, comme ces derniers, les traces de la limite de chaque carpelle; les excavalions qui se trouvent au centre des losanges formés par les sillons, seraient les ouvertures de chaque carpelle; les corps charrius, globuleux, qu'on a coutume d'appeler les baies du Kadsura, seraient des arilles charnus et complets, semblables à ceux des graines de Magnolia, fixés par un cordon ombilical très-court à la partie interne de chaque carpelle et renfermant chacun deux graines géminées.

La seconde manière de conceroir la structure anatomique de ce fruit, est de considérer le corps charnu sillonné en réseau, comme un polyphore charnu, portant des baies charnues, vrais carpelles renfermant chacun deux graines géminées. La description que $\mathbf{M}$. R. Brown donnera un jour de ces fruits, les faisant connaître exactement, apprendra d'une manière certaine quelle est celle des deux hypothèses ci-dessus qui est l'expression de la vérité. En formant la série linéaire des genres, j’ai agi comme si la première de ces hypothèses élait prouvée.

Les graines du Kadsura sont en forme de rein, toujours géminées, aplaties du côté par lequel elles se touchent; le spermoderme est cendré, le périsperme est blanc et assez dur.

Organes de la végétation. Le Kadsura est un arbrisseau du Japon, dont les rameaux nombreux disposés irrégulièrement, sont flexueux, de couleur brune, crevassés et couverts de petits corps glanduleux. Leur écorce est épaisse, charnue et visqueuse. Les feuilles portées par des pétioles cour's et d'un rouge pourpré sont épaisses, ovales ou ovales-oblongues, terminées en pointe des deux cûlés, glabres et denlées en scie, ce qui est le seul exemple de feuilles dentées dans cette famille. Les flems sont solitaires, portées par un pédoncule herbacé, long d'environ un pouce et demi, pédoncule qui derient penché et renflé au sommet après la floraison. 
Propriétés et usages. Lorsqu'on mâche, dit Kæmpfer (1), la plus petite partie de l'écorce de cet arbuste, la bouche se remplit de mucosité. Les fenilles en infusion dans l'eau fournissent aussi un mucilage très-abondant. Ce mucilage est employé par les papetiers japonais dans la fabrication du papier fait avec l'écorce du Broussonetia papyrifera (2). Les femmes japonaises s'en servent pour humecter les cheveux qui doivent être rasés (3). Les graines de Kadsura ont une saveur âcre, très-désagréable, qui se fait principalement sentir dans l'arrière-bouche.

\section{I. Du genre ANONA.}

Plumier (4) avait d'abord établi ce genre sous le nom de Guanabanus, du nom américain Guanabano dont s'était servi Gonzales Oviedo (5) pour désigner une de ses espèces. Plukenet, Sloanne, G. Commelin et Catesby, signalèrent ou décrivirent ensuite plusieurs espèces du même genre sous un autre nom indien, celui d'Anona. Linné, dans sa revue générale des genres des plantes, en adoptant le genre Guanabanus de Plumier, n'adopta pas le nom de cet anteur, soit parce que ce nom avait une consonance trop analogue à celle de plusieurs autres noms de genres (6), soit parce qu'il n'était pas d'origine grecque ou latine (7). Il choisit le nom Indien Anona pour désigner ce genre, mais en doublant la lettre $n$ de la seconde syllabe pour donner à ce mot une signification latine (8). Depuis cette époque, tous les botanistes ont adopté pour ce genre le nom

(I) Aman.l. c.

(2) Kcompf. l. c. Thunberg. Flor. Jap.

(3) Thunb. l. c.

(4) Genera. p. 42. t. Io.

(5) Summ. Ind. Orient. 63. cap. 64. Hist. Gen. ind. lib. 8. cap. x 7 è Marcg.

(6) L. Critica botanica. p. 403.

(7) L. l. c.p. $40 \mathrm{~s}$.

(8) L. Philosophia botanica. p. 163: 
Anona ou Annona; ceux de l'école de Linné en l'écrivant Annona, la plupart de ceux de l'école française en l'écrivant Anona.

Ce genre a été fort bien distingué par Adanson. Linné et de Jussieu, dans leurs Genera, en ont donné une description exacte; mais Linné, dans son Species, a placé dans ce genre, sous le nom d'Anona triloba, une espèce qui doit faire partie d'un genre distinct: Ce dernier genre, comme nous le verrons plus bas, a d'abord été établi par Adanson et adopté en dernier lieu par M. de Jussieu (1).

Le genre Anona, tel qu'il doit être conservé aujourd'hui, diffère de tous les autres genres de la famille par son fruit, qui est une baie unique, résultant de la soudure d'un grand nombre de baies monospermes, de telle sorte qu'il paraît multiloculaire à loges monospermes.

Organes de la reproduction. Le calice est le plus souvent à 3 parties, petiles, sessiles, presqu'en forme de cœur à leur base, ovales, prolongées en pointe et concaves; dans un petit nombre d'espèces, ce calice est souvent campanulé à 3 ou 4-lobes et coriace: La corolle est le plus souvent formée de 6 pétales, placés alternalivement sur deux rangs, ceux du rang interne plus petits que ceux du rang externe. Deux espèces connues seulement manquent des pétales du rang interne, leurs pétales externes étant néanmoins disposés comme dans les autres espèces. La forme des pétales varie selon les espèces : dans les unes, ils sont ovales en forme de cœur à leur base, ceux du rang extérieur épais et aigus, ceux du rang interne plus délicats et obtus; dans d'autres, tous sont ou obtus ou aigus; dans certaines, ils sont triangulaires et oblongs, et le rang -interne si petit quil n'est quelquefois pas aussi grand que le calice. Dans celles-ci, les pétales sont peu ouverts et avant leur épanouissement forment par leur réunion une pyramide triangulaire, oblongue et aiguë. Ils ont à leur base une concavité ordinairement colorée autrement que le reste du pétale, et sous laquelle est logé Je faisceau des étamines. La plupart des pétales d'Anones sont épais et

(1) Anq du Mus. a6. p. 339. 
portent sur leur milieu, à l'extérieur, une nervure longitudinale. Pison et Marcgrave ( I ) rapportent que ceux de l'An. muricata font un bruit remarquable, lorsque après s'être détachés du calice, ils tombent, ce qui leur arrive bientùt après l'épanouissement de la fleur. Celles de cette espèce ont une odeur suave et forte.

Les étamines sont nombreuses (de 400 à 500 selon Adanson), à anthères presque sessiles, presque tétragones, un peu élargies au sommet, recouvrant d'une manière très-serrée un réceptacle hémisphérique, de sorte que leur ensemble est aussi hémisphérique. La position et la structure des anthères sont tout à fait semblables à celles des autres genres de la famille (2). Ordinairement d'un jaune clair dans la jeunesse de la fleur, elles acquièrent par degrés une couleur plus intense et deviennent enfin fauves. Les ovaires au centre de ces nombreuses étamines sont presque entièrement couverts par elles. Ils sont nombreux, réunis en un seul corps, surmontés par des stigmates aussi nombreux qu'eux. On en compte, selon Adanson, de 40 à 130 .

Ce corps d'ovaires étant développé forme une baie conoïde ou globuleuse, charnue, munie d'un péricarpe épais, qui est tantôt hérissé de prolongemens aigus, tantôt ayant des prolongemens oblus, tantôt portant des élévalions ou des sillons en réseaux, rarement lisse, offrant des crevasses régulières dans certaines espèces. Ces différentes formes dépendent, comme nous l'avons dit ailleurs, et du degré d'agrégation et de la forme particulière des carpelles constituans. La partie interne de cette baie multiple est charnue, pulpeuse et divisée en autant de loges qu'il entre d'ovaires soudés dans sa structure, et qu'il y a de tubercules sur la partie externe du péricarpe dans les espèces qui portent de ces tubercules. Les carpelles monospermes dont l'ensemble et la soudure forment le fruit que nous venons de décrire, peuvent être séparés les uns des autres dans les jeunes fruits de certaines espèces.

(1) L. c.

(2) Voyez page I2. 
Deux plantes regardées jusqu'a ce jour comme faisant partie du genre Anona, portent des fruits qui ne paraissent pas etre organisés comme nous venons de le dire: ce sont les Anona microcarpa, Jacq. et Anona myristica, Grerlu. Ces plantes doivent, à mon avis, constituer un genre distinct; je l'établis plus bas sous le nom de Monodora. Peut - être que quelques autres espèces d'Anones dont le fruit est lisse appartiendront à ce dernier groupe.

Les fruits des Anona amplexicaulis, glabra et grandiflora ne sont qu'imparfaitement connus. La structure de l'ensemble de leurs parties me fait penser que ces espèces pourraient bien aussi constituer un genre particulier. En attendant qu'elles soient mieux connues, je les considérerai avec les auteurs qui m’ont précédé, comme faisant parlie du genre qui nous occupe.

Organes de la végétation. Toutes les Anones sont des arbres ou des arbrisseaux à rameaux cylindriques, souvent rugueux et couverts de petits tubercules glanduleux. Leurs feuilles sont comme toutes celles des plantes de la famille, alternes, entières, munies de courts pétioles, n'ayant jamais de stipules à leur base. Celles de certaines espèces sont parsemées de glandes transparentes, semblables à celles des millepertuis. L.es fleurs portées sur de courts pédoncules sont le plus souvent axillaires, quelquefois presque opposées aux feuilles, rarement latérales; le plus souvent solitaires, quelquefois néanmoins plusieurs pédoncules partent du même point; ceux-ci sont le plus souvent uniflores, rarement à 2 ou 3 fleurs.

Toutes les Anones habitent entre les tropiques.

Propriétés et usages. Plusieurs espèces sont cultivées dans les deux Indes pour divers usages. La plupart sont recherchées pour leurs fruils, qui sont bons à manger. Les feuilles et les fleurs sont souvent odorantes et leur odeur quelquefois désagréable. Leur écorce est souvent aromatique.

Burmann ( I) dit que la racine de l'Anona Asiatica s'emploie ì Ceylan pour teindre en rouge. Les racines d'une espèce du Brésil,

(1) Thos. Zeyl.p. 2I; 
que Pison et Marcgrave (I) désignent sous le nom d'Araticu-pana, sont légeres et d'un grand diamètre. A cause de cela, elles étaient employées par les Sauvages pour faire des boucliers qui résistaient à l'action des flèches et des javelots.

Nous ne savons rien de bien précis sur les propriétés de l'écorce et des feuilles; ce que nous savons nous fait conjecturer qu'elles ont une action excitante. Ainsi, Aublet (2) rapporte que l'Anona 'Ambotay, nommée Ambotay par les Galibis, a une écorce d'un goût piquant et aromatique, que les Galibis emploient en décoclion pour guérir des ulcères de mauvaise nature, connus dans le pays sous le nom de malingres. Étant attaqué de ce mal, Aublet fit usage de ce remêde avec succès. Pison et Marcgrave (3) assurent que les feuilles de l'Anona muricata, macérées dans l'huile d'olive; sont appliquées en cataplasmes par les Brésiliens sur certaines tumeurs; elles favorisent, disent-ils, le travail de la suppuration et l'ouverture spontanée des abcès.

Le bois de quelques espèces est employé utilement. Les Galibis se servent de celui de l'Anona punctata, connu chez eux sous le nom de Pinaou. A cause de la facilité qu'ils ont à le fendre, ils en font des lattes et des chevrons (4). Dans le même pays, le bois de l'Anona palustris est employé au lieu de liége, pour boucher les bouteilles et les calebasses (5), tant il est doux et pliant, même lorsqu'il est sec.

Les fruits de quelques espèces sont recherchés dans les deux Indes; mais, en général, ils ne plaisent pas aux Européens nouvellement débarqués. Les fruits des Anona paludosa (6), palustris (7),

(I) L. c.

(2) Gui. I. p. 616 .

(3) L. c.

(4) Aubl. 1. c. 6ra.

(5) Aubl. 1. c. 6,3 .

(6) Aubl. 1. c. 6,3 .

(7) Aubl. 1. c. 615 . 
longifolia (1), glabra (2), reliculata (3), etc., sont mangés seulement par les naturels des pays où ils croissent.

Les seules espèces cultivées généralement pour leurs fruits, sont: les Anona squamosa et muricata. Les fruits de l'Anona muricata, connus sous les noms vulgaires de Corossol. (4), cachiment ou cachiman, ont une chair blanchâtre, succulente, odorante, de la consistance du beurre et d'une saveur douce, avec une légère acidité. Swartz compare leur saveur à celle des fruits du Ribes nigra. On mange ces fruits lorsqu'ils sont bien mûrs, et de la manière suivante: on les ouvre avec les mains, et on prend la pulpe qui se trouve dans l'intérieur avec une cuiller, ou on porte les morceaux à la bouche. On jette le péricarpe qui a une saveur désagréable et une odeur qui s'approche de celle de la térébenthine (5). La variété $\beta$ de cette espèce, qui est peut-être une espèce distincte, a une chair blanchâtre, fondante, d'une saveur aromatique et sucrée, exhalant une légère odeur d'ambre et de cannelle fort agréable. On fait un grand usage de ces fruits aux Antilles. Il en est de même de ceux de l'Anona squamosa, connus sous les noms français de Pomme-cannelle, Cour de bouf, etc. Leur saveur est analogue à celle des cachimans, et on les mange de la même manière. Cette espèce est cultivée dans les deux Indes; ses fruits sont beaucoup plus estimés que ceux de l'Anona muricata. Ceux de l'Anona cherimolia (Anona tripetala Willd.) sont regardés au Pérou comme des meilleurs fruits du pays; ils ont une chair fondante et vineuse, d'une saveur douce et d'une odeur suave.

Les fruits de l'Anona reticulata, ramassés avant leur maturité, et séchés, sont employés avec succès aux. Antilles dans les diarrhées tenaces $(6)$.

(i) Aubl. 1. c. 614 .

(2) Catesb. 2. p. 64:

(3) Swarlz. Obs. - Jacq. Amer. etc.

(4) Le nom français de Corossol a été employé par Lamarck pous désigner le genre Anona.

(5) Jacq. obs:

(6) Jacq. obs. l. c. 


\section{i I. Du genre MONODORA.}

Dans son inestimable ouvrage (1), Gærtner a décrit le fruit d'une espèce d'Anonacée qu'il désigne sous le nom d'Anona myristica, fruit qui differe beaucoup de ceux des autres espèces de la famille. Il est unique, simple et à une seule loge polysperme; son péricarpe est d'une seule pièce, glabre, lisse et épais; le placenta n'est pas apparent; les graines plongées sans ordre dans une substance pulpeuse qui occupe l'intérieur de ce fruit, sont organisées comme celles des autres Anonacées.

La description que donne Jacquin (2) du fruit de l'espèce qu'il appelle Anona microcarpa, prouve que la structure de celui-ci est tout-à-fait analogue à celle du fruit de l'Anona myristica de Gartner.

Ces fruits diffèrent beaucoup de ceux des aulres genres de la famille; et à cause de cela, il me paraît que les espèces qui les produisent doivent constituer un genre distinct. C'est celui que j'établis aujourd'hui sous le nom de Monodora. Il se distingue de tous les autres genres de la famille par son ovaire unique, par son fruit unique à une seule loge renfermant plusieurs graines.

M. De Candolle a vu, à Londres, dans le riche herbier de $\mathbf{M}$. Lambert, un rameau en fleurs de l'Anona myristica Gærtı., dont il a bien voulu me communiquer la description, qui va me servir pour tracer l'exposé des formes de ce genre.

Organes de la reproduction. Le calice est à 3 parties. Les pétales, au nombre de 6 , sont disposés sur deux rangs; les extérieurs sont oblongs - lancéolés très-ondulés; les intérieurs ovales sont plus épais et plus courts que les extérieurs. L'ovaire est unique, ovale, rétréci au sommet, glabre et couronné par un stigmate sessile. La baie qui résulte du développement de cet ovaire est simple, presque

(1) De fructibus et seminibus plantarum. tom. II. p. x94.t. 125.f. x.

(2) Fragmenta.p.40.t.44.f.7. 
globuleuse, glabre, uniloculaire, polysperme. Les graines ovalesoblongues sont placées sans ordre apparent dans la substance pulpeuse qui occupe l'intérieur du fruit. Comme nous l'avons dit plus haut ( 1 ), il sera extrêmement intéressant d'examiner intérieurement les ovaires et les jeunes fruits de ces espèces. Leur dissection soignée nous fera connaître leur véritable structure interne sur laquelle nous manquons de notions précises.

Organes de la végétation. Les Monodora sont, comme toutes les Anonacées, des arbres ou des arbrisseaux à feuilles alternes. Leurs fleurs sont solitaires sur des pédoncules latéraux, qui portent à leur base ou sur leur longueur de petite`s bractées.

Nous ne connaissons ni les propriétés, ni les usages de ces végétaux.

\section{I v. Du genre ASIMINA.}

Linné (2) et son école ont compris, dans le genre Anona, une espèce de la famille des Anonacées, originaire de l'Amérique septentrionale. Cette espèce diffère des vraies Anones par son fruit, qui: consiste en plusieurs baies, ordinairement trois, sessiles et séparées les unes des autres, multiloculaires, polyspermes, à graines disposées sur un seul rang. On voit, d'après cet exposé, que ce fruit diffère beaucoup de celui des Anones, composé de baies monospermes, étroitement soudées autour d'un axe commun.

Adanson (3) a fait un genre sous le nom d'Asimina, pour type duquel il a donné la plante dont nous venons de parler, et qu'il distingue principalement par les caractères tirés du fruit que nous avons énoncé ci-dessus. Michaux (4) a reproduit ce genre sous le

(1) Voyez page 14 .

(2) $S p \cdot p l \cdot 2 \cdot p \cdot 758$.

(3) Adans. Fam. des plant. 2. p. 365 :

(4) Flor. Boreal-Amcric. I. p. 329. 
nom d'Orchidocarpum, en y joignant trois espèces, deux desquelles avaient été désignées avant par Bartram comme faisant partie du genre Anona, et en ceci, Bartram a été suivi par Willdenow. M. Persoon a réuni les espèces d'Orchidocarpum de Michanx, au genre Porcelia de la flore du Pérou, sous le nom générique de Porcelia. M. de Jussieu a effectué la mème réunion en donnant au groupe le nom le plus ancien, celui d'Asimina. En outre, M. de Jussieu a rapproché de ce genre le Melodorum de Loureiro.

Il me paraît que le genre Asimina doit être distingué du Porcelia par trois caractères: $10^{\circ}$ ses pétales externes plus longs que les internes, ce qui" est le contraire dans le Porcelia ; $20^{\circ}$ ses carpelles à un seul rang de graines et non à deux rangs; $30^{\circ}$ ses péricarpes charnus et non coriaces.

La description que donne Loureiro de son genre Melodorum, me fait penser qu'on doit le rapprocher de l'Unona angustiflora, que j'ai faìt figurer planche 22. En conséquence, je réunis ses espèces à celles du genre Unona (I).

Le caractère du genre $A \operatorname{simina}$, comme je le conçois aujourd'hui, sera donc: pétales ouverts, les externes plus longs que les internes; ovaires et carpelles distincts, sessiles, à plusieurs graines disposées sur un seul rang; carpelles charnus.

Organes de la reproduction. Le calice des Asimina est à trois parties ovales, aiguës. La corolle est ouverte, presqu'en cloche, à 6 pétales alternes sur deux rangs; les internes plus petits que les externes; les uns et les autres obtus. Les élamines en trèsgrand nombre sont insérées sur un réceptacle hémisphérique, et forment par leur ensemble un hémisphère au centre duquel se trouvent les ovaires comme dans les Anones.

Les ovaires ordinairement trois, quelquefois davantage, sont distincts, sessiles, et leur développement montre des baies charnutes, multiloculaires, à un seul rang de loges, renfermant chacune une

(1) Voy. page 42. 
ou deux graines, toujours sur un seul rang. Ces carpelles on assez bien la forme des bulbes d'Orchis, ou si l'on veut celles des testicules de certains animaux; c'est pour cette raison que Michaux (1) a donné à ce genre le nom d'Orchidocarpum.

* Organes de la végétation. Les espèces connues de ce genre sont des arbrisseaux ou sous-arbrisseaux à fleurs axillaires presque sessiles, ayant quelquefois une bractée sur leurs courts pédoncules. Leurs feuilles sont caduques, entières et à courts pélioles. Les fleurs naissent avant les feuilles dans plusieurs espèces, peut-être dans toutes; alors c'est de l'aisselle d'une feuille de l'année précédente qu'on la voit sortir, c'est-à-dire au-dessus de la cicatrice qui est le résultat de la chute de la feuille.

Propriétés et usages. Une seule espèce est connue sous ce dernier rapport ; c'est l'Assiminier, ou Asiminier, Anona triloba L., Asimina triloba Nob. Michaux rapporte que l'écorce et les racines de cet arbuste ont, surtout en été, une odeur nauséabonde: c'est une chose dont je me suis convaincu par l'observation. Les fruits, selon Michaux, ne sont recherchés que des enfans qui vont les cueillir dans les bois. Quelques personnes, à Pittsburg, ont tenté avec succès d'en faire une liqueur spiritueuse.

“ L'odeur déplaisante du fruit, dit Duhamel' (2), fait qu'il n'y

- a que les sauvages qui puissent en manger; néanmoins on s'y * accoutume peu à peu : on prétend que sa chair est agréable et

" saine, mais que la peau, qui s'enlève facilement, laisse aux doigts

" l'impression d'un acide si vif, que si l'on n'a pas l'altention de les

- laver sur-le-champ et qu'on les porte aux yeux par inadvertance,

* il y cause une inflammation accompagnée d'une démangeaison in-

“ supportable. "

Si l'épicarpe de ce fruit a la singulière propriété dont parle Duhamel, il me paraît élonnant que Michaux n'en ait pas fait mention. Le bois de l'Assiminier est souple et fort dur, selon Duhamel. L. c.

(1) Flor. Bor. Amer. l. c.

(2) Arb. I. p. 56. t. х9. 


\section{v. Du genTe PORCELIA.}

Ce genre, établi par les auteurs de la Flore du Pérou (I), a été 'dédié à Don Antonio Porcel, espagnol distingué. Ses pétales aigus, les internes plus longs que les externes; ses baies cylindriques, sessiles, légèrement bosselées; ses semences disposées sur deux rangs , distinguent suffisamment ce genre de tous ceux de la famille et principalement de l'Asimina, avec lequel MM. de Jussieu et Persoon ont cru devoir le réunir.

Organes de la reproduction. Iue calice est à trois parties, à divisions ovales en forme de cœur à leur base. La corolle est à 6 pétales ovales, aigus, assez épais; les 3 extérieurs sont planes; les 3 intérieurs, plus grands, sont courbés en dedans par leur marge. Les étamines sont insérées sur un réceptacle plane. Plusieurs ovaires linéaires à stigmates sessiles et obtus occupent le centre des étamines. Ces ovaires développés deviennent des baies cylindriques, grandes, de 3 à 4 pouces de long sur un pouce de diamètre, distinctes, bosselées, portant d'un côté une suture longitudinale, polyspermes; leur péricarpe est coriace et épais; leurs graines sont nombreuses, oblongues, presqu'en forme de reins, un peu comprimées, disposées sur deux rangs et séparées par des membranes; le spermoderme est assez dur.

Organes de la végétation. Nous ne connaissons encore qu'une seule espèce de ce genre, dont la description complète n'a pas encore été publiée. C'est un bel arbre qui s'élève à 80 pieds de hauteur et qui croît dans certaines forêts du Pérou; ses feuilles sont glabres et luisantes, ses pédoncules axillaires partent plusieurs du même point, ne portent qu'une seule fleur ou un petit nombre de fleurs et sont souvent penchés.

(1) Fl. Per. Syst. veg. p. I 44: - Gen. pl. Fl. Per. p. 64. t. I6. 


\section{9}

Proprićtés et usages. Les feuilles du $\boldsymbol{P}$. nitidifolia donnent uné couleur jaune. Son bois est employé par les Indiens, pour faire des soliveaux et des poutres. Les fruits sont agréables à manger,

\section{I. Du genre UVARIA.}

Le genre Uvaria est celui des genres de la famille des Anonacées qui a été le moins exactement circonscrit. C'est ce qu'on va voir par son histoire.

Linné (I) l'établit d'abord sur une espèce de Ceylan, qui était désignée dans le Museum Zeylanicum ( 2) et dans le Thesaurus Zeylanicus (3) sous le nom d'Uva Zeylanica sylvestris mali aurantii sapore, avec des synonymes qui la plupart ne peuvent s'accorder avec la courte description que Burmann donne de sa plante: C'est sans doute du nom $U_{v a}$ que portait cette plante, que Linné fit le mot Uvaria, par lequel il désigna ce genre dont il ne put donner qu'une description un peu vague.

Les botanistes postérieurs ( $\left(\begin{array}{c}4 \\ -\end{array}\right)$ ont réuni diverses espèces à ce genre, et cela d'après la description de Linné, ou d'après les figures qu'il cite. Un examen attentif de ces espèces ou de leurs descriptions me porte à croire, que l'espèce sur laquelle linné a fondé son genre ne peut être groupée avec la plupart de celles qu'on a regardé depuis comme ses congénères. Les descriptions que nous avons de l'Uvaria Zeylanica de Linné, bien qu'elles soient toutes incomplètes, ne me laissent presque aucun doute à cet égard. Ce sont, $10^{\circ}$ la description du genre Uvaria dans le Genera de Linné (5); $20^{\circ}$ une phrase à la suite de l'indication de l'espèce dans la Flora Zeylanica

(1) Sp. 2.p. $756 . F l . Z e y l .224$.

(2) Mus. Zeyl.p. 8. et 3 I.

(3) Thes. Zeyl. Burm. 23 I.

(4) Lamarck, Swartz, Wildenow, Persoon, clc.

(5) P. 692. 


\section{0}

tu même auteur ( 1$) ; 3.0^{\circ}$ la courte description déjà mentionnée qui se trouve dans le Thesaurus Zeylanicus de Burmann. D'un côté, la comparaison de ces descriptions avec celles des synonymes de Rheed et de Rumphius, cités pour cette plante, suffit pour prouver que ces synonymes doivent être exclus. D'une autre part, on trouve dans Gærtner (2), sous le nom d'Uvaria Zeylanica, la description et la figure d'un fruit qu'il a trouvé sous ce nom dans la collection de Leyde, fruit qui se rapporte parfaitement à ce qu'en dit Burmann, et qui est à deux rangs de graines et non à un seul, comme presque tous les Uvaria des auteurs. En outre, Burmann dit que les baies de l'Uvaria Zeylanica sont molles et ont une saveur d'abricot, et les baies des Uvaria à un seul rang de graines, sont sèches et ont une saveur piquante. De ces choses, je crois être en droit de conclure que la plupart des Uvaria des auteurs ne peuvent être groupés avec l'Uvaria Zeylanica, type d'un genre distinct, voisin du genre Porcelia, auquel il se rapporte par ses fruits. Les seuls Uvaria des auteurs. qui doivent rester congénères de l'Uyaria Zeylanica, sont l'Uvaria trifoliata Gærtn. (Uvaria Gartneri Nob.) l'Uv. lutea et l'Uy. tomentosa Roxb. Toutes les autres espèces rentrent dans le genre Unona de Linné, ou dans le genre Guatteria de la. Flore du Pérou, comme nous le verrons plus bas.

Le nom d'Uvaria doit être conservé au groupe le plus ancien, celui dans lequel se trouve l'Uvaria Zeylanica, quoique ce groupe soit moins nombreux en espèces que celui qui se trouve actuellement formé presque en entier des autres espèces d'Uvaria des auteurs.

Le genre Uyaria, tel que nous. le concevons aujourd'hui, diffère de tous les autres genres de la famille, par ses baies nombreuses, charnues, ovales ou globuleuses, plus ou moins stipilées, à plusieurs graines disposées sur deux rangs. Il a beaucoup de rapport avec le genre Porcelia par la disposition des graines, mais on l'en distingue

(1) P. 224 .

(2) Gortn. de fruct. 2. p. 155. t. II 4. f. 2. 
aisément par la forme ovale ou globuleuse de ses baies stipitées et non sessiles, par la consistance charnue et non coriace de leur. péricarpe. Ce péricarpe charnu, le nombre et la disposition des graines sur deux rangs, distinguent suffisamment ce genre des genres Unona et Guatteria, dans lesquels rentrent la plupart des Uvaria des auteurs.

Organes de la reproduction. Le calice est à trois parties ovales el en cœur. Le nombre et la disposition des pétales sont les mêmes que dans les autres genres de la famille; ils sont ovales ou oblongs; ceux du rang interne sont plus longs que ceux du rang externe dans plusieurs espèces, et peut-être dans toutes. L'Uvaria tomentosa Roxb. présente ce genre de struclure d'une manière très-prononcée. Les ovaires en assez grand nombre sont souvent velus. Les carpelles qui leur succèdent sont des baies à double rang de graines, charnues, stipitées, et telles enfin que nous les avons décrites plus haut. Les graines d'une espèce, l'Uvaria Gartneri, présentent une singularité de structure que je ne dois pas passer ici sous silence. Les prolongemens de l'endosperme qui vont se nicher si étroitement dans le corps de l'albumen, au lieu d'être en forme de lames comme dans les autres espèces de la famille, sont en pointe et presque en forme d'aiguille, de telle sorte que la section de la graine, au lieu de montrer des raies transversales, offre une multitude de points presque contigus.

Organes de la végétation. De grands arbres droits, à rameaux horizontaux, et des arbusles diroits ou sarmenteux, composent ce genre: Leurs rameaux et leurs feuilles' sont disticlies. Des pédoncules axillaires, opposés aux feuilles ou laléranx, solitaires, géminés ou ternés, portent les fleurs. au nombre de $\mathrm{x}$ à 4 . Ces pédoncules sont quelquefois articulés ou munis d'une bractée vers leur partie moy'enne:

Proprićtés et usages. Peu ou point connus. Le sarcocarpe de l'Uvaria Zeylanica a une saveur agréable, analogue à celle de l'abricot. Il est vraisemblable que les Indiens en font usage, ainsi que de cenx des Uvaria lutea et tomentosa, mais nous ne savons rien de positif sur cela. 


\section{2}

\section{Du genre UNONA.}

Sous le nom d'Unona, Linné, dans son supplément(I), a établi un genre qui diffère bien évidemment par ses fruils de l'Uvaria Zeylanica, mais qui ne difière pas essentiellement de la plupart des Uvaria des auteurs. Ses fiuils sont composés de plusieurs carpelles stipités, à un seul rang de graines, plus ou moins bosselés par un rétrécissement du péricarpe au-dessus de chaque graine, de telle sorte que les carpelles sout en forme de chapelet lorsque le rétrécissement est considérable, comme dans l'Uvaria moniliforme de Gortner (2). Mais la plupart des Uvaria des auteurs ont aussi des bosselures plus ou moins prononcées, résultant d'un rélrécissement du péricarpe au-dessus de chaque graine, et ces bosselures sont telles, qu'on trouve dans les diverses espèces tous les degrés intermédiaires entre celles qui sont les plus prononcées et celles qui le sont le moins. D'après cela, il me paraît évident que les Uvaria des auteurs, à plusieurs graines disprosées sur un seul rang, qui, comme nous l'avons démontré dans le chapitre précédent, ne peuvent être groupées avec l'Uuvaria Zeylanica de Linné, doivent faire partie du genre Unona, ainsi que l'avaient pressenti plusieurs auteurs, et Swartz enlr'autres (3).

Loureiro (4) a fait un genre sous le nom de Melodorum, que M. de Jussieu a cru pouvoir rapporter à l'Asimina (5). Je crois, d'après la description qu'en donne Loureiro, qu'on doit plutút le rćunir au genre Unona. Cette description s'applique parfaitement à l'Unona acutiflora que j'ai fait figurer, plante qui est un vrai Unona de la manière dont je considère aujourd'hui ce genre. En conséquence, je réunis le genre Melodorum au genre Unona.

(1) Suppl. plant.p. 270.

(2) De fruct. 2. p. х56. t. х1 4.*

(3) Observat.

(4) Fl. Cock. r. p. 429.

(5) Ann. du Mus. tom. XVI. p. 33g: 
Le genre Desmos de Loureiro ( $\mathrm{r}$ ), comme tout le monde sait, est évidemment le même que le genre Unona de Linné, ainsi que le genre Krockeria de Necker (2). Ces deux genres doivent donc rentrer dans le genre Unona.

Le Marenteria de M. du Petit-Thonars (3), d'après sa courte description, ne me parât pas différer de l'Unona. Je ne crois pas qu'il en soit de même du Bulliarda de Necker (4), que M. de Jussieu cite comme synonyme de l'Unona (5). Le Bulliarda Neck. me paraît être tout-à-fait le Xylopia L.

La forme des fruits du Xylopia undulata de M. Palissot de Peauvois (6), prouve évidemment que cette plante est un vrai Unona.

Ce dernier genre, comme je le conçois aujourd'hui, aura le caractère essentiel suivant : calice à 3 parties, quelquefois à 3 lobes plus ou moins profonds; 6 pétales sur deux rangs, ouverts ou presque fermés; carpelles nombreux, secs, indéhiscens, plus ou moins bosselés à leur surface, ovales ou oblongs, uni ou multiloculaires, polyspermes, à graines disposées sur un seul rang.

Organes de la reproduction. Les pétales au nombre de 6 sont ouverts dans certaines espèces, resserrés ou presque fermés dans d'autres; ouverts, ils sont ou ovales et en rosette comme dans les Uvaria narum, musaria, etc., ou allongés, linéaires et pendans comme dans l'Uvaria odorata, etc.; rapprochés ou fermés, ils sont disposés de telle manière, que les 3 extérieurs forment d'abord une pyramide triangulaire allongée, qui recouvre une autre pyramide plus petite formée par les pétales internes; c'est ce qu'on voit dans les Unona aromatica, acutiflora, elc. Les pétales internes

(1) L. cit. p. 430.

(2) Neck. fund. bot. 11.0. ro97:

(3) Gener. Madag. 18.

(4) L. cit. $n .^{\circ}$ п 03.

(5) Mém. cit. p. 340.

(6) Flor. d'Owar. I. p. 27. d'après Poir. Dict. Encycl. 8. p. 8×2. 
de l'Un. acutiflora offrent à leur base des deux côtés, une échancrure qui, réunie avec celle du pétale voisin, furme un ouverture presque demi-circuaire; cette ouverture est recouverte par la concavité qui se trouve à la base du pétale externe qui lui correspond. Les pélales de toutes les espèces d'Unona, dont les corolles ont la forme d'une pyramide allongée, ont à leur base une concavité qui recouvre le faisceau des étamines et des ovaires. Dans la plupart des espèces, les pétales extérieurs sont plus longs que les intérieurs; celle diférence est surlout très-prononcée dans l'Un. tripetaloidea. La consistance des pétales varie selon les espèces.

Le fruit des Unona est tonjours composé de carpelles plus ou moins nombreux, indéhiscens, ovales ou oblongs, stipités ou presque sessiles; dans ce dernier cas, ils se rétrécissent en forme de support vers leur partie inférieure. Ils sont uni ou mu'ti'oculaires, toujours à un seul rang de graines, marqués des denx côtés longitudinalement d'une suture plus ou moins prononcée, bosselés et quelquefois presque lisses; leurs dimensions varient selon les espèces. Le péricarpe est le plus souvent sec et coriace.

Organes de la végétation. Les Unona sont des arbres ou des arbustes; quelques-uns sont sarmenteux et grimpans. Les fleurs sont en général portées sur des pédoncules axillaires, tantút uniflores, tantòt à plusieurs fleurs, mais celles-ci toujours en petit nombre. Les pédoncules portent quelquefois de petites bractées sur leur longueur.

Propriétés et usages. Toutes les parties de la plupart des espèces ont une saveur et une odeur aromatiques.

Les racines de l'Unona naruin qui jouissent à un hant degré de ces propriétés, sont les seules sur l'emploi desquelles nous ayons quelques notions. Il parait, d'après ce qu'en disent Rheed (1) et Rumphius (2), qu'elles sont d'un fréquent usage dans la médecine du Malabar et des Moluques. Elles sont employées de diverses

( ) Hortus Malabaricus. 2.p. I1. t. 9 .

(2) Rumphius. Herbarium Amboinense. 5. p. 78 : 
manières et dans plusieurs maladies, mais tonjours empiriquement, et ce que nous en savons ne peut nous donner une iriée claire de lcur action et de leur véritable ulilité. Ainsi Rheed rapporte que ces racines broyées dans l'eai, appliquées sur les gerçures de la bouche, les guérit bientut; que l'infusion de celle même substance édulcorée avec un peu du sucre, est employée utilement dans certaines fièvres et dans les inflammalions du foie; que broyée dans l'eau salée et employée en frictions, elle est utile dans les maladies vermineuses qui proviennent d'une faiblesse générale, etc. etc. C'est dans l'écorce principalement, que les propriétés de ces racines paraissent résider. Seule, elle est employée en infusion dans diverses maladies. On en retire par la distillation dans l'eau, une huile légère, claire, verdâtre, d'une odeur peu agréable, onctueuse et presque amère, qui est aussi très-employée dans la thérapeutique indienne.

Plusieurs arbres du genre Unona sont cultivés, les uns pour leur bois, d'autres pour leur feuillage, d'autres à cause de l'odeur agréable de leurs fleurs. Ainsi on fait, à Pondichery, des allées avec l'Unona longifolia (I), à cause de l'élégance de son port et de l'ombrage qu'il procure. Le bois de l'espèce que Loureiro a désignée sous le nom de Melodorum arboreum (2), est employé en Cochinchine pour la construction des édifices; celui de l'Unona tripetaloidea, quoique léger et mol, sert aux Moluques pour la contruction des habitations; son écorce; quand on l'entame, laisse découler un suc visqueux, qui, en se séchant, se condense en une gomme odorante (3). Le bois de plusieurs autres espèces est aussi employé.

Les fleurs de plusieurs Unona sont très-odorantes. A cause de l'odeur agréable que répandent an loin celles de l'Unona odorata, cet arbre est cullivé, à Java et en Chine, dans les promenades et

(1) Sonnerat. Voyage aux Indes Orientales. 2. p. 233.

(2) Lour. l. c. t. I. p. 430.

(3) Rumpliius. l.c. 2.p. 197. 
autour des habitations. L'odeur de ces fleurs, qui est excessivement forte et pénétrante, a quelque chose d'analogue à celle des narcisses et des oillets. Les Européens la trouvent trop forte; mais les Indiens la mettent au-dessus de toutes les autres, parce qu'ils n'estiment les odeurs que d'après leur degré d'intensité. Ils mettent ces fleurs dans leurs chereux, dans leurs vêtemens, dans leurs habitations et jusque dans leurs lits; ils en usent beaucoup dans les jours de fèle, et en préparent une pommade dont ils se servent pour divers usages, et surtout pour communiquer une agréable odeur à divers. objels.

Les fruits d'Unona sont en général d'un goût piquant et aromatique. Je ne ferai mention ici que de ceux qui sont d'un usage un peu général. Les naturels d'Oware (I) se servent de ceux de l'Unona undulata comme d'épices; souvent même ils les mangent crus et sans les mélanger avec aucun aliment. Les Nègres de la Gruiane (2) se servent, au lieu de poivre, des fruits de l'Unona aromatica qu'on connait dans le pays sous le nom de poivre des Nègres, poivre d'Ethiopie, Maniguette ou Malaguette. Cette espèce est très-voisine et peut-être la même que celle dont les botanistes du moyen âge font mention, espèce dont ils ne connaissaient que les fruits qui, à cette époque, étaient un objet de commerce. Pomet (3) parle encore de ces fruits, comme les ayant vus dans le commerce, sous. Ies divers noms de Poivre long noir, Poivre d'Éthiopie, Poivre des Maures, Grain de Zelim. Il paraît que les négocians n'inportent plus cette denrée en Europe, où elle n'est aujourd'hui d'aucun usage. Il est du moins certain qu'elle ne se trouve presque plus dans le commerce de France; mais il paraît évident que les nations nègres de la côte occidentale de l'Afrique cultivent avec soin une ou plusieurs espèces d'Unona (4), qui

(a) Palissot de Beauvois. Ouvr. cité. I. p. 27. t. I6.

(2) Aublet. Ouv. cit. I. p 605.

(3) Histoire générale des drogues. x. p. 97.

(4) Unona undulata, aromatica, Africana, 


\section{7}

produisent cette épicerie dont ils font un fréquent usage. Le nom de Malaguette ou Maniguette, par lequel les Nègres désignent cette substance, est le même que celui d'une grande province de Guinće, connue aussi sous le noin de Pays des graines. La substance dont nous nous occupons a-t-clle reçu son nom de celui de cette contrée? C'est ce que je n'ai pu éclaircir. On connaît aujourd'hui dans le commerce européen, sous le nom de Maniguette, Melaguette ou graine de Paradis, la graine d'une espèce d'Amomum, employée comme épicerie; celte substance vient aussi d'Afrique, et tire vraisemblablement son nom du pays connu sons le nom de Malaguette, où il paraît que la plante qui la produit, croit abondamment. Pomet dit que cette graine tire son nom de celui d'une ville d'Afrique appellée Melega, d'où elle était autrefois exportée. La ville de Melega dont parle Pomet, ne seraitelle pas Melela, village du désert de Barca près de Bengasi?

Quoi qu'il en soit, il me paraît vraisemblable que les Nègres ont transporté avec eux le condiment qu'ils appellent Malaguette et l'arbrisseau qui le produit, par-tont où ils ont été exportés par les Européens. Ainsi il est tout-à-fait probable que l'Unona aromatica, cullivée aujourd'hui en Amérique par les Nègres, y a été transportée par eux et qu'elle est originaire d'Afrique.

Avicenne () et d'autres Arabes parlent d'une graine dont l'odeur et la saveur étaient aromatiques, qu'ils connaissaient sous le nom d'Azelem, Zelem, graine qui était extrêmement recherchée de leur temps, très - répandue et nommée par quelques - uns Poivre des Noirs. Avicenne dit que le Zelem élait une semence grasse, de la grosseur d'un pois chiche, fort odorante, jaune en dehors, blanche en dedans, et qu'on apportait de Sherzur. Il est vraisemblable que ce Zclem est la graine d'une espèce d'Unona. Mais nous manquons entièrement de données pour savoir à quelle espèce elle appartient.

(1) Avicennce medicorum Arabum principis liber canonis, de medicinis. sordialibus et cantica. Basitece. 1556. p. 240. Veniliis. I608. I. p. 326; 
V I I . Du gente XYLOPIA.

Ce genre a d'abord été établi par Brown (1), sous le nom de

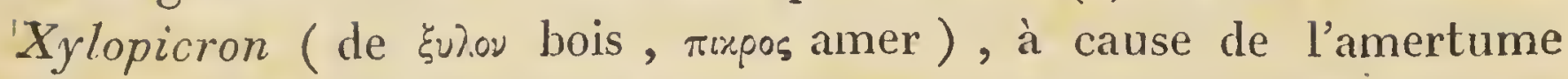
du bois des espèces qui le composent. Linné (2) a fait du nom Xylopicron celui de Xylopia, qui a été adopté par tous les botanistes; il ne connaissait ce genre qu'imparfaitement, puisqu'il ne lui suppose qu'un seul style et un seul ovaire. Ses carpelles quelquefois indéhiscens, plus souvent capsulaires à une ou deux valves, se rétrécissant à leur base en manière de pédoncule, à une ou deux loges et à une ou deux semences, distinguent suffisamment ce genre de tous ceux de la famille.

Organes de la reproduction. Le calice des Xylopia est campanulé, le plus souvent à 3,4 ou 5 lobes obtus, quelquefois à trois parties. La corolle est à 6 pétales, toujours sur deux rangs, les externes plus grands que les internes. Dans la plupart des espèces, ces pétales sont oblongs-linéaires, presque toujours fermés, formant par leur ensemble une pyramide triangulaire, dont la base concave loge les organes sexuels. A une époque de la floraison, ces pétales se détachent ensemble par leur base, pour laisser à découvert les étanines et les pistils.

L'ensemble des étamines est un hémisphère qui n'offre au premier coup d'cil que des sommets d'étamines. Le Xylopia prinoides fait seul exception à celte forme. Dans cette espèce, les pétales ovales s'ouvrent en roue; les étamines, moins nombreuses que dans les autres espicés, sont plus longues, assez distinctes les unes des autres, et ue forment pas une masse serrée par leur ensemble.

Le nombre des ovaires est de 2 à r.5 dans. chaque fleur; leur développement donne naissance à des baies. sèches ou à des capsules

(1) The civil and notural history of Jamaica. I 756 .

(2) Gen. I027. 
sessiles, rétrécies en pédoncule à leur base, ce qui est cause qu'on les a dites pédonculées. Les capsules sont à une ou deux valves, sèches, coriaces, comprimées, renfermant ordinairement deux graines lisses, luisantes, convexes extérieurement et planes du côté par lequel elles se touchent. Chaque valve ou chaque côté de la valve, quand celle - ci est unique, porte un renflement lisse à l'endroit sur lequel la graine s'applique. Lorsqu'il n'y a qu'une valve, elle s'ouvre par le côté interne; la capsule dans ce cas a toujours un sillon ou une suture du côté opposé, qui indique l'endiroit où elle s'ouvrirait si elle était à deux valves. La structure de ces capsules est tout-à-fait analogue à celle des carpelles indéhiscens de certains $X$ ylopia et des Unona. Ceux-ci, à la vérité, sont toujours indéhiscens, mais ils portent sur leur longueur une ou deux sutures longitudinales. On peut dire anatomiquement que les fruits de tous les Xylopia, comme ceux des Unona, sont à denx valves, constamment soudées et indéhiscentes dans certaines espèces, déhiscentes dans d'autres, tantôt d'un seul côté seulement, tantôt des deux côtés à la fois. La différence de consistance du péricarpe est peut-être la seule cause de ces différences de formes.

Les graines des Xylopia sont tantôt géminées dans un fruit à une seule loge, tantìt solitaires dans chaque loge d'un fruit ordinairement à deux loges. Ses graines sont ovales-oblongues ou obovées, plus ou moins prolongées en pointe vers:leur base; celles qui sont géminées sont aplaties du côté par lequel elles se touchent; les autres sont arrondies de tous les còtés. Celles de plusieurs espèces sont munies à leur base; d'un arille incomplet, blanchâtre, formé par une membrane spongieuse qui renferme une huile âcre, très-odorante.

Organes de la végétation. Les Xylopia sont des arbres de médiocre grandeur ou des arbrisseaux, la plupart à feuilles luisantes et. toujours verts. Leurs fleurs sont axiliaires, solitaires ou en grand nombre, toujours portées par de courts pédoncules; ceux-ci sont toujours munis de petites bractées, sessiles, concaves, presqure rondes et obluses.

Propriétés et usages. Le bois de ces arbres est amer. L'écorce 
du Xylopic frutescens d'Aublet (I), est piquante et aromatique; elle est très-souple et très-flexible; à cause de cela, les Brésiliens s'en servent pour faire des cordes (2). Les capsules du même végétal ont un goût àcre et une odeur de térébenthine; ses graines -màchées sont piquantes et aromatiques comme l'écorce. Les Nègres en font usage en guise d'épiceries. Les fruits de toutes les espèces du genre, jouissent des mêmes propriétés.

\section{Du genre GUATTERIA.}

Aublet (3) établit ce genre sur une seule espèce de la Guiane. Il lui donna mal-à-propos le nom de Cananga que Rumphius (4) avait assigné précédemment à deux espèces d'Anonacées des Indes Orientales, qui font partie de notre genre Unona.

Le genre Cananga d'Aublet fut d'abord adopté par M. de Jussieu (5), qui y réunit avec raison le genre Aberemoa du même auteur. Plusieurs botanistes avaient décrit avant, ou ont décrit depuis, sous le nom d'Uyaric, plusieurs espèces qui appartiennent au genre Cananga d'Aubiet. Ruiz et Pavon (6), croyant que les fruits de ce genre élaient des capsules, ont établi un genre sous le nom de Guatteria, qui ne diffère du Cananga d'Aublet que par ses fruits indẻhiscens.

En admettant même que, comme le dit Aublet, les carpelles de son Cananga soient de véritables capsules, je crois qu'il faut réunir ce genie au genre Guatteria, ainsi que M. de Jussieu l'a fait en dernier lieu (7); mais îl est évident pour moi que les carpelles du Cananga ouregou d'Aublet ne sont pas toujours déhiscens; je suis porté à croire, au contraire, qu'ils ne le sont jamais, et c'est pourtant l'espèce qui est

(1) Guj. l.c. 1. p. 602 .

(2) Pis. p. 79. Marg. p. 99.

(3) L.c. I. p. 60 $7^{*}$.

(4) Herbarium Amboniense. t. 2. $p$. 195.

(5) Gen. p. 284 .

(6) Fl. Per. Gen. p. 85. t. I7 . Syst. veget. Fl. Per.

() Ana. du Mus. t. i6. p. 340 . 


\section{1}

Ie type du genre d'Aublet, celle de laquelle on a dit les fruits capsulaires. Deux choses me font penser que les carpelles du Cananga ouregou sont toujours indéhiscens: $10^{\circ}$ La figure qu'en donne Aublet, représente ces fruits comme indéhiscens. $20^{\circ}$ Les échantillons que j’en ai vus, qui étaieul parvenus à la plus grande maturilé, ne m'ont offert que des baies scrches, indéhiscentes, portant de chaque côté une nervure longitudinale, ainsi que les représente la figure d'Aublet.

D'après ce que je viens d'exposer, il est évident que le genre qui nons occupe maintenant doit comprendre les genres Cananga et Aleremoa d'Aublet, le genre Guatteria de la Flore du Pérou et plusieurs espèces décriles par les auteurs sous le nom générique dUraria. Nous n'adopterons pas le nom de Cananga employé par Aublet et M. de Jussieu pour désigner ce genre, parce que, comme nous l'avons dit plus haut, ce nom a été employé précédemment pour désignier deux espèces des Indes Orientales qui ne font pas partie de ce genre. Nous adopterons le nom Guatteria des auteurs de la Flore du Pérou, nom qui rappelle la mémoire de Jean Bapt. Guatter, Professeur de Botanique de Parme.

Le genre Guatteria se distingue de ceux dè la même famille, par ses pétales souvent étalés et assez petits, par ses étamines souvent moins nombreuses et moins serrées que dans les autres genres, et surtout par ses carpelles secs, indéhiscens, uniloculaires et naturellement monospermes.

Lamarck (1), réunissant le genre Cananga au genre Uparia, a appelé ce dernier en français Canang, en. conservant en latin le nom d'Uvaria.

Organes de la reproduction. Le calice des Guatteriı est à 3 parties, ovales, aignës. Ses pétales, au nombre de 6 , sont ordinairement ouveris et étalés, quelquefois droits et rapprochés; le plus souvent les extérieurs sont un peu plus grands que les intérieurs; mais daus le Guatteria cerasoides ils sont égaux, et dans le Guatteria suberosa, les ex!ernes. sont deux fois plus courts que les.

(I) Dict. Encycl. I. p. 595. 
internes. I.es étamines, dont les anthères sont sessiles, ne sont ni aussi nombreuses ni aussi serrées que dans les autres genres, et ne forment pas autant l'hémisphère au centre de la ficur.

Les ovaires des Guattcria sont en grand nombre et deviennent des carpelles indéhiscens, ovales ou presque globuleux, oblus ou aigus, secs, coriaces, toujours pédicellés et monospermes. Le péricarpe est tantôt de la consistance du parchenin, tantôt plus dur et comme osseux. Chaque carpelle ne renferme qu'une seule graine qui le remplit entièrement et qui a sa forme.

Organes de la végétation. Ce genre renferme des arbres et des arbrisseaux. Leurs pédoncules sont le plus souvent axillaires, quelquefois opposés aux feuilles, solitaires ou 2 à 3 ensemble, souvent uniflores. Ces pédoncules sont ordinairement courts et droits; le Guatteria pendula seul en a de très-longs et pendans.

Propriétés et usages. Les racines et les feuilles de plusieurs espèces, probablement celles de tontes, ont une saveur âcre et aromalique (1). Les fleurs du Guatteria virgata ont une odeur suave. Les fruits de quelques espèces ont une saveur analogue à celle des feuilles. Le bois des Guatteria virgata et laurifolia est recherché ̀̀ cause de sa ténacité et de son élasticité (:). Les feuilles du G. sempervirens sont employées au Malabar en décoction, dans les douleurs rhumatismales. Le suc exprimé de ces mêmes feuilles, combiné avec un peu d'opium, est employé dans le cominencement des fièvres intermittentes, afin de modérer l'intensité des accès (3). D'après ces notions imparfaites, on ne peut savoir quelle est leur action.

Après avoir tracé successivement l'histoire et la description de la famille des Anonacées, l'histoire et la description des divers genres qui la composent, il me reste à faire connaître les espèces groupées dans les genres auxquels elles appartiennent. C'est ce que je vais faire dans la langue de la science botanique.

(I) Guatt. Korinti, sempervirens, virgata, laurifolia, Ouregou, etc.

(2) Swartz. Flora Indice Occidentalis. 2. p. Iоor.

(3) Hortus Malabaricus. Pars 5. p. 3ı. t. 16.* 


\section{I.}

\section{O N O GR A P H I A.}

\section{A NONACE王.}

Coadunatarum genera. L. Ord. nat. - Anonarum gen. Adans. Fam. 2.p. 35g.* - Anonæ. Juss. Gen. 283.* - Glyptospermæ. Vent: Tabl. 3.p. $75 .^{*}$

\section{Character differentialis.}

Calyx monophyllus, 3-4 partitus aut 3-4 lobus; corolla 6-petala, petalis duplici serie dispositis, 3 exterioribus cum 3 interioribus alternis, petalis interioribus interdùm nullis; stamina numerosa; ovaria sæpissimè plurima, rarò ovarium unicum; fructus s. carpelli nunc distincti, nunc coadunati; seminum endoplevra s. tunica interior intùs plicata, processibus lamellosis aut subulatis intrà albuminis rimas aut foramina altè demersis.

\section{Character naturalis fructificationis:}

CALYX monophyllus, brevis, 3-partitus vel 3-lobus, interdùm 4-partitus, 4-lobus, persistens.

Corolla. Petala 6, duplici ordine disposita, sapè crassa, sub- 


\section{4}

coriacea; 3 exteriora interdùm calycem interiorem æmulantia, cum tribus interioribus alterna; 3 interiora nunc exterioribus majora, nunc minora, interdùm nulla.

Stamina numerosa, adpressa, receptaculum hemisphæricum aut planum oblegentia ; filamenta brevissima ; anthera subsessiles, connectivo apice glanduloso subtetragnno interdùm nectarifero, extrorsùm et deorsùm loculos antherarum longitudinaliter dehiscentes gerente.

Pistrllum. Ovaria interdùm solitaria, sæpius numerosa, receptaculo medio imposita, confertissima, vix ab antheris disincta et iisdem quasi oblecta, nunc distincta, nunc coadunata; styli totidern, breves aut subnulli; stigmata totidem sæpè pilosa.

Fructus. Carpelli tolidem baccati vel capsulares, mono aut polyspermi, nunc distincti, sessiles aut stipitati, et receptaculo communi imposili; nunc plures coadunati in fructum unicum pulposum, numerosis loculis monospermis aut dispermis.

SEMuna ovata vel ovato-oblonga; tunica exterior membranaceocrustacea, fragilis; tunica interior s. endopleyra membranacea, pluriès inì̀s plicata, processibus plurimis innumeros distinguentibus lobulos albuminis, processibus nunc lamellosis, nunc subulatis et ferè acicularibus, intrà albuminis rimas aut foramina allè demersis : albumen semini conforme, carnosum, durum, sulco depresso marginem totum cingente sæpissimè inscriptum, nunc p: ofundis rimis transversalibus undique incisum, nunc loco rimarum, innumeris foraminibus contiguis exsculptum; embryo minutus, rectus, in regione umbilicali albuminis locatus; cotyledones breves; radicula teretiuscula.

\section{Character naturalis vegetationis.}

Arbores s. frutices; rami et ramuli sæpè distichi, cortice sæpiùs reticulato aut verrucoso. Folia alterna, sæpè disticha, breviter petiolata aut sessilia, solitaria, simplicia, non stipulacea, sæpis- 
simè integra, rarò dentata. Pedunculi sæpius axillares, interdùm laterales aut oppositifolii, sæè̀ bracteolati, foliis s:epiùs breviores, solitarii, $2-3-4-$ nive; uni aut pauciflori, rarò uncinati.

\section{CONSPECTUS GENERUM.}

\section{§. Ovaria concreta in unum; fructus unicus ex pluribus. carpellis concretus.}

1. Kadsura. Calyx 3-partitus; petala 6, ovata; ovaria nùmerosa super thorum carnosum aggregata et in baccas vel capsulas totidem sessiles uniloculares 2-spermas mutata.

2. ANONA. Calyx 3-partitus, interdùm 3-lobus; petala 6, 3 interiora minora, interdùm nulla ; ovaria concreta in unum; bacca unica ex pluribus concreta, intùs pulposa, ad ambitum multilocularis, loculis monospermis.

§ §. Ovarium unicum, polyspermum; bacca simplex, unilocularis! polysperma.

3. Monodora. Calyx 3-partitus ; corolla 6 - petala ; ovarium unicum, stigmate sessili coronatum; bacca simplex unilocularis, polysperma; semina in pulpầ nidulantia.

$\S \S \S$. Ovaria plurima distincta; carpelli plurimi distincti.

4. Asimina. Calyx 3-partitus ; corolla 6-petala , petalis obtusis ; interioribus minoribus; baccæ plures, ovatæ vel oblongæ, carnosæ, sessiles, polyspermæ; semina unicî serie disposita.

5. Porcelis. Calyx sub-3-partitus; corolla 6 -petala, petalis interioribus panlo majoribus; bacce 3-6, sessiles, coriacex, cylindricæ, subtorulosie, polyspermæ; semina gemino ordine superimposita. 
6. Uvaria. Calyx 3-partitus ; petala 6,3 exteriora minora? baccæ numerosæ, carnosæ, ovatæ vel globosæ, stipitatæ; polyspermæ; semina duplici serie disposita.

7. Unona. Calyx 3-partitus vel 3-lobus; petala 6 , patentia vel subclausa; baccæ ovatæ vel oblongæ, stipitatæ, polyspermæ; semina simplici serie disposita.

8. XyLopia. Calyx 3-5-partitus vel 3-5-lobus, sæpè campanulatus; petala 6 , exteriora latiora; capsulæ vel baccæ 2-15, breviter stipitatæ, so in stipitem desinentes, compressæ, coriaceæ, 1-2 valves, I-loculares, 1-2-spermæ.

9. Guatteria. Caliyx 3 -partitus; corolla 6 - pelala, petalis ovatis vel obovatis vel oblongis; baccæ siccæ? coriaceæ, numerosæ , ovatæ aut subglobosæ, stipitatæ, monospermæ.

\section{Genera excludenda.}

Nomina excludenda.

Nomina legitima.

Aberemoa. Aubl. . . . . . Guatteria aberemoa. Nob. Annonæ species. L. . . . . . . Asiminæ species. Nob. Bulliarda. Neck. . . . . . Xylopia. Nob. $\left.\begin{array}{l}\text { Canang. Lam. } \\ \text { Cananga. Poit. }\end{array}\right\}$. . . . . Guatteria. Fl. Per. Desmos. Lour. . . . . . . Unona. $L$. Krockeria. Neck. . . . . . . Unona. $L$. Marenteria. Du Pet.-Thou. . • . . Unona. $L$. Melodorum. Lour. . . . . . . Unona. $L$. Orchidocarpum. Mich. . . . . Asimina. Adans. Porceliæ species. Pers. . . . . Uvariæ species. Nob. Uvariæ species. Lam. Willd.etc. . . . Unonæ species. Nob. Xilopia. Paliss. Beauv. . . . . Unona. $L$. Xylopicron. Adans. . . . . . Xylopia. $L$. 
$\$$ Ovaria concreta in unum; fructus unicus ex pluribus carpellis concretus, intìs pulposus, ad ambitum multilocularis, loculis 1-2-spermis.

\section{K A D S U R A.}

Kadsura. Juss. Ann. du Mus. 16. p.340. - Uvariæ species. $I_{i q}$ Sp.p. 756. Thunb. Jap. 237.*

\section{Character fructificationis.}

Calyx 3-partitus.

Corolla 6-petala, petalis ovatis.

Stamina numerosa, brevia (Thunb.).

Ovaria et Fructus. Ovaria numerosa, super thorum carnosum, ovatum. s. globosum demùm ampliatum aggregata et in baccas s. capsulas totidem (30-40) sessiles uniloculares 2-spermas mutata. (Kcempf. Thunb.) Vide Hist. p. 26.

\section{Character vegetationis.}

Frutex parvus, ramosus, flexuosus. Cortex viscosus. Folia ovalia; serrata, crassa. Pedunculi uniflori.

1. Kadsura JAPONICA.

Frutex viscosus procumbens, folio telephi vulgaris æmulo, fructra racemoso. Kompf. Aman. 476. et r 85. t. 477. Hist. Jap. 458. ic. - Uvaria Japonica. L. Sp.pl. 756. - Thunb. Jap. 237.* - Willd. Sp. pl.2.p. 1265. - Lam. Dict. 1.p.597.

Futò Kadsura, sive sàne Kàdsura, sive Oreni Kàdsura. Japonicè

è Komıpf.

Hab. in Japoniâ (Kampt.) circà Nagasacki et alibi. ( $T h_{\odot}$ ) . 5. Floret septembri. 


\section{8}

Frutex parvus, ramosus, procumbens, vago flexu serpens, fuscus, hiulcus, verrucosus; cortex carnosus, viscosus. Folia breviter petiolata, petiolis rubro-purpurascentibus, ovalia, seu oblongoóvalia, utrinque acuta, serrata, glabra, crassa, interdùm repandoundulata. Pedunculi uniflori, solitarii, "pauci, vix pollicem longi, oppositifolii? post florescentiam cernui. Flores albi : baccæ s. arilli carnosi, rubri, super polyphorum carnosum intùs album densè ugregati. E Kampf.l.c.

\section{I. A N O N A.}

Guanabanus. Plum. Gen.p. 42. t. 10.* Annona species. Lin. Gen.p. 279. n. ${ }^{\circ}$ 693.* - Anonæ species. Juss. Gen.p. 283.* - Lam. Illust. t. 494. - Anona. Adans. Fam. p. 365. ${ }^{\star}$ - Juss. Ann. du Mus. 16.p. 33g.* - Corossol. Gallicè. Lam. Dict. 2. p. 122.

\section{Character differentiatis.}

Calyx tripartitus, interdùm trilobus; petala 6,3 interiora minora, interdùm nulla; ovaria concreta in unum, stigmatibus numerosis tectum: bacca unica ex pluribus concreta, intùs pulposa, ad ambitum multilocularis, loculis monospermis.

\section{Character naturalis fructificationis.}

CALYX interdùm trilobus, sæpius tripartitus, laciniis subcordatis concavis acuminatis s. acutiusculis.

Corolla. Petala 6 , duplici serie disposita, alterna; 3 interiora minora, interdùm nulla; omnia plus minusve crassa, nunc cordata aut subcordata, ovala, acuminata vel obtusa, concava; nunc oblonga, concava, obtusa; nunc lineari-oblonga, angusta, pyramiclata, apice triquetra, basi solummodò concava, interiora sapè minutissima.

STAIINA numerosa. Antheræ adpressæ, subsessiles, sub 4-5-gonæ, apice latiores, receptaculum hemispharicum obtegentes. 
Pistillum. Ovaria numerosa, concreta in unum, stigmatibus numerosis tectum, vix $a b$ antheris distinctum et iisdem quasi obtectum.

Fructus. Bacca unica ex pluribus carpellis concreta, sessilis, cortice muricato aut squamoso aut reliculato aut rarius lævi, intùs pulposa, ad ambitum multilocularis, loculis 1-spermis.

Semina ovato-oblongat, sæpè rufescentia aut fusca.

\section{Character naturalis vegetationis.}

Arbores aut frutices, cortice sæpè reticulato, glanduloso, aromatico. Folia integra, interdùm pellucido - punctata. Pedunculi axillares aut suboppositifolii, sæpè solitarii, uniflori ant pauciflori, quandoquè bracteas minutas gerentes.

\section{ConsteCtUS SPECIERUM.}

A. Petalis concavis, crassis, subcoriaceis, cordatis ovatisqute.

\$. Petalis exterioribus acutis, interioribus obtusis pauto minoribus.

1. A. muricata. A. caule subarboreo, foliis ovato-lanceolatis glabris subnitidis, pedunculis solitariis axillaribus unifloris, petalis exterioribus cordatis acuminatis, fructibus muricatis, mucronibusearnosis.

2. A. purpurea. A. caule arborescente, foliis subsessilibus lanceolatis subtùs subferrugineis, floribus axillaribus subsessilibus, petalis exterioribus cordatis, interioribus subrotundis purpureis.

3. A. Humboldtii. A. caule fruticoso, foliis oblongo-acuminatis glabris leviter punctatis, pedunculis solitariis axillaribus unifloris brevibus, petalis exterioribus ovato-subcordatis acutis, interioribus obtusiusculis.

4. A. laurifolia. A. caule fruticoso, fuliis ovato-lanecolatis glabris, pedunculis solitariis unifloris pendulis, petalis exterioribus 
cordatis aculis, interioribus rotundatis, fructibus levibus mammiformibus.

\section{$\S$ s. Petalis exterioribus obtusis.}

5. A. obtusiftora. A. caule arboreo, foliis distichis oblongolanceolatis undulatis glabris nervosissimis acuminatis, pedunculis axillaribus unifloris pendulis, petalis exterioribus obtusis.

$\S \S \S$. Petalis omnibus acutis, interioribus paulò minoribus.

6. A. palustris. A. caule arborescente, foliis ovato-oblongis coriaceis glaberrimis ', floribus solitariis pedunculatis, fructibus glaberrimis subareolatis.

7. A. longifolic. A. caule fruticoso, foliis lineari-oblongis apice acuminatis mucronatis glabris, floribus axillaribus pedunculatis, fructibus ovato-globosis punctatis reticulatis.

8. A. punctata. A. caule fruticoso, foliis ovato-oblongis acutis glabris, floribus axillaribus solitariis subsessilibus, fructibus subglobosis levibus punctatis.

9. A. Peruviana. A. caule fruticoso, foliis oblongo-ellipticis acutis subcoriaceis, pedunculis axillaribus bracteolatis unifloris, fiuctibus globosis reticulatis.

го. A. ambotay. A. caule fruticoso, foliis oblongo-ellipticis acutis subtùs ferrugineo-tomentosis, floribus axillaribus solitariis brevissimè pedunculatis.

11. A. paludosa. A. caule fruticoso, foliis oblongis acutis suprà tomentosiusculis subtùs nervosis tomentoso-sericeis rufescentibus, floribus solitariis geminisve axillaribus breviter pedunculatis, fruclibus ovatis tuberculatis.

B. Petalis exterioribus ovatis concavis acutis coriaceis, interioribus nullis.

12. A. echinata A. ramis rugosis divaricatis, foliis ovato-lanceo- 
$6 t$

latis acutiusculis suprà glaberrimis subtùs subtomentosis, pedunculis solitariis unifloris, fructibus ovoideis echinatis.

3. A. sericea. A. ramulis tomentoso-sericeis, foliis ovato-oblongis acuminatis suprà glabris subtìs ferrugineo - tomentosis sericeis, floribus solitariis axillaribus pedunculalis extùs ferrugineis.

C. Petalis exterioribus lineari-oblongis angustis apice triquetris; basi solummodo concavis, scopè clausis, genitalia basi occul-. tantibus; petalis interioribus minutissimis.

14. A. squamosa. A. caule arborescente, foliis lanceolatis glabris pellucido-punctatis, pelalis exterioribus subclausis, fructibus ovoideis squamosis.

15. A. Asiatica. A. foliis oblongo-lanceolatis glabris nitidis lineatis, petalis exterioribus subclausis, fructibus squamosis.

16. A. cinerea. A. ramis rugosis, folis lanceolato-ellipticis obtusiusculis cinereis pellucido-punctatis subtùs pubescentibus, petalis exterioribus subclausis, fructibus ovato-globosis squamosis.

17. A. cherimolia. A. caule arborescente, foliis ovato-lanceolatis acutis impunctatis subtùs tomentoso-sericeis, petalis exterioribus subclausis extùs tomentosis, fructibus subglobosis subsquamosis.

18. A. reticulata. A. caule arboreo, foliis oblongo-lanceolatis glabris acutis, petalis exterioribus subclausis, fructibus ovatoglobosis reticulato-areolatis.

19. A. mucosa. A. caule arborescente, foliis oblongo-lanceolatis; petalis exterioribus apice patulis, fructibus areolatis, areolis gibbosis.

D. Petalis exterioribus oblongo-ellipticis obtusis, interioribus minoribus lanceolatis obtusiusculis; calyce coriaceo, trifido, magno, subcampanulato; fructibus conoideis levibus?

20. A. glabra. A. caule arborescente, foliis ovato-lanceolatis glabris, pedunculis oppositifoliis bifloris, fructibus conoideis obtusis levibus, 
2I. A. grandiflora. A. ramis glabris punctatis, foliis ovatolanceolatis glabris coriaceis suprà nitidis, pedunculis axillaribus colitariis, fructibus ovoideis glabris subpunctatis.

22. A. amplexicaulis. A. ramis glabris rimosis, foliis cordatooblongis acutis amplexicaulibus, pedunculis axillaribus solitariis unifloris.

\section{E. Anona non satis nota.}

23. A Senegalensis A. ramis teretibus, foliis latis subcordatis coriaceis glaucis, pedunculis geminis ternisve infrafoliaceis.

24. A? uniflora. A. ramis teretibus, foliis oblongis acuminatis glabris subtùs glaucis, pedunculis oppositifoliis tomentosis candicantibus.

25. A? exsucca. A. caule arboreo, ramis glaberrimis, foliis glaberrimis ovali-oblongis coriaceis suprà lucidis, pedunculis suboppositifoliis simplicibus vel bifidis.

26. A. Africanc. t. A. foliis lanceolatis pubescentibus.

\section{HISTORIA SPECIA LIS。}

A. Petalis concavis, crassis, cordatis oyatisque.

§. Petalis exterioribus cordatis acutis, interioribus obtusis paulo minoribus.

\section{ANONA MURICATA.}

A. caule subarboreo, foliis ovato-lanceolatis glabris subnitidis, pedunculis solitariis axillaribus unifloris, petalis exterioribus cordatis acuminatis, interioribus obtusis, fructibus muricatis, mucronibus carnosis.

Araticu species. Marcg. Bras. 93. - Pis. Bras. 69.

A. foliis ovali-lanceolatis glabris nitidis planis, pomis muricatis. Hort. Cliff. 222.* - Gron, virg. 61. - Roy. Lugd.6. 494 . 
A. I. foliis oblongo-ovatis nitidis, fructibus spinis mollibus tumentibus obsitis. Brospn. Jam. 254 .

A. muricata. L. Sp. 2. p. 756. - Mill. Dict. n. ${ }^{2} .^{*}$ - Aubl. Guj. 1. p. 617. - Lam. Dict. 2. p. 122.* - Swartz. Obs. 220.* -Ait. Kew.2.p. 252. - Willd. Sp. 2.p. 1264. - Moc. et Sessé. Pl. mex. ic. ined.

Corossol ; cachimant; cachimantier ; pomme de cannelle. Gallice (Lam. l. c.). Cachiman morveux. (Aublet. l. c.)

a. Fructibus cordato-oblongis subincurvis.

Guanabanus fructu è viridi-lutescente, molliter aculeato. Plum. Gen. 43. - Mss. 6. t. I12. è Lam. l. c. - Sur.herb. 65 et I68 Lam.

Anona indica, fructu conoide viridi, squamis veluti aculeato. Pluk. Alm. 132. t. 135. f. 2. mala.

Zuuirsack. Merian. Sur. 14.

Anona. Comm. Hort. 1. p. ז33. t. 69?

A. maxima, foliis latis splendentibus, fructu maximo viridi conoide; tuberculis s. spinulis innocentibus aspero. Sloan. Jam. Hist. 2.p. I66. t. 225. mala.

Anona muricata. Jacq. Obs. I. p. 10.t. 5.* exclus. syn. Plum. ic Soursop. Anglicè.

B. Fructibus subspharicis rectis. An species?

Guanabanus, fructu aureo et molliter aculeato. Plum. Gen. 43. t. 1о. - Mss. 6. t. I 14. - Sur.herb.n.68.-Plum. Amer. t. 143. f. I.

Hab. in insulis Caribæis; frequens in ericetis (Savanes) Jamaicæ (Brown. ), culla in Mexico (Moç. $)$, in Brasiliâ $\left(P_{i s_{\bullet}}\right)$, in Peruviâ (Humb. et Bonpl.), in insulis Mauritianis (Commers.).s. (v. s. h. H. et B. ) (DC. v. s. h. Juss. )

Arbor parvus, 8-15-pedalis. Cortex, folia et flores graveolentes. Lignum durissimum. Folia nitida, viridia, sublùs pallidiora, impunctata. Pedunculi axillares, solitarii, breves, crassi, uniflori. Flos magnus. Petala exteriora coriacea, extùs viridia, intùs sordidè lutea, interiona obtusa, lutea. Anthera basi pilosa. Fructus 


\section{4}

edulis, usitatissimus, magnus, carnosus, muricibus s. mucromibus ovatis acutis apice recurvis tectus.

\section{Anona purpurea. tab. 2.}

A. caule arborescente, foliis subsessilibus lanceolatis subtùs subferrugineis, floribus axillaribus subsessilibus, petalis exterioribus cordatis acutis, interioribus subrotundis purpureis.

A. purpurea. Moc. et Sessé. Pl. Mexic. ined.

Hah, in Mexico. s.

Caulis arborescens, fuscus, ramosus, ramis lignosis fuscis, casu foliorun cicatriculis notatis. Folia in ramis junioribus solummodò visa, brevissimè petiolata, oblongo-lanceolata, subtùs piloso-subferruginea, suprà viridia undulata. Flores subsessiles, super ramos seniores nascentes. Calyx parvus, tripartitus, laciniis ovatis acutis. Corollá magna, 6-petala, petalis concavis, 3 exterioribus ovatis acutis luteo-fuscis, 3 interioribus purpureis subrotundis obtusis. Fructus ignolus.

3. Anona Humboldtir. tab. 3. ex icone Humboldtii expressa.

A. caule fruticoso, foliis oblongo-acuminatis glabris leviter punctatis, pedunculis brevibus solitariis axillaribus unifloris, petalis exterioribus ovato-subeordatis acutis, interioribus obtusiusculis.

Anona. Humb. e et Bonpl. ined.

Chylinolia. Vutgò in Cumanâ.

Hab. i: Cumanæe provinciâ. (v. s. h. H. et B.)

Frutex. Ramuli glabri, rugosi, punctulis albidis notati. Folia breviler petiolata, oblongo-acuminala, subfalcata, subreliculala, margine subunlulata, subrevoluta, per lentem punctata, subtùs nervosa, nervis paralleiis. Pedunculi uniffori, breves, apice incrassati. Cally $\mathrm{x}$ viridis, punciatus, punclibus flavis, trilobus, lobis obt usis subrotunlatis. Corolla 6-petala; exteriora carnoso-coriacea, externè flavescentia, internè basi maculà purpureâ notata ; interiora minora, extùs: carinata, flavescentia, punctis rubris adspersa, intùs pur- 
purea, basi maculis flavis notata. Stamina super receptaculum globosum imposita. Antheræe subsessiles, 5-6-augulatæ, extus striatæ. Ovaria sessilia, 4-6-gona. Ex Humb. et Bonpl. ined.

\section{Anona laurifolia.}

A. caule fruticoso, foliis ovato-lanceolalis glabris, pedunculis solitariis unifloris pendulis, petalis exterioribus cordatis acutis, interioribus rotundatis, fructibus levibus mammiformibus.

A. fructu levi viridi, pyri inversi formâ. Catesb. Car.2. p.67.t.67.

A. glabra $\beta$. Lam. Dict. 2. p. I 25.*

Hab. in insulis S. Doming. , Ilatera, Andros et in continente usque ad tropicum septentrionalem. s.

Frutex ro-12-pedalis, ramis flexuosis. Folia ovato-lanceolata, foliis lauri nobilis similia. Flores laterales, solitarii, penduli, patentes, subtriangulares. Petala exteriora magna, cordata, acuta, viridia; petala interiora rotundata, alba, minora. Fructus viridis, levis . pyri inversi formà. Semina conica, fusca, pauca.

\section{$\S$ §. Petalis exterioribus obtusis.}

\section{ANONA OBTUSIFLORA.}

A. caule arboreo, foliis distichis oblongo - lanceolatis undulalis. glabris acuminatis nervosissimis, junioribus tomentosis, pedunoulis axillaribus unifloris, petalis exterioribus obtusis.

A. obtusiflora. Tussac. Fl. Antill. t. 28.

Hab. ex Asiâ orta? in insulâ Domingensis culta. s (Tussac.) Pedunculi axillares, uniflori, bracteati, nutantes. Corolla hexapetala, 3 exterioribus apice latiori obtuso. Fiuctus subrotundus tuberculatus.

$\$ \$ S$. Petalis omnibus acutis, interioribus paulà minoribus...

\section{AnONa palustris.}

A. caule arborescente, foliis ovato-oblongis coriaceis glaberrimis, floribus solitariis pedunculatis, fructibus glaberrimis subareolatia. 
Guanabanus palustris, fructu levi viridi. Plum. Mss. è Willd. Anona Americana juxtà fluviorum ripas innascens pyriformi fructu. Pluck. Alm. 32. t. 240. f. 6.

Anona aquatica, foliis laurinis atro-virentibus, fructu minore conoide luteo, cortice glabro in areolas distincto. Sloan. Jam. 205. Hist. 2. p. 169. t. 228. f. 1.* ${ }^{\star}$ Raj. Dendr. 78 .

A. uliginosa, foliis nitidis ovatis, fructibus areolatis odoratis. Brown. Jam. 256 .

Annona palustris. L. Sp. pl. $757 .-$ Mill. Dict. $0^{\circ} 4 .-S_{w a r t z .}$ Obs. 223.* - Lam. Dict. 2. p. 124. exclus. syn. Aubl. - Willd. Sp. 2. p. 1267 .

Hab. in Americâ juxtà fluviorum ripas. s (DC. v. s. h. Desf.) Arbor parva, orgyalis ( $\left.S_{w a r t z}\right)$; 30-40-pedalis (Sloanne). Flos magnitudine $A$. muricata. Calyx 3-partitus, ferè triangularis. Petala flava, 3 exteriora concava, subrotunda, acumine brevi, crassa, coriacea, extùs venosa, intùs glabra, pallida, basi sanguineo - maculata ; petala 3 interiora, exterioribus dimidio breviora, angustiora, acuta, concava, extùs albida, intùs atro-sanguinea. Bacca magna, glaberrima, subareolata.

\section{AnONa LONGifolia.}

A. caule fruticoso, foliis lineari-oblongis apice acuminatis mucronatis glabris, floribus axillaribus pedunculatis, fructibus ovatoglobosis punctatis reticulatis.

A. longifolia. Aubl. Guj. I. p. 6r5. t. 248.* -Willd. Sp. 2. p. 1267. - Lain. Dict. 2.p. 1 26.*

Pinaioua. Nomen Caribrum.

INab. ad ripas amnis Galibiensis; Gui.s (v. s. s. flore h. DC.)

Frutex 15 -pedalis. Folia brevissimè petiolata, deflexa, sublùs nervosa, reliculata. Pedunculi petiolis multotiès longiores. Flos magnus. Petala ovato-oblonga, omnia acuta, purpurascentia, interiora minora. Bacca carnosa, ovata, subrotunda, punctata, reticulata, incarnata, gelatinosa, edulis. 
8. Anona punctata.

A. caule fruticoso, foliis ovato-oblongis acutis glabris, floribus axillaribus solitariis subsessilibus, fructibus subglobosis levibus punctatis.

A. punctata. Aubl. Guj. 1. p. 614. t. 247*. -Willd. 2.p.1267.

A. palustris, $v^{s}$ B. Lam. Dict. 2. p. 124.*

Pinaou. Nomen Caribaum.

Hab. in Sylvis Sinemariensibus et propè amnem Galibiensem: Guj. s:

Frutex 25-pedalis. Folia breviter petiolata, apice angustata, acuta: Pedunculi solitarii, axillares, longitudine petiolorum. Flos parvus. Petala acuta, lutea. Bacca ovato-subrotunda, punctata, obscurè rufa, carnosa, intùs rubescens, edulis. Aubl. l. c.

\section{Anona Peruviana.}

A. caule fruticoso, foliis oblongo-ellipticis acutis subcoriaceis, pedunculis axillaribus bracteolatis, fructibus globosis reticulatis.

A. Peruviana. Humb. et Bonpl. ined.

Hab. in Pèruviæe uliginosis, propè Guayaquil frequentissimè. (v*. s. h. H. et B. )

Rami rugosi, subcostati decurrentiâ foliorum. Folia super ramoz subarticulata, petiolata, petiolis decurrentibus, subcoriacea, apice: subfalcata, margine subrevoluta, suprà nitida, subtùs pallidiora, utrinque venosa, venis parallelis. Pedunculi pollicares, solitarii, uniflori, crassi, bracteầ aculà basi amplexi. Calyx tripartitus, laciniis ovatis acutis reflexis. Corolla 6-petala, flava; petala ovata, acuta, crassiuscula; 3 exteriora intùs ad basin maculì rubrî̀ notata; 3 interiora, breviora. Fructus globosus, reticulatus, levis, diametro 4-pollicare, non edulis. (Ex Humb. et Bonpl. Mss. Herb.)

\section{Anona Ambotay.}

A. caule fruticoso, foliis oblongo-elliplicis aculis subtùs férrugineotomentosis, floribus axillaribus solitariis brevissimè pedunculatis. 
A. Ambotay. Aubl. Guj. 1. p. 616. t. 249.* - Lam. Dict. 2. p.126.* - Willd. 2. p. 1268.*

Ambotay. Nomen Caribaum.

Hab. in sylvis Sinemaricnsibus. Guj. 5

Frutex 8-pedalis, caulibus tortuosis, ramosis. Folia brevissimè peliolata, suprà glabra. Pedunculi graciles, longitudine petiolorum. Flores exigui, subvirides, solitarii, axillares.

ii. ANONA PALUDOSA.

A. caule fruticoso, foliis oblongis acutis suprà tomentosiusculis subtus nervosis tomentoso-sericeis rufescentibus, floribus solitariis geminisve axillaribus breviter pedunculatis, fructibus ovatis tuberculalis.

Guanabanus fructu turbinato minori luteo. Barrer. Equin. 53. A. paludosa. Aubl. Guj. 1. p. 6r1. t. 246.* - Lam. Dict. 2. p. 12f.* - Willd. 2. p. 1265.

Petit Corossol. . . . . . .

Petit Cœur de Bœuf. .. Gallicè. Aubl. Lam. Barrer.

Corossol sauvage. .....

Hab. in pratis paludosis Courou et Timoutou Gujanæ. s (v. s. h. DC.)

Frutex 4-5-pedalis, supernè ramosus. Rami tomentoso-rufescentes. Folia breviter petiolata, marginata, supernè viridia, subtùs nervosa, nervis parallelis, tomentosa, pilis sericeis rufo-ferrugineis. Flores solitarii vel bini, axillares, breviter pedunculati. Petala extùs subsericea, subcordata, ovata, acuta, viridia ; exteriora coriacea, interiora minora. Bacca lutea, ovata, tuberculis acutis retrorsùm uncinatis muricata.

B. Petalis exterioribus ovatis concavis acutis coriaceis, interioribus nullis.

12. AnONa echinata. tab. 4 .

A. ramis rugosis divaricatis, foliis ovato-lanceolatis acutiusculis 
69

suprà glaberrimis subtùs subtomentosis, pedunculis solitariis unifloris, fructibus ovoideis echinatis.

Hab. in Cayennâ. s (v. s. h. DC. )

Rami rugosi, tuberculati, nigrescentes, gialri, divaricali. Folia breviter petiolata, ovato-lanceolata, acutiuscula, suprà glaberrima; obscurè viridia, sublùs nervosa, parcè tomentosa, cinereo-ferruginea. Pedunculi peliolis tripló longiores, tomentosi, post efflorescentiam incrassati. Calyx 3-partitus. Petala 3 exteriora subcordatoovata, coriacea, intùs concava; interiora nulla. Tomentum brevissimum.

13. ANONA SERTCEA. tab. 5.

A. ramulis tomentoso-sericeis, foliis ovato-oblongis acuminatis suprà glabris subtùs ferrugineo-tomentosis sericeis, floribus solitariis axillaribus pedunculatis extùs ferrugineis.

Hab. in Cayennâ. s (v. s. h. DC.)

Rami tereles, tomentoso-sericei, rufescentes. Folia breviter petiolata, petiolis rufescentibus, ovato-oblonga, acuminata, interdùm emarginata, suprà glabra, obscurè viridia, subtùs sericeo-tomentosa, pilis mollissimis rufo-ferrugineis. Pedunculi uniflori, teretes, rufo-pubescentes. Flores floribus An, echinata similes. Calyx 3partitus. Petala exteriora ovata, extùs ferruginea; interiora nullai Fruclus ignotus.

C. Petalis exterioribus lineari-oblongis angustis apice triquetris, basi solummodò concavis, sapè clausis, senitalia basi occul-ì tantibus; petalis interioribus minutissimis.

\section{Anona squamosa.}

A. caule arborescente, foliis- lanceolatis glabris pellucido - punctatis, petalis exterioribus subclausis, fructibus ovoideis squamosis,

Guanabano. Ovied. 1. 8. c. 17. è Marcgr.

Guanabani fructus, Oviedo. Lugd. p. 1835 
Ate vel ahate de Panucho. Hern. Mex. 348, fo 2; et 454. $f$. 2: Atamaram. Rheed. Mal. 3. p.21. t.29.*

Guanabanus fructu subcœruleo. Plum. Mss. 6.t. 113? è Lam. Anona indica, fructu è viridi luteo, cortice squamato aspero, nucleis nigricantibus parvis. Pluk. Alm.3r.t. 134.f. 3.

A. foliis odoratis minoribus, fructu conoide squamoso parvo dulci. Sloan. Jam. 205. hist. 2.p. 168. t. 227. - Raj. Dendr. 77 .

A. tuberosa. Rumph. Amb. 1.p. 138. t. 46.*

A. 2. foliis oblongo-ovatis undulatis venosis, floribus tripetalis, fructibus mammillatis. Brown. Jam. 256 .

Annona squamosa. L. Sp. $757 .-$ Mill. Dict. n. $0^{0} 3{ }^{*}-J a c q$. Obs. I. p. 13. t. 6. f. 1.* - Swartz. Obs. $2210^{*}-$ Lam. Dict. 2.p. 123.* - Ait. Kew. ed. 2. vol. 3.p.334. - Gartn. fruct. 2.p. 193.t. 138. - Moç. et Sessé. Pl. Mex. ic.ined.

Coeur de Bœuf. è Mill. l.c. . • • Gallicè in Gujanâ et insulis

Pommier de Cannelle. E Jacq. . . $\left\{\begin{array}{r}\text { Gallice in Gujana } \\ \text { Marie baise. Ex Aubl. . . . . . }\end{array}\right.$

Attier. Ex Aubl. Gallicè in insulâ Francia.

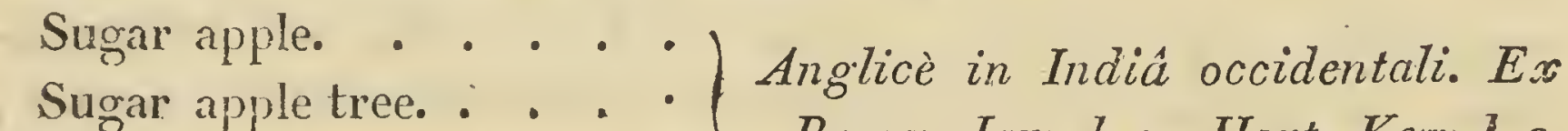

Undulated custard-apple. . Brown.Jam.l.c., Hort. Kew. l.c. Sweetsop. . . . . . et Swartz.l. c.

Steenappeiboom. Batav. E Jacq. l. c.

$\left.\begin{array}{l}\text { Atoa. • • • . · } \\ \text { Manil-panosou. . . } \\ \text { JonaJaka.... . . }\end{array}\right\}$ Brachm. E Rheed.

JonaJaka. . . . .

Atas. • . . . $\}$ Lusit. in Indiâ orientali. E Rheed.

Manoa papawa. Malaicè. E Rumph.l.c.

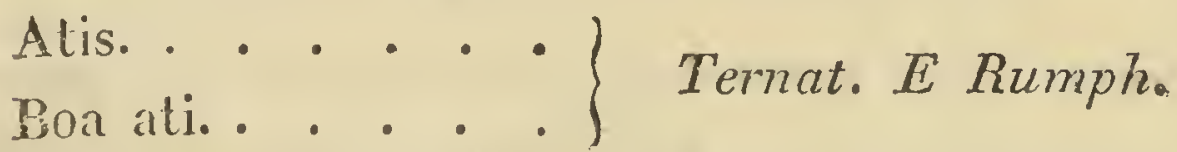

Siri Kaya. Javanicè. E Rumph. et Leschen.

Manil jaka. Malcub. E Rheed.

Hab. in India utraque culta intrà tropicum, ex India occidentali grta? s. ( vo s. h. DC. ) 
Arbor 20-pedalis, cortice fungoso. Folia pellucido-punctata, glabra: Pedunculi uniflori s. biflori, nunc solitarii oppositifolii, nunc 3-4 aggregati, laterales, foliis non oppositi. Calyx triparlitus, laciniis latis brevibus obtusiusculis. Flores vix dehiscentes, oblongi, apice obtu= siusculi. Baccæ edules, conoideæ, squamosæ, carnosæ, squamis extùs tuberculatis. Semina elliptica, compressa aut obsoletè angulata, sublucida, castanea aut nigricantia.

\section{Anona Asiatica.}

A. foliis oblongo-lanceolatis glabris nitidis lineatis, petalis exterioribus oblongis subclausis, fructibus squamosis.

A. sylvestris. Burm. Zeyl. 21. - Mus. Zeyl. 59.

A. foliis lanceolatis glabris nitidis secundùm nervos sulcatis. Hort, Cliff. 222. - Fl. Zeyl. $100, n 0^{\circ} 225$.

Annona Asiatica. L. Sp. 2. p. 758. - Mill. Dict. n.07. - Vahl. Symb. 3. p. 73. - Lam. Dict. 2. p. 1 26. - Willd. Sp. 2. p. 1267i exclus. Syn. Plum.

Alughas s. ahugas. Zeylanicè.

ß. Foliis minoribus subtùs glaucis.

A. glabra. Forsk. Descrip. 102.* Ic. t. 15. E Vahl, l.c.

Keschta, kichta, s. chescta. Arabicè.

Hab. in Zeylonâ; $\beta$. in AEgypto. 5

Species non satis nota, A. squamosæ similia. Differe videtur : foliis angustioribus elongatis.

16. Anona cinerea. tab. 8.

A. ramis rugosis, foliis oblongo-ellipticis s. lanceolatis obtusius culis cinereis pellucido-punctatis subtùs pubescentibus, petalis exterioribus subclausis, fructibus ovato-globosis squamosis.

Hab. in insulâ S. Thomas. s (v. s. h. DC. h. H. et B.)

Rami rugosi, tuberculati, subglabri, dilutè rubescentes. Ramuli, folia, pedunculi floresque pubescentes, cinerei. Folia petiolata, pellucido-punctata, præcipuè subtùs cinerea et pubescentia. Pedunculi uniflori, 2-3-aggregati. Flos oblongo-pyramidalis, basi gibbosus: 
Calyx parvus, tripartitus. Petala exteriora basi concava, supernè triquetra, coriacea; petala interiora ovata, concavitate petalorum: exteriorum minora. Fructus immaturus ovato-globosus, constans è plurimis squamis carnosis obtusis.

\section{ANONA CHERIMOLIA.}

A. canle arborescente, foliis ovalo-lanceolatis acutis impunctatis subtùs tomentoso - sericeis, petalis exterioribus subclausis extùs tomentosis, fruclibus subglobosis subsquamosis.

Guanabanus perseæ folio, flore intùs albo, extùs virescente, fructu nigricante squamato, vulgò cherimolia. Feuill. Peruy. 3. p. 24. t. $170^{*}$

- Anona foliis ovatis acutis, flore albido ungue purpureo, fructu uniformi tuberoso nigricante. Trew. Ehret. $p$. 16. t. 49. è Lam. et Willd.

A. cherimolia. Lam. Dict. 2. p. 124.* - Mill. Dict. r. 5.

Annona tripetala. Ait. Kew. 2. p. 252. - Wendl. Obs. 24 . $t .3$. f. $24 .-$ Willd. Sp. 2. p. 1264 .

Hab. in Peru. (v. s. h. DC. h. H. et B.)

Arbor 3-4-orgyalis, ramis pendulis. (Humb. et Bonpl.). Folia ovata, mollia, petiolata, sụbtùs tomentoso - sericea dilutè ferruginea, graveolentia. Pedunculi opposilifolii, uniflori, solitarii, interdìm terni quaternive, villoso - ferruginei. Petala exteriora, oblonga, coriacea, extùs tomentoso-ferruginea, supernè subteretia, basi concava, maculâ nigrà notata; petalia interiora minutissima. Fructus gratissimus.

i8. ANONa Reticulata.

A. caule arboreo, foliis oblongo-lanceolatis glabris aculis, petalis exterioribus ohlongis subclausis, fructibus ovalo-globosis reliculatoareolatis.

A. foliis oblongis undulatis venosis, fructibus areolatis. Brown. Jam. 3. p. 256.

Annona reticulata. L. Sp. 757. excl. syn. Rumph. - Mill. Dich 
n.0 1. excl. syn. Rumph. - Swartz. Obs. 222. * - Ait. Kew. 2. p. 253. ed. 2. vol. 3. p. 334. - Lam. Dict. 2. p. 124.* exclus. syn。 Rumph. - Willd. Sp. 2. p. 1265. exclus, syn. Plum. et Rumph. $\alpha_{0}$. Areolis squamoso-rotundatis.

Anona-maram. Rheed. Mal. 3. p. 23. t. 30.31.

Guanabanus fructu purpureo. Plum. Burm. ic. 143. $f$. 2 .

Anona maxima, foliis oblongis angustis, fructu maximo luteo conoide; cortice glabro in areolas angulares distincto. Sloan. Jam. 264. Hist. 2. p. 167. t. 226. - Raj. Dend. 77. - Catesb. Car. 2a p. 86. $t .86$.

$\left.\begin{array}{l}\text { Parangi jaca. Malab. } \\ \text { Tsjina-Panosou. Brachm. }\end{array}\right\}$ Rheed. l. c.

Custard aple. Angl.

Fruit à coeur de bœuf. Gall. In insulis Americanis.

ß. Areolis angulatis subpentagonis.

Annona reticulata. Jacq. Obs. 1.p. 14. t.6.f. 2.*

Hab. spontè in insulis Caribæis; in Malabariâ culta. s (v. s. h. DC. h. Deless. )

Arbor comosa, multò A. squamosá vastior proceriorque, cæterùm similis. Odor magis nauseosus est. Rami patuli, teretes, subfusci, juniores tenuissimè et adpressè pubescentes. Folia breviter petiolata, oblongo-lanceolata, juniora tenuissimè et adpressè subtùs pubescentia, adulta utrinque glabra, minutissimè pelluciơo - punctata. Pedunculi laterales à basi ramosi 3-4-fiori. Calyx 3-partitus, laciniis triangularibus basi latis, apice acatis. Petala exteriora 33, linearia, crassa, triquetra, obtusa, extùs inæqualia, fusca, intùs albo-lutescentia, basi excavata, maculis atro-purpureis notata; petala 3 , interiora minutissima, calyce minora, oblonga, obtusa. Bacca fusca, nitens ; matura flavescens, interdùm subrubella. ( $v$. s. sine fruct.)

Hùc plures forsan confusæ species. Anona reliculata herb. Dombey quæ Anona vulgò in Peruviâ dicitur, differe videtur foliis amplioribus regulariter penninerviis, nervis prominulis, parenchymate non punctato-pellucido. DC. Syst. univ. ined. 
19. ANONA MUCOSA.

A. caule arborescente, foliis oblongo-lanceolatis, petalis exterioribus apice patulis, fructibus areolatis, areolis gibbosis.

Manoa. Rumph. Amb. I. p. i36. t. 45."

Anona angustifolia, fructu cancellato maximo. Rhumph. tab. l. G.

A. muscosa. Aubl. Guj. i. p. 6r 8 .

A. mucosa. Jacq. Obs. 1. p. 16.

Cachiman morveux.

Cachiman sauvage. Gallicè in insulis Caribais.

Anona-Boom. Balav.

Manoa. Malaicè.

$\left.\begin{array}{l}\text { Menoa. } \\ \text { Siricaynona. }\end{array}\right\}$ Ternat. $\}$ In Indiâ orientali, è Rumph. l. c.

Nonas. Amboin.

Menona. Band.

Sarabrassa. Macass.

Hab. in Martiniče sylvis (Jacq.); in Gujanâ (Aubl.) ; in Moluccis culta (Rumph..). s

Simillimum $A$. reticulate toto habitu; differt verò : petalis exterioribus basi coalitis, apice patulis; fructuum areolis gibbosis. Carnis magis mucosæ sapor nihil grati possidet. $E$ Jacq.

D. Petalis exterioribus oblongo-ellipticis obtusis, interioribus minoribus lanceolatis obtusiusculis; calyce coriaceo, trifido, magno, subcampanulato; fructibus conoideis levibus?

20. ANONA glabra.

A. caule arborescente, foliis ovato-lanceolatis glabris, pedunculis oppositifoliis billoris, fruclibus conoideis obtusis levibus.

A. maxima, foliis latis, fructu maximo luteo conoide, cortice glabro. Catesb. Car. 2.p.64.t.64. - L.Sp. 758. - Lam. Dict.2.p. 125.* exclus.plur. syn. - Du Roi. harbk. 1. p.62.-Willd. Sp. 2. p. 1267. 
Hab. in Carolinâ (Catesb.); in Caribaeis forsan culta (Herb. Mus. Par.). 5 (D. C. v. s. h. Mus. Par.)

Arbor sexdecim pedalis. Folia ovato-lanceolata, glabra, foliis Citri medica similia, petiolo 4-5-lineari, tereti. Pedicelli opposilifolii, bifidi, biflori, bracteas 2-3 latas orbiculares concavas deciduas gerentes, apice rufescentes. Calyx extùs rufus, campanulatus, trilobus, lobis latis brevissimis, interdìm ferè truncatus. Pelala 6 , oblonga, ferè obovata, obtusa, calyce dupló longiora. Fructus conoideus, ovatus, obtusus, extùs levis, viridi-lutescens. Semina fusca. DC. Mss. Lam. l. c.

21. Anona grandiflora. tab. 6 et 6 a.

A. ramis glabris punctatis, foliis ovalo-lanceolatis glabris coriaceis suprà nitidis, pedunculis axillaribus solitariis, fructibus ovoideis glabris subpunctatis.

Anona, foliis maximis. Commers. herb.

A. grandiflora. Lam. Dict. 2.p. 126.* - Vahl. Symb. 3. p. 73.* -Willd. 2.p. 1269.*

B. A. grandiflora Madagascariensis. Pers. Enchir. p. $9^{5}$.

Bois blanc. Gallicè in insulâ Francia. Herb. Juss.

Hab. in Madagascariâ et insulis Trancia el Borboniæ. s (v. s. h. Deless.) (DC. v. s. h. Juss. h. Mus. Par.)

Rami teretes, glabri, punctati, rugosuli. Petioli crassi, brevissimi, rugosi. Folia coriacea, palmaria, ovalia aut ovato-oblonga, alia acuminata, alia subobtusa, utrinque glabra, venoso-reticulata, suprà nitida, subtùs glaucescentia. Pedunculi solitarii, brevissimi, crassi, axillares, uniflori, basi bracleas minutas caducas gerentes s. cicatricibus bractearum deciduarum locum indicantibus notati, supernè subvelutini. Calyx subcampanulatus, extùs subvelutinas, coriaceus, trifidus, lobis latis brevibus aculiusculis. Petala 6 , oblonga, obtusa, basi angusla, coriacea, exteriora pauló latiora et longiora , interiora angusliora, pollicem circiter longa, omnia cxlùs velutina albido-cinerea, intùs glabra. Stamina innumera. Fruclus mediocris, ovoideus, glaber, leviter rugosus. Semina oblonga, acula, pulpesa. 


\section{6}

22. Anona amplexicaulis. tab. 7 .

A. ramis glabris rimosis, foliis cordato-ob!ongis acutis amplexicaulibus, pedunculis axillaribus solitariis unifloris.

A. amplexicaulis. Lam. Dict. 2. p. 127.* - Vahl. Sym.3. p. 73.* - Willd. Sp. 2. p. 1269.*

Hab. in insulis Madagascariae et Mauritii. s ( DC. v. s. h. Juss. et h. Mus.)

Rami lignosi, teretes, glabri, cortice cinereo rimoso. Folia sessilia, ulrinque glabra, venoso-reticulata; subtùs in specimine sicco purpureo - violacea. Pedanculi axillares, breves, glabri, uniflori, solitarii. Flores pollicares et ullrà. Calyx laciniis acutiusculis. Petala exteriora oblongo-elliplica, obtusa; interiora parùm minora, lanceolata; omnia basi incrassata, intùs concavitate atro-purpureầ notata.

\section{E. Anona non satis nota.}

\section{Anona Senegalensis.}

A. ramis terelibus, foliis latis subcordatis coriaceis glaucis, pedunculis geminis ternisve infrafoliaceis.

A. Senegalensis. Pers. Enchir. 2. p. 95 .

Hab. ad Senegal, (Roussillon); in Guineâ, (Valh.) , (DC. v. s. herb. Juss. )

Rami teretes, juniores tenuiter velutini. Folia petiolo 3-4 lin. longo subvelulino, ovala, supernè glabra, obscurè glaucescentia, obtusa aut subacuta, basi minimè secùs petiolum producta, subtùs glauca, pallida, nervis pennatis elevatis rufis pubescentibus utrinque circiter duodenis ad basin approximatis. Pedunculi 2-3 approximati, infrà folia lateraliter orti, subcurvi, 5-6 lin. longi, uniflori. Flores parvuli. Calyx 3-partitus, lobis obtusis. Pelala 3 exteriora ovata, obtusa, crassa, calyce triplo longiora. (DC. Syst. univ. Mss.)

\section{ANONA? UNITLORA.}

A. ramis terelibus, foliis oblongis acuminatis glabris subtùs glaucis ; pedunculis oppositifoliis tomentosis candicantibus. 
Anona? uniflora. DC. Syst. univ. incd.

Hab. in Para Brasilize.s (DC. v. s. herb. Mus. Par.)

Rami teretes, juniores pube adpressầ tomentosâ candicantes, adulti glabri, cinereo-fusci. Folia brevissimè peliolata, oblonga, apice acuminata, basi parùm atlenuata, palmam et ultrà longa, 2-3 poll. lata, penninervia, supernè glabra, sublus juniora pube tenui adpressâ candicantia, adulta glauca, glabra. Pedunculi ultimo cujusque rami folio oppositi, uniflori, teretes, tomentoso-candicantes, 6 lin. longi; bracteæ $\mathrm{x-2}$, orbiculatæ, foliaceæ, obtusæ, subtùs candicantes, supernè subglabræ. Flos solitarius. Calyx 3partitus, lobis magnis ovatis vix acutis extùs candicantibus coriaceis. Petala nondum explicata, calycinis lobis similia videntur. Fructus ignotus. Species pulcherrima sed genus dubium. DC. $l$. $c_{\text {a }}$

\section{ANONA? Exsucca.}

A. caule arboreo, ramis glaberrimis, foliis glaberrimis ovalioblongis coriaceis suprà lucidis, pedunculis suboppositifoliis simplicibus s. bifidis.

Anona? exsucca. DC. Syst. univ. ined.

Hab. in sylvis Guianæ. (Alex. Anderson.) s (DC. v. s. in h. Lamb.)

Arbor pulchra. Fructus parvus omninò exsuccus. (Ander.) Rami teretes etiam nascentes glaberrimi. Petioli superuè canaliculati 3 lin. longi. Folia glaberrima, ovali - oblonga, basi ovata, apice obtusa aut subacuta, $21 / 2-4$ poll. longa, $12-18$ lin. lata, coriacea, penninervia, nervo medio subtùs solo prominulo, lateralibus supernè reticulatim subelevatis, suprà lucida. Pedunculi suboppositifolii, simplices aut è basi imâ bifidi, tenues, 8-10 lin. longi. Alabastra triloba. DC. Syst. univ. ined.

\section{Anona Africana. + +}

A. foliis lanceolatis pubescentibus.

A. foliis lanceolatis pubescentibus. Hort. Cliff. 222. - Roj: Lugd. 6. 494. - Mill. Dict. n. ${ }^{\circ}$ G.

A. Africana. L. sp. 758. - Willd. Sp. 2.p. 1268 . cxclus. syn.

Hab, in Americâ, s E Lin. 
ANON乎 EXCLUDEND压。

Nomina excludenda. Nomina legitima.

Anona hexapetala. $L . . . . . .$. Unona uncinata. Nob. Anona triloba. $L . \ldots \ldots$. . . . . Asimina triloba. Nob.

- pygmæa. Bart. ....... - pygmæa. Nob.

- obovata. Willd........ - grandiflora. Nob.

- grandiflora. Bart. ....... - grandiflora. Nob.

- myristica. Gortn. ........ Monodora myristica. Nob.

- microcarpa. Jacq......... - microcarpa. Nob.

- uncinata. Lam. . . . . . . U Unona uncinata. Nob.

- dodecapetala. Lam. . . . . . . Talauma Caribæa. Juss.

Anona, fructu lutescente levi scrotum arietis. Catesb. . . . . . . . . A Asimina triloba. Nob.

A. foliis laurinis in summitate incisis fructu compresso scabro fusco in medio acumine longo. Catesb. . . . . . . . . Sapoteæ species dubia. Slo-

A. foliis subtùs ferrugineis, fructu annea emarginata. $L$. rotundo majore levi purpureo, semine nigro partim rugoso partim glabro. Sloan. Cat. et Hist. Jam. . . . . . . . . Chrysophyllum cainito. $L$.

A. foliis laurinis viridi-fuscis, fructu rotundo minore viridi flavo scabro, seminibus fuscis splendentibus fissurâ albâ notatis. Sloan. Cat. et Hist. Jam...... Achras sapota. $\alpha_{0} \boldsymbol{L}_{\bullet}$

A. maxima, foliis laurinis glabris viridifuscis, fructu minimo rotundo viridi-flavo, seminibus fuscis splendentibus fissurâ albâ notatis. Slocn. Cat. et Hist. ....... Achras sapota. $\beta . ~ L$.

A. Lrifolia, flore stamineo, fructu spherico ferrugineo scabro minore, allii odore. Sloan. Cato et Hist. Jam. . . . . . . Crateva tapia. $L_{*}$ 
§. Ovarium unicum polyspermum.

\section{I. MO N O D O R A.}

Annonæ species. Gurtn. Jacq.

\section{Character differentiatis.}

Calyx tripartitus; corolla 6-petala; ovarium unicum, stigmate sessili coronatum; bacca simplex, unilocularis, polysperma.

\section{Character naturalis fructificationis.}

CALYX tripartitus.

Corolla 6-petala; petala 3 exteriora oblonga lanceolata acuta; petala 3 interiora ovata crassiora exterioribus paulò breviora.

Stamina. Antheræ subsessiles, confertissimæ, circà ovarium adpressæe, eo dimidio breviores.

Ovarium unicum, ovatum, apice subattenuatum, glabrum, stigmate sessili coronatum.

Fructus. Bacca simplex, subglobosa, unilocularis, glabra, corticata, polysperma.

Semina ovato-oblonga, in pulpâ nidulantia.

\section{Character naturalis vegetationis.}

Arbores s. frutices, foliis alternis. Pedunculi laterales, uniflori, basi aut medio aut suprà medium bracteati.

\section{ConsteCTUS SPECIERUM.}

x. M. myristica. M. baccis magnis subglobosis.

2. M. microcarpa. M. baccis turbinatis obtusissimis parvis. 


\section{0}

\section{HIS'TORIA SPECIALIS.}

\section{y. Monodora myristica.}

M. ramis teretibus, foliis oblongis coriaceis, baccis magnis subglobosis.

Annona myristica. Hort. Jam. 2. è DC. Mss. - Gartn. 2. p. 194. t. 125.f. 1 .

Hab. in Jamaicâ. (Wiles.) ' (DC. vo s. in herb. Lamb.)

Rami teretes etiam juniores glabri. Folia alterna, petiolo brevi crasso instructa, etiam juniora glabra, oblonga, paululùm obovata, basi abruptè ovata, ferè subcordata, vix acuta, supernè nitida, subtùs juniora præsertim glaucescentia, coriacea , 7-8 poll. longa, 2-2 1/2 poll. lata, penninervia. Pedicelli lateraies, 3-poll. longi, graciles, unifiori, glabri, basi aut medio aut suiprà medium bracteâ ovatà sessili pedicello $3.0^{\circ} 4 .^{\circ}$ breviore instructi. Flos magnus Unonam undulatam æemulans. Calyx 3-phyllus, phyllis ovatis subobtusis patentibus demùm reflexis glabris 6 -lin. longis. Fèala 3 exteriora oblonga, lanceolata, acuta, valdè undulata, 8-9 lin. longa; petala 3 interiora, ovata, crassiora, suprà basin dilatata, intùs ad marginem ciliato-tomentosa, exterioribus paulò breviora, erecto-conniventia. Antheræ subsessiles, confertissimæ, circà ovarium adpressæe, eo dimidio breviores. Ovarium unicum, ovatum, apice attenuatum, glabrum, stigmate sessili coronatum. DC. Syst. uni . ined. Bacca simplex, subglobosa, grandis, unilocularis, glabra, corlicata. Semina in pulpâ nidulantia, ovato-oblonga, à pressione vicinorum variè angulata, ferruginea. Gartn. lo $c_{\text {。 }}$

2. Monodora MiCROCARPA.

M. baccis turbinatis, oblusissimis, parvis.

Annona microcarpa, Jacq. Fragm. p. 40. t. 44. f. 7 .

Hab. in Novâ Hollandiâ.

Solus fructus cognitus est; sed hoc solo ab omnibus congeneribus facilè distinguitur. Bacca turbinata, avellanâ nuce vix major, obtusissima, pulparn continet; semina oblonga, in pulpâ nidulantia. Fuscus totus fructus est, verosimiliter alius coloris recens. Jacq. $l$. c. 
8

\section{§§. Ovaria plurima distincta.}

\section{V. A S I I N A.}

Anona species. Catesb. Car. 2. p. 85. Juss. Gen. 283.-Annonxe species. L. p. 758. - Asimina. Adans. Fam. 2. p. 365. - Orchidocarpum. Mich. Fl. Boreal.-Amer. 1. p. 329. - Porcelia species. Pers. Enchir. 2. p. 95. - Asiminæe species. Juss. Ann. du Mus. 16. p. 339 .

\section{Character differentialis.}

Calyx tripartitus; corolla 6-petala, petalis interioribus minoribus; baccæ plures ovatæ vel oblongæ, carnosæ, sessiles, polyspermæ; semina unicà serie disposita.

\section{Character naturalis fructificationis:}

CALYX tripartitus, laciniis ovatis acutiusculis.

Corolla 6-petala, petalis obtusis ovalibus s. ovato-oblongis s. obovatis, interioribus minoribus.

Stamina numerosa, glomerata. Antheræ primùm luteæ dein fulvæ, subcoalitæ, sub apice dehiscentes, subsessiles.

Ovaria plura, plerumque 3 , ovata s. oblonga.

Fructus. Baccæ plures, plerumque 3, ovatæ, carnosæe, leves, sessiles, polyspermæ.

Semina ovato-elliptica; obtusa, unicâ serie disposita.

\section{Character naturalis vegtationis:}

Frutices. Folia sæè̀ cuneata, obtusa vel acuta. Flores axillares, subsolitarii, sessiles aut breviter pedunculati, in pluribus speciebus antè folia nascentes. 


\section{Conspettus SPEIERUM.}

I. A. parviflora. A. ramulis rufo-pubescentibus, foliis cuneatoolovvalibus mucronatis subtùs rufo-pubescentibus, floribus subsessilibus parvis, petalis exterioribus calyce vix duplò longioribus.

2. A. triloba. A. caule fruticoso, foliis oblongo-cuneatis acuminatis glabris, floribus breviter pedunculatis, pelalis exterioribus calyce quadruplò lóngioribus subrotundo-ovatis.

3. A. pygmaa. A. caule suffruticoso, foliis angustis oblongolinearibus longè cunealis oblusis glabris, floribus breviter pedunculalis, petalis exterioribus calyce multoties majoribus obovalibus oblongis.

4. A. grandiflora. A. caule fruticoso, foliis cuneato-obovalibus obtusis subtùs rufo-pubescentibus, floribus subsessilibus, petalis exterioribus obovalibus calyce multoties amplioribus.

\section{H ISTORIA S P E CIALIS.}

r. Asmina parviflora. tab. 9.

A. ramis glabris, ramulis rufo-pubescentibus, foliis cuneatoobovalibus mucronatis subtùs rufo-pubescentibus, floribus subsessilibus parvis, petalis exterioribus calyce vix duplò longioribus.

Orchidocarpum parviflorum. Mich. Flor. Boreal.-Amer. 1. p. 329. Porcelia parvillora. Pers. Enchir. 2. p.95. - Pursh. Fl. BorAm. 2.p. 383.

Hab. in Carolinâ et Georgiâ. s (v. s. h. DC. )

Rami glabri, leviter rugosi. Ramuli foliacei rufo-pubescentes. Folia brevissimè petiolata, cuneato-obovalia, basi acuta, subtùs nervosa, rufo-pubescentia, suprà glabra, viridia. Flores sessiles aut subsessiles, parvi, antè folia nascentes, in axillis cicalricularum foliorum. Pedunculi, calyces corollæque extùs, tomentoso-rufescentes. Calyx tripartitus, laciniis ovatis. Corolla calyce vix duplò 
longior. Petala ovalia, intùs obsoletè atro-purpurea. Baccæ sessiles, ovatæ, 2-3 aggregatæ, leves, parcè carnosæ, pruni magnitudine.

2. Asimina triloba.

A. caule fruticoso, foliis oblongo-cuneatis acuminatis glabris, floribus breviter pedunculatis, petalis exterioribus calyce quadruplò longioribus subrotundo-ovatis.

Anona fructu lutescente levi scrotum arietis. Catesb. Car. 2. p. 8j.

t. 85. - Trew. Ehr. t. 5. - Duharn. Arb. 1.p. 56.t. 19. E Willd. Annona triloba. L. Sp. 758. - Ait. Kew. 2. p. 254.-Lam. Encycl. 2. p. 1 25.* - Willd. 2. p. 1267.-Mill. Dict. n. ${ }^{\circ}$ 8. ic. 1. t. 35. - Mich. fils. Arb. Amer. 3. p. 16r. t. 9. - Duroi. hardk. I. p.59. è Willd. l. c. - Duh. Arb. 2. edit.2. t. 25. - Schkuhr. handb. 2.p. 95.t. 149 .

Orchidocarpum arietinum. Mich. Fl. Boreal.-Amer. 2. p. 329.

Porcelia triloba. Pers. Enchir.2.p. 95. Pursh.Fl.Bor.-Am.2.p.383.

Asiminier vel Assiminier.

Le Corossol. $\{$ Gallicè.

Papaw. Anglicè in Amcricâ septent.

Hab. in Virginiâ, Carolinâ et Floridâ, juxtà inundatas amniuma ripas. s (v. v. h. M.)

Frutex, ramis teretibus cinereis, cicatriculis notatis. Folia magna, breviter petiolata, ovato-oblonga, cuneata, acuminata, suprà glaberrima, subtùs glabriuscula, nervosa. Pedunculi breves, solitarii, uniflori, parùm recurvi, virides, pilosi, pilis simplicibus atro-purpureis brevibus. Flores subcampanulati, antè folia nascentes. Calyx tripartitus, laciniis subæqualibus concavis ovatis extùs pilosis, pilis atro-purpureis brevibus. Petala 6 , subrotundo-ovata, obtusa, rugosiuscula, primùm recta dein retroflexa, 3 exteriora pallidè purpurea, 3 interiora minora extùs purpurea, intùs basi purpurea medio. lutea supernè purpurea. Stamina numerosa. Antheræe primùm luteæ, subcoalitæ, dein fulvæ, sub apice dehiscentes, subsessiles. Ovaria tria, oblonga; stigmata tria, sessilia. Baccæ totidem, lutea, ovatooblongæ, pubescentes. 


\section{4}

3. Asmina PygmeA. tab. io.

A. caule suffruticoso, foliis angustis oblongo-linearibus longè cuneatis obtusis glabris, floribus breviter pedunculatis, petalis exterioribus calyce multoties majoribus obovalibus oblongis.

Annona pygmæa. Bartr. Trav. ed. germ.p. 21.t. 1. - Willd. Sp. 2. p. $1268.0^{\star}$

Orchidocarpum pyggmæum. Mich. Flor. Boreal.-Amer. 1. p. 33o. Porcelia pygmaa. Pers. Enchir. 2. p. 95. - Pursh. Fl. Bor-Am. 2. $p .383$.

Hab. in Georgiầ et Floridâ. s (v.s. h. DC.)

Frutex totus glaber. Rami virgati. Folia prælongè lanceolata, cuneata, oblusa. Pedunculi breves, solitarii, uniflori, bracteati, bracteis linearibus obtusis. Calyx tripartitus, laciniis concavis ovatis acutiusculis. Petala exteriora ampliora, obovali-oblonga ; interiora minora subelliptica, obtusa.

\section{Asimina grandiflora. tab. II.}

A. caule fruticoso, foliis cuneato-obovalibus obtusis subtùs rufopubescentibus, floribus subsessilibus, petalis exterioribus obovalibus calyce multoties amplioribus.

Annona grandiflora. Bartr. Trav. 18. ed. Germ. p. 20. t. 2. è Willd.

Annona obovata. Willd. 2.p. 1269.*

Orchidocarpum grandifforum. Mich. 1. p. 330.

Porcelia grandiflora. Pers. Enchir. 2. p. 95. - Pursh. Fl. Bor.Amer. 2. p. 383.

Hab. in Georgiâ et Floridâ. s (v. s. h. DC. )

Rami glabri. Ramuli, folia subtùs calycesque rufo-pubescentes. Folia cuneato-obovalia, obtusa, suprà glabra. Pedunculi brevissimi. Calyx tripartitus, laciniis concavis ovato-ellipticis, acutiusculis. Petala exteriora multoties ampliora, obovalia; interiora lineari oblonga. Baccæ oblongo-obovatæ, glabræ. 


\section{POR CELIA:}

Porcelia. Syst.veg.fl. Per. 1.p. 144.-Gen.pl. J..Per. 84.t. 16."

\section{Character differentialis.}

Calyx subtripartitus; corolla 6-petala, petalis interioribus paulò majoribus; baccæ 3-6, sessiles, coriaceæ, cylindricæ, subtorulosæ, polyspermæ, seminibus gemino ordine superimpositis.

\section{Character Naturalis fructificationis.}

CalyX subtripartitus, laciniis ovato-cordatis acutis concavis.

Corolla 6-petala ; petala ovata, acutiuscula, crassiuscula, interiora paulò majora.

Stamina. Filamenta subnulla. Antheræe numerosæ, lineares.

Pistillum. Ovaria plurima , 3-6, linearia, sessilia. Styli subnulli: Stigmata obtusa.

Fructus. Bacca 3-6, magnæe, sessiles, crassæ, coriaceæ, cylindricæ, subtorulosæ, polyspermæ, exteriùs suturâ dorsali longitudinali notatæ, receptaculo plano insidentes.

SEMrna plura, oblonga, reniformia, compressa, gemino ordine superimposita.

\section{Character naturalis vegetationis.}

Arbor 4o-ulnaris, pulcherrima. Folia ovato-lanceolata. Flores et fructus nutantes.

\section{HISTORIA SPECIAIIS.}

\section{Porcelia nitidifolia.}

P. caule arboreo, foliis ovato-lanceolatis, floribus nutantibus: fructibus dependentibus, 
P. nitidifolia, Ruiz et Pav. Syst. veg. 1. p. 1440-Pers. Enchir. 2. $p .96$.

Platano de monte. Vulgò in Peruviá.

Hab. in Peruviæ nemoribus versùs Chincao vicum et Macora præedium. 5 (v. s. h. DC.)

Arbor satis procera, 40-ulnaris, pulcherrima. Rami subcinerei, rugosi, punctati, punctis minutis. Folia breviter petiolata, basi rotundata, oblongo-lanceolata, acuminata, glaberrima, suprà nitida, utrinque venosa. Pedunculi axillares, uni aut pauciflori, plures aggregati, apice incrassati, penduli. Calyx subtriparlitus, laciniis acutis apice recurvis. Baccæ pendulæ.

\section{P ORCELI瓜 EXCLUDEND}

Nomina excludenda.

Nomina legitima.

Porcelia triloba. Pers. Ench. 2. p. 95. . . Asimina triloba. Nob.

- parviflora. $i d . \ldots \ldots \ldots$ - parviflora. $N_{o} b$.

- pygmæa. $i d . . . . . . . .$. - pygmæa. Nob.

- grandiflora. $i d . . . . .$. - grandiflora. Nob.

\section{I. U V A R I A.}

Uvaria. L. Gen. 692. - Gartn. de Fruct. 2. p. 155. et 157. - Uvariæ species. Juss. Gen. p. 284. Ann.du Mus. 16. p. 340。 -Willd. Sp. 2. p. $126 \mathrm{r}$.

\section{Character differentialis.}

Calyx 3-partitus; petala 6,3 exteriora minora? Baccæ numerosæ, carnosæ, ovatæ s. globosæ, stipitalæ, polyspermæ, seminibus duplici serie dispositis.

\section{Character naturalis fructificationis.}

CaLYx 3-parlitus, laciniis ovatis cordatis.

Conolla 6-petala; petala ovalia vel oblonga, 3 exteriora interioribus minora? 
Stamina numerosa, receptaculum hemisphericum obtegentia.

Ovaria ovato-oblonga, sæpè villosa.

Fructus. Baccæ carnosæ, numerosæ, plus minùsve stipitatæ; ovatæ vel globosæ, multiloculares, polyspermæ.

SEMINA ovata aut oblonga aut obovata, glaberrima, castanea duplici serie disposita, in loculis solitaria.

\section{Character naturalis vegetationis.}

Arbores s. frutices, caulibus erectis vel sarmentosis. Folia integra. Pedunculi axillares, oppositifolii vel laterales, I-4-flori, solitarii gemini ternive, sæpè bracteolati vel medio articulati.

\section{CONSPECTUS SPECIERUM.}

I. Uv. Zeylanica. U. caule fruticoso sarmentoso, foliis ovato lanceolatis glabris, baccis pluribus in stipitem attenuatis, ovatocylindricis, seminum integumenti processibus internis lamellosis.

2. Uv. Gartneri. U. baccis ovatis in stipitem attenuatis, seminum integumenti processibus internis subulatis et ferè acicularibus.

3. Uv. lutea. U. caule arboreo, ramis teretibus punctatis, foliis oblongis acuminatis nitidis, pedunculis $\mathrm{I}-3$ floris solitariis, baccis oblongis hexaspermis.

4. UD. tomentosa. U. caule arboreo, ramis numerosis horizontalibus, foliis oblongis acutis tomentosis, pedunculis unifloris subsolitariis, baccis globosis 4-spermis.

5. Uv.dulcis. U. ramis teretibus superioribus villosis, foliis oblongo-elliplicis nunc acuminatis nunc obtusiusculis basi attenuatis cordatis subtùs velutinis, pedunculis geminis axillaribus vel oppositifoliis medio bracteatis aut articulatis.

6. U৩. Javana. U. ramis teretibus punctatis supernè villosis, foliis basi cordatis oblongo-elliplicis acuminatis vel obtusiusculis subtùs tomentosis ferrugrineis, pedunculis paucifloris axillaribus aut oppositifoliis, pedicellis suljumbellatis medio bracteatis. 
7. Uv. velutina. U. caule velutino, foliis subsessilibus velutinis ovato-cordatis acuminatis, pedunculis lateralibus ramosis velutinis, pedicellis unifloris.

8. Uv? spectabilis. U. ramis teretibus junioribus ferrugineoyelutinis, foliis oblongis, pedunculis unifloris lateralibus aut oppositifoliis, petalis obovatis, 3 interioribus paulò majoribus apice bifidis.

\section{Historia SPECIALIS.}

\section{UVaria ZeYlanica.}

U. caule fruticoso sarmentoso, foliis ovato-lanceolatis glabris, baccis pluribus in stipitem attenuatis ovato-cylindricis, seminum integumenti processibus internis lamellosis.

Uva Zeylanica sylvestris, mali aurantii sapore. Mus.Zeyl. p. 8. et 31. E Burm. Thes. Zeyl. 231.* exclus. syn.

Uvaria. L. Fl. Zeyl. 224.* exclus. syn. Rai. et Rheed.

Uvaria Zeylanica. L. Sp. 2. p. 756. exclus. syn. Rumph. et Rheed. - Gartn. 2. p. 155. t. 114. f. 2. - Lam. Illust. t. 495. f. 2. nec Willd. Spec. nec Lam. Dict.

Palukena. Zeylanicè. Burm. l. c.

Uves de mato. Lusitanicè in Indiâ orientali. Burm. l. c.

Hab. in Zeylan. 5

Frutex sarmentosus; rami rugosi. Folia ovato-lanceolata, glabra, acuminata, petiolata. Flores punicei, stellati. Fructus : bacca 6-7, subhirsulæ, molles, cinereæ, parvæ, teretes, semi-unciales, sapore vinoso malæ armeniacæ æmulante. L. Fl. Zeyl. Burm. l. c. Bacce, cornmuni receptaculo subgloboso insistentes, breviter stipitatie, ovato-cylindricx, ad seminum sedem nodulosæ, cinereoalbidx, intùs in tolidem loculamenta horizontalia gemino ordine posita divisae quot sunt semina. Semina in loculis solitaria, in tolî̀ autem baccì diodena circiter aut pauciora, semi-circularia, utrinque plana, glaberrima, castanea. Gartn. I.c.

Uyaria Zeylanica at D. Prugmans missa et in herb. Jussiaei des- 
89

cripta, est specimen unicum sine flore ab omnibus sub eodem nomine in herb. Burmanni servatis diversum. Rami teretes, grisei, glabri, apice summo vix pubescentes. Folia oblonga, breviter petiolata, dependentia, glabra, utrinque acuminata, coriacea, nervo medio subtùs prominente, cæeterum vix venosa. DC. Syst. univ. ined.

\section{Uvaria Gæertneri.}

U. baccis ovatis, in stipitem attenuatis, seminum integumenti processibus internis subulatis et ferè acicularibus.

Uvaria trifoliata. Gartn. Sem. 2. p. 157. t. 114. $f_{0}$ 2. - Lam: Illust. t. $49^{5} \cdot f \cdot 3$.

Hab. . . . . . . è collect. sem. hort. Lugdb. cum nomine Uע. Zeylanica.

Baccæ ovatæ, baccis Uv. Zeylanica majores, sensim in stipitem attenuatæ, carnosæ. Dissepimenta transversalia, crassa, carnosa. Semina, duplici serie posita, octona aut plura, obovata, lenticulari compressa, obsoletis foveolis oblongis rugata, è cinereo-spadicea. Integumenti processus interni non lamellosi sed subulati et ferè aciculares, quare etiam albumen, loco rimarum, innumeris foraminibus contiguis exsculptum. Gortn. $l$. $c$.

\section{Uvaria lutea.}

U. caule arboreo, ramis teretibus punctatis, foliis oblongis acuminatis nitidis, pedunculis I-3-floris solitariis, baccis oblongis hexaspermis.

U. lutea. Roxb. Corom. 1: p. 32. t. 36.* - Willd. 2. p. 1263.* - Poir. Dict. Suppl. 2. p. 7 1. $^{*}$

U. coriacea. Vahl. Symb. 3. p. 72.? è Willd.

Hab. in Indiæe orientalis montibus. 3 (DC. v. s. h. Lamb.) Floret per menses calidos.

Arbor salis procera. Pami teretes, cortice cinereo, albidopunctati, glabri; ramuli villosi. Folia brevissimè petiolata, subcoriacea, bipollicaria, acuminata, obtusiuscula, suprà avenia, levia, nitida, subtùs venosa. Pedunculi plerumque oppositifolii, solitarii, f-3-flori, longitudine petioli: pedicelli subumbellati, pedunculo 


\section{0}

longiores, villosi. Bractea oblonga versùs basim pedicelli. Calyx laciniis ovatis acutis. Petala 6 , coriacea, extùs subcinerea. Vahl.l.c. Petala rufescentia, ovata, obtusa. Baccæ oblongæ, basi atienuatæ, luteæ', hexasperma', magnitudire pruni. Willd.l.c.

\section{Uvaria tomentosa.}

U. caule arboreo, ramis numerosis horizontalibus, foliis oblongis acutis tomentosis, pedunculis uniforis subsolitariis, baccis globosis 4-spermis.

U. toinentosa. Roxb. Coroin. 1.p. 31. t. 35.* - Willd.2.p. 1262.* -Poir. Dict. Suppl. 2.p. 7 I.* $^{*}$

Hab. in Indiz orientalis montibus.'s Floret per menses calidos.

Arbor magna, cymâ ingente. Truncus rigidıs. Rami numerosi, horizontáles ; ramuli bifarii. Folia breviter petiolata, oblonga, 2-3poll. longa , 1-2-poll. lata, acuta, tomentosa. Pedunculi unifiori, tomentosi, solitarii, folio dimidio breviores. Petala 3 exteriora lineari-subulata, inierioribus triplò breviora, virescentia; 3 interiora ovata, acutiuscula, rufescentia. Baccæ tetraspermæ, magnitudine figurî et colore pruni minoris. Semina sæpiùs 4, reniformia , magnitudine phaseolorum. Roxb.l.c.

5. Uyaria Dulcis. tab. I3.

U. ramis teretibus superioribus villosis, foliis oblongo-ellipticis nunc acuminatis nunc obtusiusculis basi attenuatis cordatis subtùs velutinis, pedunculis geminis axillaribus vel oppositifoliis, medio bracteatis aut articulatis.

Uv. Zeylanica. Herb. Delessert.

Hab. in Java. s (v.s. h. Deless.)

Rami teretes, leviter rugosi, basi glabri, supernè villosi, ferruginei. Folia brevissimè petiolata, 2-4-pollicaria, oblongo-elliptica, basi attenuata, cordata, apice nunc acuminata, nunc obtusa, nunc subobvata, margine subundulata, subtùs penninervia, velutina, rufo-cinerea, nervo longitudinale rufescente, suprà glabriuscula aut pilosiuscula, pilis minutissimis oculo armató sölummodò- visibilibus. 
$9 \mathbf{l}$

Pedunculi villosi, ferruginei, axillares vel oppositifolii, gemini, medio articulati vel bracteam unicam amplexicaulem gerentes. Calyx profundè trifidus, villosus, ferrugineus, laciniis lato-ovatis acutiusculis. Petala villosa, margine leviter undulata, exteriora extùs ferruginea, intùs cinerea, obtusiuscula, interioribus latiora paulò minora; interiora aculiuscula, oblonga, basi attenuata, utrinque præcipuè intùs cinerea. Pistilla villosa.

\section{Uvaria JaVANA. tab. I4.}

U. ramis teretibus punctatis supernè villosis, foliis basi cordatis oblongo-ellipticis acuminatis vel obtusiusculis subtùs tomentosis ferrugineis, pedunculis paucifloris axillaribus aut oppositifoliis, pedicellis subumbellatis medio bracteatis.

Hab. in Java. Lahaie. ' (v. s. h. Delessert.)

Rami teretes, punctis cinereo-albidis notati, supernè tomentoso-ferruginei. Folia brevissimè petiolata, basi altenuata, cordata, oblongo-elliptica, margine undulata, subfalcata, apice nunc acuminata, nunc obtusa, subtùs tomentosa, ferruginea, penninervia, suprà subnitida, glabriuscula vel pilosiuscula, pilis minutis lentis ope visibilibus, nervo longitudinali suprà tomentoso. Pedunculi pauciflori, solitarii vel gemini, villoso-ferruginei, uti pedicelli, calyces corollæque extùs. Pedicelli uniflori, 2-3-4 subumbellati, basi articulati, medio bracteam unicam amplexicaulem gerentes. Calyx profundè trifidus, laciniis lato-ovatis acutiusculis. Petala 3 exteriora rotundo-ovata, acutiuscula, intùs cinerea, interioribus paulò minora ; 3 interiora, ovato-oblonga, acutiuscula, rufo-cinerea. pistilla villosa.

\section{Uvaria velutina.}

U. caule velutino, foliis subsessilibus ovatis basi cordatis acuminatis velutinis, pedunculis lateralibus ramosis velutinis, pedicellis unifloris.

U. villosa. Roxb.

U. velutina. DC. Syst. univ. ined. 


\section{$9^{2}$}

Mab. in Indià orientali. Roxburg/l. 5 (DC.v. s. h. Lamb.)

Peamuli, folia utrinque, petioli, pedunculi calycesque tomento brevissimo molli subcinerascente velutini. Rami teretes. Folia brevissimè petiolata, ferè sessilia, ovata, basi cordata, acuminata, 2-3-poll. longa, $1^{1} / 2-2-$ poll. lata, penninervia, nervis subtùs prominulis magis velutinis. Pedunculi laterales, ramosi, pedicellis paucis 3-4 subcorymbosis elongatis unifioris. Calyx parvus, 3-partitus. Pelala 3 ovata, obtusa, crassa, extùs velutina, intùs glabra fuscata. Antheræ numerosæ, brevissimæ, subsessiles. Ovaria confertissima, subvelutina. DC. Syst. univ. ined.

\section{UVARta? SPECTABILIS.}

U. ramis teretibus, junioribus ferrugineo-velutinis, foliis oblongis, pcdunculis unifloris lateralibus aut oppositifoliis, petalis obovatis, 3 interioribis paulò majoribus apice bifidis.

Uvaria? spectabilis. DC. Syst. univ. ined.

Hab. in Guianâ. Martin. s (DC. v. s. h. Lamb.)

Rami teretes, juniores ferrugineo - velutini. Folia brevissimo callosoque petiolo instructa , 6-8-poll. longa, 2-poll. lata, oblonga, integerrima, basi vix attenuata, apice abruptè acuminata, penninervia, nervis lateralibus alternis sublùs prominulis omnibus in nervulum margini parallelum confluentibus, nascentia subtùs rufo-velutina, demùm glabra, nervo medio subtùs basi velutino. Pedunculi brevissimi, ferrugineo-velutini, uniflori, laterales aut oppositifolii. Flores ampli. Calyx 3-phyllus, lobis ovatis extùs pubescentibus coriaceis, intùs glabris, 3-4 lineas longis. Petala 6-9-1 r-lin. longa, obovata, basi subangustata, coriacea, utrinque pube sericeâ adpressâ candicantia, 3 exteriora paulò minora apice integra, 3 interiora paulò majora apice bifida, lobulo altero rarissimè subbifido. Stamina seriei exterioris abortiva, coriacea, oblonga, fusca, super stamina fertilia subincumbentia iis paulò longiora, intùs apice bisulcata; stamina fertilia, innumera, multiscrialia, conferta, compressa. Ovaria confertissima vix distincta. Fructus ignotus. DC. Syst. univ. ined. 


\section{$9^{5}$}

UVARIA EXCLUDENDT.

\section{Nomina excludenda.}

Uvaria Japonica. L. Sp. pl. Thunb. Jap. Kadsura Japonica. Nob.

- febrifuga. Humb. et Bonpl. ined. Unona Xylopioides. Nob.

- aromatica. Lam.. $\}$....... _ - aromatica. Nob.

- monilifera. Gartn. ........ - - discreta. $L$.

- ligularis. Lam. Dict. ....... - - ligularis. Nob.

- lucida. Vent. herb. Deless.. . . . . - nitidissima. Nob;

- longifolia. Lam. . . . . . . . - longifolia. Nob.

- odorata.Lam. ......... - - odorata. Nob.

- uncata. Vahl. herb. Deless. .... - lessertiana. Nob.

- uncata. Lour. .......... - hamata. Nob.

- esculenta. Roxb. . . . . . . - - esculenta. Nob.

- violacea. Moz. et Sessé...... - violacea. Nob.

- tripeiala. Lam. ......... - - tripetaloidea. Nob.

- penduliflora. Moz. et Sessé.... - - penduliflora. Nob.

- Zeylanica. Lam. Willd. . . . . . - narum. Nob.

- monosperma. Lam. . . . . . . Guatteria ouregou. Nob.

- tomentosa. Vahl. in herb. Juss... - - rufa. Nob.

- cerasoides. Roxb. Corom..... - - cerasoides. Nob:

- suberosa. Roxb. . . . . . . . . - suberosa. Nob.

- lanceolata. ) Swartza.........

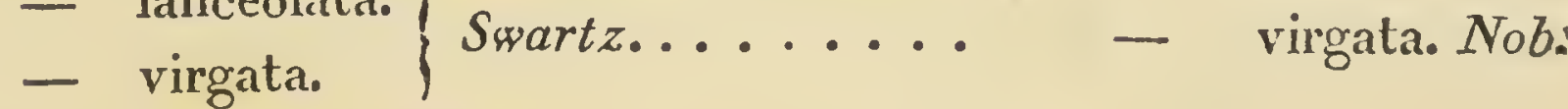

- laurifolia Swartz.......... 


\section{$9^{4}$ \\ V I I. U N O N A.}

Unona. L. Suppl. p. 270.- Juss. Gen. 283.* Ann. du Mus. t. 16. p. 340. exclus. syn. Bulliarda Neck. - Poir. Dict. 8. p. 186. - Willd. Sp. 2. p. 1271. - Vahl. Symb. 2. p.63. - Uvariæ species Juss. Gen.284. * Ann. du Mus. tom. 16.p.340. - Lam. Dict. 1. p. 595.* - Willd. Sp. 2. p. 1261. - Desmos. Lour. Coch. I. p. 430.* - Melodorum. Lour. Coch. I. p. 429.* - Krockeria. Neck. Fund. Bot. n. ${ }^{\circ}$ 1097.* - Marenteria. Du Pet.-Th. Gen. Mad. 18.* - Xilopiæ species. Palis. Beauy. Fl. d'Owar. r. p. 27.-Poir. Dict. 8.p. 812.

\section{Character differentialis.}

Calyx tripartitus vel trilobus; petala 6 , patentia vel subclausa; baccæ ovatæ vel oblongæ, stipitatæ, polyspermæ, seminibur simplici serie dispositis.

\section{Character fructificationis.}

Calyx 3-partitus, laciniis ovatis acutis, quandoquè 3-4-fidus, lobis ovatis acutiusculis.

Corolla. Petala 6 , duplici serie disposita, 3 interiora minora; nune patentia, ovata vel oblonga vel lineari-oblonga; nunc subclausa, lineari-oblonga, acuta, triangularia, basi concava, genitalia tegentia.

Stamina uti in Uvariá.

Ovaria plurima.

Fructus. Baccæ siccæ? indehiscentes, stipitatæ, ovatæ vel oblongæ, uni vel multiloculares, nunc subleves, nunc torulosæ, nunc toruloso-moniliformes, polyspermæ.

SEvina simplici serie disposila, subrotundo-ovata, vel ovatooblonga, sæpè splendentia. 


\section{$9^{5}$ \\ Character naturalis vegetationis.}

Arbores s. frutices; rami interdùm scandentes. Folia in'egerrima, breviter petiolata. Pedunculi sæpè axillares, uni aut mulliflori, sæepè bracteolati.

\section{ConsteCtUS SPECIERUM.}

A. Floribus patentibus; baccis sublevibus vel leviter torulosis.

\section{§. Petalis ovatis subcequalibus.}

1. U. Narum. U. caule sarmentoso, foliis lanceolatis acuminatis; pedunculis lateralibus solitariis unifloris, petalis subrotundo-ovatis subæqualibus inflexis, baccis sublevibus longè stipitatis.

2. $U$. musaria. U. caule sarmentoso, foliis basi cordatis elliptico-lanceolatis acuminatis, pedunculis unifloris solitariis axillaribus, petalis subrotundo-ovatis subæqualibus reflexis, baccis subtorulosis stipitatis teretibus.

3. U. penduliflora. U. caule arborescente sarmentoso? foliis subsessilibus subcordatis oblongo-lanceolatis undulatis, pedunculis retroflexis pendulis, petalis inflexis, baccis substipitatis longis.

4. $U$. marenteria. U. ramulis scandentibus, foliis ovalibus obtusis glaberrimis, pedunculis erectis unifloris subterminalibus, petalis ovalibus extùs velutinis subinæqualibus, carpellis substipitatis ventricosis.

\section{§.. Petalis coriaceis obovatis vel oblongis subcqualibus.}

5. U. crassipetala. U. ramis r'ugosiusculis, foliis glabris oblongoellipticis acuminatis, petalis oblongis crassis obtusisque.

6. U. fuscata. U. ramis leviusculis, foliis glabris oblongoacuminatis penninerviis, petalis ovalibus aut suboblongis subæqualibus acutiusculis. 
7. U. obtusiflora. U. ramis leviusculis, foliis glabris ovali-oblongis, utrinque acuminatis penninerviis, petalis oblongis aut obovatis obtusissimis.

8. U. acuminata. U. ramis leviusculis, foliis glabris oblongis utrinque acuminatis penninerviis, petalis oblongis acutis.

9. U. macrocarpa. U. ramis glabriusculis, foliis ovalibus utrinque obtusis glaberrimis coriaceis, petalis ovali-oblongis acutiusculis.

ı. U. ovata. U. ramis junioribus ferrugineo-tomentosis, foliis ovatis acutis suprà glabris subtùs nervo medio ferrugineo-tomentoso, petalis ovali-oblongis acutiusculis.

§§. Petalis exterioribus ovatis acutis, interioribus minutissimis.

I. U. tripetaloidea. U. caule arboreo, foliis lanceolatis suprà rugosis subtùs subtomentosis; baccis triangularibus.

§§§§. Petalis lineari-lanceolatis longis angustisque, interdùm basi clausis. Cananga.

12. U. violacea. U. ramis teretibus punctatis, foliis ellipticis obtusiusculis, pedunculis oppositifoliis cernuis unifloris, foliolo unico amplexis, petalis longis lanceolato-oblongis.

13. U. uncinata. U. ramis glabris divaricatis, foliis oblongolanceolatis glabris acuminatis nitidis, pedunculis oppositifoliis infrì medium uncinatis, baccis ovalibus.

14. U. hamata. U. caule fruticoso, ramis scandentibus, foliis oblongis acuminatis glabris nitidis, pedunculis solitariis uncinatis, petalis lanceolatis basi constrictis, baccis ovatis utrinque acuminatis glabris.

15. U. esculenta. U. caule scandente, foliis ovato-lanceolatis glabris cirrhosis, pedunculis unifloris, petalis lanceolatis.

16. U. Lessertiana. U. ramis glabris teretibus, foliis oblongoellipticis suprà glabris nitidis, pedunculis lateralibus unifloris bracteatis, petalis oblongis subcrispis. 
17. U. odorata. U. caule arbored erecto, foliis oblongo-lanceolatis aculis, pedunculis axillaribus unifloris, petalis lineari-lanceolatis, baccis teretibus stipitatis apice umbilicatis.

I8. U. longifolia. U. caule arboreo, foliis angustis oblongolinearibus margine undulatis, floribus racemoso-corymbosis subumbellatis, petalis lineari-lanceolatis aculis, baccis ovoideis slipitalis.

rg. U. nitidissima. U. ramis teretibus rugosis, foliis oblongoellipticis utrinquè acuminatis glaberrimis nitidissimis, pedunculis brevibus axillaribus unifloris, petalis linearibus obtusiusculis.

20. U. ligularis. U. caule fruticoso, foliis ovato - lanceolatis acutis, pedunculis multifloris, petalis longis linearibus, baccis subglobosis stipitatis.

B. Petalis lanceolatis, oblongis vel linearibus, interdium subclausis;

baccis torulosis, subarticulatis, multilocularibus? plus minisve moniliformibus. Desmos.

21. $U$. discreta. U. caule arboreo, foliis oblongo-lanceolatis subtùs sericeis, baccis moniliformibus longè stipitatis.

22. U. undulata. U. caule fruticoso, foliis ovato-oblongis, floribus solitariis axillaribus longè pedunculatis, petalis linearibus longissimis, exterioribus undulatis, baccis oblongis submoniliformibus.

23. U. discolor. U. caule arboreo, foliis ovato-oblongis glabris, floribus solitariis patentibus longè pedunculatis, baccis moniliformibus breviter stipitatis.

24. $U$. desmos. U. caule fruticoso, foliis lanceolatis tomentosis, floribus solitariis clausis longè pedunculatis, baccis torulasis submoniliformibus subsessilibus.

25. U. aromatica. U. caule arboreo, foliis oblongis acuminalis glabris, floribus axillaribus solitariis geminisve, baccis oblongoteretibus torulosis subsessilibus.

26. U. Athiopica. U. ramis terelibus, foliis ovato-lanceolatis acutis subtùs glaucis, baccis terelibus subtorulosis subsessilibus. 


\section{$9^{8}$}

27. U. oxypetala. U. ramis teretibus, foliis ovato-oblongis acuminatis supernè levibus subtùs subglaucis, floribus axillaribus solitariis brevissimè pedunculatis, petalis linearibus acuminatis.

28. U? leptopetala. U. ramis teretibus glabris, foliis ovali-oblongis acuminatissimis glaberrimis, pedunculis axillaribus ramosis, pedicellis unifloris, petalis oblongo-linearibus acuminatis.

C. Floribus pyramidatis angustis elongatis; petalis linearitriangularibus acutis sapè clausis, basi genitalia tegentibus; baccis sublevibus vel leviter torulosis. MELODORUM.

29. U. latifolia. U. foliis latis oblongo-lanceolatis subtùs lanuginosis, floribus racemosis, baccis numerosis 2-3-spermis.

3o. U. sylvatica. U. caule arboreo, foliis ovato-oblongis subtùs tomentosis, floribus solitariis carnosis, baccis ovato-oblongis asperis subsessilibus.

3. U. dumetorum. U. caule fruticoso, ramis diffusis, foliis lanceolatis glabris, floribus solitariis, baccis ovato-oblongis asperis subsessilibus.

32. U. lucida. U. ramis teretibus, foliis ovali-oblongis suprà nitidis utrinque acuminatis glaberrimis, pedunculis simplicibus unifloris? baccis oblongis obtusis subcompressis subtorulosis breviter stipitatis.

33. U. acutiflora. U. ramis subrugosis, foliis ovato-lanceolatis glabris rigidiusculis acutis, pedunculis solitariis unifloris, baccis ovato-oblongis mucronatis breviter stipitatis.

34. U. Xylopioides. U. caule arboreo, foliis oblongo-acuminatis subtùs sericeis nitidis margine revolutis, pedunculis axillaribus brevibus 2-3-4-nisve.

35. U? polycarpa. U. ramis teretibus, foliis oblongis acuminatis subglaucis, baccis numerosis longè stipitatis. 
HISTORIA STECIALIS.

A. Floribus patentibus; baccis sublevibus vel leviter torulosis,

§. Petalis ovatis subaqualibus.

I. UNONA NARUM.

U. caule sarmentoso, foliis lanceolatis acuminatis, pedunculis lateralibus solitariis unifloris, petalis subrotundo-ovatis subrequalibus inflexis, baccis sublevibus longè stipitatis.

Narum-panel. Rheed. Mal. 2. p. 11. t. 9.*

Funis musarius angustifolia. Rumph. Amb. 5. p. 78.?

Frutex baccifer, fructu ad singulos flores multiplici. Rai. Hist. 1636 .

Uvaria Zeylanica. Lam. Encycl. I. p. 596. exclus. syn. Rumph. - Willd. Sp. 2. p. 126r. exclus. syn. Rumph. Non est Uv. Zeylanica. L.

Baala-paleti. $\{$ Vulgò Malabar. H. Mal.

Hab. in Malabariâ. 5

Frutex juxtà arbores scandens, ramis teretibus virgatis nigrescentibus. Radix fibrosa, cortice nigricante. Folia brevissimè petiolata, petiolis crassiusculis intùs striatis, oblongo-lanceolata, acuta, venosa, glabra, suprà viridiora et nitidiora. Flores breviter pedunculati, solitarii, laterales, patentes. Petala 6 , subrotundo-ovata, inflera, intùs concava, crassa, primùrn viridi-fusca, posteà rubescontia, dein rubro-sanguinea. Anthera in capitulo medio aggregatae, lumorem unctuosum exsudantes, primùm albido-flavescentes, dein rufescentes et fuscescentes. Baccæe stipitatæe, rarissimè subglobosæ, sæep̀ ovato-oblongæe, vel ellipticæ, sæpissimè oblusæ, subleves, ad maturitatem flavo-rubescentes. Semina subovoidea, intùs plana; matura, viridi-subflava, cum venulis fuscescentibus; sicca, subrufa; secundùm simplicem seriem disposita. Rheed. l. ca 
Un. musaria simillimum. Differt: foliis basi acutis nec cordalis; lloribus lateralibus nec axillaribus; petalis inflexis nec reflexis; baccis brevioribus sublevibus, interdùm depressis, nec torulosis.

\section{UNONA MUSARIA.}

U. caule sarmentoso, foliis basi cordatis elliptico-lanceolatis acuminatis, pedunculis unifloris solitariis axillaribus, petalis subrotundo-ovatis subæqualibus reflexis, baccis subtorulosis stipitatis terelibus.

Funis musarius latifolia. Rumph. Amb. 5. p. 78. t. 42.*.

Tali pissang. Malaicè.

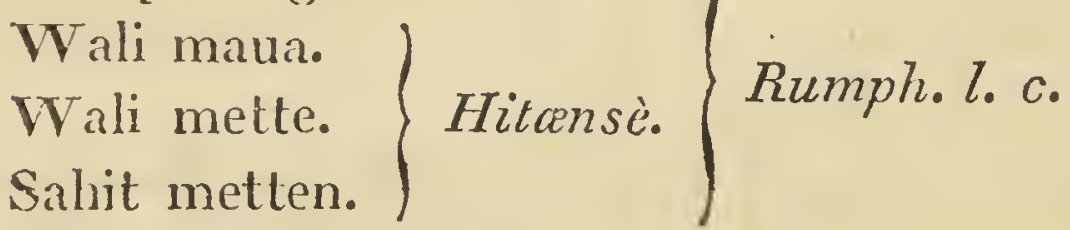

Salit metten.

Hab. in insulis Mollucis ad oras altorum montiun. s:

Frutex sarmentosus, super arbores scandens, ramis lentis, fusconigricantibus. Folia oblongo-lanceolata, acuta, basi subcordata, palmaria, intensè viridia. Pedunculi solitarii, breves, axillares, uniflori, bracteati? Flores patentes. Petala 6 , subæqualia, subrotundo-ovata, acuta, reflexa, fusca s. sanguinea. Stamina viscosa. Fructus : baccæ stipitatæ, numerosæ, circiter ı, oblongo-teretes, subtorulosæ, lineâ longitudinali prominente notatæ. Semina rubra, giabra, plana. Rumph. l. c.

3. UnOna penduliflora. tab. 28.

U. caule arborescente, foliis subsessilibus subcordatis oblongolanceolatis undulatis, pedunculis retroflexis pendulis, petalis inflexis, baccis substipitatis longis.

U. penduliflora. Moz. et Sessé. Pl. Mex. ic. pict. ined.

Hab. in Mexico.'s

Caulis arborescens, fuscus. Rami teretes. Folia brevissimè petioJata aut subsessilia, subcordata, oblonga, acuta, undulata. Pedunculi longissimi, apice incrassati, axillares, basi retroflexi, penduli. Flores patuli. Calyx 3-phyllus. Petala 6, tribus exterioribus subn. 
rotundo-ovatis mucronatis intùs luteo-virescentibus; tribus interioribus paulò minoribus, latis, inflexis, subemarginatis, extùs lutenvirescentibus, intùs rubro-luteis. Stili plures. Bacca circiter 7, substipitatx, incurva, leguminiformes, polyspermx, utrinque sulcatæ. Semina $9^{-10}$, oblongo-elliptica, primùm luteo-alba, postcà rubrofusca, dein nigrescentia.

\section{UnONA MARENTERIA.}

U. ramulis scandentibus, foliis ovalibus obtusis glaberrimis, pedunculis erectis I-floris subterminalibus, petalis ovalibus exlùs velutinis subinæqualibus, carpellis substipitatis ventricosis.

Unona marenteria. DC. Syst. univ.ined.

Marenteria. Pet.-Th. Nov. gen. Madag. p. 18.n. ${ }^{\circ}$ 6o. è DC. l. ci

Hab. in Madagascar. Pet.Th. 5 (DC. v. s.)

Fruticulus ramulis scandentibus. Folia brevissimè peliolata , ovalia , obtusissima, interdùm subemarginata, basi attenuata, utrinquè glabra et levia, pollicem longa, 7-g-lin. lata. Pedunculi I-flori, erecti, nudi, folio breviores, terminales aut ultimo folio oppositi. Calyx 3-partitus, lobis obtusissimis. Petala 6 , extùs rufovelutina, ovalia, 3 exteriora patentia majora et 3 interiora erecta ( Pet.-Th.) ; omnia subrequalia, subinflexa, in specimine sicco. Carpella baccata 4-5, subpedicellata, horizontalia, scabra, ventricosa, inæequalia. Semina plura supernè affixa simplici ordine. DC. l. c.

\section{§.. Petalis coriaceis obovatis vel oblongis subaqualibus,}

5. Unona crassipetala. tab. 24.

U. ramis rugosiusculis, foliis glabris oblongo-elliplicis acuminatis; petalis oblongis crassis obtusisque.

Hab. in Cayennâ.'s (v. s. h. DC.)

Rami tereles, rugosiusculi. Folia brevissimè peliolata, 6-7-pollicaria, suprà nitida, subtùs nervosa. Pedunculi axillaxes, breves, solitarii, apice incrassati, uniflori, pilosi, pilis rufis. Calyx tripar- 
titus, laciniis coriaceis, ovatis, acutiusculis. Petala coriacea, oblonga, obtusiuscula, rubro-fusca, poliicaria. Fructus ignotus.

\section{Unona fuscata.}

U. ramis leviusculis, foliis glabris oblongo-acuminatis penninerviis, petalis ovalibus aut suboblongis subæqualibus acutiusculis.

U. fuscata. DC. Syst. univ. ined.

Hab. in Guianâ. Martin. ' (DC. vo so in h. Lamb.)

Prami teretes, glabri, fusci, leviusculi. Folia petiolo brevissimo calloso instructa, oblonga, in acumen subobtusum apice attenuata, integerrima, adulta glabra, nervo medio vix basi pubescente, penninervia, nervis lateralibus subtùs prominulis apice subconfluentibus, 6-8-pollices longa, 2 poll. lata. Pedunculi axillares petiolo subbreviores, pilos fuscos gerentes, uniflori. Calyx tripartitus, lobis latis ovato-cordatis obtusis extùs pubescentibus coriaceis margine subtomentosis. Petala 6 , fusco-rufescentia, adpressè subvelutina, ovalia aut suboblonga, aqualia, subacuta, 4-5-lin. longa, $2 x / 2-3-$ lata. Stamina brevia, conferlissima, subangulata; ovaria densè approximata, staminum longitudine æqualia. Fructus ignotus. DC. Syst. univ. ined.

\section{UNONA OBTUSIFLORA.}

U. ramis leviusculis, foliis glabris ovali-oblongis utrinque acuminatis penninerviis, petalis oblongis vel obovatis obtusissimis.

U. obtusiflora. DC. Syst. univ. ined.

Hab. in Guianâ. Martin. s (DG. v. s. h. Lamb.)

Rami teretes, glabri, leviusculi. Pelioli callosi, 4-5-lin. longi. Folia ovali-oblonga, basi acutissimè secùs petiolum altenuata, apice in acumen obtusiusculum abruptè desinentia, glabra, nervo medio sublùs prominulo basi lentis ope vix subpubescente, penninervia, nervis lateralibus pauló infrà apicem confluenlibus. Peấunculi axillares, solitarii, 9-12-lin. longi, 1-flori, graciles, adpressè vix pubescentes; bracteis deciduis ad basin stipali. Calyx 3-partitus, laciniis brevibus obtusis. Petala 6, coriacea, fusco-cinerascentia, 
adpressè velutina, basi intùs subglabra, oblonga aut obovata, obtusissima, apice latiora, sensim aqualia , 4-5-lin. longa, 2-3-lin. lata. Stamina et ovaria ut in $U n$. fuscatá cui affinis. DC. Syst. univ. ined.

\section{UNONA ACUMinata.}

U. ramis leviusculis, foliis glabris oblongis utrinque acuminatis penninerviis, petalis oblongis acutis.

U. acuminata. DC. Syst. univ. ined.

Hab. in Guianâ. Martin. s (DC. v. s. h. Lamb.)

Rami teretes, glabri, virentes, leviusculi. Petioli callosi 2-lin. longi. Folia oblonga, basi sensim acutissimè secùs petiolum attenuata, apice magis abruptè in acumen longum acutum ferè lineare desinentia , 5-7-poll. longa, sesquipoll. lata, glabra, penninervia, nervis apice subconfluentibus, lætè viridia. Pedunculi axillares, solitarii, pollicem longi, graciles, I-flori, vix lentis ope adpressè pubescentes, propè basin bracteolas caducas 2 gerentes. Flores minores quam in $U n$. obtusiflorâ cui affinis. Calyx 3-partitus, lobis ovatis acutis. Petala 6 , oblonga, acuta, coriacea, fusco-cinerascentia, adpressè velutina, subæqualia, 3-4-lin. longa. Stamina et ovaria ut in $U n$. fuscat $\hat{a}$.

\section{UNONA MaCROCARPA.}

U. ramis glabriusculis, foliis ovalibus utrinquè obtusis glaberrimis coriaceis, petalis ovali-oblongis acutiusculis.

Uvaria macrocarpa. Vahl. in herb. Juss.

Unona macrocarpa. DC. Syst. univ. ined.

Hab. in Guineâ. s ( DC. v. s. herb. Juss. )

Rami teretes, fusci, glabri, nascentes pilis adpressis nonnullis subpubescentes. Folia ovalia, ulrinque obtusa, adulta glaberima, juniora subtùs pilis adpressis raris subpubescentia, coriacea, $1 x / 2-2-$ poll. longa, nervo medio subtùs prominulo, venis lateralibus vix distinctis, petiolo brevissimo. Pedunculi laterales, breves, ramosi, 2-3-flori; bractex ovato-rotundæe, obtus $x$, caduca. Calyx campa- 
104

nulatus extùs rufo-velutinus, 3-lobatus, dentibus latis brevissimis. Petala 6, ovali-oblonga, subcoriacea, aequalia, pube tenuissimấ subvelutina. Catera ignota. DC. Syst. univ. ined.

IO. UNONA OVATA.

U. ramis junioribus ferrugineo-lomentosis, foliis ovatis acutis suprà glabris subtùs nervo medio ferrugineo - tomentoso, petalis ovali-oblongis aculiusculis.

Unona ovata. Vahl. in herb. Juss. DC. Syst. univ. ined.

Hab. in Guineâ. 5 (DC. v. s. h. Juss.)

Rami teretes, tenues, juniores villis ferrugineis subtomentosis hispidi. Folia ovata, acuta, pollicem longa, supernè glabra, nervo medio ferrugineum tomentum gerente, subtùs juniora undiquè villis sericeis ferrugineis adpressis onusta, adulta in nervo medio rufo-tomentosa, cæeterùm pilos sparsos hinc indè gerentia. Petioli brevissimè rufo-tomentosi. Flores 2 subpedunculati oppositifolii. Calyx rufo-velutinus. Petala 6 , subæqualia, ovali-oblonga, acutiuscula, purpurea, subcoriacea, tenuissima, pube (lentis ope) velutina. Catera ignota. DC. Syst. univ. ined.

In herb. Lambert, De Candolle vidit specimina in Sierra Leona ab Afzelio collecta huic in foliis similia, sed adulta omninò (excepto nervo ) glabra, fusco-ferruginea. Baccæ 3-4, brevissimè stipitatæ, ovatæ, obtusæ, non torosæ, tomento brevi denso ferrugineo onustæe, intùs 3-4-spermæ. Semina ovato-ablonga, subcompressa, brunnea, levia. $D C$. $l . c$.

$\S \S$. Petalis exterioribus ovatis acutis, interiaribus minutissimis.

\section{UNONA TRIPETALOÏDEA.}

U. caule arboreo, foliis lanceolatis suprà rugosis subtùs subtomentosis, baccis triangularibus.

Cananga sylvestris prima s. trifolia. Rumph. Amb. 2. p. 197. 1. 66. $f . x^{*}$ 
Uvaria tripetala. Lam. Dict. 1. p.597.*

Cananga oetan. Malaicè.

Coppana bat.

Coeban abbal.

Matta aw we.

Leyitis poeti.

Matta ayn.

Ay-hoa-maroca.

Boa Djoeojaroe.

$\int$ Rumph. l. c.

Arbor, habitu Michelia champacca, cortice gummoso. Folia breviter petiolata, 9-pollicaria, lanceolata, suprà subgranulosa , subtùs subtomentosa. Flores pedunculati, subsolitarii, suaveolentes. Calyx parvus, trilobus. Petala 3 exteriora, magna, ovata, acuta, striata ; 3 interiora minutissima, stamina tegentia. Baccæ stipitatæ, ovato-angulosæ, acutæ, sulcatæ, granulosæ, 3-spermæ, pruni magnitudine. Semina pulposa, pulpâ mucosâ.

\section{$\S \S \S$. Petalis lineari-lanceolatis longis angustisque. C.ANAngA.}

12. UNONA VIOLACEA, tab. 25 .

U. ramis teretibus punctatis, foliis ellipticis obtusiusculis, pedunculis oppositifoliis cernuis unifloris foliolo unico amplexis, petalis longis lanceolato-oblongis.

Uvaria. Moz. et Sessé. Pl. Mex. ic. pict. ined.

Hab. in Mexico.'s

Rami teretes, punctati. Folia breviter petiolata, elliptica, obtusiuscula. Pedunculi uniflori, oppositifolii, cernui, foliolo unico sessile ovato acuto amplexi. Calyx tripartitus, laciniis ovatis, concavis, acutis. Petala 6 , bipollicaria, lineari-lanceolata, purpureofusca, tribus interioribus sublongioribus, hasi intùs albis sulcatis.

13. Unona Uncinata. tab. 12, et 12. a.

U. ramis glabris divaricatis, foliis oblongo-lanceolatis glabris 


\section{6}

acuminatis nitidis, pedunculis oppositifoliis infrà medium uncinatis.

Modira Valli. Rheed. Mal. 7.p. 87. t. 46?? ?

Annona hexapetala. L. Suppl. 270? - Ait. Kew. 2. p. 253 ?

- Willd. 2. p. 1266 ?

Anona uncinala. Lam. Dict. 2. p. 127.*

Long-yen s. longan. In insulis India orientalis. D. Poivre, ex herb. Juss.

$\beta$. Pedunculis simplicibus arcuatis. Ex herb. Commers. Lam.

Hab. in insula Mauritii, et aliis insulis Indiæ orientalis; Mich. Sonnerat. Commerson. in Chinâ. L? s (v. s. h. Deless. ) (DC. v. s. h. Juss. flor. )

Rami teretes, glabri, divaricati. Folia nitida, breviter petiolata. Pedunculi uniflori, sæẹè oppositifolii, infrà medium uncinos subcompressos gerentes. Flos satis magnus. Calyx tripartitus, laciniis ovatis acutis. Petala ovato-lanceolata, supernè rubro-fusca, unguiculata, unguibus latis tomentosis intùs concavis supernè angustis ; petala exteriora majora (Lam. l. c.). Baccæ 3-4, carnosæ, ovatorotundałæ, mono. s. polyspermæ, magnitudine fructûs juglandis regiæ, leves, leviter punctatæ. Semina magna, oblonga, unica vel plura secundum longitudinem fructus disposita.

14. UNONA HaMATA. tab. 27.

U: caule fruticoso, ramis scandentibus, foliis oblongis acuminatis glabris nitidis, pedunculis solitariis uncinatis, petalis lanceolatis basi constrictis, baccis ovatis utrinque acuminatis glabris.

Uvaria uncata. Lour. Fl. Coch. 1. p.426.*-Poir. Dict. Suppl. 2. p. $7 \mathrm{I}^{*}$

Uvaria Zeylanica. Herb. Delessert.

Ym chào. Chinensè. Cây bùt dieo. Cochinch.

Hab. Cantone Sinarum: ubi ad vestiendos parietes pulchrè aptatur, et absque violentiâ extenditur et attollitur. Lour. l. c. ( v. s. h. Deless. ) (DC. v. s. ex Chinâ h. Lamb. )

Frutex magnus, caule erecto, ramis glabris, longis, scandentibus, junioribus subangulatis, demùm teretibus cinerascentibus: Folia 
oblonga, acuminata, glabra, nitida, brevissimè petiolata, 3-4-poll. longa, 10-12-lin. lata, petiolis glaberrimis. Pedunculi solitarii, uniflori, subtùs uncinati. Calyx 3-partitus, laciniis parvis, reflexis. Petala 6, lanceolata, erecta, ad basin constricta, genitalia occultantia. Antheræ 80 circiter, oblongæ, sessiles. Ovaria 30 ferè, oblonga ; stigmatibus linearibus, sessilibus, erectis. Baccæ tolidem, ovatæ, utrinque acuminatæ, luteæ, glabræ, I-loculares, 2-spermæ. Semina intùs plana, extùs convexo-ovata. Lour. $l$. $c$.

\section{UNONA ESCULENTA.}

U. caule scandente, foliis ovato-lanceolatis glabris apice cirrhosis, pedunculis unifloris, petalis lanceolatis.

Uvaria esculenta. Roxb. Rottl. et Willd. in nov. act. nat. cur. oberol. 4. p. $20 \mathrm{I}$.

Hab. in Indiâ circà Madras. Fl. novemb. (Rottl.) 51

Frutex scandens. Folia ovato-lanceolata, integerrima, glabra. Cirrhi terminales, incurvati, ramorum apice quasi producto incurvato, bifidi, quorum divisio altera in pedunculum recurvatum uniflorum, altera in foliationis novæ initium terminatæ. Fructus edules. Rottl. Folia petalaque lanceolata. Pedunculi 1 -flori. Willd. Hæe videtur Uvaria odoratissima Roxb. ex herb. Lamb. quae non differt Uvariẩ uncatâ. Lour. ( DC. Syst.univ.)

r6. Unona Lessertiana. tab. 26.

U. ramis glabris teretibus, foliis oblongo-ellipticis suprì glabris nitidis, pedunculis lateralibus unifloris bracteatis, petalis oblongis subcrispis.

Uvaria uncata. Vah. herb. Delessert.

Hab....... s (v. s. h. Deless.)

Pami leretes, fusci, vix punctati, glabri; nascentes vix pubescentes. Petioli breves, leviter velutini; folia oblongo-elliptica, apice sæpè acuminata, interdùm obtusa, basi obtusa, suprà glabra, nitida, subtùs pallidiora subrufescentia, pilis leprosis adpressis. oculo armato tantùm visibilibus, penninervia. Pedunculi graciles, 


\section{8}

laterales, infrafoliacei, uniflori, bracteolam oblongam acutam sessilem infrà medium gerentes, post anthesin intorti, persistentes, cirrhiformes, 8-10-lin. longi. Calyx 3-partitus, lobis ovalibus acutiusculis adpressis aut patulis, nec reflexis. Petala 6 , erecta, oblonga, subcrispa, æqualia, subvelutina, dilutè rufescentia.

\section{UVARIa ODORATA.}

U. caule arboreo erecto, foliis oblongo-lanceolatis acutis, pedunculis axillaribus unifloris, petalis lineari-lanceolatis, baccis teretibus stipitatis apice umbilicatis.

Cananga. Rumph. Amb. 2.p. i 95. t. 65.*

Arbor saguisan. Raj. Suppl. luz. 83.

Alanguila de la Chine. Sonnerat. ex Lam.

Uvaria odorata. Lam. Encycl. r. p. 595.* - Illust. t. 495.f. Iq - Willd. Sp. 2. p. 1262.

$\left.\begin{array}{l}\text { Bonga Cananga. } \\ \text { Canangan. }\end{array}\right\}$ vulgò Malaicè.

Tsjampe. Javanicè.

Fula cananga. Batav.

Fula betele. Indost.

Seja cananga. Ternat.

Cananga. Macassar.

Sondat. Baleyens.

Cumbang Cayrano. Banda.

Coppabar et Coppanabbal. Amboin.

Copa Waarita. Leytimor.

Rumph. l.c.

Hab. in insulis Mollucanis et in Chinâ.' ( v. s. h. DC. h. Delessert.)

Arbor culta, satis alta. Caulis teres, erectus, levis, cinereus. Folia breviter petiolata, lata, oblonga, acuta, basi rotundata, interciùm subcordata, suprà glabra, subtùs nervosa, levissimè pubescentia. Pedunculi simplices, uniflori, pubescentes, vix pollicares, axillares. Calyx extùs tomentosus (4-phyllus, Rumph. in figurâ.). Petala 6, viridia s. lutescentia, suaveolentia, linearia, sesquipollicaria. Fructus: baccæe plures, circiter 9 , slipitatæ, polyspermæ, 
subteretes, obtusæ, obscurè fuscæ, apice umbilicatæ. Semina pallidè fusca, nitida, 9 , plana, rugosa, in pulpầ nidulantia. Pulpa dulcem et jucundum spirat odorem.

\section{UNONA LONGIFOLIA.}

U. caule arboreo, foliis angustis oblongo-linearibus margine undulatis, floribus racemoso-corymbosis subumbellatis, petalis lineari-lanceolatis acutis, baccis ovoideis stipitatis.

Uvaria longifolia. Lam. Dict. 1. p. 597.* - Vahl. Symb. 3. p. 72.*, -Willd. Sp. 2. p. 1263.

Arbre de mâture. Sonnerat. Voyage aux Indes. 2. p. 233.t. 13r. Hab. in Bengal, Roxb. in Javâ, Commers. s (DC. v. s. h. Juss. h. Lamb. )

Aŗbor altissimus, erectus, levis. Rámi glabri, cortice purpureo, supernè parùm flexuosi. Folia petiolata, spithamæa, membranacea, . venosa, utrinque glaberrima, sensim attenuata, acuta, integerrima, margine undulata. Pedunculi laterales, plures aggregati, brevissimi, tomentosi ; pedicelli $6-7$, subumbellati, pollicares, villosi, supernè parùm crassiores, medio foliolo minuto ovato tomentoso amplexi. Calycis laciniæ ovatæ, tomentosæ, petalis quadruplò breviores. Petala 6, lanceolata, attenuata, unguicularia, acuta, lutea. Baccæ stipitatæ, ovoideæ, uniloculares, glabræ, polyspermæ ( $V a h l$. et Lam. l. c.), monosperma, (Sonnerat.)

\section{UnONA Nitidissima, tab. 23.}

$\mathrm{U}$. ramis teretibus rugosis, foliis oblongo-ellipticis utrinque acuminatis glaberrimis nitidissimis, pedunculis brevibus axillaribus unifloris, petalis linearibus obtusiusculis.

Uvaria lucida. Vent. herb. Delessert.

Hab. in Novâ Caledoniâ. s ( v. s. h. Deless.)

Rami lignosi, teretes, rugosi, cinereo-nigricantes, punctis elevatis exasperati. Folia brevissimè petiolata, oblongo-elliptica, utrinque acuminata, leviter reliculata, margine subundulata, nitidissima pracipuè suprà; sublùs venosa. Pedunculi filiformes, breves, basi 


\section{0}

bracteolati, uniflori, solitarii, axillares. Calyx minutus, tripartitus, laciniis ovatis acutis. Petala oblongo-linearia, obtusiuscula, exteriora paulò minora.

\section{UNONA LIGULARIS.}

U. caule fruticoso, foliis ovato - lanceolatis acutis, pedunculis multifloris, petalis longis linearibus, baccis subglobosis stipitatis.

Cananga sylvestris secunda sive angustifolia. Rumph. Amb. 2. p. 198. t. 66. f. 2.*

Uvaria ligularis. Lam. Dict. 1. p. 597.* - Willd. 2. p. 1263.

Hab. in Amboinâ. 5

Folia ovato-lanceolata, acuta, 9-pollicaria, 2-3-pollic. lata. Pedunculi multiflori, solitarii geminive. Pedicelli pedunculo longiores, subumbellati. Petala 6 , linearia, subæqualia, longa. Baccæ circiter 10, stipitatæ, subglobosæ, nucis avellanæ magnitudine. Semina squamosa, tenuia, plana.

B. Petalis lanceolatis, oblongis vel linearibus, interdìm subclausis; baccis torulosis, subarticulatis, multilocularibus? plus minùsve moniliformibus. Desmos.

\section{UNONA DISCRETA.}

U. caule arboreo, foliis oblongo-lanceolatis angustis subtùs sericeis, baccis moniliformibus longè stipitatis.

Unona discreta. Vahl. Symb. 2.p.63. - Lin. Suppl. 270.-Willd. 2.p. 1271.* - Poir. Erucycl. 8. p. 186.*

Uvaria monilifera. Gartn. 2. p. 156. t. I 4 ? - Lam. Illust. tab. $43^{5} \cdot f \cdot 4$ ?

Pericoboom. Surin. è Poir. l. c.

Nlab. in Surinamo. C. G. Dalberg. è Willdenow. s

Arbor ramis virgatis angustis flexilibus pubescentibus. Folia vix peliolata, sesquipollicaria, glabra, integerrima, angusta, salicina. 
Flos Anona. Baccæ purpurea, sapida, aromatica. Vahl. l. c. Baccæe oblongo-lineares, longè stipitatæe, moniliformes, I-2-3loculares, loculamentis ovatis monospermis. Semina ovato-globosa, glabra, splendentia, è luteo-spadicea. Gartn. l. c.

\section{UnONA UNDUlata.}

U. caule fruticoso, foliis ovato-oblongis, floribus solitariis axillaribus longè pedunculatis, petalis linearibus longissimis, exterioribus undulatis, baccis oblongis submoniliformibus.

Xylopia undulata. Paliss. Beauv. Fl. Owar. 1. p. 27. t. 16. - Pers. Enchir. 2. p. 96. - Poir. Dict. 8.p. 812.*

Hab. in regno Oware. s (v.s. h. DC. )

Fruticulus ramis glabris, teretibus. Folia ovato-oblonga, acuminata. Pedunculi solitarii, axillares, longi, medio bracteâ sessiliâ obtusâ concavâ subrotundâ amplexi. Petala exteriora longissima, eleganter margine undulata, interiora duplò breviora. Baccæ oblongæ, obtusæ, stipitatæ, subarticulatæ, articulis 1-2-spermis, sapore aromatico.

\section{UNONA DISCOLOR.}

U. caule arboreo, foliis ovato-oblongis glabris, floribus solitariis patentibus longè pedunculatis, baccis moniliformibus breviter stipitatis.

Desmos Chinensis. Lour. Cochinch. 431?

Unona discolor. Vahl. Symb. 2. p. 63. t. 36.* - Willd. Sp. 2. p. 1271 .

Câu stit fung. Chinens.

Hab. in agrestibus propè Cantonem Sinarum; ( Lour.) in Indiâ

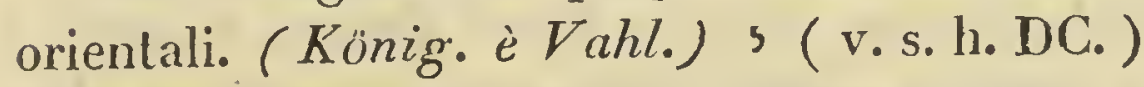

Arbor, ramis terelibus purpurascentibus, glabris, apice vix villosis. Folia petiolata, tripollicaria, basi rotundata, apice acuminata, obtusiuscula, integerrima, membranacea, nervosa, subtùs subvenosa, glauca; tenella subtius villoso-sericea. Pctiolus vix semi-unguicularis, villosus. Pedunculi laterales, infrafoliacei, sesquipollicares, 


\section{2}

supernè parùm crassiores, medio foliolo lanceolato obtuso sessile, uniflori, solitarii. Calyx 3-partitus, extùs villosus, laciniis ovatis acutis. Petala coriacea, tomentosa, lanceolata, pollicaria; 3 interiora angustiora. Baccæ stipitatæ, umbellatæ, 2-3-articulatæ?, articulis globosis piso parùm minoribus, terminalibus mucronatis, glabris. Vahl. l. c.

\section{UNONA DESMOS.}

U. caule fruticoso, foliis lanceolatis tomentosis, floribus solitariis clausis longè pedunculatis, baccis subsessilibus torulosis submoniliformibus.

Desmos Cochinchinensis. Lour. Cochin. p. $43 \mathrm{I} . *$

Unona tomentosa. Willd. Sp. 2.p. 127 1.-Poir. Ency.cl. 8.p. 186."

Cây Châp chời : Cây Cồ chay. Cochinch.

Hab. in Cochinchinæ dumetis.,

Frutex 5-pedalis, caule erecto, lignoso; ramis debilibus, reclinatis. Folia lanceolata, integerrima, tomentosa, petiolata. Flos luteo-viridis, terminalis, solitarius, longè pedunculatus. Petala 6 , lanceolata-linearia, clausa, erecta, tria interiora minora, basi genitalia claudentia. Baccæ rubro-virides, subsessiles, exsuccæ, longæ, tenues, torulosæ, subarticulata, articulis I-spermis. Semina ovata. E Lour. l.c.

\section{UNONA AROMATICA.}

U. caule arboreo, foliis oblongis acuminatis glabris, floribus axillaribus solitariis, baccis oblongo-teretibus torulosis subsessilibus.

Waria Zeylanica. Aubl. Guy. 2. p. 605. t. 243.* exclus. syn.

Uvaria aromatica. Lam. Encycl. 1.p. 596.* exclus. syn. Pluk.

Unona concolor. Willd. Sp. 2.p. 1 $2710^{\star}$ - Poir. Encycl. 8.p. 1 87.*

Acacia procera, non aculeata, flore albo, siliquis teretibus piperatis, racenatim congestis. Barr. Franc. Equinox.

Poivre des nègres; Poivre d'AEthiopie; la Maniguette; Bois d'écorce. Gallicè. Aubl. I. c. Barr. l. c.

Hab. in sylvis Guyanna et pracipuè in sylvis Timoutou. Aubl. s 
Arbor trunco 20-pedali et ampliùs, in summitate ramoso, ramis hinc et indè sparsis, ramulis foliosis. Folia ovata, acuta, glabra; integerrima, subsessilia. Flores axillares, solitarii aut gemini. Calyx 3-partitus, laciniis subrotundo-ovatis, acutis, carnosis, concavis. Petala $6 ; 3$ exteriora longiora, ovato-oblonga, extùs villosa, cinerea, intùs glabra, violacea; 3 interiora minora, glabra, violacea, unguibus latis concavis. Baccæ rufescentes, numerosæ (12-25), oblongæ, subteretes, breviter stipitatæ, ab uno latere longitudinaliter sulcatæe, uniloculares. Semina 3-6, orbiculata, rufescentia. Ex Aubl. l. c.

Conferantur Arbores Mauritiani, Bois blanc à grandes feuilles et Bois blane à petites feuilles. Aubl. l. c.

\section{UNONA AETHIOPICA.}

U. ramis teretibus, foliis ovato-lanceolatis acutis subtùs glaucis , baccis teretibus torulosis subsessilibus.

Azelem, allezen, alzelen? Avicenn. Hab alzizi? Arab.

Piper AEthiopicum. Math. Comment. I. p. 434. ic.-Lob. ic. 2, p. 205. - Lugd. 1809. ic. - Tabern. 917. ic. - Cast. p. 344. ic.

Carpesium. Cord. Hist. lib. 4. p. 195.

Amomum officinarum nonnullarum et longa vita. Lob. l. c:

Piper AEthiopicum siliquosum. J. B. 2. p. 187 .

Piper oblongum nigrum. Bauh. Pin.412.

Halzeli et piper nigrorum serapioni, ex Bauh. $P_{i n}$.

Crone et granum anescen Avicenno. Ang. ex Bauh. Pin.

Dolceghini? Apud Venetos.

Poivre d'Ethiopie; Poivre long noir; Poivre des Maures; grain de Zelim. Gallicè.

Hab. in Africâ; in AEthiopiâ (Math. Lob. Bažl.etc.); in Sierrî Leonâ. (Herb. De Cand. Herb. Lamb.) s (v. s. h. DC.) ( DC. v. s. herb. Lamb. )

Prami teretes, glabri, fusco-cinerascentes. Folia brevissimè petion lata, ovali-oblonga, acuminata, glabra, subtùs glauca, sicca subrufescentia. Pedunculi brevissimi. Thorus subglobosus, areolis 


\section{4}

seu cicatricibus circiter 20 notatus; baccæ teretes, subtorulosæ, subsessiles, glabræ, 5-6-spermæ. (v. s. h. DC. ex Sierrâ Leonâ.)

\section{UNONA OXYPETALA.}

U. ramis teretibus, foliis ovali-oblongis acuminatis suprà levibus subtùs subglaucis, floribus axillaribus solitariis brevissimè pedunculatis, petalis linearibus acuminatis.

U. oxypetala. DC. syst. univ. ined.

Hab. in Sierrâ Leonâ. Afzelius. , (DC. vo so in herb. Lamb.)

Rami teretes, fusco-cinerascentes, juniores pilis patentibus subferrugineis hispidi, adulti glabri. Folia ovali-oblonga, acuminata, brevissimè petiolata, 2-3-poll. longa, 6-12-lin. lata, juniora subtùs in nervo adpressè pubentia, adulta glaberrima, supernè levia, subtùs subglauca. Flores axillares, solitarii. Pedunculi brevissimi cum bracteis 2-3 latis brevibus obtusissimis deciduis pubescentes, uniflori. Calycis lobi lati, breves, obtusi, subvillosi. Alabastra conica elongata, gracilia, pubescentia. Petala linearia, acuminata, æqualia, basi lineam lata, extùs pubescentia, ferè pollicem longa. Thorus post anthesin dilatatus, depressus, cicatricibus i5-20 notatus. DC. Syst. uniw. ined.

\section{UNONA? LEPTOPETALA.}

U. ramis teretibus glabris, foliis ovali-oblongis acuminatis glaberrimis, pedunculis axillaribus ramosis, pedicellis unifloris, petalis oblongo-linearibus acuminatis,

$\mathrm{U}$ ? leptopetala. DC. Syst. univ. ined.

Hab. in insulâ Timor. Leschenault. ' (DC. v. s. herb. Mus.)

Rami teretes, glabri, fusci. Folia petiolo 4-6-lin. longo, ovalioblonga, acuminatissima, glaberrima, supernè nitida, penninervia, nervis subì̀s prominulis, palmam et ultrà longa. Pedunculi axillares, teretes, pube tenui cinereo-velutini, ramosi ; pedicelli 5-8, tenues, I-flori, subumbellati, pedunculo ferè longiores, velutino- 
cinerei. Calyx 3-partitus, velutinus, lobis ovatis subacutis margine interdùm basi revolutis. Petala 6 , æequalia, oblongo-linearia, acuminata, calyce sextuplò longiora, pollicem et ultrà longa, vix basi 3-lin. lata, pube tenuissimâ subvelutina. ( DC. l.c.)

C. Floribus pyramidatis angustis elongatis; petalis linearitriangularibus acutis sapè clausis, basi genitalia tegentibus; baccis sublevibus vel leviter torulosis. MELODORUM.

\section{UNONA LATIFOLIA.}

U. foliis latis oblongo-lanceolatis subtùs lanuginosis, floribus racemosis, baccis numerosis $2-3$-spermis.

Cananga sylvestris tertia sive latifolia. Rumph. Amb. 2. p. 198.* Hab. in Moluccis. 5

Folia illis Michelice champacca accedentia, subtùs nempè lanuginosa, multò tamen majora et superiùs subrotunda, 8-pollic. longa, 4, lata. Flores racemosi. Petala sex, clausa, tria interiora genitalia tegentia. Ovaria 20-25 plures abortiunt. Baccæ matura; magnitudine nucis avellanæe, primùm albescentes, dein rubescentes, demùm nigræ, 2-3-spermæ. Semina odorata. Ex Rumph.

\section{3o. UNONA SYlVATICA.}

U. caule arboreo, foliis ovato-oblongis subtùs tomentosis, floribus solitariis carnosis, baccis ovato-oblongis asperis subsessilibus.

Melodorum arboreum. Lour. Fl. Cochin. 1.p. 430.*

Cây Nahoc. Cochinch.

Hab. in sylvis Cochinchina.'s

Arbor magna, ramis ascendentibus. Folia ovato-oblonga, acuminata, integerrima, subtùs tomentosa, petiolala. Flos albo-viridis, carnosus, tomentosus, solitarius, sparsus, pedunculis brevissimis, antheris et stigmalibus plurimis sessilibus. Bacca multa, oratooblongæ, subteretes, asperæ, I-loculares, polyspermæ. Lour.l.c. 


\section{6}

3I. UNONA DUMETORUM.

U. caule fruticoso, foliis lanceolatis glabris, floribus solitariis, baccis ovato-oblongis asperis subsessilibus.

Melodorum fruticosum. Lour. ז. p. 430.*

Cây Bỏ giè. Cochinch.

Hab. in dumetis Cochinchinæ. 5

Frutex 4-pedalis, erectus, ramis diffusis. Folia lanceolata, integerrima, glabra, odora. Flos luteo-fuscus, solitarius, sparsus. Baccæ ro, ejusdem coloris, sesquipollicem longæ, ovato-oblongæ, subteretes, asperæ, I-loculares. Semina plurima; pulpa parca quidem sed gratissima. Lour. l. $c$.

\section{UNONA LUCIDA.}

U. ramis teretibus, foliis ovali-oblongis suprà nitidis utrinque acuminatis glaberrimis, pedunculis simplicibus unifloris?, baccis oblongis obtusis subcompressis subtorulosis breviter stipitatis.

Un. lucida. DC. Syst. univ. ined.

Hab. in Peruviâ. Jos, de Jussieu. 5 (DC. v. s. in herb. Juss.)

Affinis ex fructu $U$. acutiflorce. Rami teretes, glabri, nascentes vix apice rufo-velutini. Folia ovali-oblonga, supernè nitida, utrinquè et imprimis apice acuminata, glaberrima, nervis lateralibus vix perspicuis, 3-4-poll. longa, pollicem lata, peliolo brevi vix z-lin. longo. Flores ignoti. Pedunculi simplices, breves, uniflori videntur. Pericarpia 6-7, subbaccata, indehiscentia, oblonga, subcompressa, obtusa, subtorulosa, stipite gracili 2-3-lin. longo, intùs 5-6-locularia. Semina simplici ordine disposita. DC. Syst. univ. ined.

33. UNONA ACUTIFLORA. tab. 22.

U. ramis subrugosis, foliis ovato-lanceolatis glabris rigidiusculis aculis, floribus solitariis, baccis ovalo-oblongis breviter stipitatis.

Hab. in Anericà meridionali. 5 (v. s. h. DC.)

Pami numerosi, teretes, subrugosi, tuberculati, tuberculis minimis; ramuli pilosi, pilis simplicibus rufescentibus. Folia breviter 
petiolata. Pedunculi solitarii, uniflori, axillares, brevissimi, bracteati, vix longitudine petiolorum. Calyx 3-fidus, laciniis ovatis acutiusculis extùs sericeis. Petala extùs sericea, oblonga, acuta, clausa, tria exteriora basi concava, tria interiora basi utrinque emarginata. Baccæ plures , 9-10, in stipitem brevem attenuatæ, ovato-oblongæ , leviter incurvæ, mucronatæ, multiloculares. Semina simplici ordine disposita.

\section{UNONA XYLOPIOIDES. tab. 21.}

U. caule arboreo, foliis oblengo-acuminatis subtùs sericeis nitidis, margine et præcipuè basi revolutis, floribus axillaribus 2-3-4-nisve breviter pedunculatis.

Uvaria febrifuga. Humb. et Bonpl. ined.

Hab. ad Orenocum. s (v. s. h. Humb. et Bonpl. )

Arbor 70-pedalis. Rami penduli, glabri, rugosi, apice sericei, pilis luteo-rufis. Folia breviter petiolata, oblongo-acuminata, basi subrotunda, revoluta, subtùs sericea, pilis sericeis adpressis nitidis rufescentibus, nervosa, nervo medio magno, nervis lateralibus minutis, suprà viridia, glabra, subnitida, venosa, nervo medio piloso. Pedunculi gemini, terni, quaternive, axillares, bracteolati, bracteis subrotundis medio acutiusculis. Calyx urceolatus, semi-3-4fidus, extùs sericeus. Corolla 6-petala, petalis 3 exterioribus oblongolinearibus acuminatis longioribus, extùs fusco-sericeis, intùs albis, basi concavis; petalis 3 interioribus linearibus albis basi rubris apice subtriquetris. Ovaria numerosa. Baccæ siccæ, numerosæ, oblongæ, subcurvata, multiloculares, loculis monospermis.

\section{UNONA? POLYCARPA.}

U. ramis teretibus, foliis oblongis acuminatis subglaucis, baccis numerosis longè stipitatis.

$\mathrm{U}$ ? polycarpa. DC. Syst. univ. ined.

Hab. in Sierrâ Leonâ. Afzclius. , (DC. v.s. sinè fl. in herb. Tamb.)

Rami teretes, nascentes apice vix pubentes, dein glabri. Folia oblonga, acuminata, brevissimè petiolata, subglauca, nascenlia 


\section{8}

subtùs lentis ope subpubentia, dein glabra; exceptâ nervi medii basi utrinque subtomentosa, 4-poll. longa, 12-15-lin. lata. Flores ignoti. Pedunculus semi-pollicaris, uniflorus. Thorus planiusculus, stipites circiter 30 pollicem et paulò ultrà longos teretes apice subclavatos umbellatos monocarpos nudos gerens. Hi stipites cum thoro continui post anthesin persistunt, et pericarpia apice stipitum articulata deciderunt omnia. Genus dubium, species distinctissima. DC. Syst. univ. ined.

\section{X Y L O P I A.}

Xylopia. L. Gen. 1027. Aubl. Guj. 1. p. 602. - Xilopia. Juss. Gen. 283. - Xylopicron. Brown. Jam. 25o. Adans. Fam. 2.p. 365. - Bulliarda. Neck. Fund. n. 1 ro3.

\section{Character differentialis.}

Calyx 3-5-partitus, s. 3-5-lobus, sæè̀ campanulatus. Petala 6 , exteriora latiora. Capsulæ s. baccæ 2-15, breviter stipitatæ vel in stipitem desinentes, compressæ, coriaceæ, I-2-valves, I-loculares, 1-2-spermæ.

\section{Character naturalis fructificationis.}

CALYX nunc campanulatus coriaceus 3-5-fidus, nunc tripartitus laciniis ovatis acutiusculis.

Corolla 6-petala, exteriora majora, nunc oblongo-linearia acuta vel acutiuscula, basi concava subclausa; nunc ovata acutiuscula patentia.

Stamina sæpè receptaculo globoso imposita ; interdùm receptaculum planum obtegentia.

Ovaria 2-15.

Fructus. Capsulæ vel baccæ totidem, breviter slipitatæ, s. in stipitem desinentes, compressæ, coriaceæ, nunc leves, nunc. 
muricatæ, 1-2-valvæ, $x$-loculares, sæpissimè z-sperma , interdùm monospermæ.

Semina obovata, vel ovato-oblonga, supernè obtusa, basi acuminata, nitida, interdùm arillata, arillo incompleto albo.

\section{Character naturalis vegetationis.}

Arbores s. frutices. Folia sæpè oblonga. Pedunculi axillares uni aut multiflori, bracteolati.

\section{Constectus SPECIERUM.}

I. X. muricata. X. caule fruticoso, foliis lanceolatis acuminatis subtùs strigosis apice barbatis, pedunculis multifloris, fructibus muricatis.

2. X. frutescens. X. caule arboreo?, foliis oblongo-lanceolatis acuminatis subtùs sericeis, pedunculis brevissimis 1-2-3-nisve, fructibus glabris.

3. X. salicifolia. X. ramis punctatis, foliis angustis oblongoacuminatis acumine obtuso subtùs sericeis, pedunculis bracteolatis brevibus unifloris?

4. X. ligustrifolia. X. ramis punctatis, foliis oblongis àcutiusculis utrinque glabris, pedunculis brevibus paucifloris bracteolatis.

5. X. glabra. X. caule arboreo, foliis oblongo-ovalis glabris, pedunculis unifloris solitariis geminisve, fructibus glabris.

6. X. nitida. X. ramis rugosis, foliis oblongo-lanceolatis utrinque glabris suprà nitidis, floribus racemosis, racemis parvis, pedicellis bracteolatis.

7. X. acuminata. X. ramis teretibus rugosis, foliis glaberrimis coriaceis oblongo-ellipticis acuminatissimis, capsulis uniralvis dispermis.

8. X. prinoides. $\mathrm{X}$. ramis virgatis, foliis membranaceis ovatolanceolatis acuminatis apice obtusiusculis glabris, floribus solitariis, capsulis subbivalvis. 


\section{HISTORIA SPECIALIS.}

\section{r. Xylopia muricata.}

X. caule fruticoso, foliis lanceolatis acuminatis subtùs strigosis apice barbatis, pedunculis multifloris, fruetibus muricatis.

Xylopicrum fruticosum, foliis ovatis acuminatis productis alternis, capsulis punctatis, floribus confertis ad alas. Brown. Jam. 250 . t. $5 . f .2$.

Xylopia muricata. L. Sp. 1367. - Willd. 2. p. 1270. - Poir. Encycl. 8.p. 811.*

Xylopia frutescens. Gartn. de fruct. et sem. 1. p. 33g. t. 69. fig. 7. exclus. syn. Aubl.

The smaller bitter-wood. Anglicè.

Hab. in montibus Jamaïcæ. s,

\section{Xylopia FRUtescens.}

X. caule fruticoso, foliis oblongo-lanceolatis acuminatis subtus sericeis, pedunculis $1-2-3-$ nisve, fructibus glabris.

Embira s. pindaiba, Pis. Bras. p. 7 1. ic.

Ibira. Marcgr. Bras. 99. ic. Mala.

Xylopia frutescens. Aubl. Gui. 1. p. 602.t. 292.* exclus. syn.

Xylopia frutescens. Willd. Sp.2.p. 1270.-Poir. Dict. 8.p.811.* - Lam. Illust. gen. $t .495$.

Xylopia setosa. Poir. Dict. 8. p. 812.*

Cougnerecou. Galibis. (Aubl.) Jejerecou. Gallicè in Cayenná. (Aubl.)

Hab. in Guianâ ( $A u b l$. ) ; in Brasiliâ. ( $P_{i s .}$ ) (v. s. h. DC.)

Arbor?, ramis distichis, punclibus albidis notatis, ramulis pilosis rufescentibus. Folia oblongo-lanceolata apice acuminata, acumine obtusiusculo, margine revoluta, suprà glabra, subtùs sericea, pilis sericeis albis adpressis. Pedunculi pilosi, brevissimi, bracteolati, 1-2-3-nive, axillares. Calyx pilosus, laciniis ovatis acutis. Petala ablonga, subclausa, extùs sericea. 
3. Xylopia salicifolia. tab. 17 .

X. ramis punctatis, foliis angustis oblongo-acuminatis acumine obtuso subtùs sericeis, pedunculis bracteolatis brevibus unifloris?

X. salicifolia. Humb. et Bonpl. ined.

Hab. propè Espinal. Amer. s (v. s. h. Humb. et Bonpl.)

Arbor. Rami nigrescentes, punctis albidis notati. Folia breviter petiolata, angusta, sesqui-bipoll. longa, 3-4-lin. lata, oblongoacuminata, avenia, acumine obtuso, suprà glabra viridia, sublùs sericea, pilis sericeis cinereo-rufescentibus adpressis. Pedunculi breves, bracteolati. Capsulæ sub-indehiscentes, 5-7-næve, gibbosæ, gibłis submucronatis, I-2-loculares. Semina 2 , interdùn semen unicum.

4. Xylopia ligustrifolia. tab. 18.

X. ramis punctatis, foliis oblongis acutiusculis utrinque glabris, pedunculis brevibus paucifloris bracteolatis.

Xylopia ruscifolia Humb. et Bonpl. ined.

Hab. in Buga. Am. Mer. 5 (v. s. h. Humb. et Bonpl.)

Rami teretes, nigricantes, rugosi, punctis subalbidis exasperati. Folia parva, sesquipollic. longa, 4-lin. lata, oblonga, acutiuscula, brevissimè petiolata, utrinque glabra, juniora subtùs sericea, suprà subnitida, subtùs pallidiora, subavenia. Pedunculi breves, axillares, 3-4-flori, bracteolati, bracteolis sessilibus subrotundis concavis. Calyx parvulus, tripartitus, laciniis ovatis acutis. Petala 6, 3 exteriora longiora, apice patentia, basi subconcava, oblongolinearia, extus velutina, pilis adpressis rufescentibus, 3 interiora minora. Stamina numerosa. Capsulæe indehiscentes ${ }_{2}$ mono s. disperma, rugosæ, subtorulosæ.

\section{Xylopia glabra. tab. 19 .}

$\mathrm{X}$. caule arboreo, foliis oblongo-ovatis glabris, pedunculis uniforis solitariis geminisve, fructibus glabris.

Xilopicron arbor barbadensibus lignum amarum nominata. Pluk. Alm. 395. t. 238. $f \cdot 4$. 


\section{2}

Xylopicrum folis amplioribus nitidis ovatis, peliolis brevibus, fructibus glabris. Brown. Jam. 25 r.

Xylopia glabra. L. Sp. 1367. - Willd. Sp. 2.p. 1270. - Poir. Dict. 8. p. ¿ें 2.*

The larger bitter-wood. Anglicè.

Hab. in Jamaicâ et Barbados. s (v. s. h. DC. )

Pedunculi bracteolati.

6. Xylopia nitida. Lab. $=0$.

X. ramis rugosis, foliis oblongo-lanceolatis suprà nitidis, floribus racemosis, racemis parvis, pedicellis bracteolatis.

Hab. in montibus Orjac propè Cayennam. Martin.s (v.s. h.DC.)

Arbor mediocris. Pami rugosi, recti, lignosi. Folia oblongo-elliptica, subtùs venosa, pallida, subsericea, pilis minutis adpressis oculo armato visibilibus, suprà viridia, nitida, glaberrima, marginata, margine interdùm revoluta. Racemi 4-5-flori, parvuli, subcorymbosi. Pedunculi pedicellique fusci, bracteolis subrotundis amplexi. Calyx urceolatus, subinteger, coriaceus, fuscus. Corolla oblongo-linearis, triangularis. Petala acuta, clausa, basi genitalia tegentia. Fructus ignotus. Confert Unona xylopioides.

7. Xylopia acuminata. tab. 16.

X. ramis teretibus rugosis, foliis glaberrimis coriaceis oblongoellipticis acuminatissimis, capsulis univalvis dispermis.

Hab. in Cayennâ. 5 (v. s. h. DC.)

Rami teretes, rugosi. Folia longa, brevissimè petiolata, nitida, margine revoluta. Inflorescentia ignota. Fructus: capsulæe substipitatæ, univalvæ, subbivalvæ, dispermæ. Semina nigra, nitida, obovata, extùs convexa, intùs plana.

8. XYlopia prinoides. tab. 15.

X. ramis virgatis, foliis membranaceis ovato-lanceolatis acuminatis apice obtusiusculis glabris, floribus solitariis, capsulis subbivalvis.

Hab. in Cayennâ. (v. s. h, DG.). 
Rami rugosiusculi, virgati. Folia breviter petiolata, suprà nitida, subtùs subglauca. Pedunculi breves, axillares, solitarii, uniflori, bracteolam minutissimam gerentes. Calyx bracteolatus tripartitus. Petala ovata, acuta, parva. Capsulæ in stipites desinentes, subbivalvæ, dispermæ. Semina extùs convexa, intùs plana.

\section{XYLOPIA EXCLUDENDA.}

Nomen excludendum.

Nomen legitimum.

Xylopia undulata. Palis. Beauv. Fl. Owar.

1. $p .27 . t .16 . \ldots \ldots \ldots \ldots$.... Unona undulata. Nob.

\section{X. G U A T T E R I A.}

Cananga. Aubl.Gui. 1.p.607.*non Rumph.-Juss. Gen.p. 284. Ann. du Mus. t. 16. p. 340. - Aberemoa. Aubl. p.610. t. 245.* - Uvariæ species. Lam. Dict. r. p. 5g5. - Willd. Sp. 2. p. 126 г. - Guatteria. Ruiz. et Pav. Gen. Fl. Per.p.85. t. 17.*-Pers, Ench. 2. p. 95 .

\section{Character Differentinlis.}

Calyx 3-partitus; corolla 6-petala, petalis ovatis vel obovatis ? bассæ siccæ, coriaceæ, numerosæ, ovatæ aut subglobosæ, stipitatæ, monosperma.

\section{Character naturalis fructificatronis.}

CALYX 3-partitus, laciniis ovalis acutis subcordatis patentibus.

Corolla 6-petala; petala ovata vel obovata, 3 exteriora nume parim longiora, nune subequalia, nunc minora.

Stamina sapè receptaculo plano imposita; anther subsessiles.

Pistrlla. Ovaria numerosa, minima, sessilia, ovata s. obovata. Styli simplices. Stigmata simplicia. 


\section{4}

Fructus. Baccæ siccæ, coriaceæ, numerosæ, ovatæ aut subglobosæe, acutæ vel obtusæ, stipitatæ, monospermæ.

Semina ovata, obovata vel oblonga.

\section{Character naturalis vegetationis.}

Arbores et frutices. Rami sæpè expansi, teretes. Folia breviter petiolata, integerrima. Pedunculi axillares s. oppositifolii, solitarii, 2-3-nive, sæpè uniflori, quandoque pauciflori.

\section{CONSPECTUS SPECIERUM.}

I. G. Aberemoa. G. caule fruticoso, foliis ovato-oblongis tomentosis, floribus solitariis axillaribus, baccis numerosis mammiformibus breviter stipitatis.

2. G. brevipes. G. Jamis glabris teretibus, foliis ovalibus subacuminatis utrinque glabris lucidis, pedunculis axillaribus unifloris, baccis ovatis breviter stipitatis.

3. G. ouregou. G. caule arboreo, foliis oblongo-ellipticis acuminatis glabris subtùs ferrugineis, pedınculis axillaribus I-2-3-nisve, baccis ovatis acutis longè stipiratis.

4. G. podocarpa. G. ramis teretibus glabris, foliis ovali-oblongis abruptè acuminatissimis glabris, pedunculis axillaribus unifloris solitariis, baccis ovatis submucronatis longè stipitatis, stipite recto baccâ ipsâ triplò quadruplòve longiore.

5. G. cerasoides. G. caule arboreo, foliis lanceolatis acutis subtùs pubescentibus, pedunculis axillaribus solitariis, petalis subæqualibus, baccis subglobosis, stipite baccâ duplò longiore.

6. G. suberosa. G. caule arboreo, cortice suberoso rimoso, foliis oblongis acutis glabris, pedunculis suboppositifoliis, petalis exterioribus minoribus, baccis globosis, stipite gracili baccâ duplò longiore.

7. G? rufa. Gr. ramis junioribus rufo-tomentosis, foliis ovalibus apice acuminalis basi cordatis subtùs rufo-tomentosis, pedunculis brevissimis lateralibus vel oppositifoliis. 


\section{5}

8. G? cordata. G. ramis apice pilosis, foliis oblongis basi cordatis acutiusculis subtus tomentosiusculis, racemis brevibus oppositifoliis paucifloris, pedicellis medio bracteolatis.

9. G. $\operatorname{criopoda}$. G. caule arboreo, foliis oblongo-lanceolatis basi subattenuatis acuminatis, pedunculis solitariis lateralibus unifloris tomentoso-hispidis.

Io. G. hirsuta. G. caule fruticoso, foliis lanceolatis acuminatis, pedunculis axillaribus, floribus hirsulis.

Ix. G.pendula. G. caule fruticoso, foliis lanceolatis, pedunculis axillaribus longissimis pendulis.

12. G. ovalis. G. caule arboreo, foliis oblongis ovalibusque, pedunculis axillaribus.

13. G. glauca. G. caule arboreo, foliis oblongis ovatisque acuminatis, pedunculis axillaribus.

14. G. virgata. G. caule arboreo, ramis virgatis, foliis ovatis acuminatis glaberrimis subsessilibus, pedunculis brevissimis axillaribus solitariis unifloris, baccis stipitatis ovatis parvis.

15. G. laurifolia. G. ramis rigidis, foliis, oblongis utrinque acuminatis, pedunculis axillaribus vel infrafoliaceis, baccis stipitatis elliptico-ovoideis mucronatis.

I6. G. sempervirens. G. caule suffruticoso, foliis ovato-oblongis glabris nitidis, pedunculis lanuginosis, petalis oblongis acutis, baccis globosis stipitatis.

17. G. Korinti. G. caule fruticoso, foliis ovato-oblongis glabris nitidis, petalis oblongis obtusiusculis, baccis globosis stipilatis.

18. G. Malabarica. G. foliis lanceolato-oblongis angustis, pedunculis geminis ternisve, $1-3$-floris, petalis inflexis.

19. G. acutifolia. G. caule suffruticoso, foliis ovato-oblongis acutis crassis glabris, laciniis calycinis obtusis, petalis acutissimis, baccis globosis stipilatis.

20. G. umbilicata. G. ramis teretibus, foliis oblongo-ellipticis acuminatis, pedunculis bracteolatis, baccis globosis basi umbilicatis apice depressis. 


\section{HISTORIA SPECIALIS.}

\section{i. Guatteria aberemoa.}

G. caule fruticoso, foliis ovato-oblongis acutis tomentosis, baccis numerosis mammiformibus breviter stipitatis.

Aberemoa Guianensis. Aubl. p.610. t. 245.*

Aberemou. Nomen cariboum.

Hab. in sylvis Sinemariensibus. Gui. 5

Frutex 2o-pedalis. Caulis ramosus. Folia ampla, ovato-oblonga, acuta, integerrima, utrinque tomentosa, obscurè viridia, subsessilia. Flores solitarii, axillares. Cal. cor. stam. pist. desiderantur. Fructus : baccæ numerosæ, exsuccæ, breviter stipitatæ, ovato-acutæ s. mammiformes, subluteæ, uniloculares, I-spermæ. Semen solitarium, subrotundum, testâ fragili inclusum. Aubl. $l$. c.

In herb. mus. Paris. adest specimen huic satis simile, sed fructu paulo minori fortè distinctum. DC. Syst. univ. ined.

\section{Guatteria brevipes.}

G. ramis glabris teretibus, foliis ovalibus subacuminatis utrinque glabris lucidis, pedunculis axillaribus unifloris, baccis ovatis breviter stipitatis.

G. brevipes. DC. Syst. univ. ined.

Hab. in Guianâ. Martin. s ( DC. v. s. herb. Lamb.)

Rami teretes, fusci, glabri. Folia ampla, utrinque glabra, lucida, brevissimè petiolata, ovalia, subacuminata, penninervia, 8-12-poll. lata. Pedunculi axillares, uniflori, fructu maturo circiter pollicem longi, imâ basi bracteolati. Flores ignoti. Baccæe siccæ, 7-8, ovatæ, basi in stipitem baccâ ipsầ breviorem attenuatæ, monosperma. DC.l. ca

\section{Guatteria Ouregou.}

G. caule arboreo, follis oblongo - ellipticis acuminatis glabris, pedunculis axillaribus $1-2-3$-nisve, baccis numerosis ovatis aculis longè stipitalis.

Cananga Ouregou. Aubl. Gui. p. 608. to 244.* 
Uvaria monosperma. Lam. Encycl. г.p. 5g G.* - Willd.2.p. 1262. Ouregou. Nomen Caribaum.

Hab. in sylvis Guianxe. s (v. s. h. DC.)

Arbor 5o-pedalis. Caulis teres, levis, maculatus. Folia brevissimè petiolata, ovato-oblonga, acuminata, integerrima, suprà glabra, viridia, subtùs subrubescentia, ferruginea, penninervia. Pedunculi, calyces corollæque extùs pilosi, pilis rufescentibus. Flores axillares, I-2-3-nive, breviter pedunculati. Calyx laciniis aculis. Petala patentia, subcrassa, acuta, exteriora majora. Baccæ siccæ, coriaceæ, lutescentes, ovatæ, acutæ, uniloculares, 1-spermæ, capsuliformes; plurimæ, interdùm 48 , stipitatæe, stipite gracili baccâ longiori.

\section{Guatteria podocarpa.}

G. ramis teretibus glabris, foliis ovali-oblongis abruptè acuminatissimis glabris, pedunculis axillaribus unifloris solitariis, baccis ovatis submucronatis longè stipitatis, stipite baccầ ipsâ triplo quadruplove longiore.

G. podocarpa. DC. Syst. univ. ined.

Hab. in Cayennâ. s (DC. v. s. h. mus. Par. h. Lamb.)

Affinis Guat. ouregou sed distincta. Rami teretes, fusci, glabri, vix ac nevix apice pubescentes. Folia ovali-oblonga, abruptè acuminatissima, glabra, penninervia, nervis prominulis, junioribus subtùs adpressè puberulis. Pedunculi axillares, I-flori, solitarii, hispiduli, vix 6-lin. longi. Calyx 3-partitus, laciniis crassis ovatis aculis. Petala 6 , crassa, fusco tomento rufido vestita, oblonga, acuta, ferè æqualia, interiora basi paulò latiora. Baccæ 14-18, ovatæ, sulmmucronatæ, monospermæ, exsuccæ, subcostatæ, magnitudine duplâ quam in G. ouregou, stipite recto baccâ ipsâ triplo quadruplore longiore. DC. Syst. univ. ined. In herb. Lambert, thorus ampliatus circiter 40-foveolis notatus; stipites baccis quadruplo longiores; baccre ovatae mucronatæ non costatæ. DC. $l$. c.

5. Guatterja cerasoides.

G. caule arboreo, foliis lanceolalis acutis subtùs pubescentibus 


\section{8}

pedunculis axillaribus solitariis, petalis subæqualibus, baccis globosis.

Uvaria cerasoides. Roxb. Corom. I. $p$ 30. t. 33.* - Willd. 2. $p$. 1261.-Poir. Dict. Suppl. 2. p. 71. exclus. syn. Rheed.

Duduga. Apud Telingas. Roxb.

Hab. in Indiæe orientalis montibus. 5 (DC. v. s. h. Lamb.)

Arbor magna. Truncus erectus, strictus, longus. Rami diffusi, horizontales, ramulis bifariis velutinis. Folia bifaria, breviter petiolata, lanceolata aut oblonga, acuta, subtùs villoso-velutina, superne nervo medio basi tomentoso, circiter 4-poll. longa, I r/2 lata. Pedunculi axillares, simplices, solitarii, uniflori, teretes, velutini, pollicem circiter longi, propè basin bracteati, bracteis $1-2$ alternis ovatis foliaceis. Calyx 3-phyllus, laciniis oblongis acuminatis subreflexis. Petala 6 ovali-oblonga, obtusiuscula, fusca, crassa, æqualia, erectopatentia, vix calyce longiora. Filamenta brevia. Ovaria circiter 40 , oblonga, sessilia, pilosa; styli breves; stigmata lata, purpurea. Baccæ plures, stipitatæ, divergentes, atro-rubræ, globosæ, parvi cerasi magnitudine et huic maturæ similes, r-loculares. Semen r, rotundum, baccæ conforme. Baccæe edules, nimis astringentes. Roxb.l. c.

\section{Guatteria suberosa.}

G. caule arboreo, cortice suberoso rimoso, foliis oblongis acutis glabris, pedunculis suboppositifoliis, petalis exterioribus minoribus., baccis globosis, stipite gracili baccât duplò longiore.

Uvaria suberosa. Roxb. Corom. 1. p. 31. t. 34.* Willd. $s_{p} .2$. p. $126 \mathrm{I}$.

Uvaria Coromandeliana. Herb. Deless.

Chilcka duduga. Apun Telingas. Roxb.

B. Foliis basi angustioribus, margine crispulis. DC. ined.

$\gamma$. Foliis exactè oblongis, pallido-glaucis, rumulis villosis. DC. ined.

Hab. in Indiâ orientalio s (v. s. h. Deless.) (DC. v. s. h. Lamb. B et y h. mus. Par.)

G. Cerasoide vulgatior et minor. Truncus strictus. Rami horizontales, bifarii, nascentes vix pubescentes, dein glabri. Cortex suberosus, 
rimosus. Folia brevissimè petiolata, basi inæqualia, oblonga, acuța, glabra. Pedunculi uniflori, solitarii, suboppositifolii. Petala 3 exteriora ovata viridia duplò interioribus breviora; 3 interiora lanceolata, albida. Baccæ 15-20, ovato-globosæ, mucrone minimo obtusiusculo terminatæ, glabræ, atro-rubræ, magnitudine pisi minoris, stipite gracili paulò baccâ longiore.

Varietates $\beta$ et $\gamma$ siccas, in Coromandeliâ lectas à Macè, in herb. Mus. Par. vidit De Candolle. $\beta$. Folia basi paulò angustiora, magis attenuata et secùs margines crispula. $\gamma$. Folia exactè oblonga, pallidoglauca; ramuli villosi. DC. Syst. univ. ined.

\section{Guatteria rufa. tab. 29.}

G. ramis junioribus rufo-tomentosis, foliis ovalibus apice acuminatis basi cordatis subtùs rufo-tomentosis, pedunculis brevissimis lateralibus vel oppositifoliis.

Uvaria tomentosa. Vahl. in herb. Juss, non Poxb.

Hab. in Indiâ (Poivre. Lahaie.); in Timor. (Riedley.) s (v. s. h. Deless. ) (DC. v. s. h. Juss. h. mus. Par. )

Rami teretes, juniores rufo-tomentosi. Folia ovalia, apice acuminata, basi cordata, penninervia, 2-4-poll. longa, subtùs rufo tomento subvelutina, supernè rufo-virescentia, ferè glabra, sed nervus longitudinalis tomentosus et superficies tota pilis minimis lentis ope visibilibus scabra. Pedunculi laterales aut oppositifolii, brevissimi, post anthesin paulò elongati, 1-2-flori. Calyx 3-fidus, velutinus, lobis latis brevibus. Petala 6 , æqualia, purpurea, ovalia, vix acutiuscula, subcoriacea, intùs tenuissimè velulina, extùs tomentosiuscula. Receptaculum post anthesin pilosum. Pericarpia ovata, subbaccata, indehiscentia, tenuissimè velutina, obtusa, stipitata, slipite baccæ ferè longitudine, intùs unilocularia, monosperma?

8. Guatteria cordata. tab. 30.

G. ramis apice pilosis, foliis basi cordatis oblongis acutiusculis; racemis oppositifoliis brevibus pauciflaris, pedicellis medio bracteolatis. 


\section{0}

Uvaria Zeylanica. Herb. Deless.

Mab. in Javà. 5 ( v. s. h. Deless.)

Rami teretes, rugosinsculi, punctulati, apice tomentoso-pubescentes, pilis ochraceo-rufis. Folia breviler petiolata, oblonga, basi cordala, apice acutiuscula, penninervia, 4-6-pollices longa, $1^{1} / 2-2-$ pollices lata, subtùs leviter tomentosa, tomento tenui ochraceorufescente, suprà scabra, pilis minutis lentis ope visibilibus. Racemi oppositifolii. Pedunculi brevissimi. Pedicelli 4-6-plò longiores, tomentosi, ferruginei uti calyces corollæque extùs, medio bracteam concavam sessilem decurrentem gerentes. Calyx semi-3-fidus, subcampanulatus. Corolla 6 -petala, ovata, acutiuscula, intùs ferruginea, tenuissimè velutina. Antheræ longæ; exteriores breves, latæ, petaloidea , steriles.

\section{Guatteria eriofoda.}

G. caule arboreo, foliis oblongo-lanceolatis basi subattenuatis acuminatis, pedunculis solitariis lateralibus unifloris tomentoso-hispidis.

Uvaria Zeylanica. Domb. herb. non $L$.

Hab. in Peruviâ circà Cochera. Dombey. 5 (DC. v. s. herb. Juss. h. Mus. Par. )

Arbor 3-orgyalis (Domb.) Rami teretes, fusci, adulti glabri, juniores pilis subferrugineis hispidi. Folia oblongo-lanceolata, basi subattenuata", acuminata, 3-4-poll. longa, 15-18-lin. lata, penninervia, subtùs vix pallidiora, petiolo brevissimo donata, juniora utrinque et subtùs imprimis hispido-villosa, dein pilis caducis vix pilosa, demùm supernè glabra, subtùs vix basi pilosiuscula. Pedunculi laterales, solitarii, I-flori, ex parte ramulorum jam glabratâ orti, pilis confertis rufis subtomentosis hispidi. Calyx 3-partitus, lobis ovatis tenuiter velutinis. Petala 6 , ovalia aut suboblonga, patentia, æequalia, fuscata, pube tenuissimâ cinereâ velutina. Antheræ subsessiles approximatæ. DC. Syst. univ. ined.

Afinis Guatteria hirsuta. Fl. Per. t. 17. sed descriptio deest. Nostra non habet flores hirsutos sed velutinos, et pedicelli in icone Fl. Per. sunt glabri nec hirsuti. DC. $l . c_{\text {e }}$ 
Io. Guatteria hirsuta.

G. caule fruticoso, foliis lanceolatis acuminatis, pedunculis axillaribus, floribus hirsutis.

G. hirsuta. Syst. veg. Fl. Per. 1. p. I 46.

Hab. in Peruvixe nemoribus versùs Chinchao vicum, s Floret à julio ad septembrem.

Frutex biorgyalis.

Guatteriæ Flor. Peruv. nondùm satis notæ.

i i. Guatteria pendula.

G. caule fruticoso, foliis lanceolatis, pedunculis axillaribus longissimis pendulis.

G. pendula. Syst. veg. Fl. Per, r. p. 1 46.

Hab. in Chinchao et Pozuzo nemoribus. 5'

Floret à maio ad julium.

Frutex biorgyalis.

12. Guatteria ovalis

G. caule arboreo, foliis oblongis ovalibusque, pedunculis axillaribus.

G. ovalis. Syst. veg. Fl. Per. I. p. 146.

Hab. in Pozuzo nemoribus. 5

Arbor 4-orgyalis. Floret à junio ad augustum.

13. Guatteria glauca.

G. caule arboreo, foliis oblongis ovatisque acuminatis, pedunculis. axillaribus.

G. glauca. Syst. veg. Fl. Per. 1. $p$. r 45 .

Hab. in Peruviæ nemoribus versùs Cuchero et Chinchao vicos. g

Arbor triorgyalis. Floret à junio ad augustum.

14. Guatteria virgata. tab. 3 I.

G. caule arboreo, ramis virgatis, foliis ovatis acuminatis glaberrimis subsessilibus, baccis coriaceis ovoideis obtusiusculis.

Uvaria lanceolata. $S_{\$ a r t z .}$ Prod.p. 87. - Willd. $S p .2 . p .126 \mathrm{i}_{\alpha}$ exclus. syn. Brown. - Pers. Enchir. 2. p. 94. 
Uvaria virgata. Swartz. Flor. Ind. occid. 2. p. 999.*.

Cananga lancea. Poit.

Lancevood. Jamaicè.

Bois de lance franc. S. Doming.

Hab. in montosis sylvestribus Jamaicæe occidentalis (Swartz.); in insulâ Doming. Poit. 5 (v. s. h. DC. )

Arbor mediocris et arbuscula, cortice levi. Rami horizontaliter divergentes, patuli, teretes, ramulis flexilibus, ultimis filiformibus, glabris. Folia brevissimè petiolata, subsessilia, ovato-lanceolata, acuminata, sæpè altenuata, apice extimo obtùso, sesqui-pollicaria, utrinque glabra, subnitida, venosa, rigidiuscula. Pedunculi axillares, petiolis vix longiores, solitarii, squamulosi, uniflori. Flores parvi, inexplicati, subrotundi, albidi, suaveolentes. Calyx tripartitus, laciniis minutis, orbiculatis, integris. Petala 6,3 exteriora majora, 3 interiora paulò minora, subrotunda, integra, alba. Filamenta nulla. Antheræ 16-20, incumbentes, incurvæ, albæ. Ovaria 8 , oblonga, erecta. Baccæ stipitatæ, ovatæ, parvæ, monospermæ.

15. Guatteria laveifolia. tab. 32.

G. ramis rigidis, foliis oblongis utrinquè acuminatis, baccis ov oideis mucronatis.

Uvaria laurifolia. Swartz. Fl. Ind. occid. 2. p. 1001.*

Uvaria excelsa. Vahl. in herb. Juss.

Cananga pseudo-lancea. Poit.

Arbor, foliis ovatis glabris, utrinque acuminatis, floribus umbellatis, umbellulis sparsis. Brown. Jam. 370. n. ${ }^{\circ}$ I.

Bois de lance bâtard. $S$. Doming. Poit.

Wab. in sylvis interioribus montium Jarnaicæe et Hispaniolæ, Swartz.; in insulâ Doming. Poit.s (v. s. h. DC.) (DC.v.s. h. Juss.)

Ramuli flexuosi, virgati. Folia subdisticha, brevissimè petiolata, 3-ŕ-pollicaria, oblonga, utrinque acuminata, suprà nitida. Pedunculi axillares et infrafoliacei, plerumque 3-4 conferti, necnon solitarii, 3-4-lineares, teretes, uniflori. Flores inexplicati, ovati, trigoni. Calyx tripartitus, laciniis rotundatis concavis margine 
ciliatis minimis. Petala alba, subæqualia. Antheræ 16 , acuminatæ; receptaculo globoso foveolis excavalis infrà germina insertæ, basi extùs dehiscentes. Ovaria 6-8, oblonga, angulata, hirta, contigua. Stigmata obtusa. Baccæ coriaceæ, elliptico-ovoideæ, mucronatæ.

i6. Guatteria sempervirens.

G. caule suffruticoso, foliis ovato-oblongis glabris nitidis, petalis oblongis acutis, baccis globosis stipitatis.

Tsjerou-Panel. Hort. Mal. 5.p. 3 г. t. 16.*

Baala paletti. Malab.

Apacaro. Brachm. Rheed. H. Mal.

Clyn Heyl-wortel. Belg.

Hab. in Malabariâ, præsertim in Angicaimal. s

Arbuscula humilis, semper viret, floret frugetque. Folia breviter petiolata, ovato-oblonga, acuminata, crassa, glabra, suprà atroviridia, nitida, subtùs subviridia, nervosa, nervo medio viridiflavescente. Pedunculi tereles, virides, lanuginosi. Calyx tripartitus, exiguus. Petala sex, rubescentia, oblonga, cuspidata. Baccæ plurimæ, circiter 9 , globosæ, nigricantes, glabræ, carne succulentâ, acido-dulci. Semen globosum, nigricans.

17. Guatteria Korinti.

G. caule fruticoso, foliis ovato-oblongis glabris nitidis, petalis oblongis obtusiusculis, baccis globosis stipitatis.

Corinti-Panel. Hort. Mal. 5. p. 27. t. 14.*.

Corinti s. Korinti. Brachm.

Apocaro. Brachm.

Pao costus do mato. Lusit.

Heylwortel. Belg.

Rheed. H. M.

Hab. ubiquè in Malabariâ et præsertim in locis arenosis et petrosis. 5

Frulex 5-6-pedalis. Radix albicans, cinereo ac lanuginoso cortice tecta. Folia ovato-oblonga, acuminata, crassa, glabra, nitida, șuprà atro-viridia, sublùs subviridia, nervosa. Calyx tripartitus: 
Petala sex, viridia, oblonga, obtusa, apice reflexa. Baccæ circiter 3, globosæ, primùm virides, dein rubicundæ, carne subdulci. Semen globosum, rubro-fuscum, intùs albidum.

\section{Guatteria Malabarica.}

G. foliis angustis lanceolato-oblongis, pedunculis geminis ternisve, 1 -3-floris, petalis inflexis.

Kaltsjerou-Panel. Malab. Hort. Mal. 5.p.33.t. 17.*

Avali-apocaro. Brachm.

$\left.\begin{array}{l}\text { Pao costus da serra menor. Lusit. } \\ \text { Berg Heylwortel. Belg. }\end{array}\right\}$ Rheed. H. M.

Hab. in Malabariæ locis montanis et petrosis circà Paracaro.

Semper viret, floret frugetque. Folia breviter petiolata, angusta, oblongo-lanceolata, acuminata, suaveolentia, aromatica. Calyx, in figura 3-4-fidus. Petala 6 ; fructus ignotus.

\section{Guatteria acutifolia.}

G. caule suffruticoso, foliis ovato-oblongis acutis crassis glabris, laciniis calycinis obtusis, petalis acutissimis, baccis globosis stipitatis.

Katsjau-Panel, s. Panel sylvestris. Hort. IMal. 5.p. 35. t. 18.*

Kasjau-Panel. Malab.

Pee apocaro. Brachman.

Pas costus bravo. Lusit.

Wild Heilwortel. Belg.

Uvaria Zeylanica. Herb. Deless.

Hab. in Malabarixe locis montanis circà Mangatti. s? ( v. s. h. Deless. )

Arbuscula humilis, 4-pedalis, semper viret, floret frugetque. Caulis tenuis, ramosus, ramis subviridibus. Lignum albicans, cortice cinereo, intùs viride. Folia oblongo-elliptica, acuta, densa, glabra, suprà atro-viridia, nitida, subtùs subviridia. Flores axillares, breviter pedunculati. Calyx tripartitus, laciniis rotundatis, obtusis. Petala 6 , aculissima. Fructus ut in Guatteria sempervirente.

In specimine sub nomine Uvaric Zeylanica in herb. Delessert : 
rami glabri, rugosi, teretes; folia coriacea, subsessilia, oblongo. elliptica, glaberrima, utrinque præcipuè apice acuminata, subtùs reticulata, subrubiginosa, suprà dilutè viridia; calyx 3-partitus, laciniis ovatis acutiusculis. Petala 6 , oblonga, acuta.

20. Guatteria umbilicata. tab. 33.

G. ramis teretibus, foliis oblongo-ellipticis acuminatis, peduna culis bracteolatis, baccis globosis basi umbilicatis apice depressis.

Hab. . . . . . Forsyth. s (v. s. h. DC.)

Folia nitida præcipuè suprà, subtùs nervosa. Pedunculi bracteolati, versùs apicem bracteis tribus verticillatis amplexi. Flores ignoti. Baccæ circiter 6 , stipitatæ, globosæ, basi umbilicatæ, apice depressæ, cerasi parvi magnitudine.

\section{TABULA ANONACEARUM CHRONOLOGICA.}

$\begin{array}{ll}\text { 1523. Oviedus. } & \text { Anona squamosa. } \\ \text { 1544. Mathiole. } & \text { Unona AEthiopica. }\end{array}$

1648. Pison et Marcgraye. Xylopia frutescens? Anona muricata:

1678-1703. RHEEDE. Anona reticulata. Unona narum. Guatteria Korinti; G. sempervirens; $\mathrm{G}_{\mathrm{g}}$ Malabarica; G. acutifolia.

1693-1 703 . Plumier. Anona palustris.

i6g5-1705. Plukenet. Xylopia glabra.

I 7 I 2. KCEMPFER.

171 4. Feuillèe.

173 I. Catesby.

1737. LinNé.

I737. Burmann.

1741. BARRERE.

174 . Rumphus.

1756. Brown. Jam.
Kadsura Japonica.

Anona cherimolia.

Anona laurifolia; A. glabra; Asimina triloba.

Anona Africana. $†$. Uvaria Zeylanica.

Anona Asialica.

Anona paludosa.

Unona musaria, odorata, ligularis, tripetaloüdea, latifolia.

Xylopia muricata, glabra. 


\section{6}

1775. AUBLET.

I783. SONNERAT.

9786. LAMARCK.

7 78. Swartz.

7791. G无RTNer.

793. Bartram.

1793. Loureiro.

7798. Ruiz et Pavon.

\800. Roxburg.

1800 . JACQUIN.

I 803 . Michaux.

805. Palissot-Beauyous.

1807. PERSOON.

1817. Humboldt et Bonpe ined. Anona Humboldtii, Peruviana.

Unona xylopioides. Xylopia salicifolia, ligustrifolia.

1817. DE CANDOLLE. ined. Anona uniflora, exsucca. Uvaria velutina, spectabilis. Unona fuscata, obtusiflora, oxypetala, leptopetala, acuminata, ovata, polycarpa, lucida, macrocarpa. Guatteria brevipes, eriopoda, podocarpa, rufa.

1817. Dunal.

Anona echinata, sericea, cinerea. Unona nitidissima, angustiflora, Lessertiana, Javana, dulcis, crassipetala. Xylopia nitida, acuminata, prinoides. Guatteria cordata, umbilicata.

817. Moçino ET SESSÉ ined. Anona purpurea. Unona penduliflora, violacea. 


\section{TABULARUM EXPLICATIO.}

Rami.

1. Ramuli fragmentum.

2. Alabastrum.

3. Flos integer intùs visus.

4. Flos integer extùs visus.

5. Flos apertus genitalia exhibens.

6. Calyx extùs visus.

7. Calyx extùs visus oculo armato.

8. Calyx lateraliter visus.

9. Calyx lateraliter visus oculo armato.

10. Calyx cum genitalibus lateraliter visus.

I1. Calyx cum genitalibus lateraliter visus oculo armato.

12. Caly $\mathbf{x}$ cum genitalibus intùs visus.

13. Calyx cum genitalibus intùs visus oculo armato.

14. Calyx apertus et in medio genitalia.

15. Petala externa.

15. a. Petala externa oculo armato visa.

16. Petala interna.

17. Petala externa cum internis alterna.

18. Petala externa cum internis alterna oculo armato visa.

19. Genitalia.

20. Stamen extùs visum.

21. Stamen extùs et oculo armato visum.

22. Antheræ extùs et oculo armato visx.

22. a. Antheræe intùs visa.

23. Antheræ suprà et oculo armato visæ.

24. Receptaculum.

25. Receptaculum longitudinaliter sectum.

26. Fructus. 
27. Fructus longitudinaliter sectus.

28. Carpellum integrum.

29. Carpellum medio transversè secturn.

3o. Carpellum medio longitudinaliter sectum.

3. Semen extùs visum.

32. Semen intùs visum.

33. Semen longitudinaliter sectum.

34. Folii fragmentum suprà et oculo armato visum.

35. Folii fragmentum subtùs et oculo armato visum.

36. Pili.

37. Folii paginæ superæ pili.

38. Folii paginæ inferæ pili.

\section{VOCUM ABBREVIATARUM EXPLICATIO.}

v. v. h. M.

v. s. h. DC.

v. s. s. flore h. DC.

จ. s. h. H. et $P$.

v. s. h. Deless.
Visa viva in horto Monspeliensi.

Visa sicca in herbario D. ${ }^{\text {ni }}$ De Candolle.

Visa sicca sine flore in herbario D. ${ }^{\text {ni }}$ De Candolle.

Visa sicca in herbario D.orum Humboltd et Bonpland.

Visa sicca in herbario D. ${ }^{\text {ni }}$ Delessert.

DC. v. s. h. Mus. Pars. De Candolle vidit specimen siccum in herb. Musæi Parisiensis.

DG. v. s. h. Juss.

De Candolle vidit specimen siccum in herbario D. ${ }^{\text {ni Jussicu. }}$

DC. v. s. h. Lamb. De Candolle vidit specimen siccum in herbario D. ${ }^{\text {ni }}$ Lambert.

DC. v. s. h. Desf. De Candolle vidit specimen siccum in herbario D. ${ }^{\text {ni }}$ Desfontaines. 


\section{N D E G E N E R M}

\section{SPECIERUM ET SYNONYMORUM.}

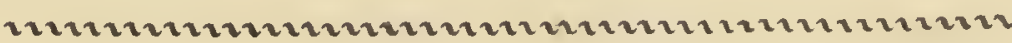

\section{ABEREMOA.}

Aberemoa Gnianensis.

Hist. Mon.

2о..50. 56. 123. Anona cinerca.

Aberemou.

Acacia procera, non aculeata, flore albo, siliquis teretibus piperatis, racentatim congestis.

Achras sapota. $\alpha_{0}$ L. Achras sapota. $\beta$. $L$.

$9 \cdot$

Achras sapota zapota. IFilld. 9 .

Achras sapota zapotilla. Willd. g.

Alanguila de la Chine.

Allezen, alzelen.

Alugas so ahugas.

Ainbotay.

Amomum officinarum nonnullarum et longa vita.

ANNONA.

Annonce species. Grertn. Jacq.

Annonce species. $T$.

29.

ANONA. 7.9. 11.13 .18 .79 .23$. 24. 26. 28. 29. 30.3r.33.35.

Anona. Comm.

Anona Africana. $t$.

Anona Ambotay.

32.

Anona Americana juxtà fluviorum ripas inmascens pyriformi fructn.

Anona amplexicaulis.

$3 x$.

Anona angustifolia, fructu cancellato maximo.

Anona aquatica, folits laurinis atroyirentibus, fructu minore conoide luteo, cortice glabro in areolas distincto.

Anona Asiatica.

Anona-Boom.

Anona cherimulia:
9.

32.

126. Anona dodecapetala. Xam.

IIist.

126. Anona echinata.

Anona? exsucca.

Anona foliis lanceolatis nịtidis secum

1x2. dum nervos sulcatis.

78. Anona foliis lanceolatis pubescentibus.

78. Anona foliis laurinis in summitate incisis, fructu compresso scabro fusco in medio acumine longo.

108. Anona foliis laurinis viridi-fuscis,

1x3. fructu rotumdo minore viridi flavo

71. scabro; seminibus fuscis splenden-

68. tibus fissurâ albâ notatis.

Anoma foliis maximis.

1.3. Anona foliis oblong is undulatis yerosis, fructibus areolatis.

79. -Anona $\mathrm{x}$. folitis oblongo-ovatis nitialis,

56.59.3r. fructibusspinis mollibus tumentibus obsitis.

55. 58. Anona 2. foliis oblongo-ovatis undu-

63. latis venosis, floribus tripetalis,

62. 77. fructibus manmillatis.

60. 67. Anona foliis odoratis minoribus, fructu conoide squamoso parvo dulci.

66. Anoma foliis ovali-lanceolatis glabris

$6276 . \quad n i t i d i s$ planis, pomis muricatis. Anona foliis ovatis acmlis, flore

74. albido nngue purpureo, fructu uniformi tnberoso nigricante.

Anona folits subtis ferrugineis, fructu rotundo majore levi purpurso,

66. semine nigro partim rigoso partim 6r. 7r. glabro.

74. Anona fructu levi viridi, pyri in-

33. 61. 72. versiforma.
Mon.

$\mathrm{Gr}-7 \mathrm{x}$.

79.

6o. 68 .

62.77.

Tr.

$7 \%$

78.

28.

75 .

72.

63.

20.

70

62.

$2 x:$

g.

(5. 


\section{0}

Hist.

Anona, fructu lutescente leoi scrotum arietis.

Anona hexapetala. L.

Anona Humboldtii.

Anona glabra.

Anona glabra. Forsk.

Anona glabra. $\beta$.

Anona grandiflora. Lam.

Arona grandiflora. Bart.

Auona grandiflora Madagascarirnsis.

Anona indica, fructu conoide viridi, squamis veluti aculeato.

Anona indica, fructu è viridi luteo, cortice squamato aspero, nucleis nigricantibus parsis.

Anona laurifolia.

Anona longifolia.

Anona-maram.

Anona maxima, foliis latis, fructu maximo luteo conoide, cortice gialurn.

Anona maxima, foliis latis splendentibus, fructu maximo viridi conoide, tuberculis s. spinulis innocentibus aspero.

Anona maxima, foliis laurinis glabris viridi-fuscis, fructu minimo rotundo viridi-flavo, seminibus fuscis splendentibus fissurâ albâ nolatis.

Anona maxima, foliis oblongis anGustis, fructu maximo luteo conoide; cortice glabro in areolas angulares distincto.

Anona microcarpa.

31. 34.

Anona mulcosa.

Anona muricata.

Anona muscosa.

Anona myristica.

Anona obovata.

Anona obtusiflora.

Anona paludosa.

Anona palusiris.

Anona palustris. P. Lam.

Annua Peruviana.

Aliona punctata.

Anona purpurea.

Arona pygmaca.
Dion.

Hist. Mor.

Anona reticulata.

78. 83. Anona Senegalcnsis.

27. 33. 6r. 72.

62. -76

$6 r .69$.

78. 106. Anona sericea.

59. 64. Anona squamosa.

5. $33.6 \mathrm{r} .69$.

7I.

71. Anona trifolia, flore stamineo, fructu

65. spherico ferrugineo scabro minore,

62. $-5 . \quad$ allii odore.

S. 84. Anona triloba. L.

-5. Anona tripetala. 33.

Anona tuberosa. jo.

63. Anona uliginosa, foliis nitidis ovatis, fructibus areolatis odoratis. 66.

Anona uncinata. Lam. 78. ro6.

70. Anona? uniflora. 62.76.

59. 65. ANONACE 2 . $\quad$ 6. et suiv. 53.

6o. 66. ANONARUII GEN. Adans. 53.

73. ANONA. Juss. 53.

Anoncespecies. Calesb. Sr.

7'. Apacaro. 133 .

Apocaro. $\quad 133$.

Araticu species. 62.

63. acuminatis, floribus umbellatis, umbellulis sparsis. $\quad 132$ :

Arior saguisan. $\quad$ ro8.

Arbre de mâture. $\quad$ rog.

78. ASIMINA. 18. 19.23.24. 35. 36. 37. 38. 42. $55.8 \mathrm{r}$.

Asimina grandiflora. $\quad$ 78. 82.84 .86 .

Asimina parviflora. 12. 82.86 .

73. Asimina pygmæa. $\quad 78.82 .34 .86$. 78. 8o. Asimina triloba. 15. 19.37. 78.82.33.86. 61. 74 . Asimina species. 81 .

59. Assiminier ou asininier. $\quad 37 . \quad 83$.

7'́l. Atamaram.

78. So. Lltas, $\quad$ 7\%

78. 84. Lite rel ahate de Pantchor

6o.65. Atis.

6o. 68. Atoa.

6o. 65. Atocira. 70 .

6r. Ativie. $\quad$ ro.

6n. 6r. Avali-apocaro: 134.

33. 6n. 67. Ay-hoa-maroca: 105.

5ij. 6if. Azelem. 47. 113.

78. 34. Baala-paleti. $\quad 99.133$. 


\section{1}

Berg Heylwortel.

Bitler-mood (the larger.)

Bitter-2vood (the smaller.)

Boa ati.

Boa Djoeojaroe.

Bois blanc.

Bois blanc à grandes feuilles.

Bois blano à petites feuilles.

Bois d'écorce.

Bois de lance-bâtard.

Bois de lance franc.

Bonga cananga.

BTLLIARDA.

Cachiman.

Cachiman morveux. Aubl.

Cachiman sauvage.

Cachimantier.

Cachiment.

C. $1 N \wedge$.

Calo-apocaro.

C.ANANGA.

CANANGA.

Cananga. Rumph:

Cananga lancea.

Cananga oetan.

Cananga ouregou.

Cananga pseudo-lancea.

Cananga syluestris prima s. trifolia.

Conanga syloestris secunda sive angustifolia.

Cananga syloestris tertia sive latifolia.

Canangan.

Carpesium.

Câu stit fung:

Cây Bo gie.

Cây biut dieo.

Cây châp chôi ; Cầy cô chay:

Cây nahoc.

Chesita.

Chilcka duduga.

Chrysophyllum cainito. $\boldsymbol{L} . \quad 9$

Chylimolia.

Clyn Hevl-2yortel.

CO ADITNATARUDI GENERA. I. COADITNATE.

6.

Coeban abbal.

33.

33.
Hist. Mon.

134. Cour de bauf.

122. Petit caur de bouff.

120. Copa vyaarita.

70. Coppabar et coppanabbal.

105. Coppana bat.

75. Corinti-Panel.

113. Corossol saupage.

i13. Petit corossol.

112. Corossol.

132. Cougnerecou.

32. Cratepa tapia. L.

108. Crone ot granum anescen Avicenuce.

20. 43. 56. x18. Cumbang cayrano. ros.

Hist: Mon.

$33 . \quad 7^{\circ}$

$68:$

ro8.

108:

105.

r33.

68.

68.

33. 58.63 .83 .

63. 74. Custard aple.

74. Desmos.

63. DESMOS.

20. $43 . \quad 57.94$

63. Desmos Chinensis. $11 \mathrm{I}$

56. Desmos Cochinchinensis.

99. DILLENIACEES. 6. 7.S.

96. го5. Dolceghini. 113 .

50.5r. 56. 123. Duduga.

108. Embira. 120.

132. Eupomatia laurina. 20.

105. Fagara. 7 .

126. Fruit à coeur de bauf. 73 .

132. Frutex bacifer, fructu ad singulos

104. flores multiplici.

Frutex yiscosus procumbens, folio

110. telephi vulgaris amulo, fruch

II5. racemoso.

108. Fula betele.

113. Fula cananga.

xix. Funis musarius angustifolia:

116. Funis musarius latifolia.

106. Futo Kadsura.

112. GLIPTOSPERMAE. VENT.

I15. Grain de Zeliin.

71. Ciraine de Paradis.

128. Guanabanifiuctus; Opiedo.

78. Guambano.

64. GTANABANTS. 19.2S.

133. Guauabamus fructu aurco et molliter

53. aculcato.

Guanabanus fructu è viridi-lutesconte,

105. molliter aculcato.

63. 
Hist. Mon.

Guanabanus fructu purpureo.

Guanabanus fructu sub-coruleo.

Guanabanus fructu turbinato minori.luteo.

Guanabanus palustris, fructu levi viridi.

Gubanabanus persece folio, flore intils albo, extius virescente, fructu nigricanle squamato, vulgó cherimolia.

GUATTERIA. 20. 23. 24. 40. 41.

50.51. 52. 56. 123. Manil-panosou.

Guatteria Aberemoa.

Guatteria aeutifolia.

ruatteria brevipes.

Guatteria cerasoides.

Guatteria cordata.

Guatteria eriopoda.

Guatteria glanca.

Guatteria hirsuta.

Guatteria Korinti.

Guatteria laurifolia.

Guatteria Malabarica.

Guatteria ovalis.

Guatteria ouregou.

Guatteria pendula.

Guatteria podocarpa.

Guatteria rula.

Guatteria sempervirens.

Guatteria suberosa.

Guatteria virgata.

Guatteria umbilieata.

Hab alsizi.

Halieli et piper nigrorum serapioni.

Heylziortel.

Ibira.

Illicium.

Jejerecou.

Jona-jaka.

KADSURA. 13. 16.20.23.23. 2í $25.26 .27 \cdot 28$.

Kadsura Japonica.

Kaltsjerou-Panel.

Katsjan-Panel.

Keschta.

Kichta.

Korinti.

KLIOCKERIA.

Lancezoor?
73. Leyitis poeti:

7o. Liriodendron.

68. Long-yen s. longan:

66. Magnolia.

MAGNOLI:ACÉES. MIalaguette.

72. MIaniguette. Manil jaka.

r24. 126. Mranoa.

125. 134. Manoa papava.

124. 126. MARENTERIA.

51. 93.124.127. Marie baise.

125. 129. Matta ay we.

125. 130. Mratta ayn.

125. г3т. Meloguette.

I25. 131. MELODORUM.

52. 125.133. MELODORUM.

22. 52. 93. 125. 132. Nelodorum arboreum.

125. 134. Melodorum finuticosum. 125. I3 г. MENISPERMÉES.

52. 93.124.126. Menoa.

16. 52. 125. 131. Menona.

124. 12\%. Michelia.

93. 124. 129. Modira valli.

5.. г25. х33. MONODORA.

г. 6.51 .93 .124 .128 .

12.52. 93. 125. 131. Mlonodora microcarpa.

125. 135. Mlonodora myristica.

i13. Narum-panel.

113. Nonas.

I33. Ochna.

120. OCHNACEES.

$O R C H I D O C A R P U T H$.

$7 \cdot$

120. Orehidocarpum arietinum.

7o. Orchidocarpum grandiflorum.

Orchidocarpum parviflorum.

55. 5\%. Orchidocarpum pygmaum.

57. Oreni Kàdsura.

134. Ouregou.

134. Palukena.

7I. Panel syluestris.

71. Pao costus da serra menor.

33. Pao costus do mato.

10. 43. 56.94. Papazv.

132. Parangi jaç.
Hist. Mon.

$x 05$.

106.

7.27.

6. 7.8 .

46.47 .

46.47 .

.70

II 3.

jo.

74.

70.

20. 43. 56. 94. 99.

70.

105.

105.

47.

98.115.

20. 36. 42. 56. 94.

45 . $\quad 115$.

× 16 .

7.8.

$74:$

24.

7. 25 .

זо6. 34. 31.34. 35. 55. 79.

78.79 .80 . 78.79 .80$.

99.

54.

7

6.7 .8

56. $8 \mathrm{r}$ :

83.

84.

82.

84 .

57.

127.

88.

134 .

134.

เ33.

83.

$-3$ 
Pas costus bravo.

Pee apocaro.

Pericoboom.

Platano de monte.

Pinaou.

Pinaioura.

Pindaiba.

Piper Athiopicum.

Piper Athiopieum siliquosum:

Piper oblongum nigrum.

Poivre d'AEthiopie.

Poipre des mantres.

Poivre des nègres.

Poiure des noirs.

Poivre long noir.

Pornme cannelle.

Pommier de cannelle:

\section{PORCELIA.}

Porcelia grandiflora.

Porcelia nitidifolia.

Porcelia parviflora.

Porcelia pygmeea.

Poreelia triloba.

Porcelice species. Pers.

RENONCULACEES.

Salit metten.

Sàne Kàdsura.

Sapotea species dubia. Sloannea emarginata. $L$.

Sarabrassa.

Seja cananga:

SIMAROUBEES.

Siri cay nona.

Sirikaya.

Sondat.

Soursop.

Steenappclboom:

Sugar apple.

Sugar apple tree.

Sneetsop.

Talauma caribar.

Tali pissang.

'I'sjamve.

T'sjerou-Panel.

I'sjina-Panosols.
Hist. Mon.

Hist. BIon:

134. Undulated custard-apple.

134. UNONA. 19.20.23. 24. 40.41. 42.

I10. 43.44 .45 .46 .47 .50 .

86. Unona acuminata.

32.

67. Unona acutiflora.

Ix. $42.44 .-98.116$

66. Unona Rthiopica.

97.113.

120. Unona aromatica.

97.112.

113. Unoua concolor. Willd.

ı3. Unona crassipetala.

112.

113. Unona desinos.

6. 46. 112. 113. Unona discolor.

46. I13. Unona discreta.

46. 112. Unona dumetorim.

47. Unona esculenta.

46. 113. Unona fuscata.

33. 63. Unona hamala.

7o. Unona latifolia. Unona leptopetala.

36. 38. 40. 55. 85. Unona lessertiana.

84. 86. Unona ligularis.

85. Unona longifolia.

82. 86. Unona lucida.

84. 86. Unona macrocarpa.

$3^{5.101 . ~}$

97. 112.

97. 11 I.

3. 97 . 110. $9^{8 .}$. 16 .

93. $9^{6.107}$. $9^{5.102 .}$

$9^{3} .9^{6.107} \cdot$

$9^{8}$. 115 .

98. II 4 .

$9^{3 .} 9^{6.10 \%}$.

93. 97.110.

I2. 39

53. 86. Unona marenteria.

56. 81. Unona musaria.

Unona narum.

roo. Unona nitidissima.

5;. Unona obtusiflora.

Unona odorata.

45. $9^{3} \cdot 97 \cdot 109$.

98. п 6.

96. 103.

$9^{5.101 . ~}$

43. $9^{5.100 .}$

43. 44. $9^{3 .} \cdot 9^{5} \cdot 99$.

93. 97 . 109 :

96.102.

-8. Unona orata.

74. Unona oxypetala.

ro8. Unona penduliflora.

Unona polycarpa.

74. Unona sylvatica.

ro. Unona tomentosa. Irilld.

roS. Unona tripetaloidea.

63. Unona uncinata.

7o. Unona uudulata.

70. Unoua violacea.

7o. Unona xylopioides.

7o. Tou zeylanica syluestris mali au-

78. rantii sapore. 39 .

roo. UVARIA. $\quad 7 \cdot 19 \cdot 20.23 .21 \cdot 25$.

ro8. 39.40.4r. 42.50.5r. 50.86.

133. Tivaria. L. Fl. Zeyl. SS. -3. Viaria aromatica. Lam. y3. ıг.
96. 10 4.

9 S. 114 .

16. $93.9^{5} .100$.

$9^{\text {S. } 11 \%-~}$

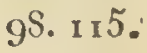

112.

78. 95. го5.

46. 97. 111. 123.

$9^{3} \cdot 9^{6} \cdot 105$.

93. 95. $11 \%$.

$\$ 8$.

8. 


\section{4}

Uvaria cerasoides. Roxb.

Uu aria coriacea. Vahl.

Uu ria coromandeliana.

Uraria dulcis.

Uvaria esculenta. Roxb.

Uvaria excelsa. Vahl.

Uparia febrifuga. $\boldsymbol{H}$. et $\boldsymbol{B}$.

Uvaria Gertneri.

Uvaria Japonica.

Uvaria Javana.

Uvaria lanceolata. Swartz.

Uvaria laurifolia. Swartz.

Uvaria ligularis. Lam.

Uuaria longifolia. Lam.

Uvaria lucida. Vent.

Uvaria lutea.

Uvaria macrocarpa. Vahl.

Uvaria monilifera.

Uvaria monosperma. Lam.

Tuvaria odorata. Lain.

Uuaria pendizliflora. Moz.et Sessé.

Uraria? spectabilis.

Uvaria suberosa. Roxb.

Uvaria tomentrsa. Ir. 40. 4r.

Uvaria tomentosa. Tahl. incl.

Tuvaria trifoliata. Gorm. 40.

Uvaria tripetala. Lam.

Tivaria uncata. Lour.

Uvarta uncala. Vahl. ined.

Uraria velutina.

Uuaria villosa. Roxb.

Uvaria violacea, Moz. et Sessé.

Tuaria zirgala. Sivartz.

Uvaria Zeylanica. Domb.

Uvaria Zeylanica. Lam. ITilld.

Tuaria Zeylanica.Her. Deless.90.106. 130. r34. Zuursack.

Uraria Zeylanica. L. 39. \{0.43. 4\%. S7. 88.

93. 132. ad alas.
Hist. Mon.

93. 128. Uvarice species: Juss. Willd. 86. 94.

89. Uvaliae species. $\boldsymbol{L}$. 57 .

93. 128. Uvaria species. Lam. Willd. etc. 96.123.

$87.9^{\circ}$. Uves de mato. 88.

93. 107. Wali malla. roo.

93. 132. Wali mette.

93. 117. Waria Zeylanica. Aubl. $\quad 9^{3.112 . ~}$

87. 89. Wild Heilzvortel. 134 :

56. 118 :

87.91. XYLOPIA. 7. 12.17.19.23.24.

93. 132. 26. $27.43 .48 .49 \cdot 56.118$.

93. 32 . Xylopia acuminata. $\quad$ I9. 122.

93. xоo. Xylopia frutescens. $50 . \quad 119.120$.

93. 109. Xylopia frutescons. Gærın. 20.

93. rog. Xylopia glabra. $\quad$ x19. $x 21$.

I19. 121.

I19. 120.

$\begin{array}{lll}\text { 42. } & \text { 3. 110. Xylopia nitida. } & \text { 119. } 122 . \\ 9^{3.127 .} \text { Xylopia prinoides. } & \text { 12. 48. } 119.122 .\end{array}$

93. 108. Xylopia ruscifolia. 121 .

$9^{3}$. Xylopia salicifolia. $\quad$ 19. 121.

88. $9^{2}$. Xylopia setosa. 120.

93. 128. XYlopia undilata. 43. III. 123.

87. 90. XYlopio species. Paliss. 194.

93. 129. XYLOPICRON. 48. 56. 118.

89. Xylopicron arbor barbadensibus

93. 1о5. lignuln amarım noininata. 12 .

93. 106. Xylopicrum foliis amplioribus ovatis,

93. 107. petiolis brevibus, fructibus glabris. 122.

88. $9^{\mathrm{r}}$. Xylopicrum fruticosum, foliis ovatis

$9^{1}$. acuminatis productis alternis, cap-

93. sulis punctatis, floribus confertis

I3o. Im chào.

9. 90. Zelem.

63.

F I N I S.

A. Montpellier, chez Jean MARTEJ, Aîné, Scul Imprimcur de la Faculté de Mélecine, près l'Hòtel de la Préfecture, n. ${ }^{\circ} 62$. I8 I 7 . 


\section{$\mathbb{R} \cap A T A$.}

Page ix derniere ligne. Voyez la planche 2. lisez Voyez la planche 22.

x 5 ligne 27, après les pays matécagcux ajuuté du lirésil

432 I, Uvaria narum, lisez Unona narum,

43 22, Uvaria odorata, liscz Unona olorala,

4633 , Enona Africana. lisez Unona Ethiopica.

53 II, carpelli lege carpella

54 I3, Carpelli totidem baccati lege Carpella totidem baccata

54 13 , capsulares lege capsularia

54 I4, polyspermi, nunc distincti, sessiles ant stipitati, lege polysperma, nunc distincta, sessilia aut stipitata,

5/ $\quad 15$, impositi ; lege imposita;

5\% 15 , coadunati lege coadunata

6428 , punctibus lege punctis

105 9, adde Hab. in Moluccis. 5

10721 , Usaria uncata. lege Uvarice uncatce.

ro8 6, Uvaria oborata. lege Unona odorata. 



ב̀

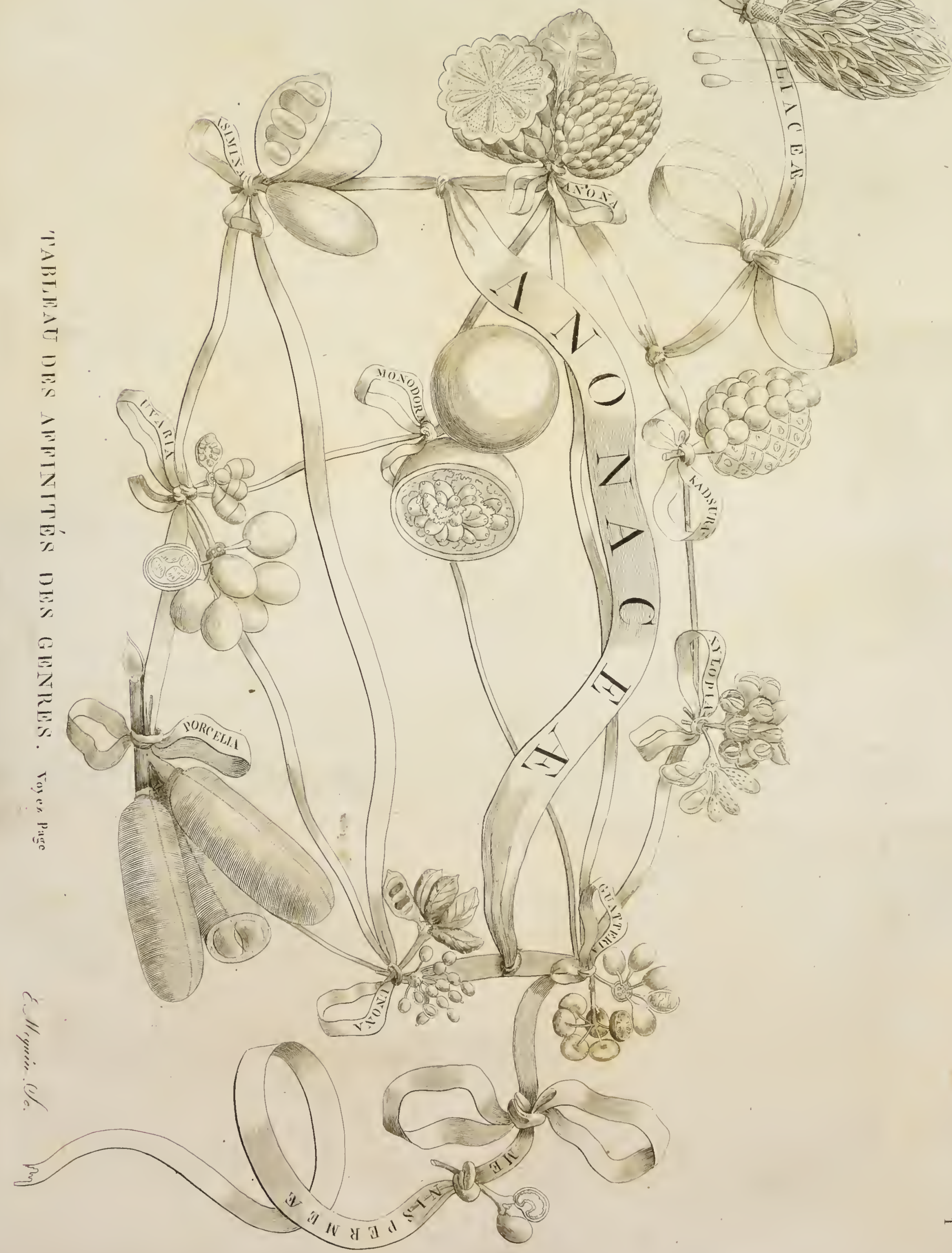





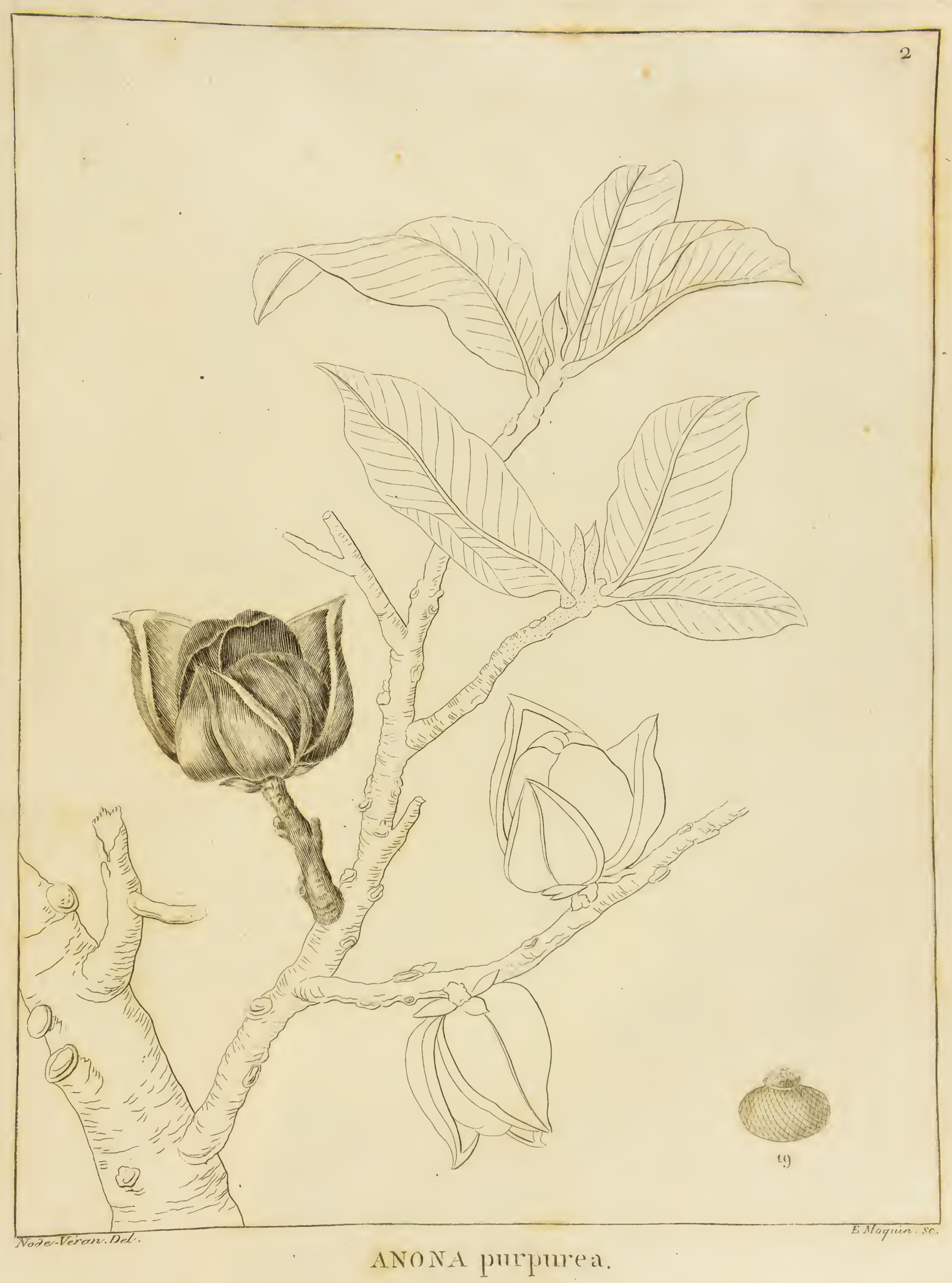





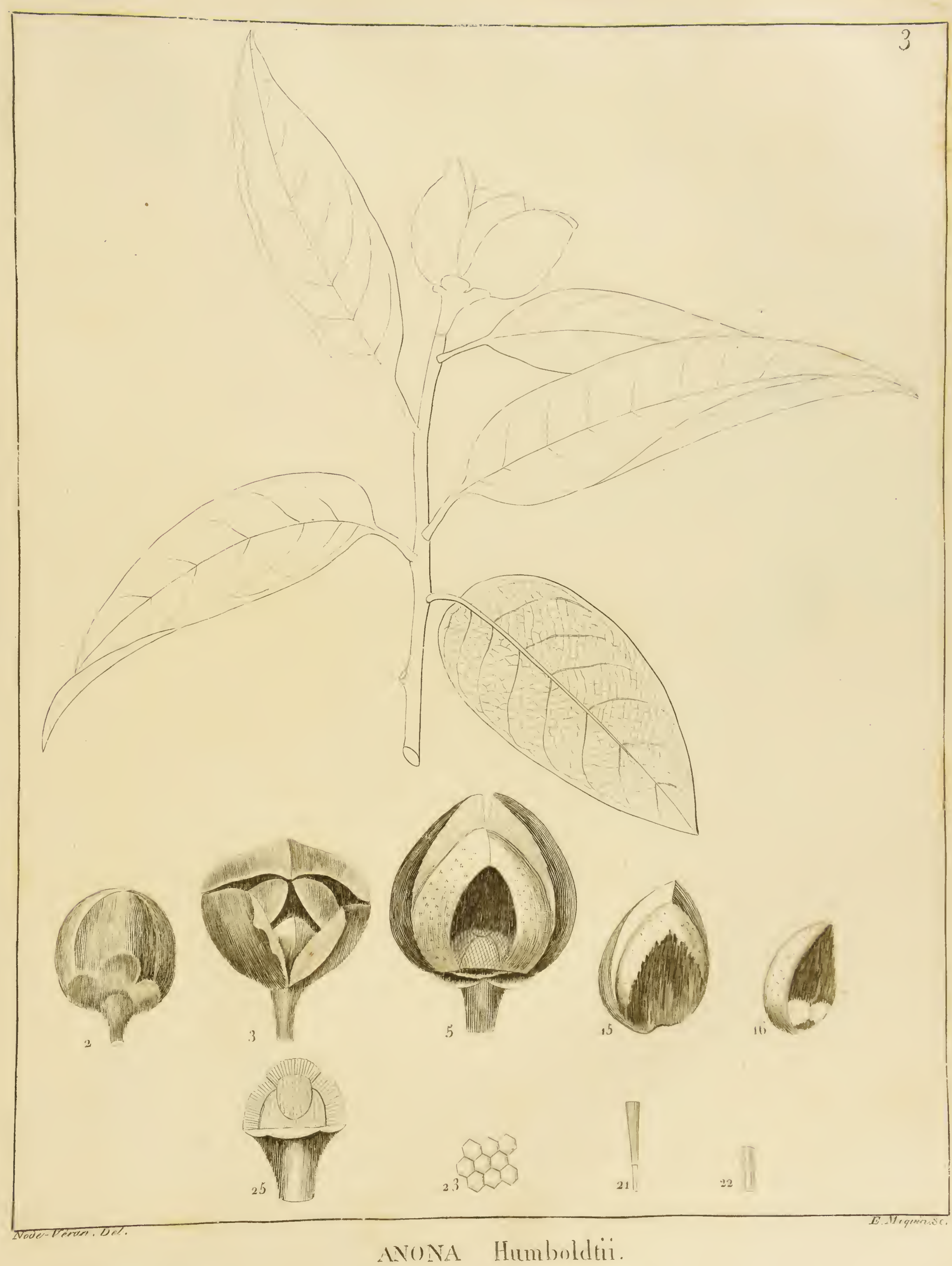





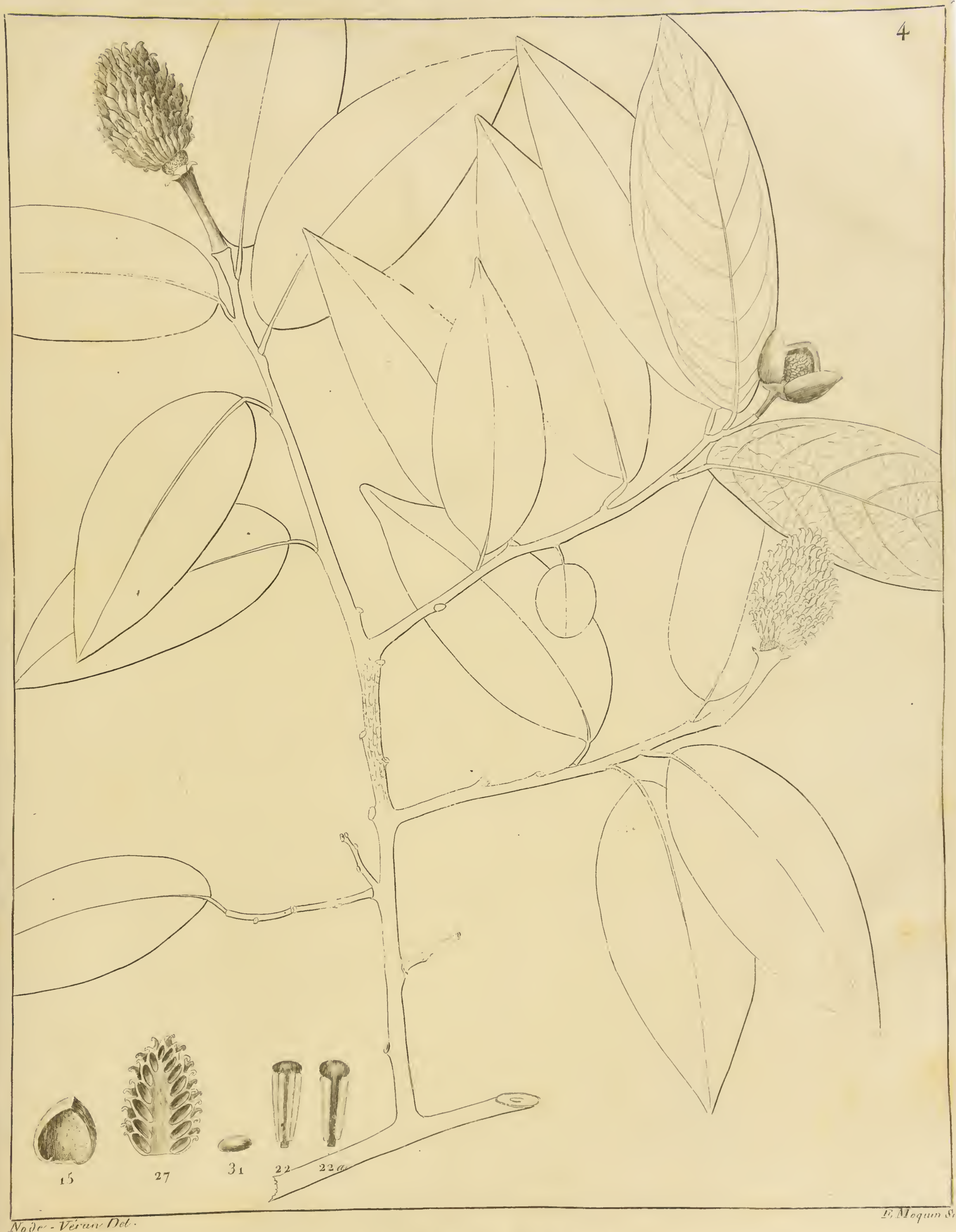

ANONA PClimala 




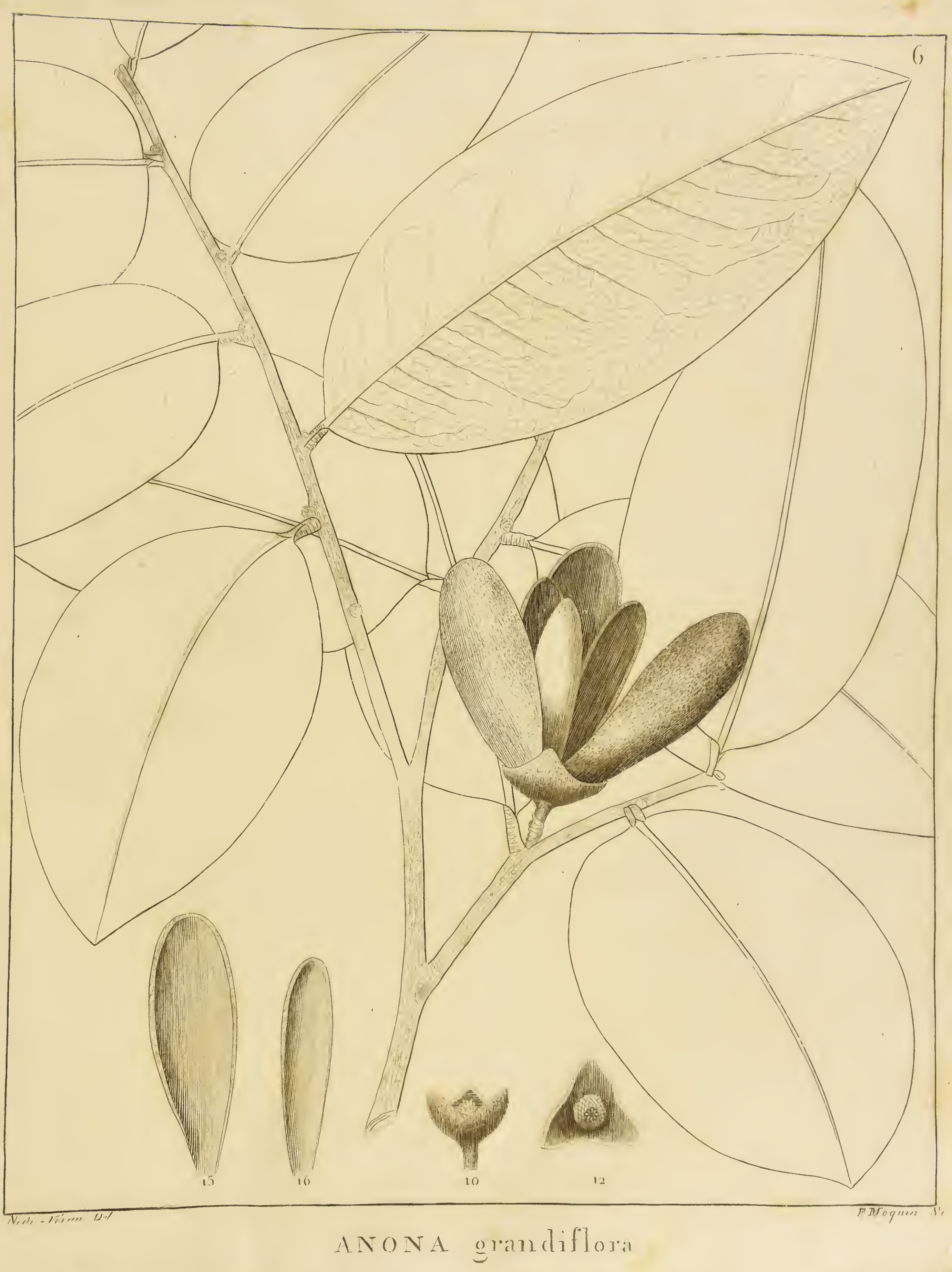





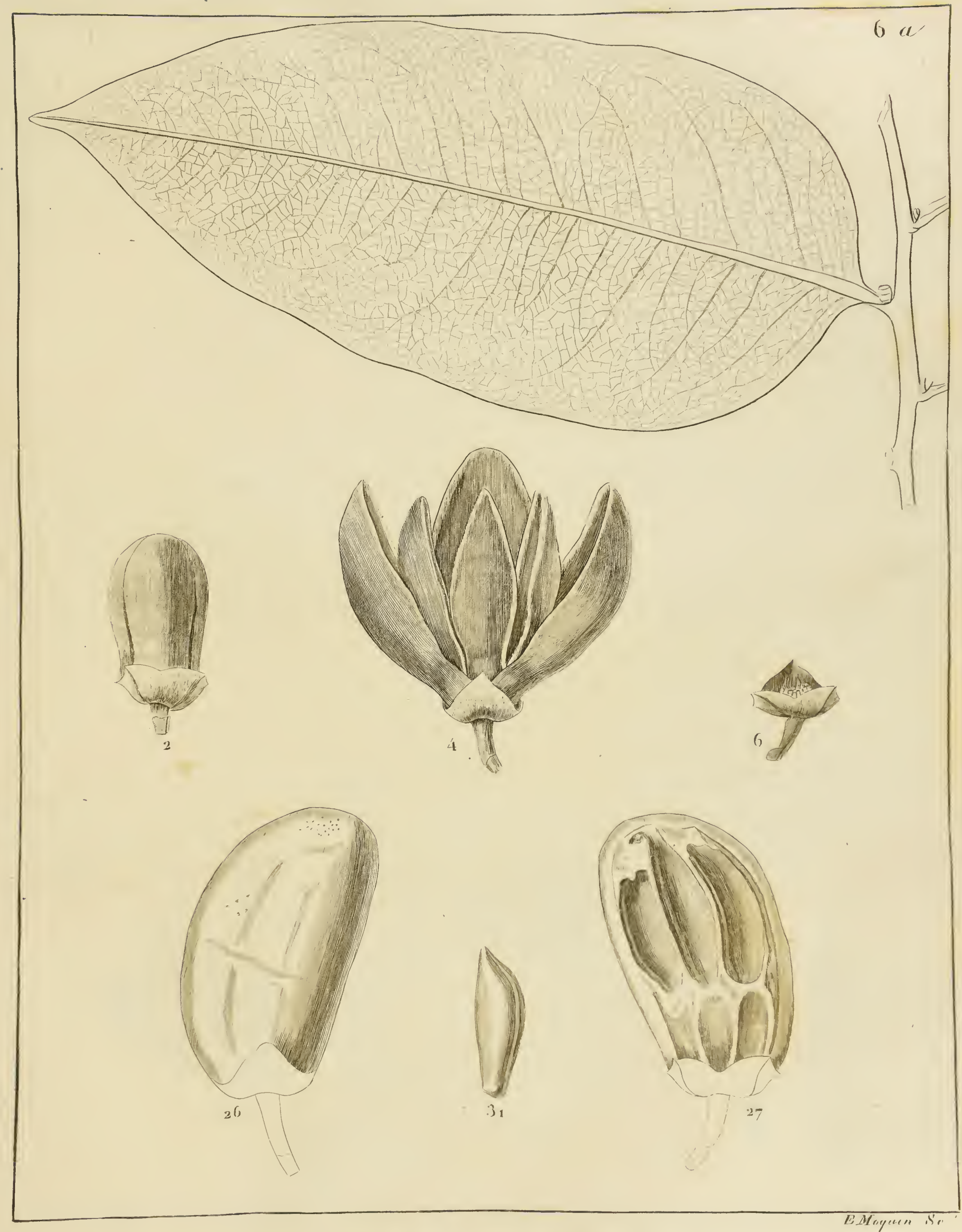

ANONA grandiflora. 




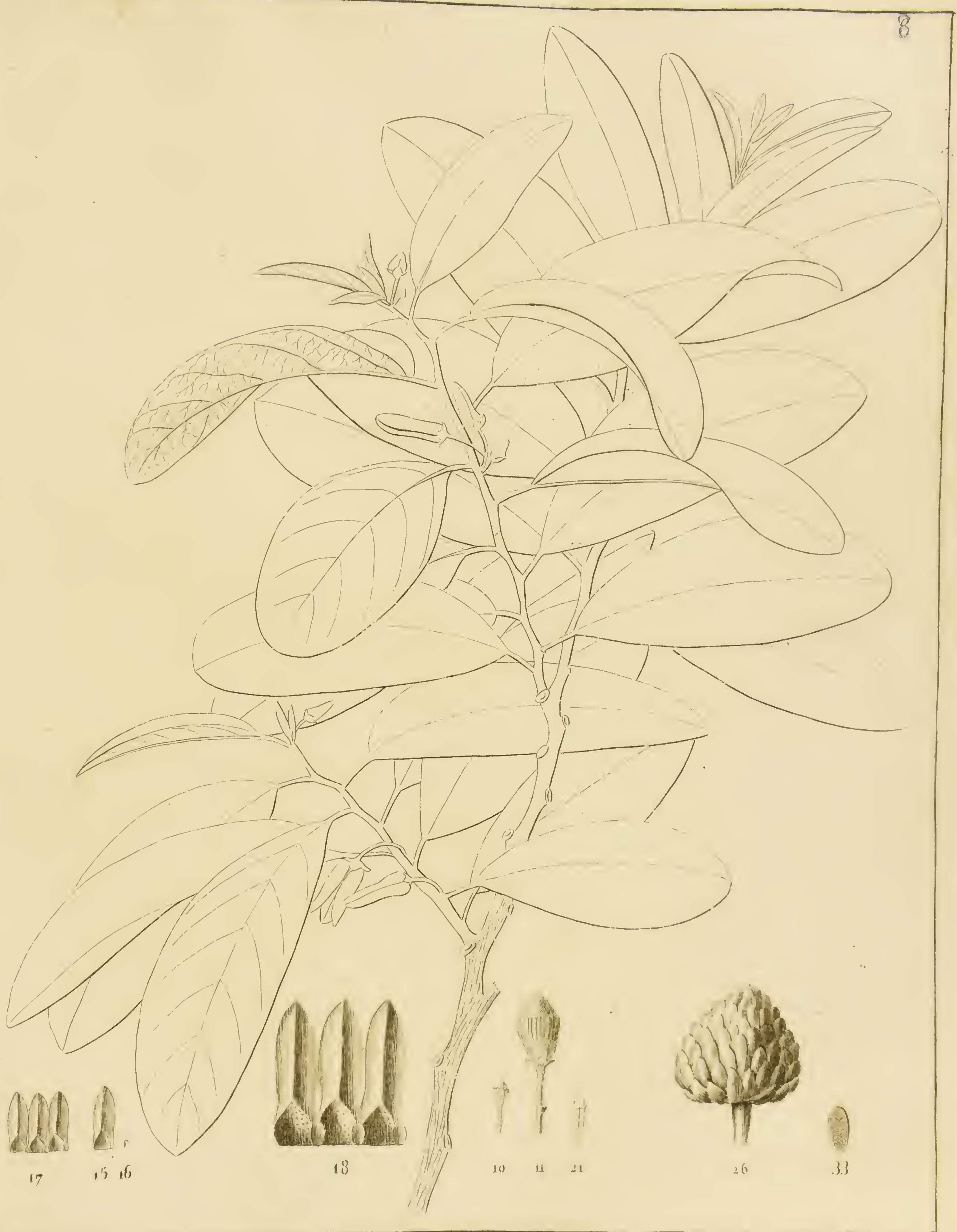

INONA GInerea 




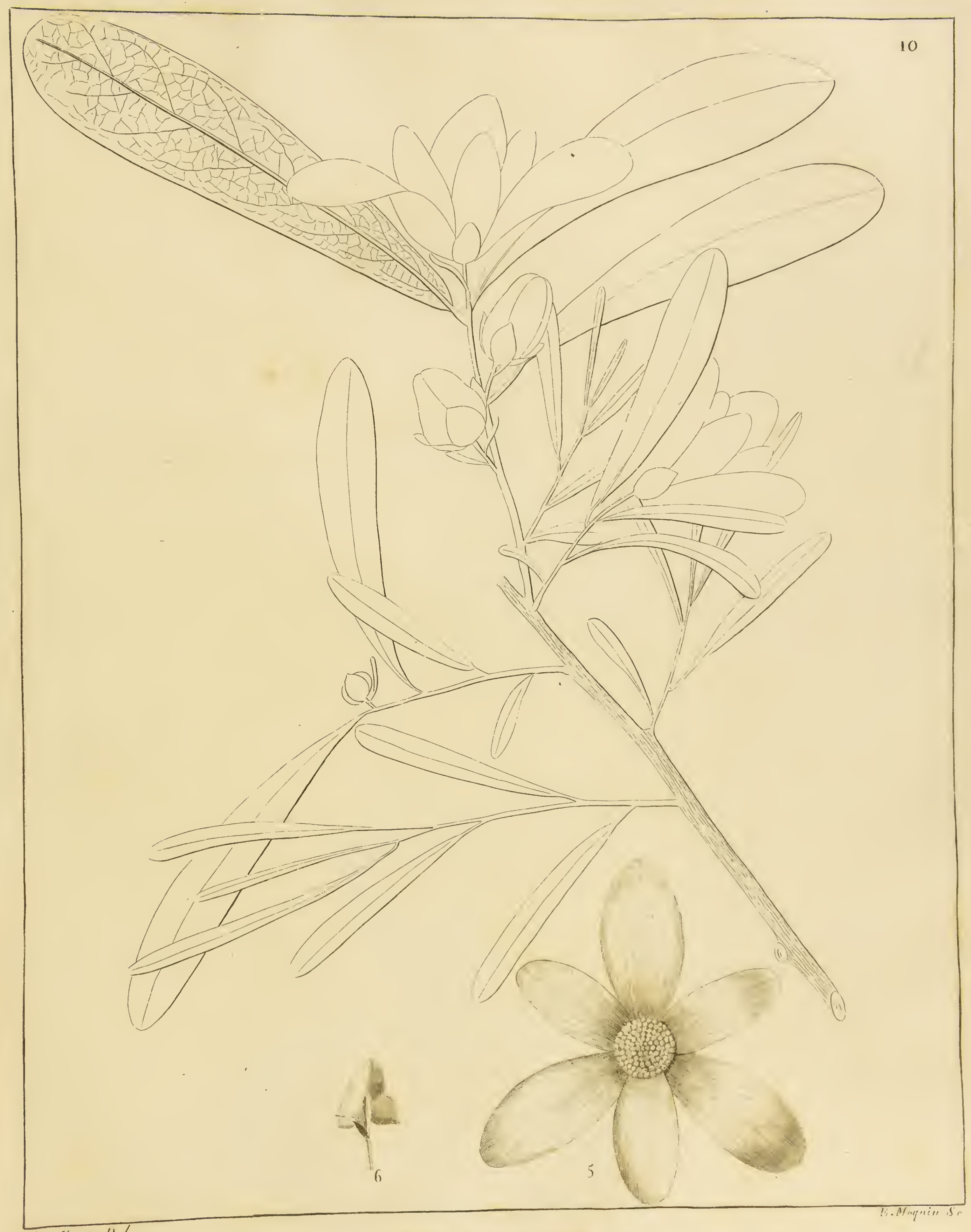

ASIMTA pygmad. 



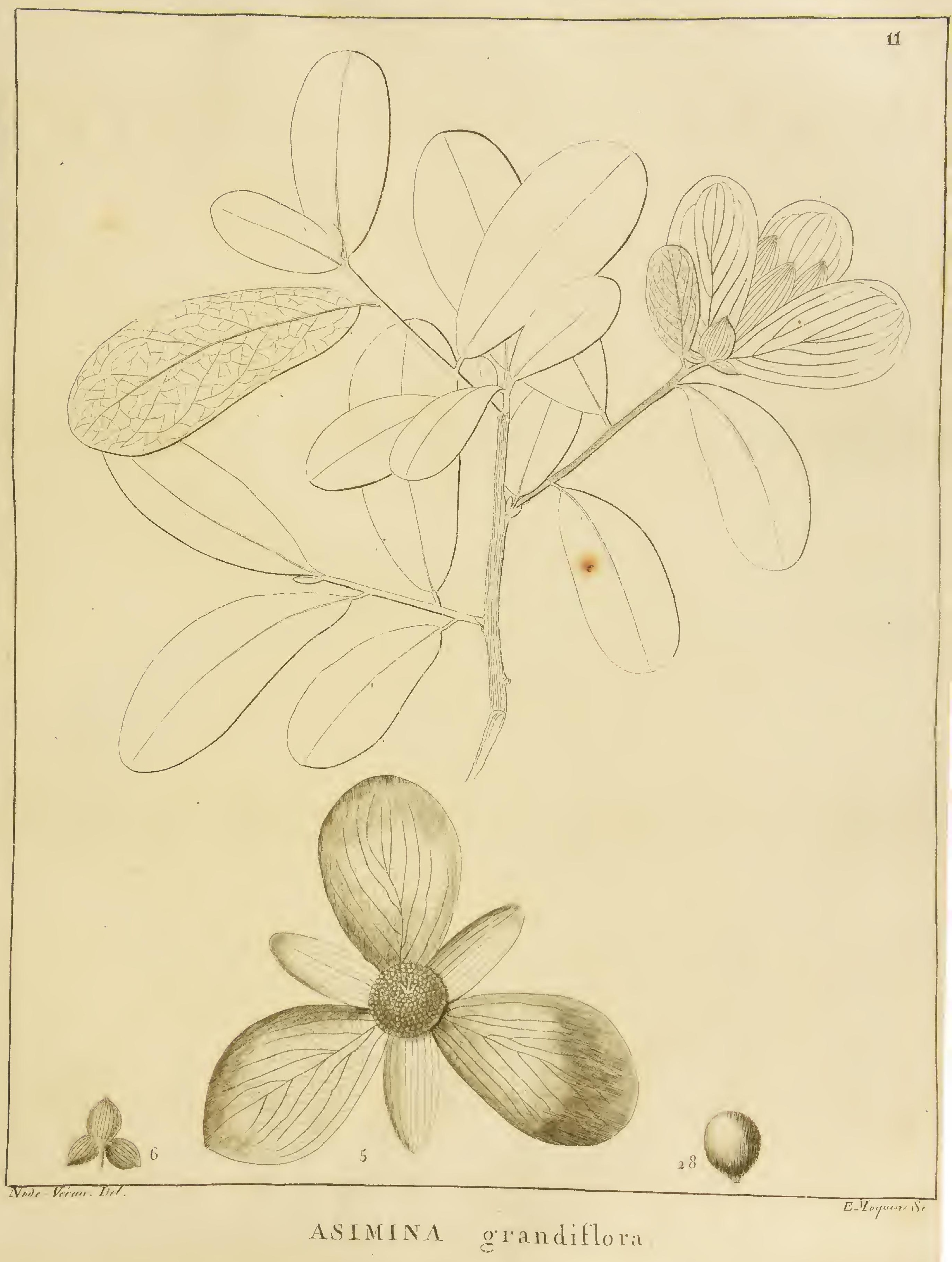





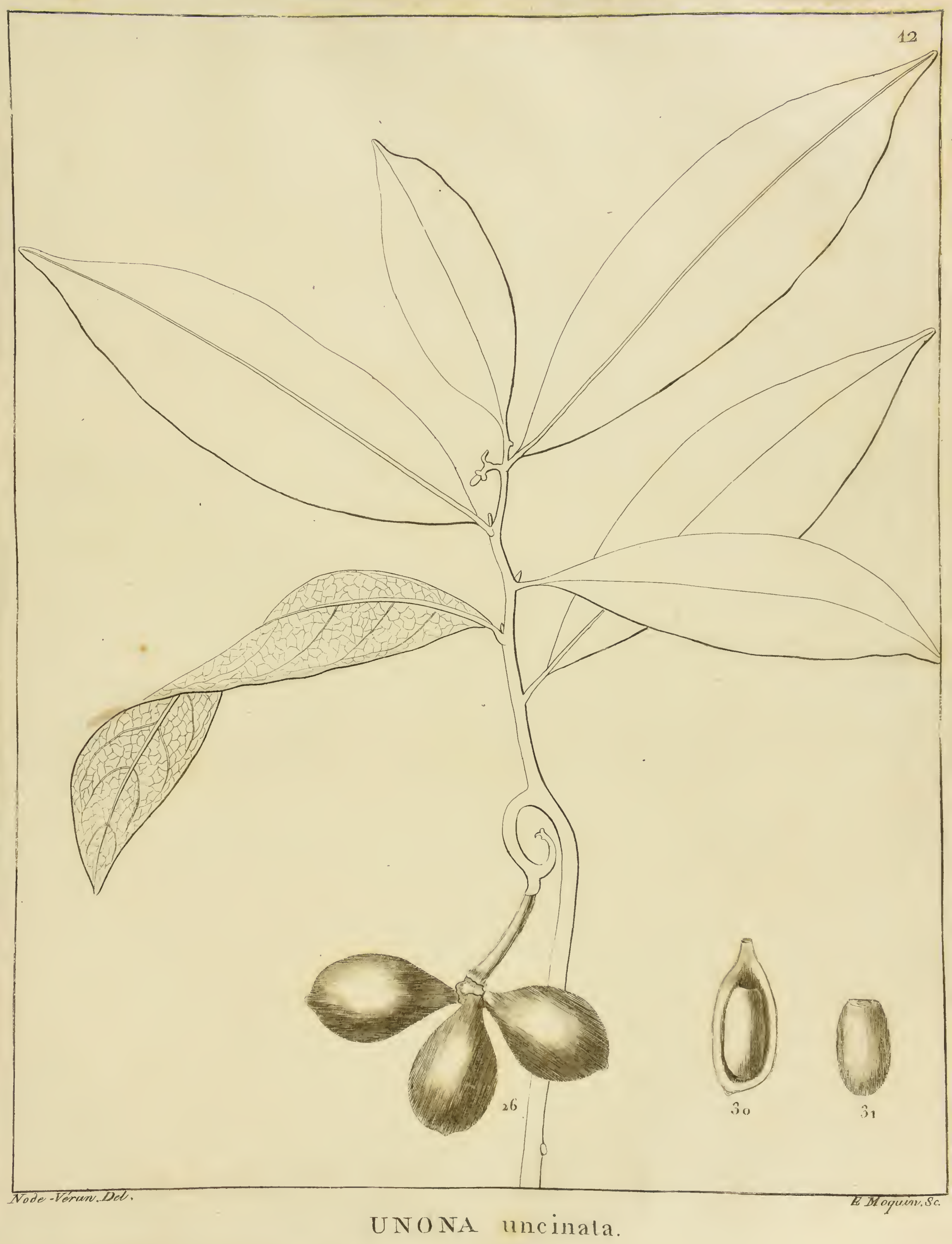





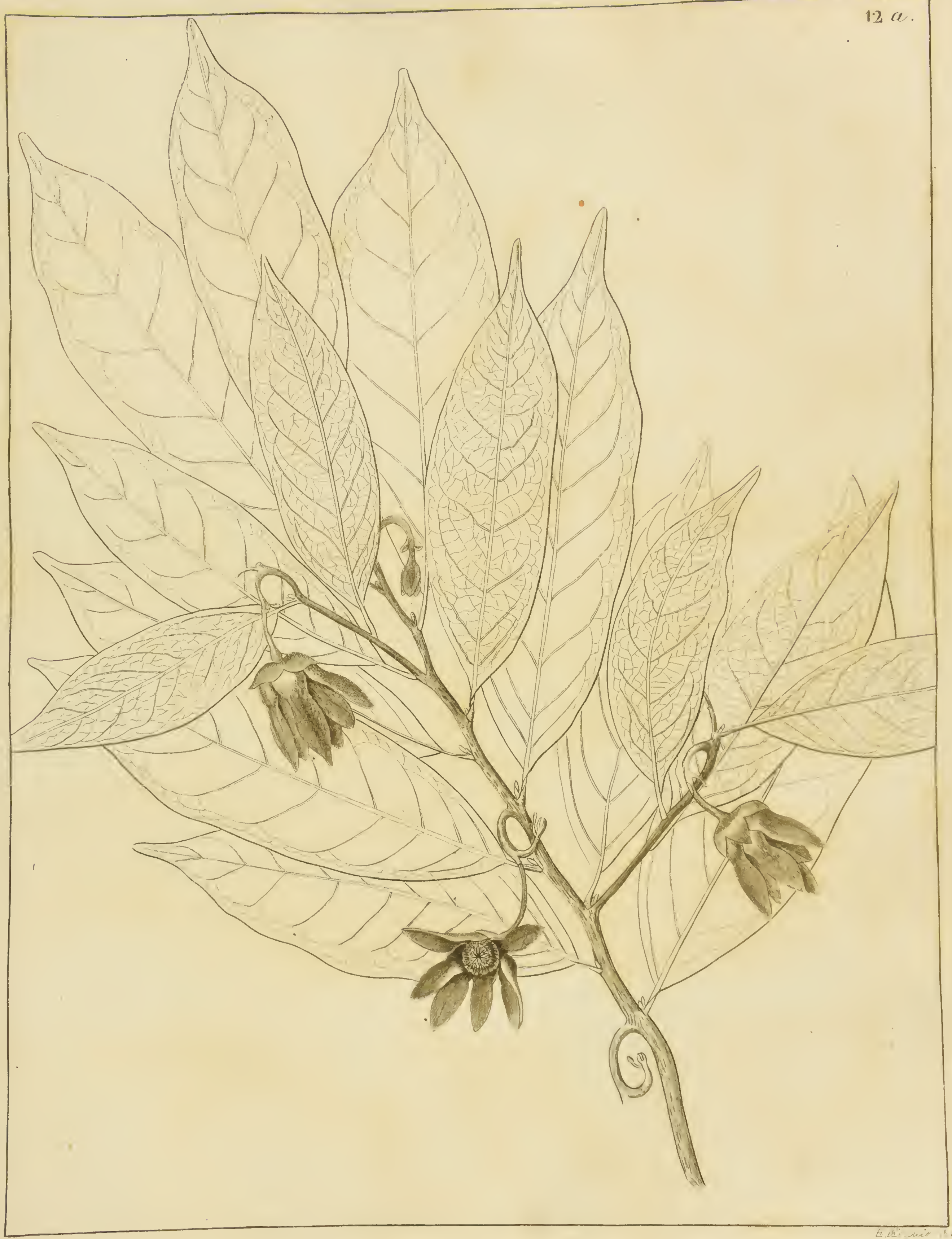

UNONA Uncinata. 



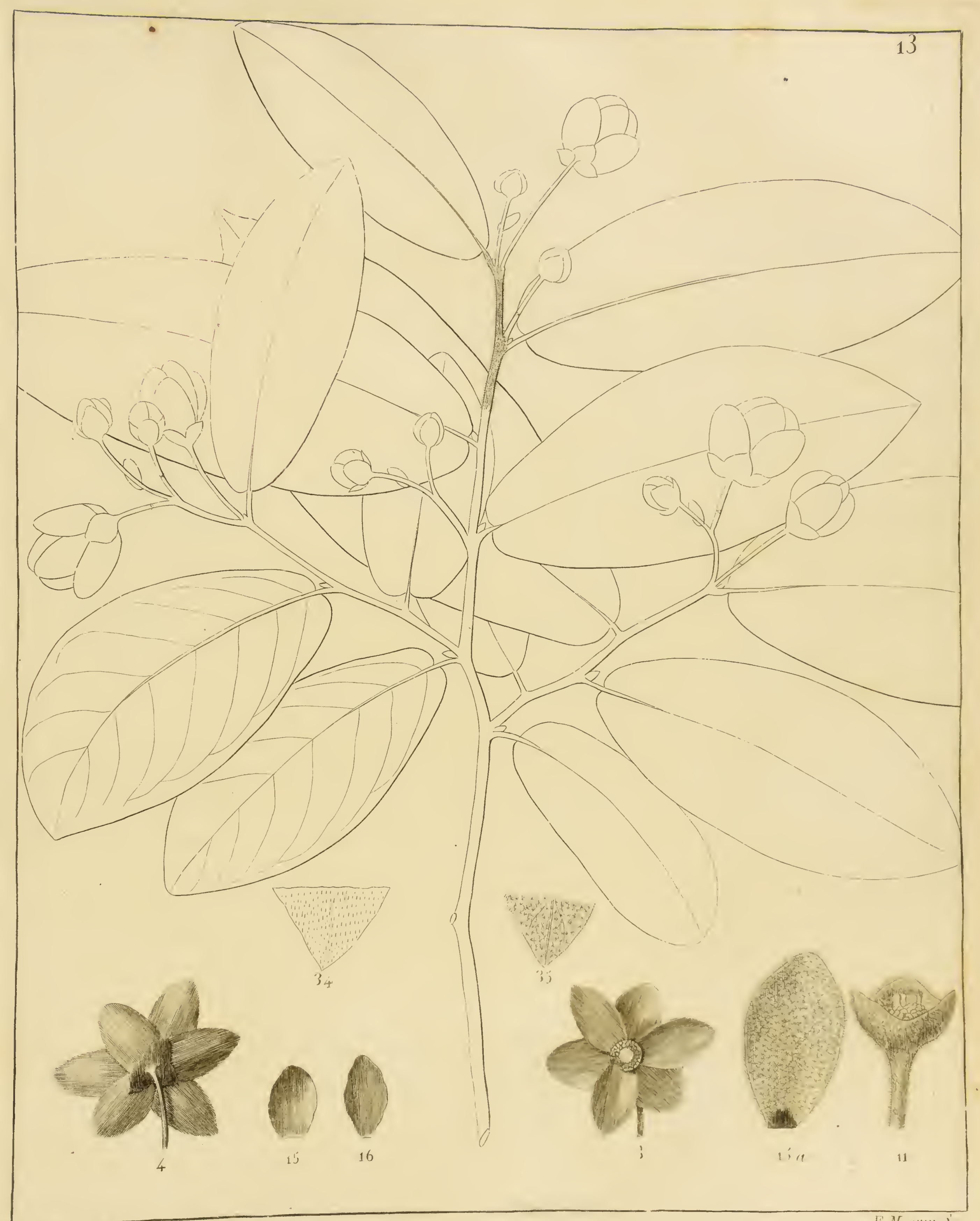

IVARLA dulcis. 



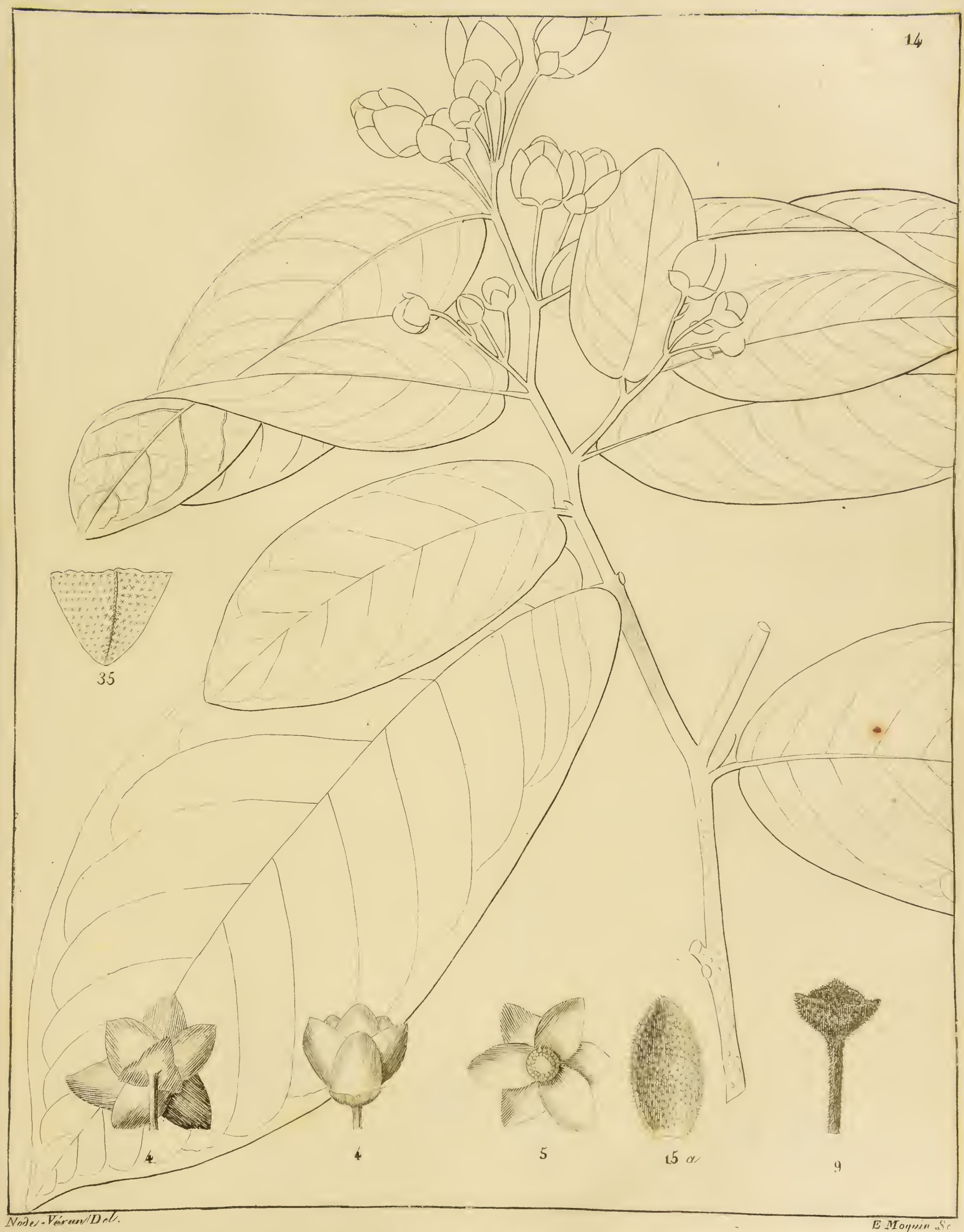

UVARIA javana. 





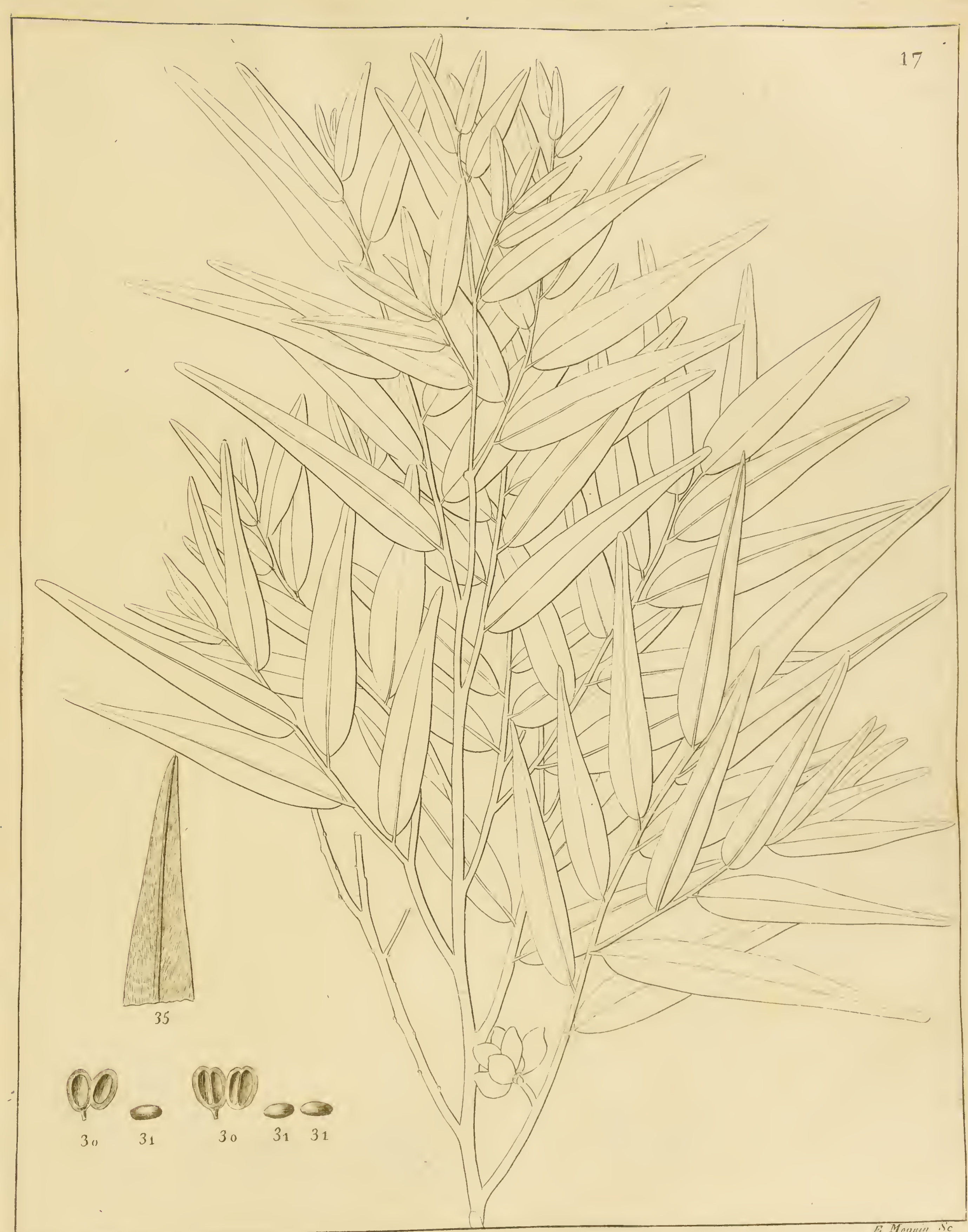

xYTOPIA salicifolia. 



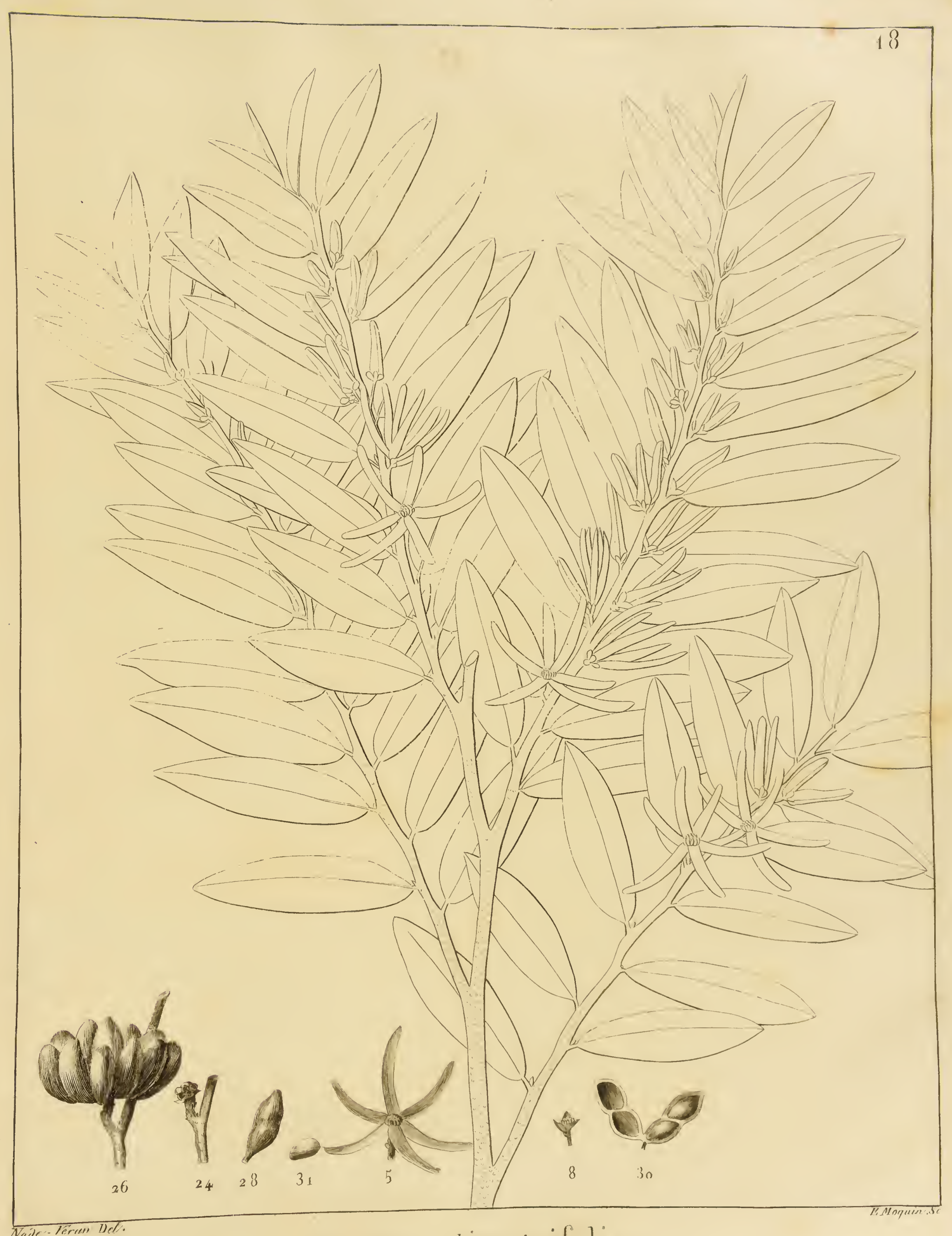

XYLOPA ligustrifolia. 



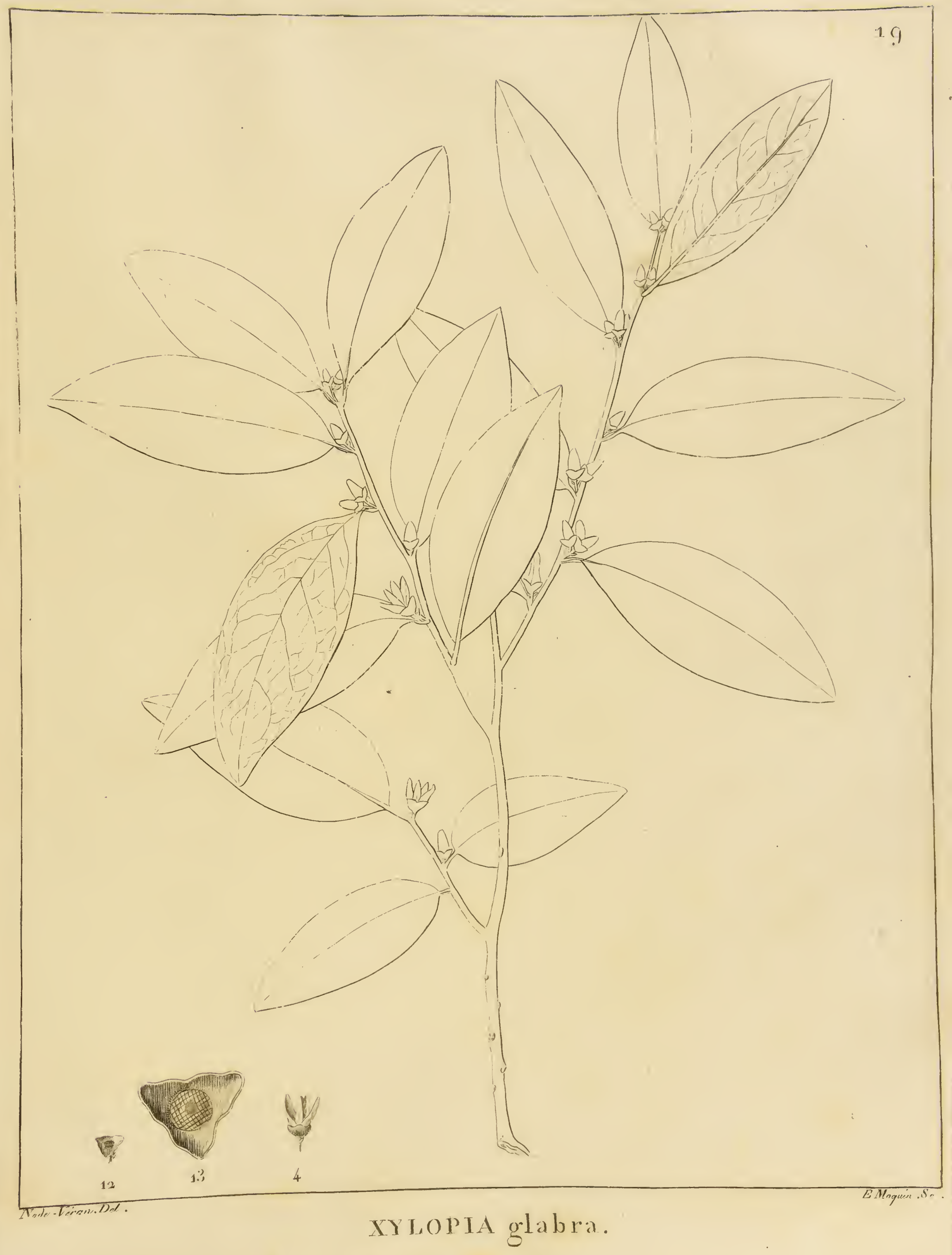





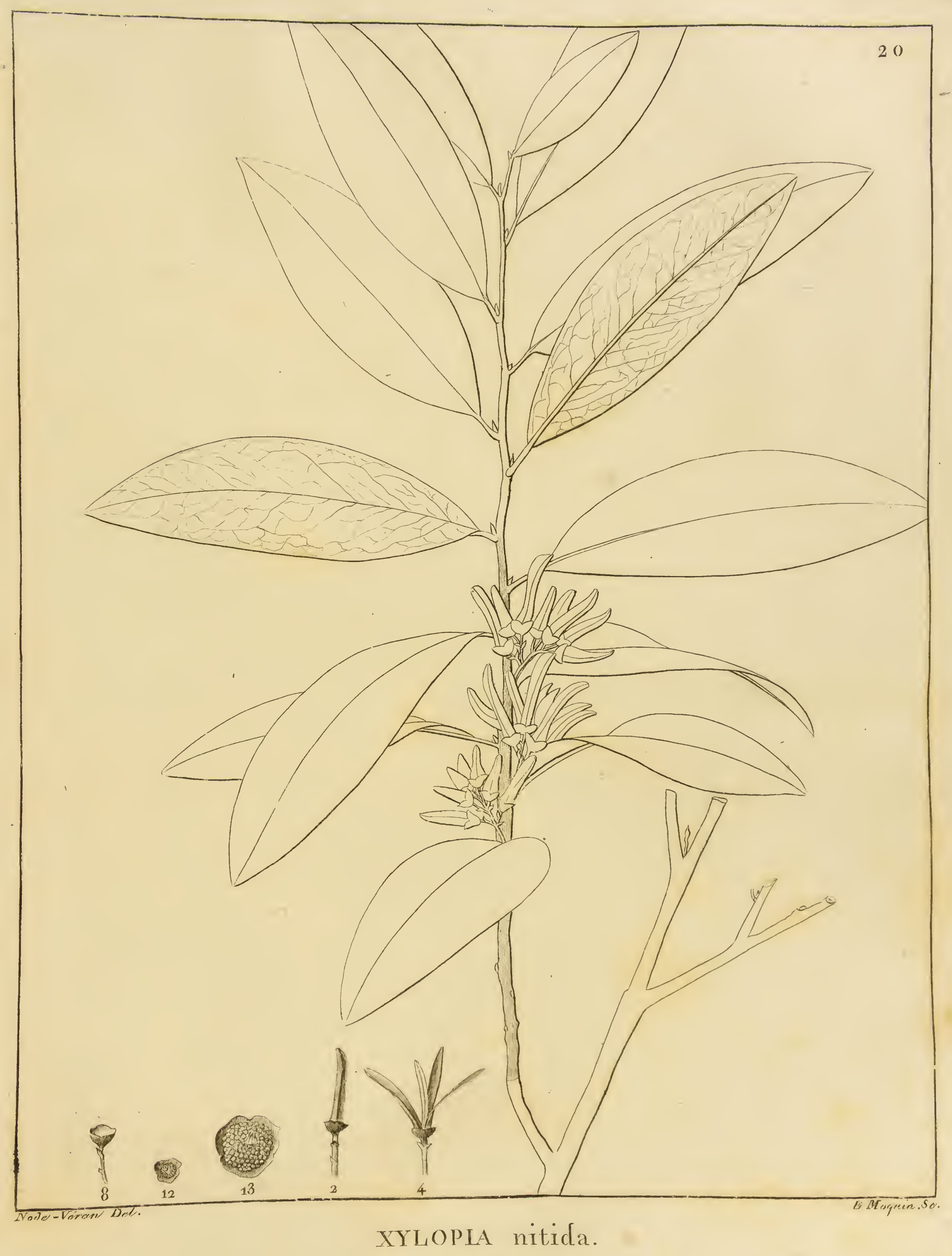





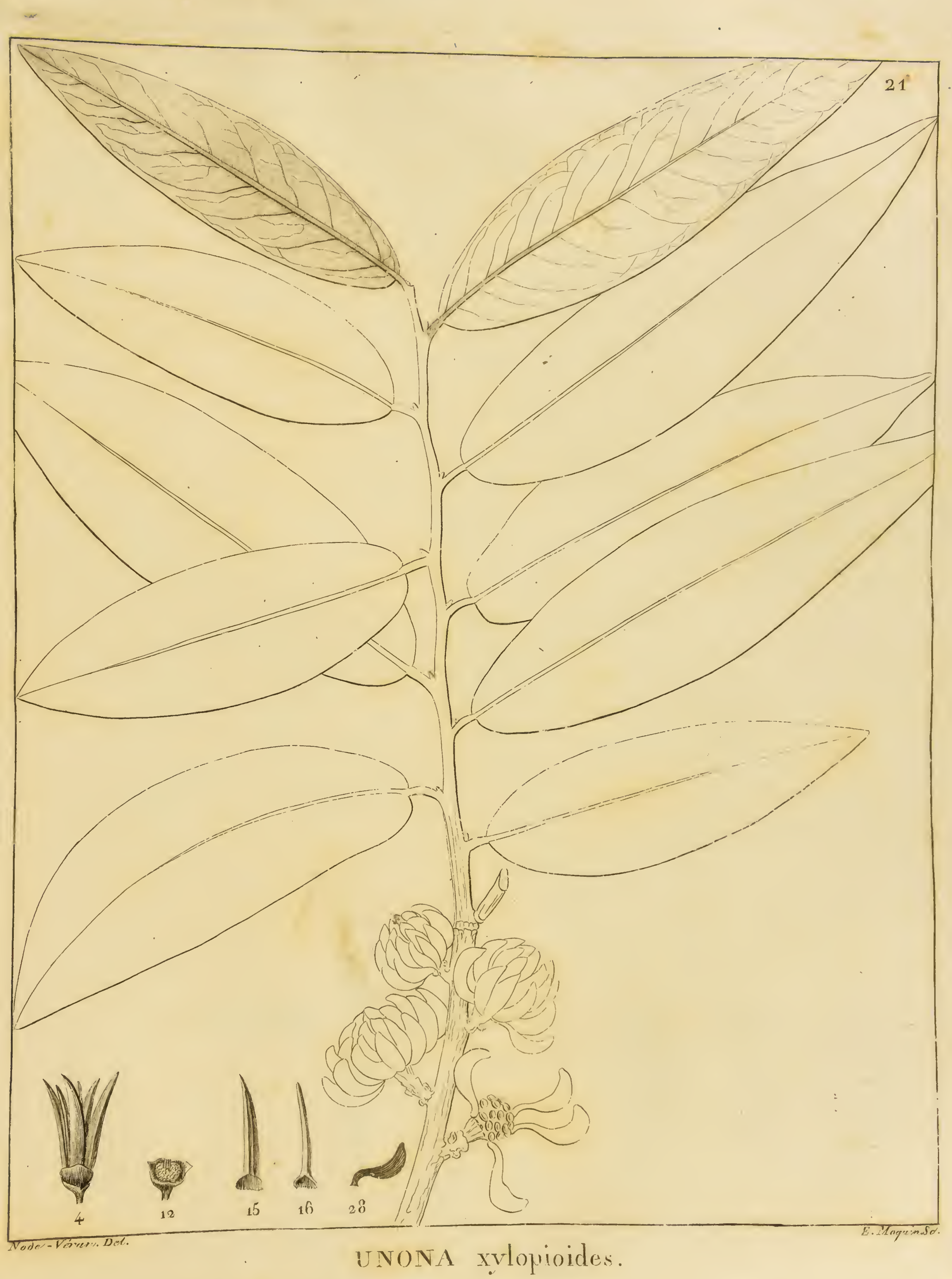





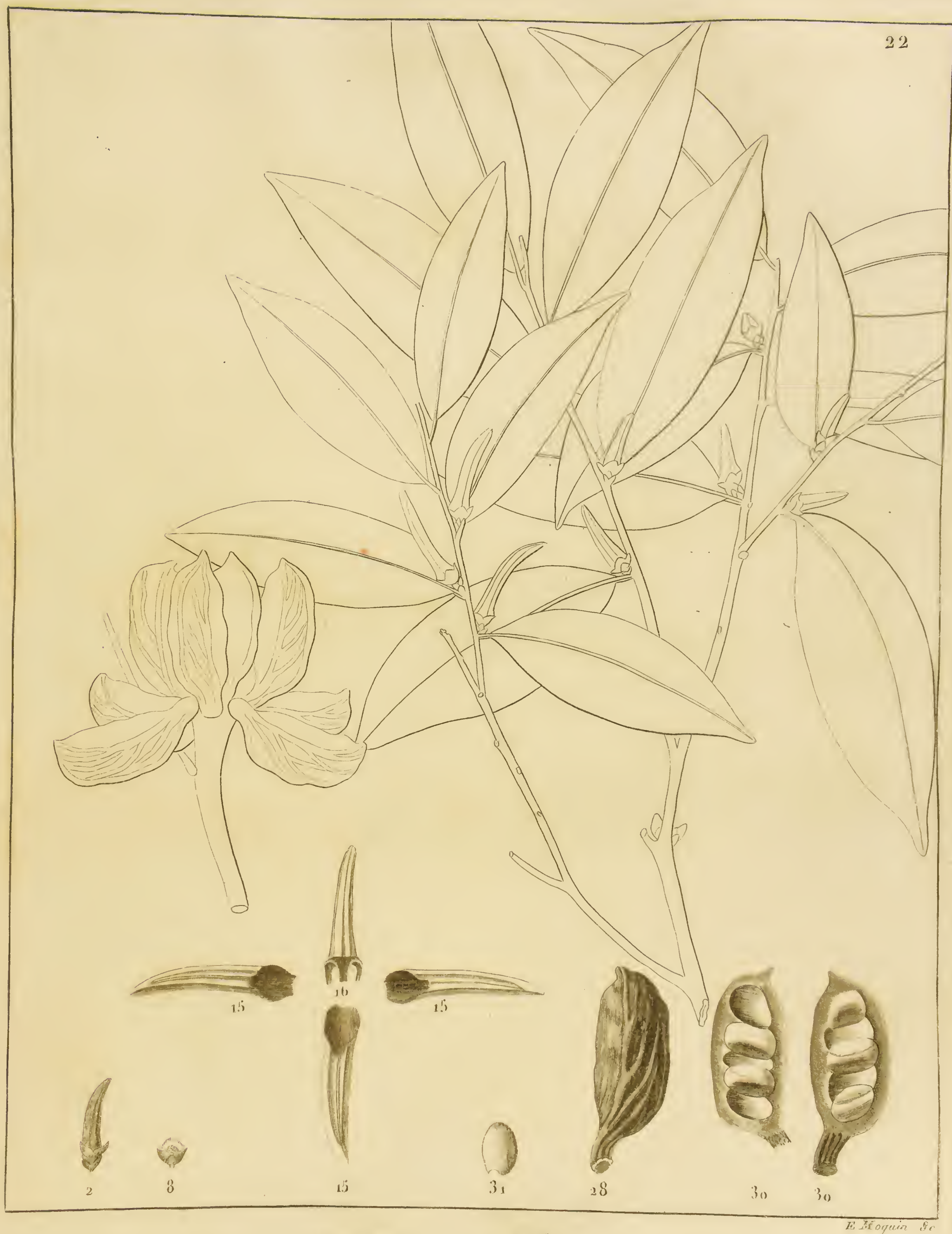

UNONA aculiflora. 



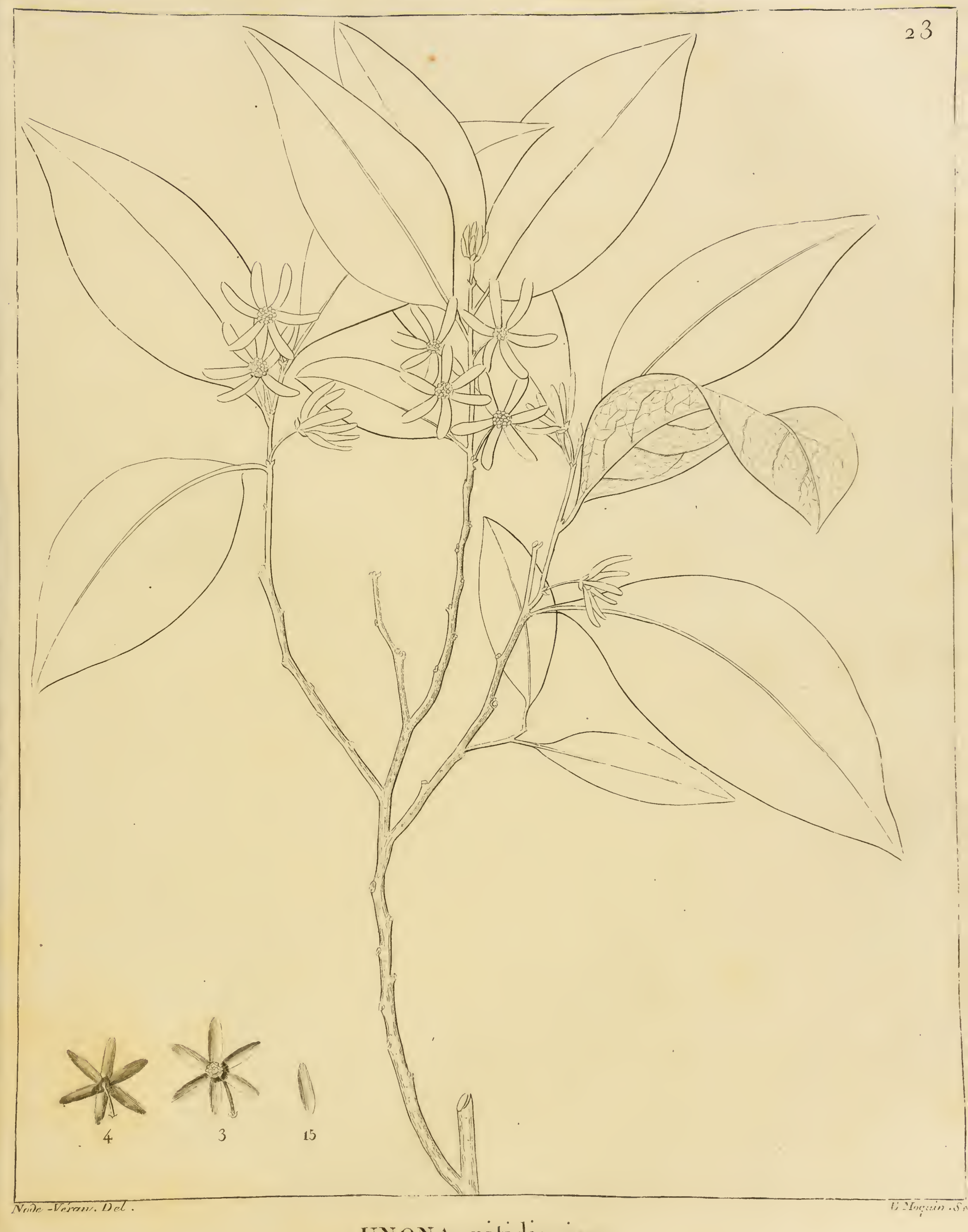

UNONA nilidissima. 



$$
\text { * * }
$$





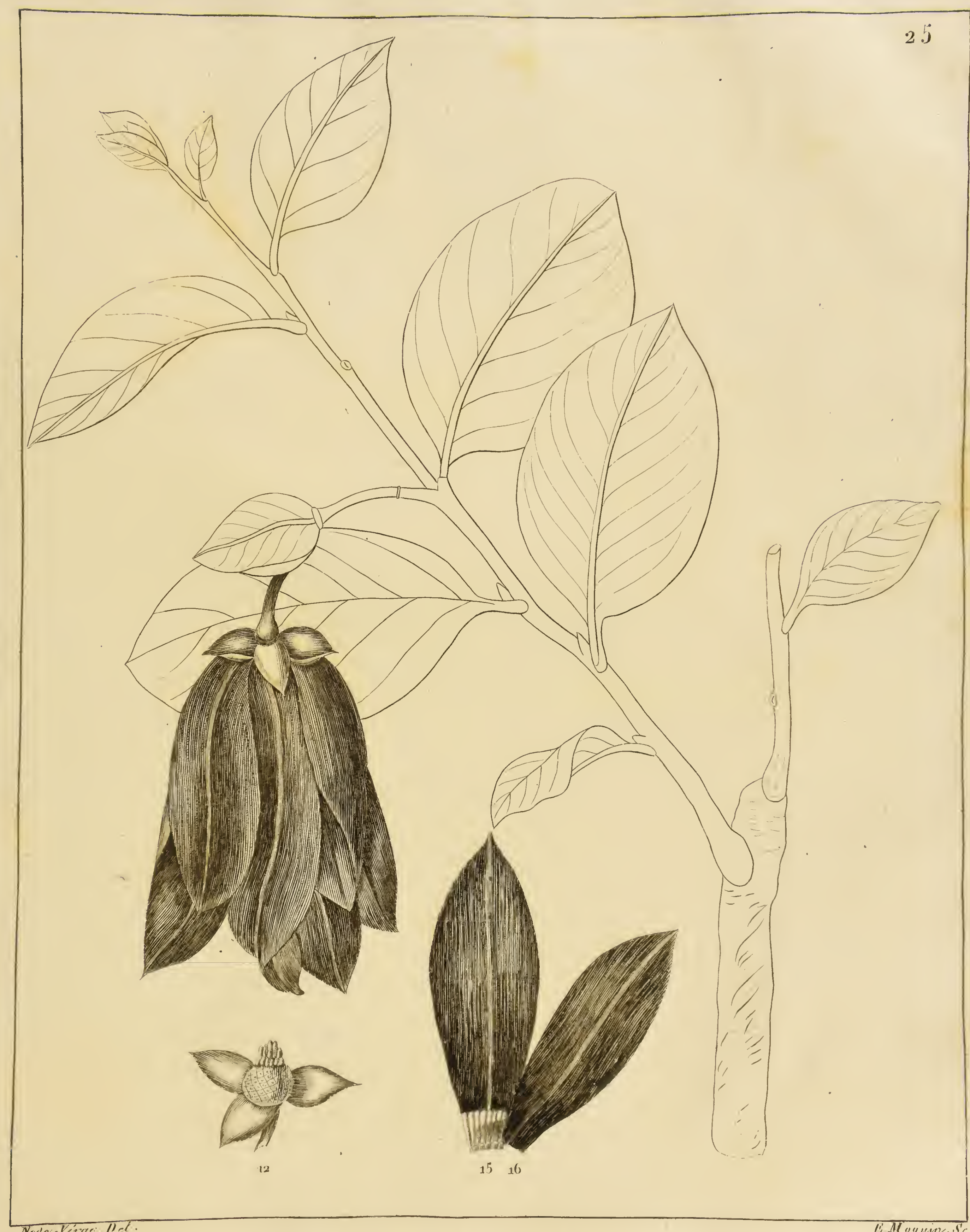

UNONA violacea. 



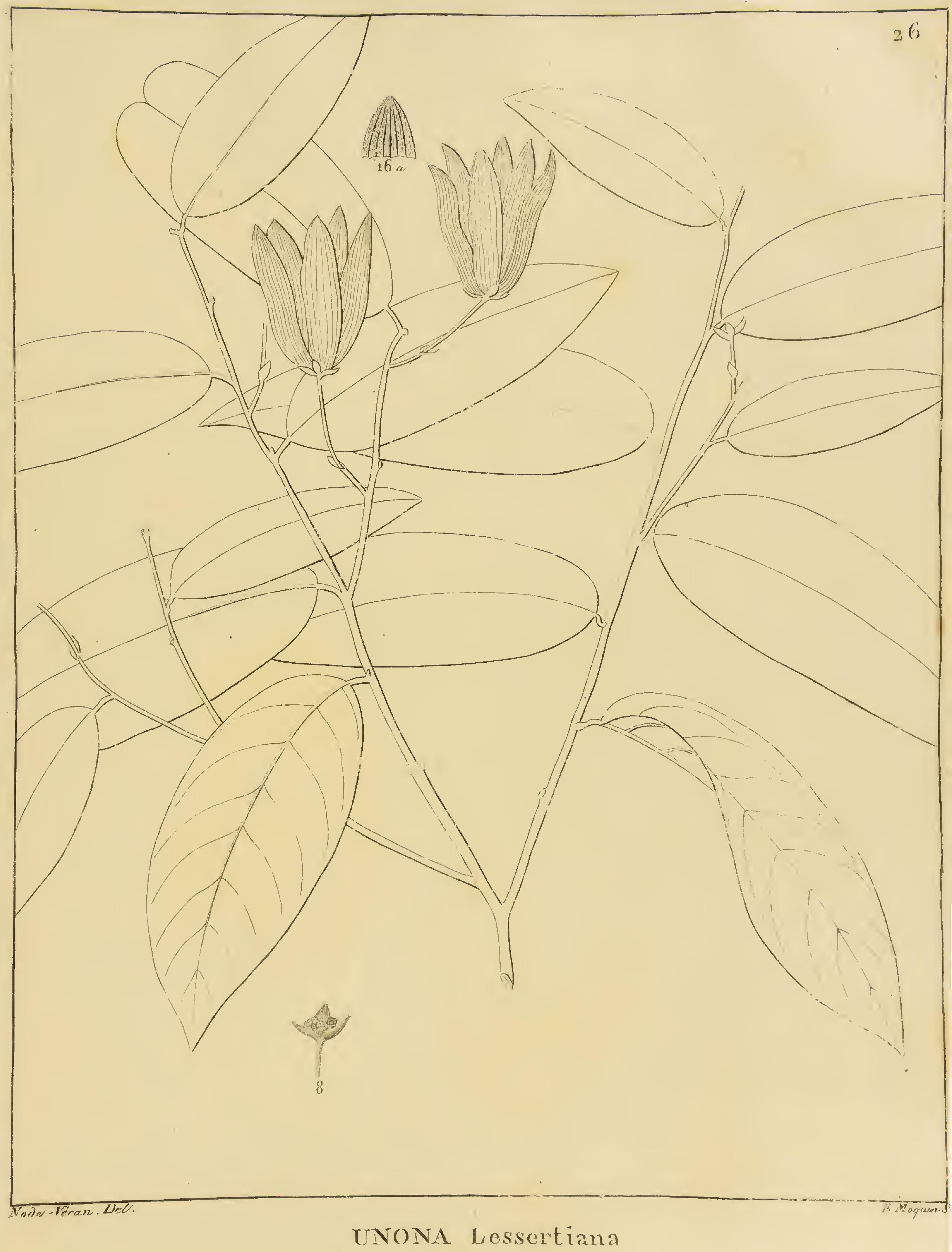





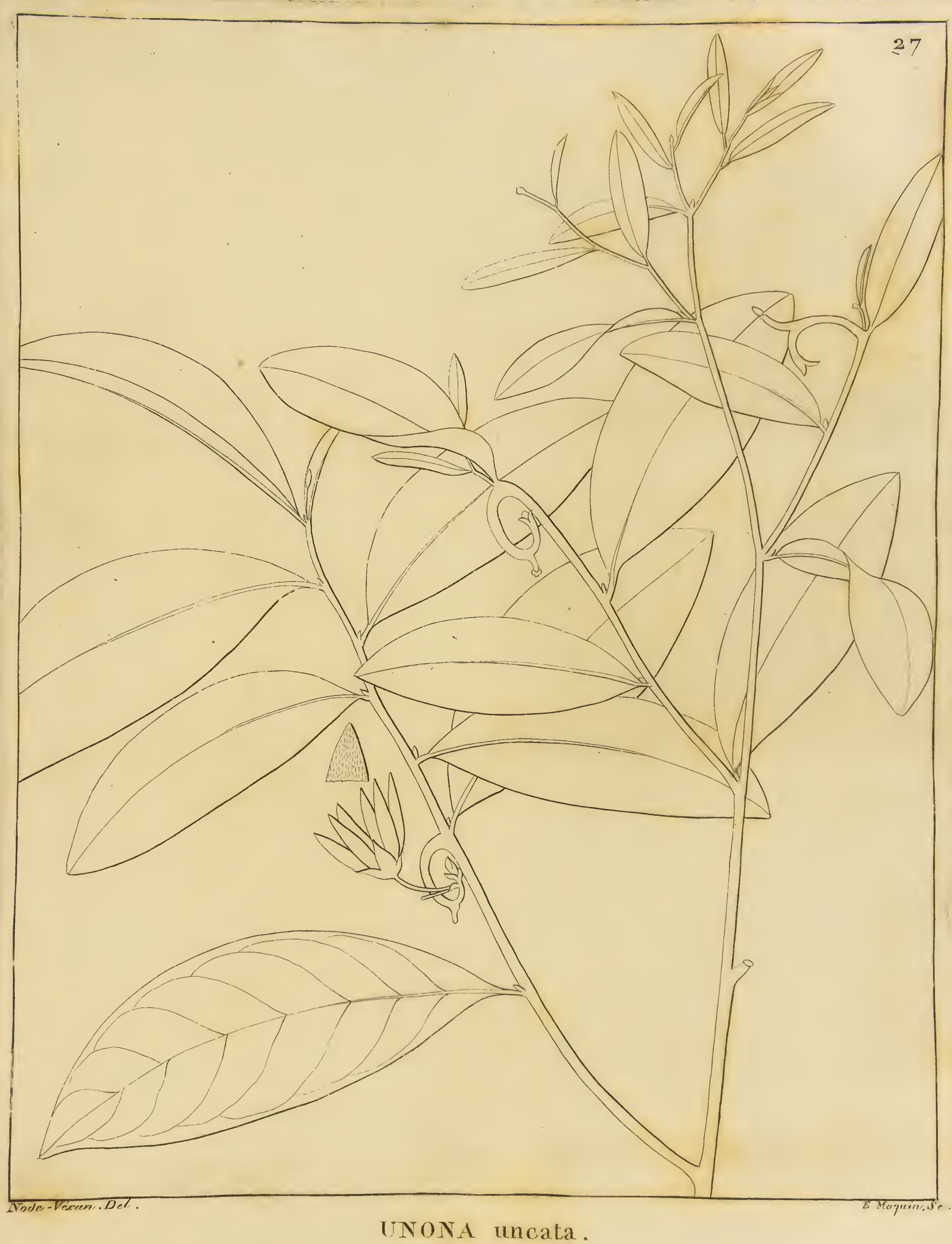





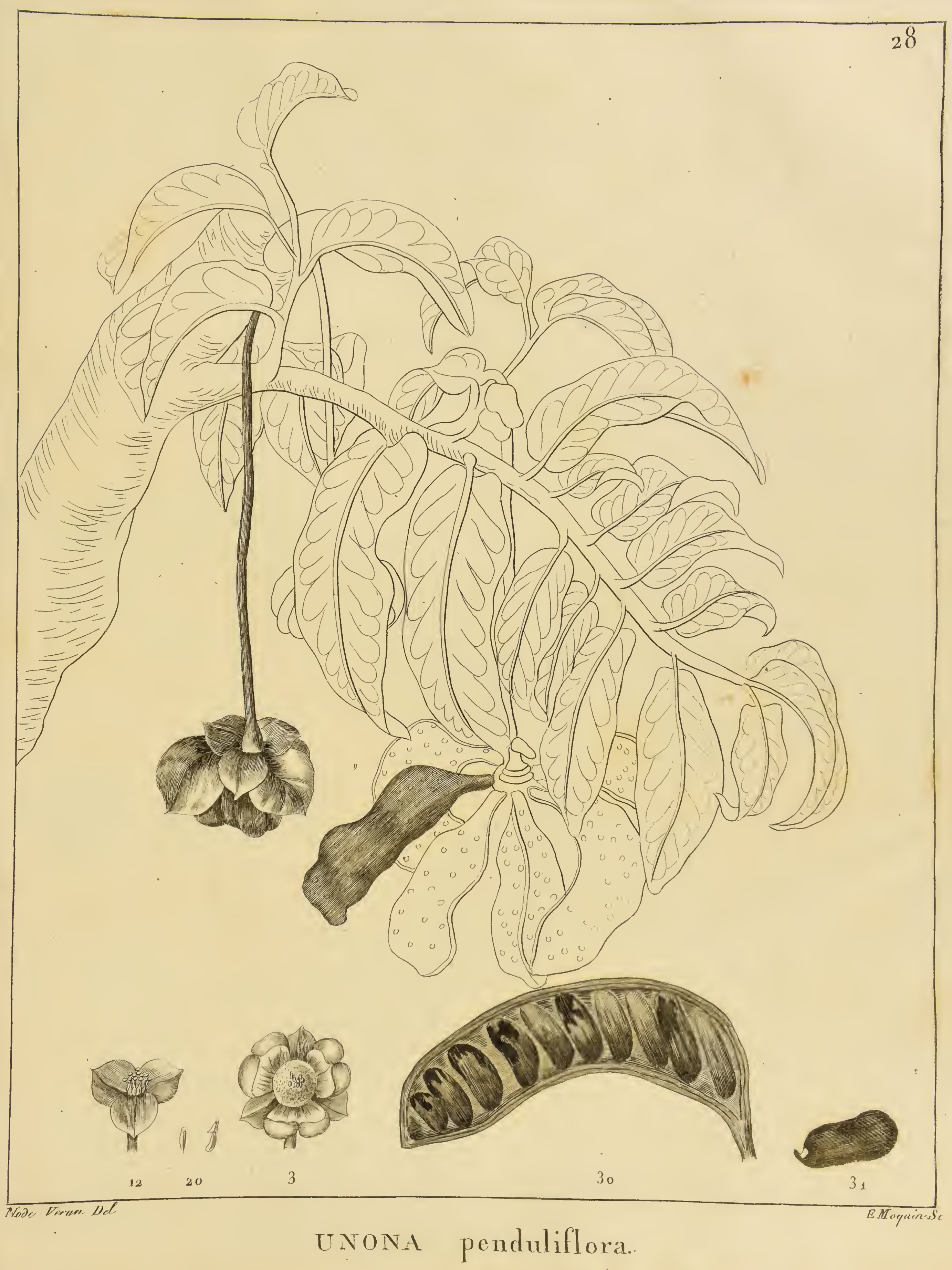






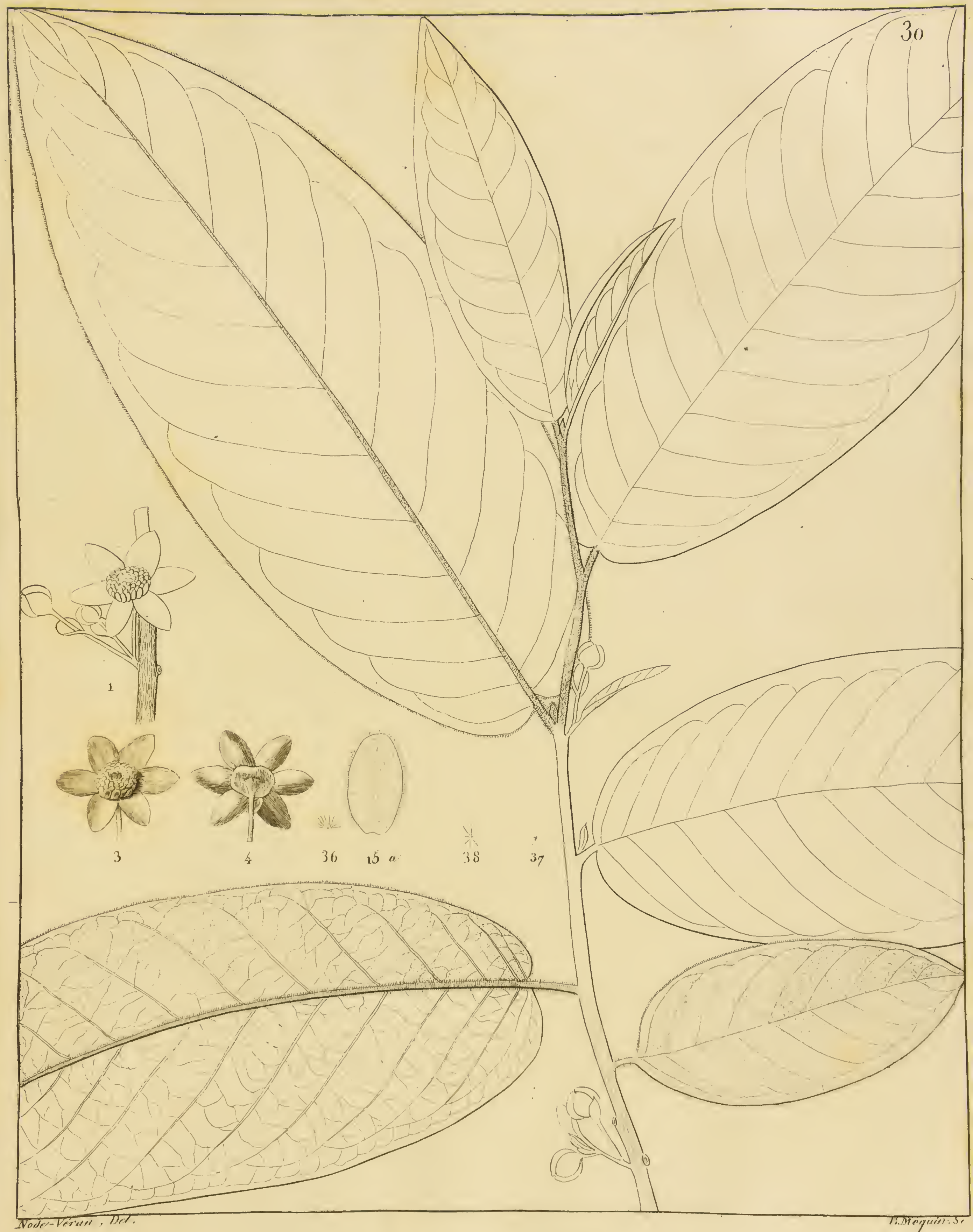

GLATERTA cordata. 



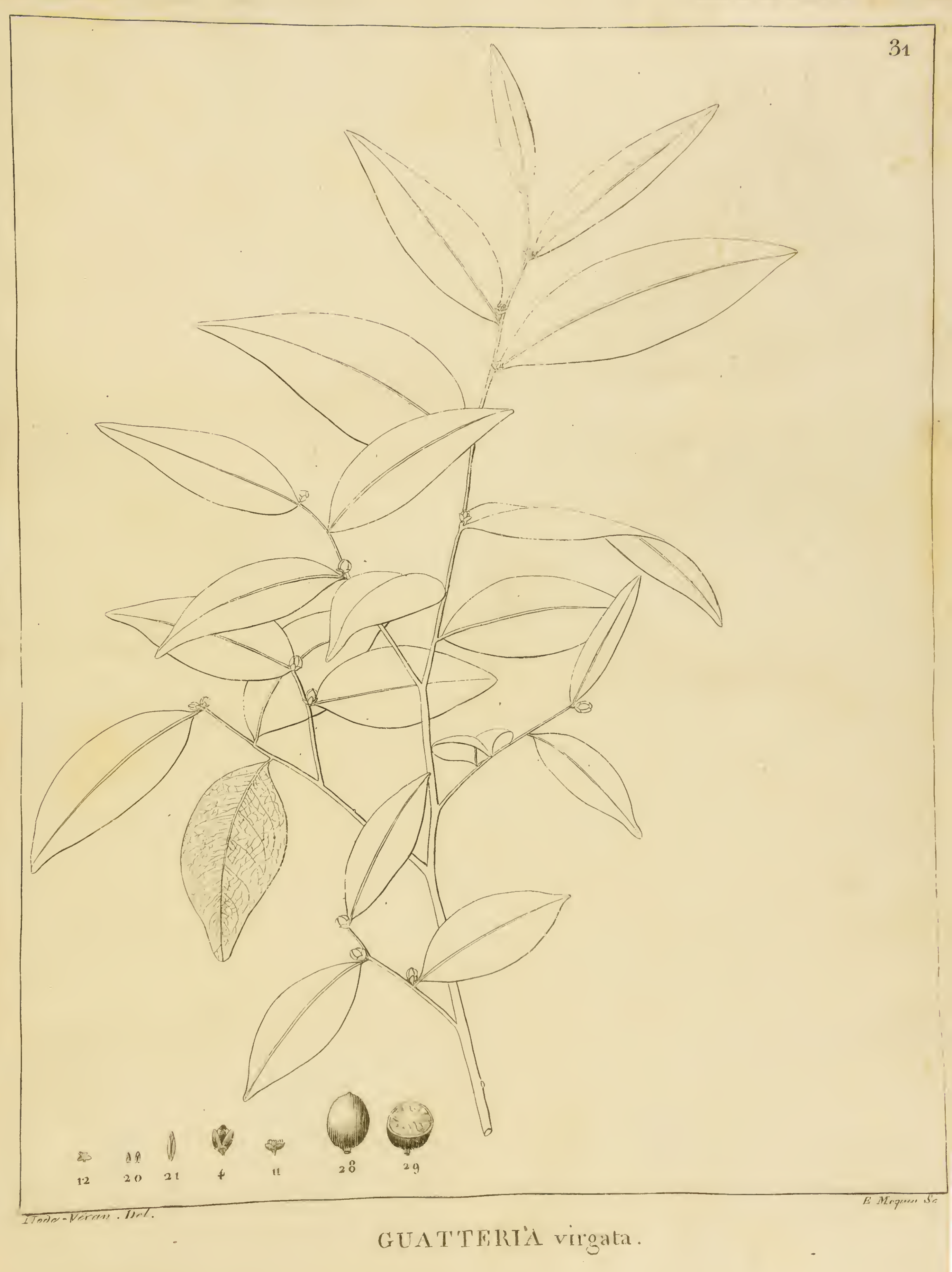






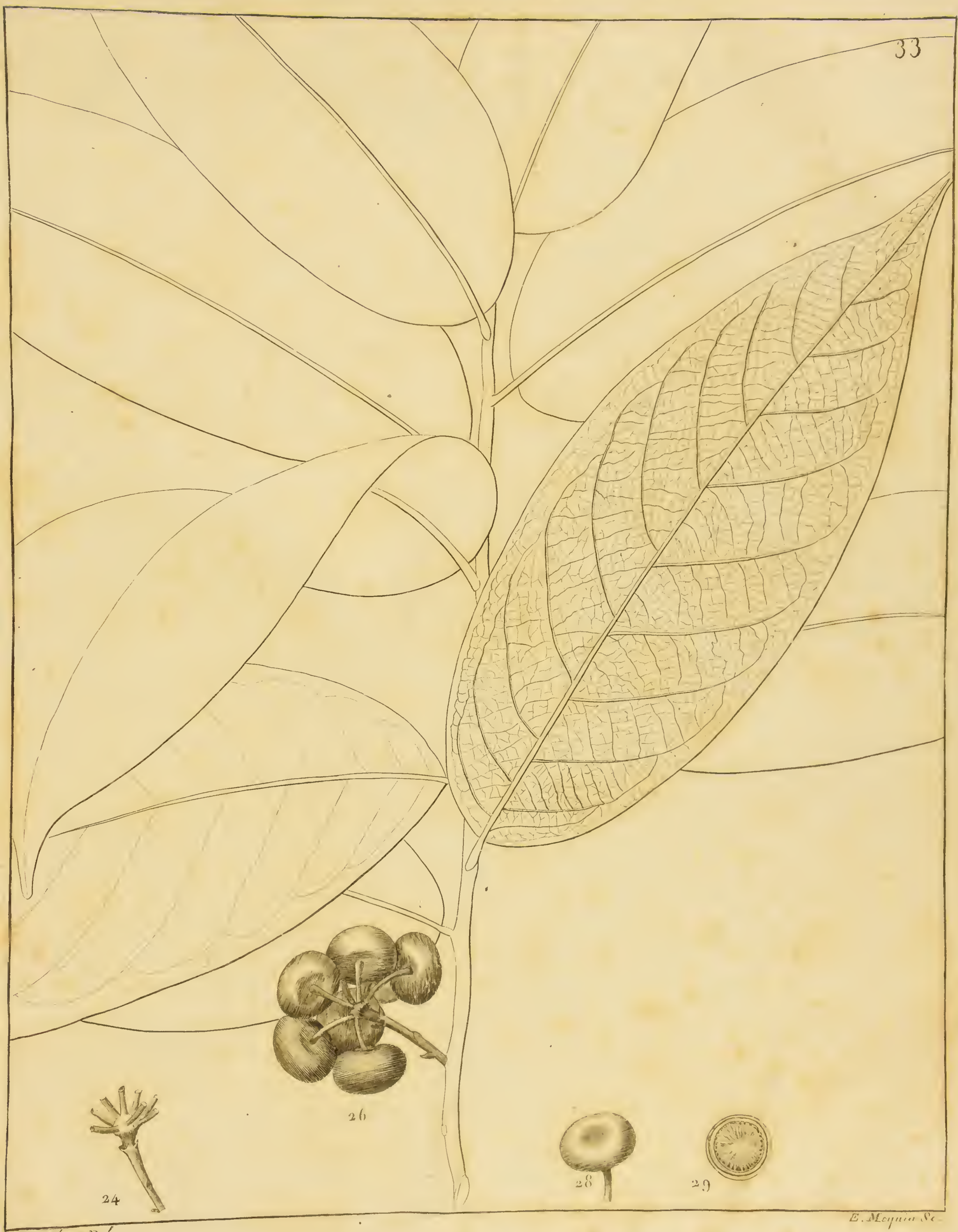







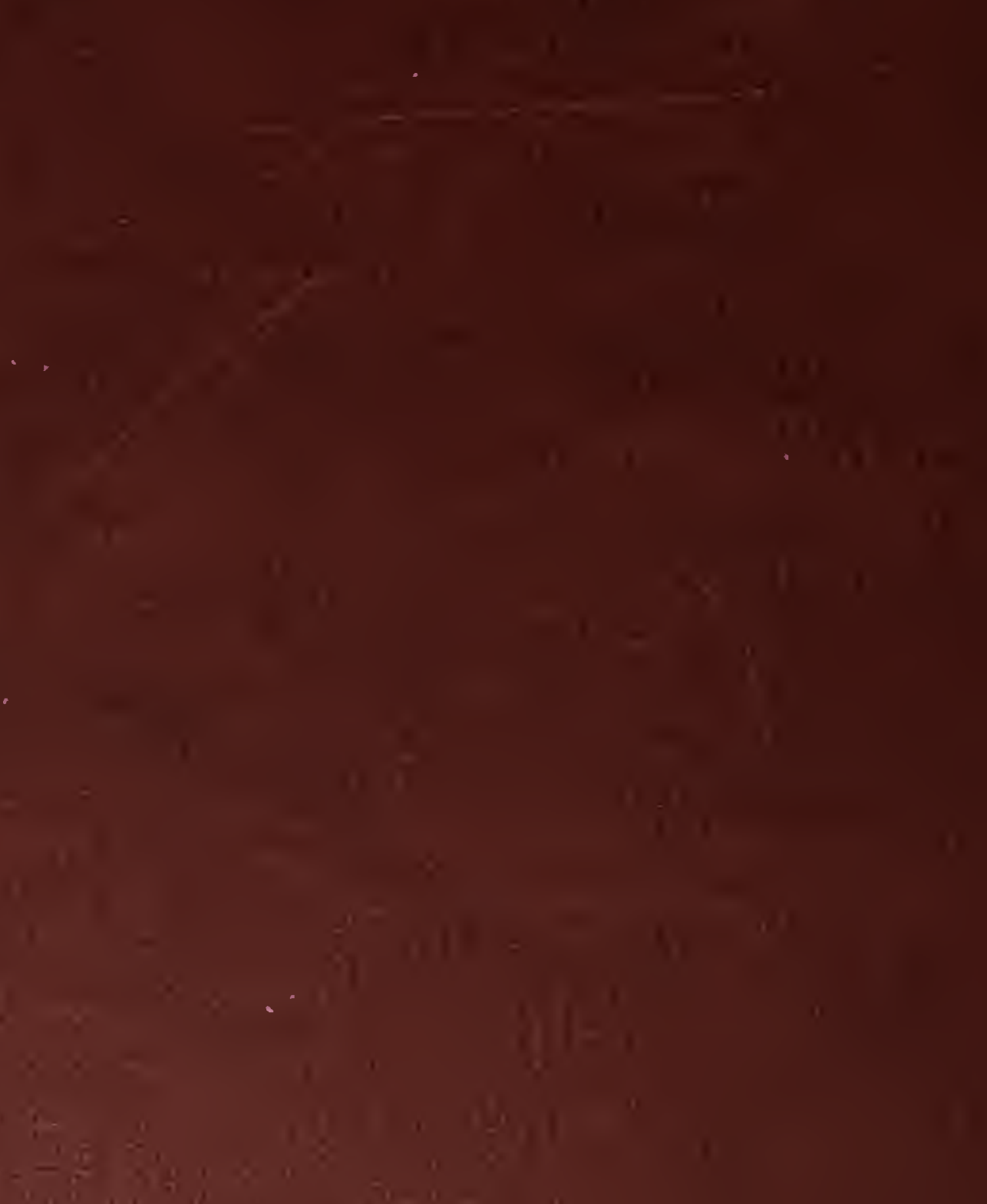

$18+28$

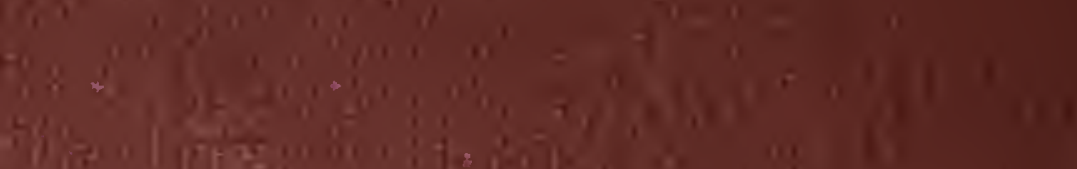

